Aus dem Institut für Neuropathologie

(Prof. Dr. med. W. Brück)

der Medizinischen Fakultät der Georg-August-Universität Göttingen

\title{
Histopathologische Veränderungen im zentralen Nervensystem nach peripherer Stammzelltransplantation
}

\author{
INAUGURAL - DISSERTATION \\ zur Erlangung des Doktorgrades \\ der Medizinischen Fakultät der \\ Georg-August-Universität zu Göttingen
}

vorgelegt von

Elisabeth Knust

aus

Magdeburg

Göttingen 2015 
Dekan:

Prof. Dr. rer. nat. H. K. Kroemer

I. Berichterstatter/in: PD Dr. med. Imke Metz

II. Berichterstatter/in: Prof. Dr. med. Gerald Wulf

III. Berichterstatter/in: Prof. Dr. med. Thomas Meyer

Tag der mündlichen Prüfung: 03.03.2016 



\section{Inhaltsverzeichnis}

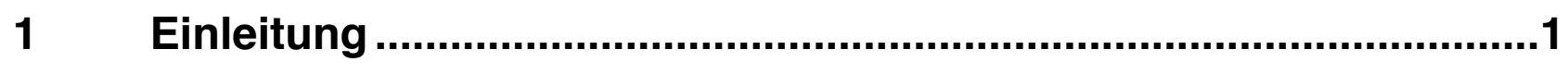

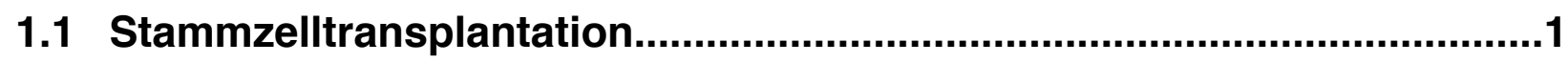

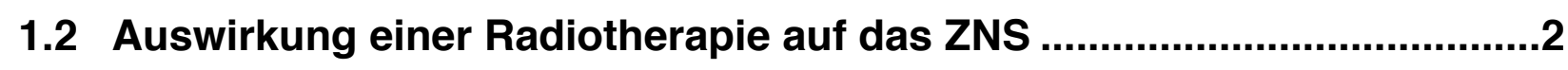

1.2.1 Wirkmechanismus .......................................................................2

1.2.2 Histologische Veränderungen.....................................................2

1.2.3 Klinische Symptomatik ....................................................................

1.3 Auswirkungen von Chemotherapien auf das ZNS .................................

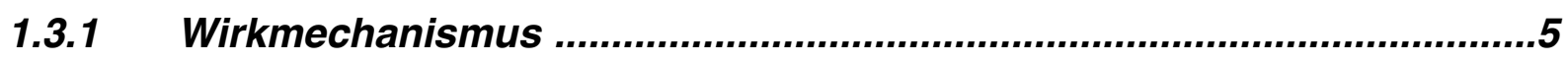

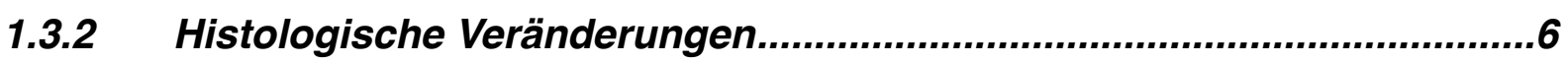

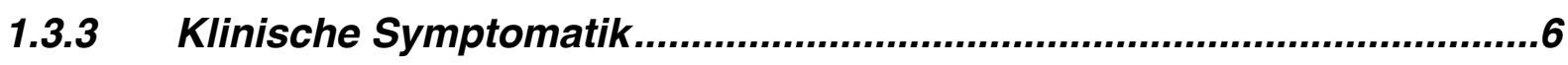

1.4 Degenerations- und Regenerationsprozesse im ZNS .............................

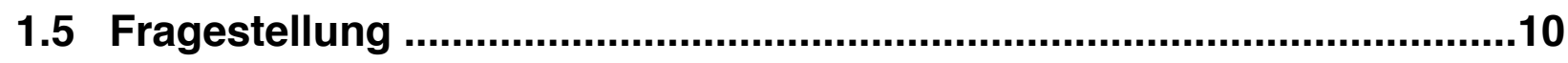

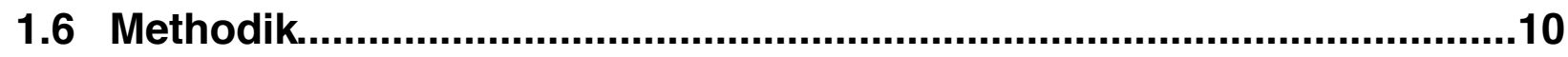

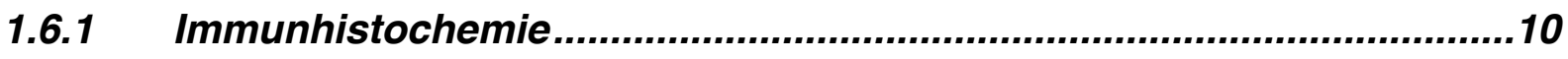

1.6.2 In-situ-Hybridisierung ....................................................................11

$2 \quad$ Material und Methoden ................................................................12

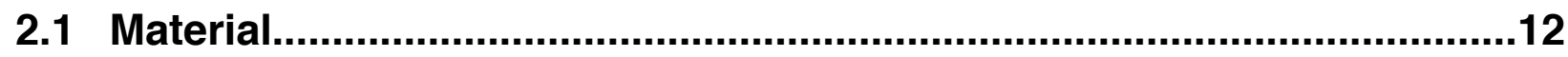

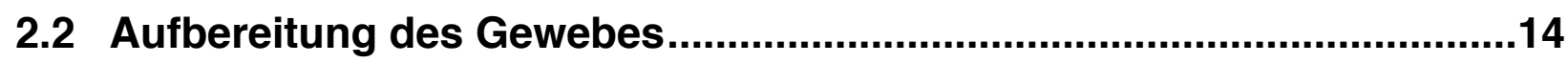

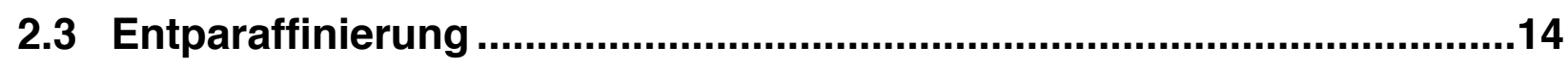

2.4 Hämatoxilin-Eosin-Färbung .............................................................14

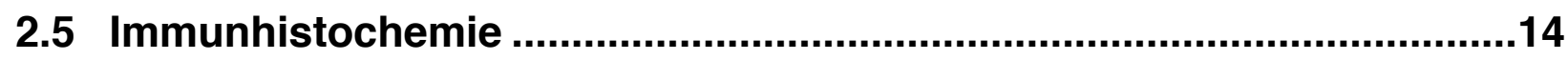

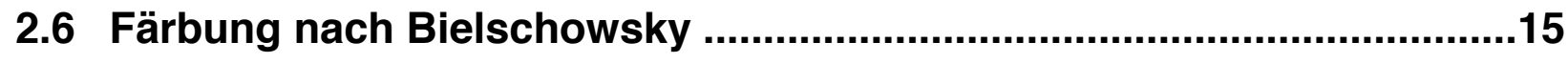

2.7 Kombinierte In-situ-Hybridisierung (Y-Chromosom) mit Immunhistochemie ...........................................................................16

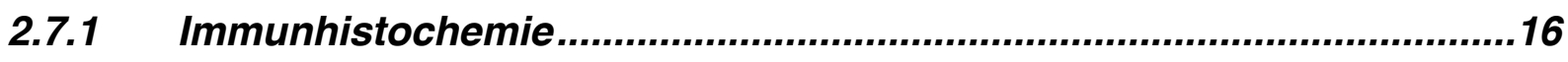




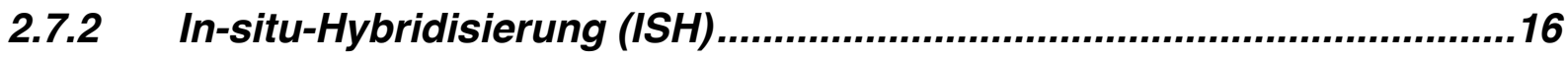

2.8 Morphometrie ....................................................................................17

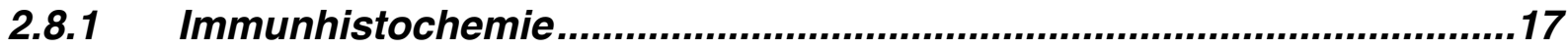

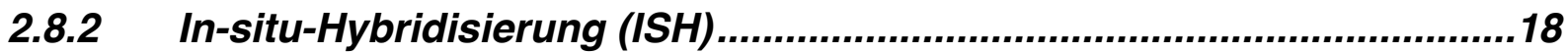

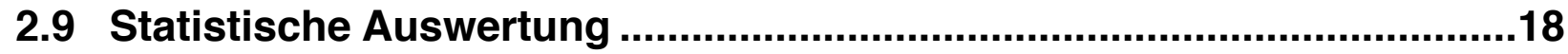

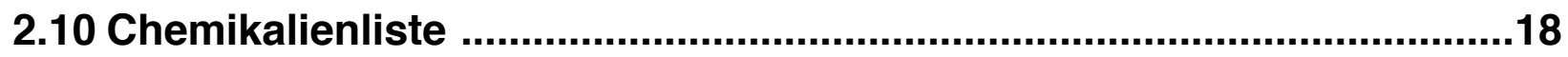

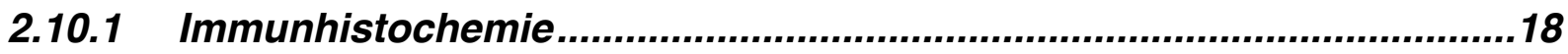

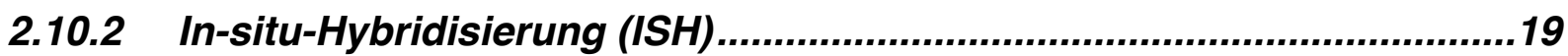

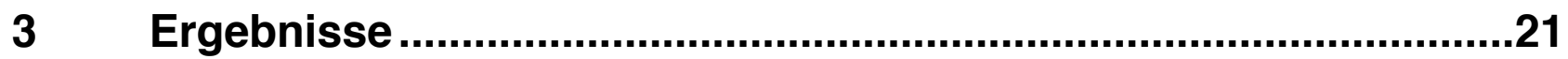

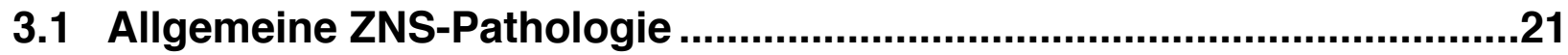

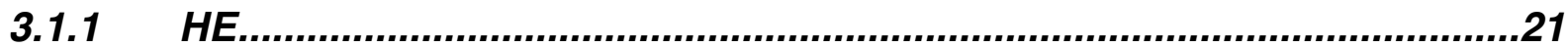

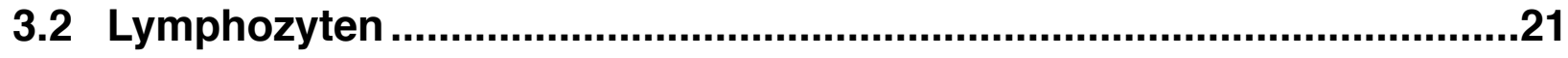

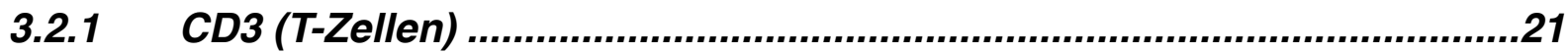

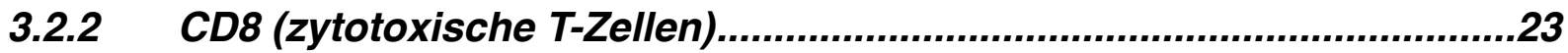

3.2.3 CD20 und CD138 (B-Zellen und Plasmazellen).......................................

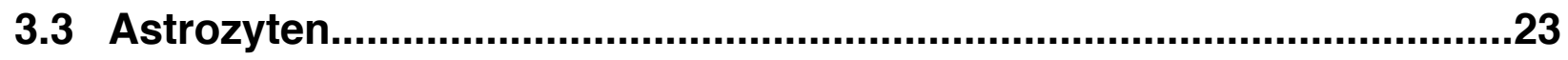

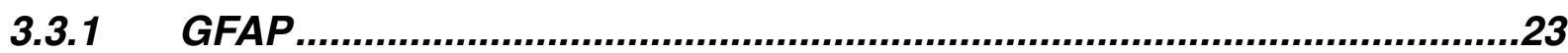

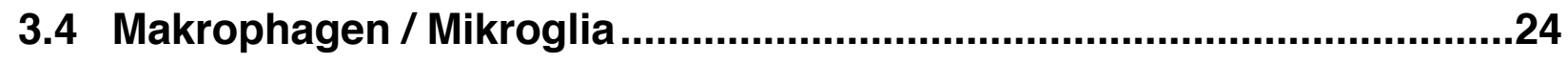

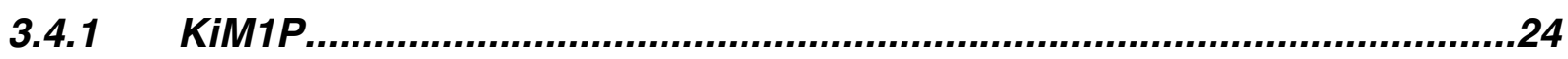

3.4.2 CR3/43

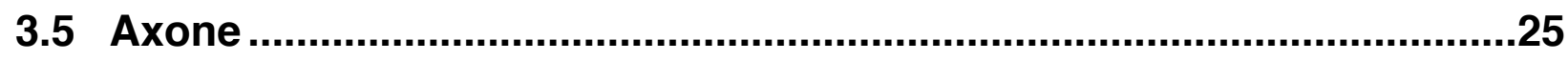

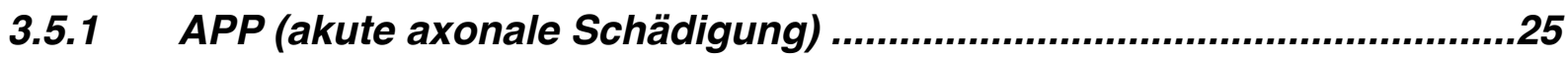

3.5.2 Bielschowsky-Versilberung (axonale Dichte) .....................................26

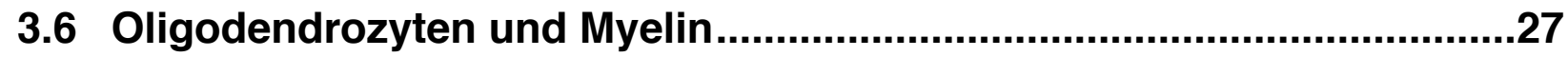

3.6.1 NogoA (reife Oligodendrozyten) .........................................................28

3.6.2 Olig2 (Oligodendrozytenvorläuferzellen und reife Oligodendrozyten) 28

3.6.3 Myelin-basisches Protein (Myelinfärbung) ….....................................30 
3.8 Korrelation des zeitlichen Abstandes der Stammzelltransplantation mit den histologischen Ergebnissen.

3.9 Korrelation des Patientenalters mit den Ergebnissen der Oligodendrozyten-Färbungen

3.10 Vergleich des Gehirngewichts von transplantierten Patienten und der

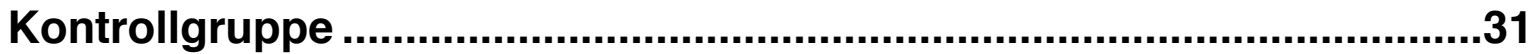

3.11 Einfluss einer Radiotherapie auf die Oligodendrozyten ........................32

3.12 Einfluss ausgewählter Chemotherapeutika auf die untersuchten Zellpopulationen...........................................................................................33

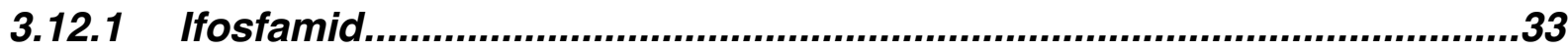

3.12.2 Etoposid

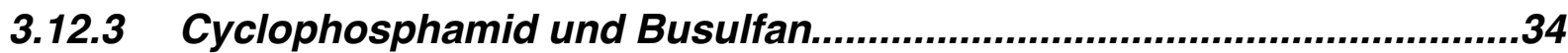

3.12.4 Vincristin, Fludarabin und Cytarabin (AraC).........................................34

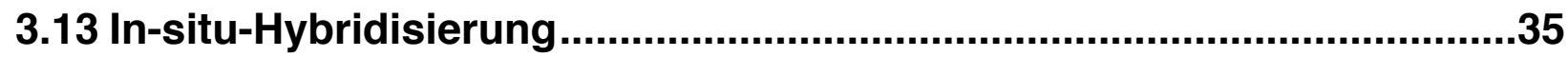

3.13.1 Makrophagen / Mikroglia, Astrozyten und endotheliale Zellen ..............36

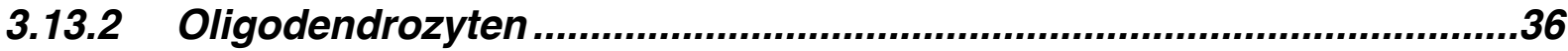

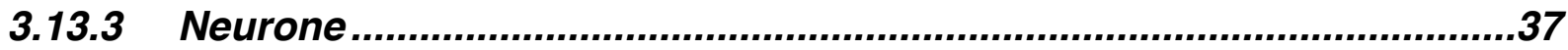

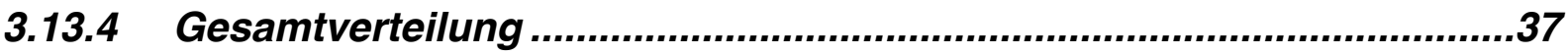

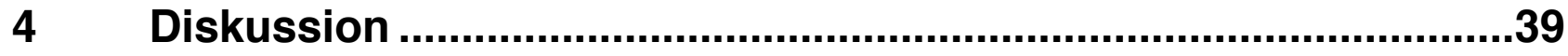

4.1 Stammzelltransplantation allgemein........................................................39

4.2 Histologische Veränderungen nach Radiotherapie ................................41

4.3 Histologische Veränderungen nach Chemotherapie ............................42

4.4 Einfluss zusätzlicher Faktoren sowie Studienlimitation .........................44

4.5 Therapieassoziierte Veränderungen der Oligodendrozyten/-vorläuferpopulation

4.6 Differenzierung von Spenderzellen im Zentralnervensystem der Empfänger. 
4.7 Stammzelltransplantation als zukünftige Therapieoption bei

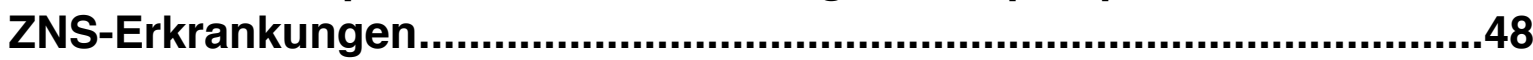

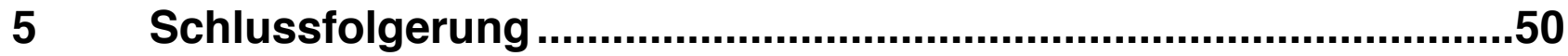

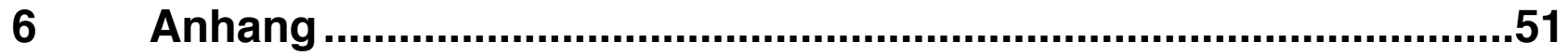

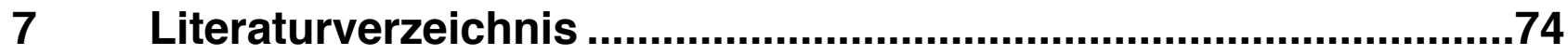




\section{$1 \quad$ Einleitung}

\subsection{Stammzelltransplantation}

Unter dem Begriff Stammzelltransplantation versteht man unter anderem die Übertragung von Blutstammzellen eines Spenders auf einen Empfänger. Diese Technik der Medizin ist relativ jung und hat ihre Anfänge in der zweiten Hälfte des letzten Jahrhunderts. Heute findet sie Anwendung in der Behandlung verschiedener Hämoblastosen und seltener auch bei einigen autoimmunologischen Erkrankungen (Jansen et al. 2005).

Man unterscheidet zwischen der autologen Transplantation, bei der Spender und Empfänger dieselbe Person sind, und der allogenen Transplantation, im Rahmen derer dem Empfänger die Stammzellen einer anderen Person übertragen werden.

Bei allogenen Transplantationen wird in der Auswahl des Spenders versucht, eine möglichst genaue Übereinstimmung mit den HLA-Merkmalen (Humanes-Leukozyten-Antigen) des Empfängers zu erreichen, um Komplikationen durch Abstoßungsreaktionen zu vermeiden (Thomas und Blume 1999). Als HLA-identisch gilt eine vollständige Übereinstimmung an den Genorten HLA-A, -B, -C, -DR, -DQ in der hochauflösenden HLA-Testung. Im Vorfeld der Transplantation ist es notwendig, eine sogenannte Myeloablation als Konditionierung (Vorbehandlung) durchzuführen. Dabei werden durch Hochdosis-Chemotherapie und/oder Ganzkörperbestrahlung sowohl die malignen Zellen im Körper des Patienten als auch sein blutbildendes System weitgehend zerstört. Ohne eine weitere Behandlung würde der Patient in der sich anschließenden Aplasie versterben. Ein bis drei Tage nach Abschluss der Hochdosistherapie erfolgt die eigentliche Stammzelltransplantation in Form einer Transfusion. Die Stammzellen finden mit Hilfe sogenannter Homing-Rezeptoren von allein ihren Weg aus dem peripheren Blut ins Knochenmark und beginnen dort mit der Blutbildung (Preiß et al. 2014).

Bei der autologen Transplantation dauert es ca. 10 Tage bis zum sogenannten Engraftment, wobei wieder reife, funktionstüchtige Zellen der Hämatopoese im peripheren Blut zu finden sind. Dieser Zeitraum kann bei allogenen Transplantationen sogar bis zu 20 Tage umfassen. Während der ersten Wochen und Monate nach der Transplantation ist der Patient stark durch Infektionen gefährdet, da er nicht mehr über ein ausreichend funktionierendes Immunsystem verfügt. Mit einer annähernden Normalisierung der B- und T-Zell-Funktion ist erst nach etwa einem halben Jahr oder länger zu rechnen.

Die transplantationsbezogene Mortalität wird für die autologe Transplantation mit 2-5\% angegeben, während sie bei der allogenen Transplantation mit 10-40\% (abhängig von Alter, Grunderkrankung, Konditionierungsverfahren, HLA-Übereinstimmung) deutlich höher liegt (Berking und Preiß 2012). Für diesen Unterschied hauptverantwortlich ist eine Komplikation der allogenen Transplantion, die sogenannte „Graftversus-Host-Disease“ (Jansen et al. 2005). Dabei wenden sich Zellen des Spender-Immunsystems gegen das Empfängergewebe. Hauptsächlich betroffen sind Haut, Darm, Leber und Lunge, aber auch einzelne Fälle von ZNS-Affektion werden beschrieben. Als Behandlungsmöglichkeit kommt eine immunsuppressive Therapie in Frage, welche wiederum das Infektionsrisiko erhöht. 
Zu den wichtigsten Kompliktationen nach einer Stammzelltransplantation zählen Infektionen. Dabei treten in der Frühphase besonders bakterielle Infektionen auf, später vorwiegend virale Infektionen und in allen Phasen Pilzinfektionen (Preiß et al. 2014). Weitere mögliche Komplikationen der Therapie können Blutungen durch die entstehende Thrombozytopenie sowie durch die Grunderkrankung sein. Ferner können ein erneuter Krankheitsschub der primären Erkrankung und Sekundärtumoren auftreten. Es spielen auch die Nebenwirkungen der Vorbehandlung mit Radio- und Chemotherapie eine Rolle, auf die ich folgend noch weiter eingehen werde.

Es gibt einige Veröffentlichungen zu den histologischen Veränderungen im ZNS nach einer Stammzelltransplantation, die sich jedoch ausschließlich mit schweren pathologischen Veränderung beim Auftreten der erwähnten Komplikationen (z. B. intrazebrale Blutungen, Infektionen) mit meist tödlichem Ausgang für die Patienten beschäftigen (Bleggi-Torres et al. 2000; Mohrmann et al. 1990; Nishiguchi et al. 2009). Eine Studie zu den weniger offensichtlichen histologischen Veränderungen der einzelnen Zellpopulationen (Entzündungszellen, Astrozyten, Oligodendrozyten und deren Vorläuferzellen, Neurone und Axone) als Folge einer Stammzelltransplantation und assoziierter Therapien ist mir nicht bekannt.

\subsection{Auswirkung einer Radiotherapie auf das ZNS}

\subsubsection{Wirkmechanismus}

Bei der Behandlung von Tumorerkrankungen durch ionisierende Strahlung macht man sich im Wesentlichen deren Wirkung auf die DNS der Zellen zunutze. Es werden Einzel- und Doppelstrangbrüche erzeugt, die vor allem in hoch-reproduktiven Geweben wie Tumoren letztendlich zum Zelluntergang führen. Außerdem entstehen durch die Energiezufuhr Radikale, welche wiederum die DNS schädigen.

Bei der Stammzelltherapie kann eine fraktionierte Ganzkörperbestrahlung mit insgesamt 10-12 Gy (Gray) Teil der Konditionierung sein (Tofilon und Fike 2000). Die Einheit 1 Gy entspricht dabei einer Energiedosis von 1 Joule pro Kilogramm Körpergewicht.

\subsubsection{Histologische Veränderungen}

Die Auswirkungen einer therapeutischen Bestrahlung des Zentralnervensystems wurden bereits in mehreren Studien hauptsächlich am Tiermodell untersucht. Die Spätfolgen einer Strahlentherapie zeichnen sich im Wesentlichen durch Entmarkung sowie Gefäßanomalien bis hin zu typischen Koagulationsnekrosen aus (Tofilon und Fike 2000). Außerdem werden ausgedehnte Entzündungsreaktionen beschrieben (Han et al. 2008). Beim Menschen ist das Auftreten von Strahlennekrosen als offensichtliche histologische Veränderung bei einer Strahlendosis von weniger als $50 \mathrm{~Gy}$ in 25 Einzeldosen eher unwahrscheinlich. Das Nekroserisiko nimmt allerdings mit steigender Gesamtdosis und Stärke der Einzeldosen sowie durch anschließende Chemotherapie zu (Ruben et al. 2006).

Es wurden im Wesentlichen zwei Hypothesen über den Schädigungsmechanismus durch eine Bestrahlung aufgestellt. 
Auf der einen Seite steht die sogenannte gliale Hypothese, die davon ausgeht, dass eine Schädigung glialer Vorläuferzellen der Auslöser für eine letztendlich folgende Demyelinisierung ist. Im adulten Gehirn gibt es nach dem momentanen Erkenntnisstand zwei Hauptorte, an denen Stamm- und Vorläuferzellen lebenslang Neurone und Gliazellen produzieren. Dies sind die subventrikuläre Zone (SVZ) und der Gyrus dentatus (GD) im Hippocampus. Von dort aus wandern die entstandenen Vorläuferzellen durch das Gehirngewebe und differenzieren sich weiter zu den jeweiligen Zelltypen (Doetsch et al. 1999b; Eriksson et al. 1998). Zu den im adulten ZNS vorkommenden teilungsfähigen Zellen gehören die O-2A-Zellen (Oligodendrozyten-Typ-2Astrozyten-Vorläuferzellen), aus denen sich je nach Stimulation Oligodendrozyten oder Astrozyten vom Typ 2 entwickeln können (Raff et al. 1983). Letztere entstehen allerdings ausschließlich unter In-vitro-Bedingungen und werden daher als Artefakte gedeutet (Franklin et al. 1995; Sawamura et al. 1995). Oligodendrozyten sind für die Ausbildung der Markscheiden im ZNS verantwortlich. Bei Ratten und Mäusen konnte in vivo nachgewiesen werden, dass eine klinisch relevante Strahlendosis zur Apoptose dieser Zellen führt (Chow et al. 2000; Li et al. 1996). Weiterhin konnte nachgewiesen werden, dass Zytokine wie TNFa, die als Folge einer Bestrahlung freigesetzt werden, auf diesen Zelltyp Apoptose-induzierend wirken (Cammer 2000).

Die Reduktion von Oligodendrozyten führt wiederum zu einer Aktivierung der selbst durch die Bestrahlung beeinträchtigten O-2A-Zellen, was auf längere Sicht zu einer Erschöpfung dieses Stammzellpools führt (Panagiotakos et al. 2007; Tofilon und Fike 2000).

Eine Forschungsgruppe hat mit Hilfe einer Färbung des Myelin-basischen-Proteins (MBP) die Auswirkungen der ZNS-Bestrahlung auf die Markscheiden von Meerschweinen untersucht (Chiang et al. 1992). Sie stellte fest, dass auf eine initiale Markscheidenreduktion zunächst eine Erneuerung, jedoch schließlich eine absolute Reduktion des Myelins folgt.

Dennoch ist der genaue Zusammenhang von Zellverlust und Beeinträchtigung der Zellproliferation mit den beobachteten Demyelinisierungen noch nicht hinreichend geklärt. Zudem liegen keine humanen Untersuchungen vor. Auch die Rolle der Zytokine lässt noch viele Fragen offen.

Auf der anderen Seite steht die sogenannte vaskuläre Hypothese, die als Ursache für die ZNS-Schädigung einen strahlungsbedingten Endothelschaden mit daraus folgenden Mikroangiopathien, Infarzierungen und einer resultierenden Minderversorgung bestimmter Hirnareale sieht (Hopewell und van der Kogel 1999; Li et al. 2003; Lyubimova und Hopewell 2004; Nguyen et al. 2000). Zusätzlich kommt es zu einer Störung der Blut-Hirn-Schranke, die ihre Schutz- und Filterfunktion nicht mehr erfüllen kann, so dass vermehrt Entzündungszellen in das ZNS einwandern können (d'Avella et al. 1992; Diserbo et al. 2002; van Vulpen et al. 2002; Yuan et al. 2006). Als sichtbare Folgen werden die Ablösung der Basalmembran sowie ein vakuolisiertes Zytoplasma und Kernschwellungen der Endothelzellen beschrieben (Phillips 1966; Verheij et al. 1994; Zollinger 1970), im weiteren Verlauf auch Thromben, Plättchenansammlungen und abnormale Endothelproliferation.

Einige Autoren berichten von einem Fortschreiten der mikrovaskulären Schädigung, auf die jedoch etwa 6 Monate nach der Bestrahlung eine teilweise Regeneration des Gewebes in struktureller und funktioneller Hinsicht folgt (Nguyen et al. 2000). Andere Autoren berichten von einer zeit- und dosisabhängigen Verminderung der Gefäßdichte und Anzahl der Endothelzellen als Folge einer Bestrahlung, die jedoch 
individuell stark variiert (Calvo et al. 1988; Reinhold et al. 1990). Diese Ergebnisse aus tierexperimentellen Studien wurden meines Wissens bisher nicht in Untersuchungen an humanem Gewebe überprüft.

Es ist anzunehmen, dass histopathologische Veränderungen nach einer Strahlentherapie Resultat einer Interaktion der unterschiedlichen Mechanismen sind (Belka et al. 2001; Chiang et al. 1993; Tofilon und Fike 2000). Einige Forscher sind der Meinung, dass der schädigende Einfluss auf andere ZNS-Zellpopulationen wie Mikroglia, Astrozyten und Neurone bisher deutlich unterschätzt wird (Tofilon und Fike 2000). Mehrere Studien berichten von einer Zunahme der Mikroglia als Folge der Bestrahlung des ZNS (Chiang et al. 1993; Mildenberger et al. 1990; Monje et al. 2002; Nakagawa et al. 1996; Schultheiss et al. 1988; Schultheiss und Stephens 1992). Die Proliferation von Mikrogliazellen kann ein Zeichen für entzündliche Veränderungen bis hin zu Demyelinisierungen wie im Falle der Multiplen Sklerose sein (Brown 2009). Eine chronische Mikrogliaaktivierung kann zu einer Freisetzung zytotoxischer Substanzen (z. B. bestimmter Cytokine, Sauerstoffradikale) und hierdurch zum Absterben von Nervenzellen führen (Tofilon und Fike 2000). Mikrogliazellen besitzen zudem eine enge funktionelle Beziehung zu den Astrozyten (Zucker-Franklin et al. 1987).

Astrozyten sind der am häufigsten vorkommende Zelltyp im ZNS (Montgomery 1994). Sie besitzen vielfältige regulative Funktionen und sind in der Lage, andere Zellen vor oxidativem Stress zu schützen (Montgomery 1994). Eine Forschungsgruppe wies Astrozyten in einem In-vitro-Experiment eine protektive Wirkung auf Neuronen gegenüber ionisierender Strahlung nach (Noel und Tofilon 1998). Im Tierversuch zeigte sich, dass die Anzahl der Astrozyten und deren GFAP (glial fibrillary acidic protein)-Intensität in der immunhistochemischen Färbung mit steigender Strahlendosis zunimmt (Chiang et al. 1993). Auch eine Hypertrophie gefäßnaher Astrozyten wurde als Folge einer Bestrahlung beobachtet (Calvo et al. 1988). Es ist jedoch anzunehmen, dass die durch Bestrahlung bedingte Astrogliose in ihrem Ausmaß nicht vergleichbar ist mit der durch Trauma oder Ischämie verursachten (Norton et al. 1992).

Ein direkter Einfluss einer Bestrahlung auf die Neurone in Form von morphologischen Veränderungen konnte im Tierversuch bisher nur bei neugeborenen Tieren nachgewiesen werden (Ferrer et al. 1996). Einzelne Autoren stellten bei ihren Versuchsreihen in vitro eine Apoptose von Neuronen durch therapeutisch relevante Strahlendosen fest (Gobbel et al. 1998). In vivo konnten bei ausgewachsenen Ratten jedoch keine morphologischen Veränderungen der Neurone beobachtet werden (Li et al. 1996).

Ein weiterer Zelltyp, der durch Bestrahlung beeinträchtigt werden kann, sind die Vorläuferzellen (siehe auch "gliale Hypothese" der Strahlenschädigung). Eine Studie an Ratten zeigte, dass eine Bestrahlung zu einer dosisabhängigen Reduktion der neuronalen und glialen Vorläuferzellen in der SVZ führt (Tada et al. 1999). Im Tierversuch konnte die langanhaltende Schädigung neuronaler Stammzellen in der SVZ bestätigt werden (Panagiotakos et al. 2007). Außerdem stellten Panagiotakos und Kollegen 2007 einen Verlust von Oligodendrozyten-Vorläuferzellen sowohl bei Nagern als auch an menschlichem Gewebe fest. Eine Studie beschäftigt sich hauptsächlich mit der hippokampalen Neurogenese (Monje et al. 2002). Im Tierversuch an Ratten stellten Monje und Kollegen 2002 eine in Folge einer Bestrahlung auftretende Abnahme von Neuronen fest. Hierbei sehen die Autoren als Hauptursache dafür weder einen Verlust von Vorläuferzellen noch die Unfähigkeit der Zellen zur weiteren Differenzierung, sondern eher eine Störung des Mikromilieus im Umfeld der Zelle. 
Bis auf wenige Ausnahmen handelt es sich bei den genannten Beobachtungen um Tierexperimente und/ oder In-vitro-Versuche. Zu den Vorgängen im menschlichen Gewebe in vivo ist abgesehen von den „Extremfällen" mit ausgeprägter und potentiell tödlicher Pathologie (wie z.B. der oben genannten Strahlennekrose oder Infektionen) und klinischen Auffälligkeiten nicht viel bekannt. Die Übertragbarkeit von Ergebnissen aus Tierversuchen auf den menschlichen Organismus bzw. aus In-vitro- auf In-vivo-Versuchsreihen ist oft nur eingeschränkt möglich (Belka et al. 2001).

\subsubsection{Klinische Symptomatik}

Neben dem pathophysiologischen Mechanismus und den morphologisch sichtbaren Veränderungen gibt es eine Reihe von Studien zu den klinischen Zeichen von Bestrahlungsfolgen. Die Auswirkungen werden dabei nach ihrem Auftreten in akute (48 Stunden bis eine Woche nach Bestrahlung), subakute (bis 6-10 Wochen nach Bestrahlung) und späte Folgen unterteilt. Erstere zeichnen sich durch Benommenheit, Übelkeit und Kopfschmerzen, im Folgenden auch Müdigkeit und Somnolenz aus und sind gewöhnlich reversibel. Hingegen sind die Spätfolgen meist irreversibel und treten beispielsweise in Form von Hirndrucksymptomen und Schlaganfällen auf (Belka et al. 2001). Mehrere Studien weisen zudem eine Abnahme der kognitiven Fähigkeiten als Folge einer ZNS-Bestrahlung nach (Abayomi 1996; Anderson et al. 2000; Crossen et al. 1994; Kramer et al. 1997; Lee et al. 1989; Moore et al. 1992; Roman und Sperduto 1995; Surma-aho et al. 2001). Hierbei ist das Alter des Patienten zum Zeitpunkt der Behandlung von Bedeutung: Bei Kindern unter 3 bis 5 Jahren werden die Auswirkungen umso dramatischer, je jünger die Betroffenen sind (Duffner 2006).

Trotz der recht umfassenden Beobachtungen zu kognitiven Beeinträchtigungen als Folge einer Strahlentherapie lassen sich in den meisten Fällen, anders als bei der Strahlennekrose mit neurologischer Herdsymptomatik, Krampfanfällen und Hirndrucksymptomatik, keine zum klinischen Bild passenden histologischen Befunde feststellen (Belka et al. 2001).

\subsection{Auswirkungen von Chemotherapien auf das ZNS}

\subsubsection{Wirkmechanismus}

Als Chemotherapeutika werden Substanzen bezeichnet, die durch ihre zytostatischen oder zytotoxischen Eigenschaften bei der Therapie von malignen Erkrankungen eingesetzt werden, um die entarteten Zellen in ihrem Wachstum zu hemmen bzw. zu zerstören. Diese Wirkung bleibt nicht nur auf das kranke Gewebe beschränkt, sondern es werden auch gesunde Körperzellen angegriffen. Die konkreten Auswirkungen sind abhängig von dem jeweiligen Medikament. Dabei spielen Dosierung und individuelle Verträglichkeit für den jeweiligen Patienten eine Rolle.

Ähnlich wie bei der Strahlentherapie wird auch bei den Nebenwirkungen der Chemotherapie zwischen Akutund Spätfolgen unterschieden. Von den Akutnebenwirkungen sind alle schnell wachsenden Gewebe wie Haare, Schleimhaut, Knochenmark etc. betroffen, während zu den Spätfolgen ein erhöhtes Risiko für Leukämien, Myelodysplasien und Zweittumoren gehört (Berking und Preiß 2012). 
Bei der Konditionierung für eine Stammzelltransplantation werden Dosierungen der Chemotherapeutika eingesetzt, die deutlich höher sind als bei der "normalen“ Krebstherapie, da hier eine Myelosuppression erwünscht ist.

\subsubsection{Histologische Veränderungen}

Es gibt kaum Studien über histologische Veränderungen im ZNS nach einer Chemotherapie. Tierversuche sind rar, ganz zu schweigen von Daten über menschliches Gewebe. Eine Forschungsgruppe untersuchte die Wirkung von 5-Fluorouracil (5-FU) im Tiermodell und konnte bei der Untersuchung an Ratten und Mäusen eine Schädigung der Oligodendrozytenvorläuferzellen und der adulten Oligodendrozyten sowohl in vitro als auch in vivo nachweisen (Han et al. 2008). Außerdem kam es längerfristig zu degenerativen Veränderungen der Myelinscheiden mit einem Verlust des Myelin-basischen-Proteins (MBP) sowie zu einer gestörten Genregulation der Olig2-Expression in den Oligodendrozyten. Die Autoren stellten fest, dass es bei den beobachteten Veränderungen keinen Zusammenhang mit entzündlichen Prozessen oder Gefäßveränderungen gibt. Dies steht im Gegensatz zu den Erkenntnissen über die Nebenwirkungen der Radiotherapie, so dass die Autoren daraus schließen, dass es sich um einen anderen Schädigungsmechanismus handeln muss (Han et al. 2008).

Eine Studie an menschlichem Gewebe beschäftigt sich mit vier Fällen von toxischer Leukenzephalopathie in Folge einer Hochdosischemotherapie (Moore-Maxwell et al. 2004). Die klinischen Symptome der Patienten waren so unspezifisch, dass die Diagnose erst postmortem gestellt werden konnte. Histologisch fielen Ödeme, Entmarkung, Gliose und eine Infiltration der weißen Substanz mit Makrophagen auf. Unter den verwendeten Chemotherapeutika finden sich BCNU (Bis-Chlorethyl-Nitroso-Urea), Melphalan, Methotrexat, Cisplatin und Purin-Analoga wie Cytarabin, Fluarabin und 5-FU. Diese Substanzen wurden schon in anderen Studien mit einer Leukenzephalopathie in Verbindung gebracht (Bashir et al. 1988; Filley 1999; Kamble et al. 2007; Mahoney et al. 1998).

\subsubsection{Klinische Symptomatik}

Im Gegensatz zu den histologischen Beobachtungen gibt es eine ganze Reihe von Untersuchungen, die sich mit den neurologischen Auffälligkeiten von Patienten nach einer Chemotherapie beschäftigen. Die neurotoxische Wirkung kann sowohl das ZNS als auch das periphere Nervensystem (PNS) betreffen. Ich werde mich jedoch ausschließlich auf das ZNS konzentrieren, da die Erkrankungen des PNS für meine Untersuchungen nicht von Bedeutung sind.

Mehrere Autoren konnten bei Krebspatienten ein vermehrtes Auftreten von Leukenzephalopathien, epileptischen Anfällen und Hirninfarkten in Verbindung mit Chemotherapien beobachten (Cordier et al. 2011; Kargiotis et al. 2011; Sioka und Kyritsis 2009). Cisplatin, L-Asparaginase, 5-FU und Methotrexat sollen das Schlaganfallrisiko nachweislich erhöhen (Saynak et al. 2008).

Bei Brustkrebspatienten, die mit einer adjuvanten Chemotherapie behandelt wurden, stellten verschiedene Studien eine kognitive Beeinträchtigung fest (Brezden et al. 2000; Wefel et al. 2010). Dagegen konnten andere Autoren in inrer Studie keine signifikanten Unterschiede vor und nach der Chemotherapie bezüglich der kognitiven Leistungen beobachten (Debess et al. 2010). 
Die meisten Therapien beruhen auf einem multimodalen Konzept, so dass im Nachhinein schwer zu beweisen ist, welche Substanz für pathologische und klinische Auswirkungen verantwortlich ist. Auch in den von mir untersuchten Fällen kamen jeweils verschiedene Medikamente zum Einsatz, die häufig nicht nur im Rahmen der Konditionierung zur Stammzelltransplantation, sondern schon im Vorfeld zur Therapie der Grunderkrankung eingesetzt wurden. Außerdem spielen eine Reihe von Faktoren eine Rolle, die das Auftreten und das Ausmaß der Neurotoxizität beeinflussen. Dazu gehören Patientenalter, Gesamtdosis sowie Anzahl und Höhe der Einzeldosen der Chemotherapeutika, Applikationsart, Nieren- und Leberfunktion des Patienten, erbliche Stoffwechselstörungen, zusätzliche neurologische Grunderkrankungen des Patienten sowie Interaktionen mit anderen Medikamenten, Chemotherapeutika oder Strahlentherapie (Dropcho 2004). Da die Anzahl der verschiedenen Chemotherapeutika relativ groß ist und nicht alle bei dem von mir untersuchten Patientenkollektiv vorkommen, habe ich mich entschieden, eine Auswahl zutreffen. Einerseits habe ich die 3 bzw. 4 häufigsten im Kollektiv vorkommenden Substanzen ausgewählt. Dabei handelt es sich um Cyclophosphamid, Etoposid, Bulsulfan und Fludarabin. Andererseits habe ich noch 3 Substanzen ausgewählt, die in der Literatur häufiger aufgrund ihrer zentralen Neurotoxizität erwähnt werden und gleichzeitig in auswertbarer Anzahl im Patientenkollektiv vorkommen. Das sind Cytarabin (AraC), Ifosfamid und Vincristin.

Cyclophosphamid ist ein häufig verwendetes Zytostatikum aus der Gruppe der Alkylanzien. Eine Neurotoxizität dieser Verbindung ist nicht bekannt, daher ist die dosisbegrenzende Nebenwirkung eine Leukopenie durch Knochenmarkssuppression (Fleming 1997). In seltenen Fällen kann es zu einer lebensgefährlichen Hyponaträmie kommen (Bruining et al. 2011).

Etoposid erreicht seine Wirkung durch die Hemmung der Topoisomerase II. In der Standarddosierung kann keine Neurotoxizität beobachtet werden, aber bei der Hochdosistherapie treten Enzephalopathien auf, die sich durch Verwirrtheit und fokalneurologische Symptome, wie z.B. eine zunehmende Halbseitenlähmung und Krampfanfälle, äußern (Leff et al. 1988). Die Autoren nehmen an, dass eine vorangegangene Bestrahlung die Symptome mit verursachen könnte, da Patienten, die auf Grund von Lungenkrebs die gleiche Therapie bekommen haben, keine dieser Auffälligkeiten zeigten (Keime-Guibert et al. 1998). In einer Studie an Ratten wurde die Wirkung von Etoposid in Abhängigkeit von der Funktion der Blut-Hirn-Schranke untersucht. Dabei konnte keine Neurotoxizität bei intakter Blut-Hirn-Schranke festgestellt werden, während es bei Störungen dieser und gleichzeitiger Kombination von Etoposid mit anderen Chemotherapeutika (wie Methotrexat oder Melphalan) zu pathologischen Veränderungen (z. B. Nekrosen, Nervenzellverluste, erhöhte Zelldichte) kam. Bei der Verabreichung von Melphalan und Methotrexat ohne Etoposid traten diese Veränderungen nicht auf (Fortin et al. 2000). Eine Forschungsgruppe stellte einen Zusammenhang zwischen der Kombinationstherapie mit Etoposid und Carboplatin bei der Behandlung von kleinzelligen Bronchialkarzinomen und dem Auftreten eines reversiblen posterioren Leukenzephalopathiesyndroms (RPLS) her, das sich durch plötzliche Kopfschmerzen, Sehstörungen, Bewusstseinsstörungen, Krampfanfälle und typische ödematöse Veränderungen im MRT auszeichnet (Ryan et al. 2012).

Auch Busulfan gehört zur Gruppe der Alkylanzien und besitzt myelosuppressive Eigenschaften. Außerdem kommt es bei 5 bis 15\% der Patienten abhängig von der Dosierung innerhalb von einigen Stunden nach Verabreichung zu generalisierten tonisch-klonischen Krampfanfällen, die normalerweise selbstlimitierend 
sind und denen man durch prophylaktische Gabe von Antiepileptika vorbeugen kann (Vassal et al. 1990). Langzeitnebenwirkungen wurden von den Forschern nicht beobachtet.

Fludarabin ist ein Antimetabolit aus der Gruppe der Purinanaloga. Eine neurotoxische Wirkung ist bei der Standarddosierung selten. Es sind jedoch einzelne Fälle von reversiblen neurologischen Defiziten und im MRT sichtbaren Läsionen der weißen Substanz beschrieben (Cohen et al. 1993). Bei Dosierungen von mehr als $40 \mathrm{mg} / \mathrm{m}^{2} / \mathrm{Tag}$ kommt es zu ersten neurologischen Störungen wie Blindheit, Enzephalopathie und Koma, die durch eine diffuse nekrotisierende Leukenzephalopathie der überwiegend okzipitalen Hirnareale bedingt wird (Chun et al. 1986; Spriggs et al. 1986). Andere Autoren berichten außerdem über das Auftreten von Krampfanfällen, Demenz und Tetraplegien (Cheson et al. 1994).

Cytarabin (auch AraC genannt) gehört auch zu den Antimetaboliten, jedoch zur Gruppe der Pyrimidinanaloga. Seine Verabreichung kann bei 10-20\% der Patienten zu einem Kleinhirnsyndrom führen, von denen viele zusätzlich eine Enzephalopathie mit Lethargie, Verwirrtheit und Krampfanfällen entwickeln (Baker et al. 1991). Einige Autoren berichten des Weiteren über Auffälligkeiten in der MRT-Bildgebung, wobei in der T2-Wichtung reversible Veränderungen der weißen Substanz der Großhirnhemisphären beobachtet wurden (Vaughn et al. 1993). Das Risiko für das Auftreten solcher Nebenwirkungen erhöht sich deutlich, wenn das Patientenalter über 50 Jahre liegt (Dropcho 2004). In selteneren Fällen kann es auch zu kraniellen Neuropathien mit Beteiligung von Hirnstamm und spinalen Motorneuronen kommen, die bei der histologischen Untersuchung mit stark eosinophilen Perikarien und karyolytischen Zellkernen auffallen (Vogel und Horoupian 1993). In einer neueren Studie, die am Tiermodell und in der Zellkultur die Nebenwirkungen von einzelnen Chemotherapeutika auf das ZNS untersucht, zeigte sich, dass Cytarabin in klinisch relevanter Dosierung stärker toxisch für die Vorläuferzellen und adulten Oligodendrozyten als für viele Arten von Krebszellen ist (Dietrich et al. 2006). Außerdem stellten die Autoren auch noch Wochen nach Abschluss der Behandlung sowohl in vitro als auch in vivo erhöhte Apoptoseraten und eine verminderte Zellteilung fest.

Ifosfamid gehört zur Gruppe der Alkylanzien und ist nahe verwandt mit dem Cyclophosphamid, von dem es sich jedoch durch seine zusätzlichen neurotoxischen Eigenschaften unterscheidet. Bei bis zu $20 \%$ der Kinder, die mit Ifosfamid wegen solider Tumoren behandelt werden, verursacht das Medikament eine Enzephalopathie, die sich in Form akuter Lethargie, Verwirrtheit, Reizbarkeit, auffälligem Verhalten, Persönlichkeitsveränderungen und Krampfanfällen äußert (Pratt et al. 1986). Bei Erwachsenen tritt dies seltener auf. Das Risiko steigt bei Kombination mit Cisplatin (Pratt et al. 1990). Für die Neurotoxizität wird ein Stoffwechselmetabolit des Ifosfamid - das Chloracetaldehyd - verantwortlich gemacht. Die neurologischen Symptome verschwinden normalerweise innerhalb einiger Tage (Dropcho 2010). In seltenen Fällen kann es zum Koma bis hin zum Tod des Patienten kommen (Shin et al. 2011). Andere Autoren berichten über 2 Fälle von neuaufgetretenem Hemiballismus bei Kindern, die mit Ifosfamid behandelt wurden (Ames et al. 2010).

Vincristin ist ein Zytostatikum aus der Gruppe der Vinca-Alkaloide, die eine mitosehemmende Wirkung besitzen. In Verbindungen mit einer Vincristin-Therapie wird von bilateralen Veränderungen der weißen Substanz, epileptischen Anfällen (Hurwitz et al. 1988) und einer kraniellen Neuropathie in Form einer Abduzenslähmung (Toker et al. 2004) berichtet. Außerdem wurden in frühen Therapiestadien neurotoxische Auswirkungen auf das olivocochleare System beobachtet (Riga et al. 2007). Bei der Behandlung von 
Kindern kam es vereinzelt zu Enzephalopathien mit Krampfanfällen, Verwirrtheit, Aphasie und vorübergehender Erblindung (Gomber et al. 2010). Elektrophysiologische Auffälligkeiten waren bei den Kindern mit aufgetretener Neurotoxizität auch noch 6 Monate nach Abklingen der klinischen Symptome feststellbar.

\subsection{Degenerations- und Regenerationsprozesse im ZNS}

Bis vor etwa 25 Jahren wurde angenommen, dass die Nervenzellen des adulten menschlichen Gehirns nicht mehr in der Lage sind sich, zu teilen und zu vermehren bzw. Verluste zu ersetzen (Gage und Temple 2013). Dies steht im Gegensatz zum peripheren Nervensystem, wo sich Axone von Nervenzellen beispielsweise nach Durchtrennung regenerieren können (Bishop 1982).

Neuere Erkenntnisse zeigen jedoch, dass es auch im ZNS Regionen mit teilungsfähigen Stammzellen gibt, die sich zu den unterschiedlichen Gliazelltypen und Neuronen differenzieren können. Das Ausmaß dieser Regenerationsmöglichkeit ist jedoch umstritten (Gage und Temple 2013). Studien weisen darauf hin, dass die subventrikuläre Zone eine der Hauptregionen der Differenzierung neuer Zellen und der Zellteilung im adulten Gehirn ist (Doetsch et al. 1999b; Menn et al. 2006; Sanai et al. 2004). Außerdem wandern von hier aus Vorläuferzellen verschiedener Zelltypen in andere Hirnregionen ein (Doetsch et al. 1999a; McTigue und Tripathi 2008; Ndubaku und de Bellard 2008). Daher habe in meiner Arbeit besonderes Augenmerk auf diese Zone gerichtet.

Im Tierversuch konnte nachgewiesen werden, dass nach einer Blutstammzelltransplantation Spenderzellen ins Gehirn einwandern und sich dort in Neurone und Gliazellen differenzieren (Crain et al. 2005; Mezey et al. 2003). Zu dem genauen Vorgang dieser Differenzierung gibt es verschiedene Theorien. Einige Autoren halten eine Fusion der Stammzellen mit den örtlichen Zellen für wahrscheinlich (Kemp et al. 2014). Dabei tragen die Stammzellen zur Rettung der jeweiligen fusionierten Zelle bei und nehmen den entsprechenden Phänotyp an (Sullivan und Eggan 2006; Terada et al. 2002). Andere Autoren gehen hingegen davon aus, dass sich entweder verschiedene Zelllinien aus einer einzelnen eingewanderten Stammzelle entwickeln oder eine größere Anzahl von Stammzellen angelockt werden, die sich dann jeweils zu verschiedenen Zelltypen entwickeln (Mezey et al. 2003). Dies könnte eventuell einen interessanten Therapieansatz bei degenerativen Erkrankungen des ZNS darstellen. Bei der Multiplen Sklerose gibt es hier bereits experimentelle Therapien (Fassas und Kimiskidis 2004; Karussis und Slavin 2004).

Um Prozesse wie Degeneration und Regeneration im ZNS in einer Studie beurteilen zu können, bedarf es der Festlegung bestimmter Untersuchungskriterien. Lichtmikroskopisch sichtbare Zeichen einer degenerativen Veränderung können sein: eine Abnahme der Axondichte, das Auftreten axonaler Sphäroide, eine Verminderung der Oligodendrozytenzahl und deren Vorläuferzellen, ein Verlust von Myelin, eine Astrogliose (kann auch protektiv wirken), ein gehäuftes Auftreten von Entzündungszellen und der Verlust von Gefäßen. Währenddessen ist es etwas schwieriger, Zeichen einer Regeneration festzustellen. Als ein Marker kann das vermehrte Auftreten von Oligodendrozyten und Oligodendrozyten-Vorläuferzellen gewertet werden (Menn et al. 2006). Auch das Auftreten von hirneigenen Zellen mit Nachweis von DNA des Spenders (bei meinen Untersuchungen der Nachweis des Y-Chromosoms in weiblichen Patienten, die ein 
Stammzelltransplantat von einem männlichen Spender erhielten) könnte hinweisend auf eine Regeneration sein.

\section{$1.5 \quad$ Fragestellung}

Die Blutstammzelltransplantation ist heute ein etabliertes Verfahren zur Behandlung verschiedener schwerer Erkrankungen vor allem von Blut und Knochenmark. Darüber hinaus gibt es neue vielversprechende Ansätze dieses Therapieverfahrens beispielsweise auf dem Gebiet der Autoimmunerkrankungen. Eine detaillierte Untersuchung der Effekte und Nebenwirkungen dieser Therapie auf histologischer Ebene im menschlichen Gehirn ist mir nicht bekannt.

Diese Studie hat daher folgende Zielsetzung:

1. Untersuchung degenerativer Veränderungen durch Analyse verschiedener Zellpopulationen und der axonalen Schädigung der weißen Substanz bei transplantierten Patienten im Vergleich zu nicht transplantierten Kontrollen

2. Genauere Betrachtung der Ergebnisse in Hinsicht auf unterschiedliche Konditionierungsverfahren

3. Untersuchung der Gehirne von weiblichen transplantierten Patienten mit männlichem Spender auf eingewanderte Spenderzellen und Analyse des jeweiligen Zelltyps zum Nachweis der Regeneration im ZNS

4. Abwägung von potentiellen Schäden durch die Therapie und dem zu erwartenden Benefit für den Patienten.

\section{$1.6 \quad$ Methodik}

\subsubsection{Immunhistochemie}

Für die vorliegende Studie wurde Autopsiegewebe von Gehirnen transplantierter Patienten untersucht und unter verschiedenen histologischen Gesichtspunkten mit nicht-transplantierten Patienten verglichen. Besonderes Augenmerk wurde auf die Myelin-bildenden Zellen des ZNS, die Oligodendrozyten, gerichtet. Es wurden gegen NogoA und Olig2 gerichtete Antikörper verwendet. Während der anti-NogoA-Antikörper adulte Oligodendrozyten anfärbt, erlaubt es der anti-Olig2-Antikörper anhand der Färbungsintensität zwischen Vorläuferzellen und adulten Zellen zu unterscheiden (Kuhlmann et al. 2008). Die Myelinscheiden wurden mittels des Markers anti-MBP untersucht. Zum Vergleich der Axondichte und -schädigung wurden die Versilberung nach Bielschowsky und der Antikörper anti-APP genutzt. APP (Amyloid-Precursor-Protein) ist ein Membran-Glykoprotein, das eine wichtige Rolle unter anderm bei neurodegenerativen Prozessen spielt (Nalivaeva und Turner 2013). Es akkumuliert in geschädigten Axonen und zeigt eine akute axonale Schädigung an (Imai et al. 2002).

Des Weiteren wurde die Zelldichte der Zellen des spezifischen Immunsystems untersucht. Dabei wurden die Antikörper gegen CD3 für T-Lymphozyten, CD8 für zytotoxische T-Zellen, CD20 für B-Zellen und CD138 für Plasmazellen verwendet. Zur Untersuchung der unspezifischen Immunabwehr wurde die Zelldichte von Mi-krogliazellen und Makrophagen mit den Antikörpern KiM1P und CR3/43 bestimmt. Außerdem wurde die 
Astrozytendichte mit dem Antikörper gegen GFAP ermittelt. Die Gefäßpathologie und -dichte wurde morphologisch mittels der HE-Färbung verglichen.

\subsubsection{In-situ-Hybridisierung}

Die In-situ-Hybridisierung erfolgte zum Nachweis von männlichen Spenderzellen bei weiblichen transplantierten Patienten in Form eines Y-Chromosomen-Nachweises. Außerdem erfolgte eine Kombination mit einer immunhistochemischen Färbung mit jeweils unterschiedlichen Antikörpern zur Bestimmung des Zelltyps der eingewanderten und differenzierten männlichen Spenderzelle. 


\section{Material und Methoden}

\subsection{Material}

Insgesamt untersuchten wir 19 Patienten mit einer Stammzelltransplantation (siehe Abb. 01), davon 17 in der genauen histologischen Analyse und 2 Patienten mittels In-situ-Hybridisierung. Für die detaillierten histologischen Untersuchungen wurden Subgruppen analysiert: Es wurde zwischen Fällen ohne erkennbare ZNS-Erkrankung bzw. offensichtliche Pathologie und solchen mit einer Pathologie, die jedoch keinen Einfluss auf die Oligodendrozytenpopulation haben sollte, unterschieden. Die detaillierten neuropathologischen Befunde sind in den Tabellen 21-23 aufgeführt. Untersucht wurden dabei im ersten Teil der Arbeit 7 Autopsien aus dem Zeitraum 2004 bis 2009 mit unauffälligem neuropathologischem Befund. Fälle mit Hirninfarkten, Infektionen oder Rezidiven der Grundkrankheit oder ähnliche wurden nicht in diesen Teil der Untersuchung eingeschlossen. Im zweiten Teil der Arbeit wurden bei der Untersuchung der Oligodendrozytenpopulation zusätzlich 10 Fälle mit eingeschlossen, die neuropathologische Auffälligkeiten zeigten, welche jedoch keinen Einfluss auf die Oligodendrozytenpopulation in den untersuchten Hirnarealen haben sollten, wie beispielsweise Hirninfarkte in entfernten Hirnregionen oder Subarachnoidalblutungen. Als Kontrollen dienten 12 Autopsien aus den Jahren 2008 und 2009 von Patienten ohne Stammzelltransplantation, deren neuropathologischer Untersuchungsbefund keine pathologischen Veränderungen aufwies. Bei der Auswahl der Kontrollen wurde die Alters- und Geschlechtsverteilung der Patienten berücksichtigt, um eine möglichst hohe Vergleichbarkeit zu erzielen.

Besondere Einschlusskriterien wurden zusätzlich für die In-situ-Hybridisierung erhoben. Die Patienten mussten weiblich sein und eine Stammzelltransplantation von einem männlichen Spender erhalten haben. Dazu wurden gesondert 2 Fälle und eine Kontrolle (männlicher Patient ohne Stammzelltransplantation) aus dem Jahr 2011 genauer untersucht.

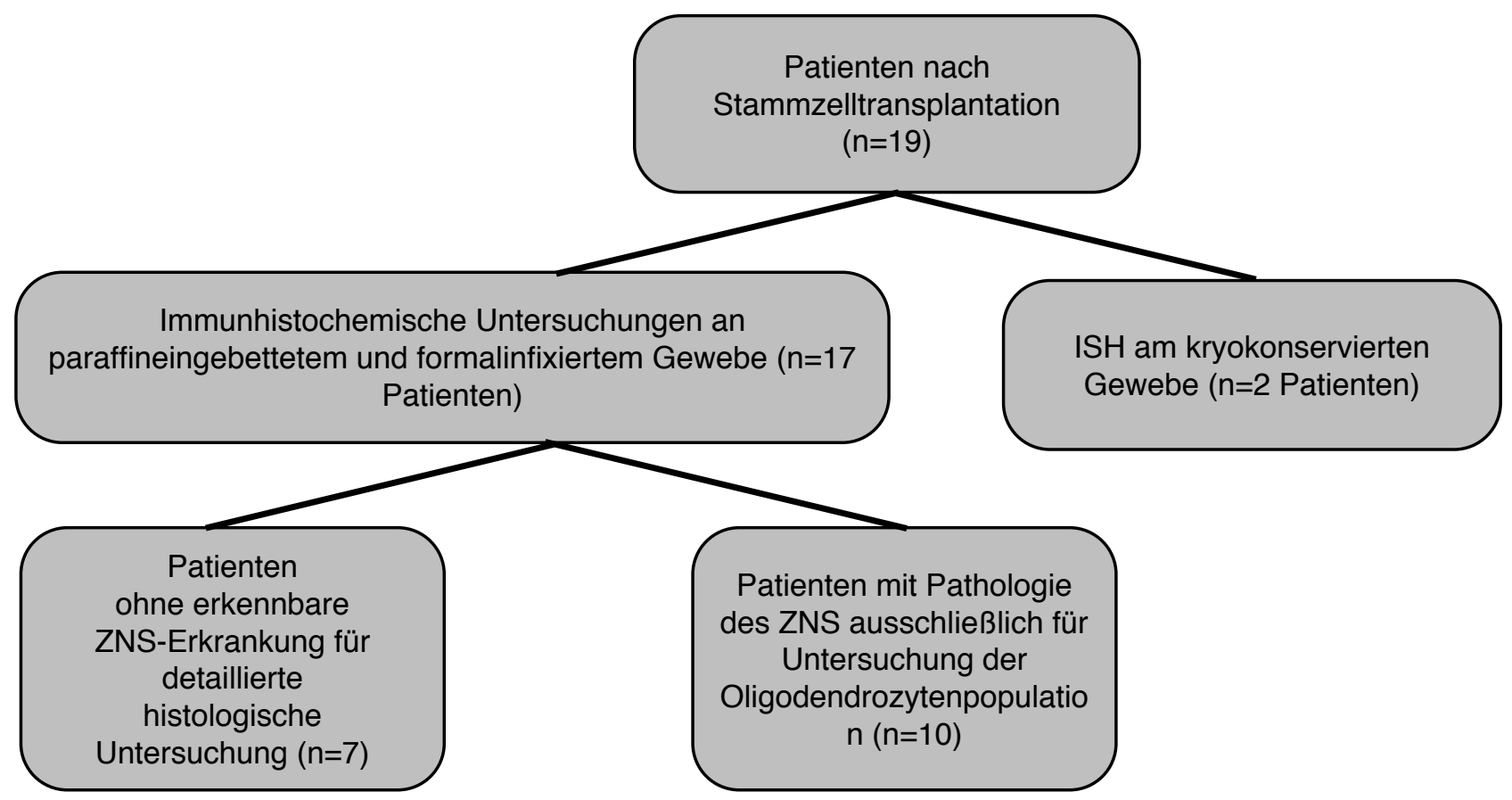

Abb. 01: Untersuchte Patienten 
Alle Präparate stammen aus dem Institut für Neuropathologie der Universitätsmedizin Göttingen und wurden nach neuropathologischer Standardmethode in Formalin fixiert und in Paraffin eingebettet oder kryokonserviert für die ISH, da sich bei dieser Technik an Paraffingewebe keine verlässlichen Ergebnisse produzieren ließen. Untersucht wurden Gewebeblöcke aus dem Frontalhirnbereich, da diese zum Standard der neuropathologischen Untersuchung gehören und somit relativ zuverlässig verfügbar waren. Außerdem war das Verhältnis von weißer und grauer Substanz für die Untersuchungen günstig sowie der meist vorhandene Anteil der subventrikulären Zone. Für die Untersuchung der Oligodendrozytenpopulation wurden die Regionen Marklager, Balken und subventrikuläre Zone (SVZ) unterteilt und jeweils genauer untersucht. Die adulten Oligodendrozyten und Oligodendrozytenvorläuferzellen in diesen Bereichen wurde bereits in verschiedenen Studien quantifiziert (Dietrich et al. 2006; Menn et al. 2006), so dass ein zusätzlicher Vergleich mit der Literatur möglich ist. Eine detaillierte Auflistung der einzelnen untersuchten Fälle und Kontrollen findet sich im Anhang (Tab. 21-23). Für die Untersuchungen sind in den Abbildungen und Tabellen jeweils die Anzahl der tatsächlich untersuchten Fälle angegeben, da aufgrund fehlenden Materials oder fehlender Anfärbbarkeit nicht immer alle Fälle auswertbar waren. Für diese Studie liegt ein Ethikvotum der Ethikkommission der Medizinischen Fakultät der Universität Göttingen vor (14/05/03; Ergänzte Bewilligung vom 05.07.2010).

\begin{tabular}{|c|c|c|c|c|c|c|c|c|c|c|c|}
\hline Färbung & CD3 & CD8 & CD20 & CD138 & KiM1P & CR3/43 & APP & MBP & NogoA & Olig2 & GFAP \\
\hline $\begin{array}{l}\text { Typ - } \\
\text { monoklonal / } \\
\text { polyklonal }\end{array}$ & $\begin{array}{l}\text { mono- } \\
\text { klonal }\end{array}$ & $\begin{array}{l}\text { mono- } \\
\text { klonal }\end{array}$ & $\begin{array}{l}\text { mono- } \\
\text { klonal }\end{array}$ & $\begin{array}{l}\text { mono- } \\
\text { klonal }\end{array}$ & $\begin{array}{l}\text { mono- } \\
\text { klonal }\end{array}$ & $\begin{array}{l}\text { mono- } \\
\text { klonal }\end{array}$ & $\begin{array}{l}\text { mono- } \\
\text { klonal }\end{array}$ & $\begin{array}{l}\text { poly- } \\
\text { klonal }\end{array}$ & $\begin{array}{l}\text { mono- } \\
\text { klonal }\end{array}$ & $\begin{array}{l}\text { poly- } \\
\text { klonal }\end{array}$ & $\begin{array}{l}\text { mono- } \\
\text { klonal }\end{array}$ \\
\hline Hersteller & Serotec & Dako & Dako & Dako & $\begin{array}{l}\text { Prof. } \\
\text { Radzun } \\
\text { Patho- } \\
\text { logie, } \\
\text { Göttin- } \\
\text { gen }\end{array}$ & Dako & $\begin{array}{l}\text { Chemi- } \\
\text { con }\end{array}$ & Dako & $\begin{array}{l}\text { Santa } \\
\text { Cruz }\end{array}$ & IBL & Dako \\
\hline $\begin{array}{l}\text { Vorbehand- } \\
\text { lung }\end{array}$ & $\begin{array}{l}\text { MW } \\
\text { Citrat }\end{array}$ & $\begin{array}{l}\text { MW } \\
\text { Citrat }\end{array}$ & o. V. & $\begin{array}{l}\text { MW } \\
\text { EDTA }\end{array}$ & $\begin{array}{l}\text { MW } \\
\text { Citrat }\end{array}$ & o. V. & $\begin{array}{l}\text { MW } \\
\text { Citrat }\end{array}$ & o. V. & $\begin{array}{l}\text { MW } \\
\text { Citrat }\end{array}$ & $\begin{array}{l}\text { MW } \\
\text { Citrat }\end{array}$ & o. V. \\
\hline $\begin{array}{l}\text { Spezies } \\
\text { primärer } \\
\text { Antikörper/ } \\
\text { eingesetzte } \\
\text { Verdünnung }\end{array}$ & $\begin{array}{l}\text { Ratte; } \\
1: 50 ; \\
1 \% \\
\text { Triton } \\
\text { statt } \\
\text { FCS }\end{array}$ & $\begin{array}{l}\text { Maus; } \\
1: 50\end{array}$ & $\begin{array}{l}\text { Maus; } \\
1: 100\end{array}$ & $\begin{array}{l}\text { Maus; } \\
1: 100\end{array}$ & $\begin{array}{l}\text { Maus; } \\
\text { 1:5000 }\end{array}$ & $\begin{array}{l}\text { Maus; } \\
1: 50\end{array}$ & $\begin{array}{l}\text { Maus; } \\
\text { 1:2000 }\end{array}$ & $\begin{array}{l}\text { Kanin- } \\
\text { chen; } \\
1: 1000\end{array}$ & $\begin{array}{l}\text { Maus; } \\
\text { 1:15000 }\end{array}$ & $\begin{array}{l}\text { Kanin- } \\
\text { chen; } \\
\text { 1:500 }\end{array}$ & $\begin{array}{l}\text { Kanin- } \\
\text { chen; } \\
1: 200\end{array}$ \\
\hline Zielstruktur & $\begin{array}{l}\text { T- } \\
\text { Zellen }\end{array}$ & $\begin{array}{l}\text { Zyto- } \\
\text { toxisch } \\
\text { e } \\
\text { T- } \\
\text { Zellen }\end{array}$ & $\begin{array}{l}\text { B- } \\
\text { Zellen }\end{array}$ & $\begin{array}{l}\text { Plasma } \\
\text { zellen }\end{array}$ & $\begin{array}{l}\text { Makro- } \\
\text { phagen, } \\
\text { Mikro- } \\
\text { glia }\end{array}$ & $\begin{array}{l}\text { Makro- } \\
\text { phagen, } \\
\text { Mikro- } \\
\text { glia }\end{array}$ & $\begin{array}{l}\text { Amyloid } \\
\text {-Pre- } \\
\text { cursor- } \\
\text { Protein }\end{array}$ & $\begin{array}{l}\text { Myelin } \\
\text { Basi- } \\
\text { sches } \\
\text { Protein }\end{array}$ & $\begin{array}{l}\text { adulte } \\
\text { Oligo- } \\
\text { dendro- } \\
\text { zyten }\end{array}$ & \begin{tabular}{|l|} 
Oligo- \\
dendro- \\
zyten / \\
Oligo- \\
dendro- \\
zyten- \\
vor- \\
läufer- \\
zellen
\end{tabular} & $\begin{array}{l}\text { Astro- } \\
\text { zyten }\end{array}$ \\
\hline
\end{tabular}

Tabelle 01: primäre Antikörper

Abkürzungen: $M W=$ Mikrowelle; o. V. = ohne Vorbehandlung 


\subsection{Aufbereitung des Gewebes}

Mit einem Schlittenmikrotom wurden $1 \mu \mathrm{m}$ dicke Paraffinschnitte angefertigt und auf Superfrost Plus ${ }^{\circledR}$ Objektträger aufgebracht. Anschließend wurden diese bei $37^{\circ} \mathrm{C}$ im Wärmeschrank über Nacht getrocknet. Zum Abtropfen des Paraffins wurden die Schnitte 30 Minuten bei $45^{\circ} \mathrm{C}$ in den Wärmeschrank gestellt.

Für die In-situ-Hybridisierung wurden $5 \mu \mathrm{m}$ dicke Kryoschnitte angefertigt und ebenfalls auf Superfrost Plus®Objektträger aufgebracht

\subsection{Entparaffinierung}

Die Gewebeschnitte wurden vor dem Färben entparaffiniert. Dazu wurden sie viermal für zehn Minuten in Xylol gewaschen. Anschließend wurden sie in einer absteigenden Alkoholreihe (Isoxylol, zweimal Isopropanol 100\%, 90\%, 70\%, 50\%) für je fünf Minuten rehydriert und in Aqua bidest. überführt.

\subsection{Hämatoxilin-Eosin-Färbung}

Im Vorfeld der Untersuchungen wurden die Gewebe anhand der Standardfärbung Hämatoxilin-Eosin (HE) auf pathologische Befunde untersucht, die eventuell das Ergebnis beeinflussen könnten. Die Gefäßmorphologie wurde beurteilt. Dafür wurden die Gewebeschnitte nach dem Entparaffinieren zunächst für 8 Minuten in Hämalaun gestellt, danach kurz 2-3 mal in Aqua dest. gespült, 2-3 mal in HCl-Alkohol getaucht und anschließend für 10 Minuten in fließendem Leitungswasser gebläut. Nach erneutem Spülen in Aqua dest. erfolgte die Färbung mit Eosin (6 Minuten). Anschließend wurden die Präparate nach 2-3maligem Spülen in Aqua dest. in einer aufsteigenden Alkoholreihe schnell entwässert (Isopropanol 50\%, 70\%, 90\%, 100\%; je 20 Sekunden), danach für 5 Minuten in Isopropanol 100\% und viermal 10 Minuten in Xylol getaucht und schließlich mit Depex eingedeckt.

\section{$2.5 \quad$ Immunhistochemie}

Das Prinzip der Immunhistochemie beruht im Wesentlichen auf einer Antigen-Antikörper-Reaktion. Ein primärer Antikörper mit einer hohen Affinität zu einem spezifischen Epitop des nachzuweisenden Zelltyps wird auf das Probengewebe gegeben. Im nächsten Schritt wird ein enzymgekoppelter sekundärer Antikörper, der gegen den primären Antikörper gerichtet ist, hinzugegeben. So entstehen am Präparat gebundene Komplexe aus Epitop, primärem Antikörper, sekundärem Antikörper und Enzym. Nicht gebundene Antikörper werden in den Zwischenschritten entfernt. Im letzten Schritt wird ein Chromogen als Substrat für das Enzym zugegeben, das zu einer lokalen Farbreaktion führt. Von uns werden biotinylierte sekundäre Antikörper genutzt, an die in einem Zwischenschritt Avidin-gekoppelte Peroxidase gebunden wird. Die Peroxidase setzt aus Wasserstoffperoxid Protonen frei, welche wiederum das Chromogen DAB (Diaminobenzidin) oxidiert und einen bräunlichen Farbumschlag auslöst. 
Abhängig von der Art der Färbung waren verschiedene Vorbehandlungen nötig, um bei der Fixierung durch Quervernetzung der Proteine verloren gegangene Antikörperbindungsstellen zu demaskieren (Antigen-Retrieval). Die Präparate für die Färbungen APP, CD3, CD8, KiM1P, Olig2 und NogoA wurden fünfmal für je 3 Minuten mit Citratpuffer in der Mikrowelle $(800 \mathrm{~W}$ ) gekocht. Nach dem Abkühlen wurden die Schnitte in Aqua dest. gespült und in PBS überführt. Nach demselben Prinzip erfolgte die Vorbehandlung für CD138 mit EDTA-Puffer. Die Präparate der übrigen Färbungen wurden direkt in PBS überführt. Um unspezifische Signale zu vermeiden, wurde die endogene Peroxidase mit Wasserstoffperoxid ( $3 \%$ in PBS für 20 Minuten bei $4^{\circ} \mathrm{C}$ ) blockiert.

Nach einer 20-minütigen Vorinkubation mit 10-prozentigem Kälberserum (Ausnahme: CD3-Färbung mit 1\% Triton) (100 $\mu \mathrm{l}$ pro Schnitt) zur Vermeidung einer unspezifischen Antikörperbindung erfolgte die Beschichtung mit dem jeweiligen primären Antikörper (siehe Tab. 01). Die Schnitte wurden über Nacht mit Deckgläsern in einer feuchten Kammer inkubiert.

Nach Entfernung der Deckgläser und dreimaliger Spülung in PBS erfolgte die Inkubation mit dem sekundären biotinylierten Antikörper (in der vom Hersteller angegebenen Verdünnung mit 10\% FCS in PBS) für eine Stunde bei Raumtemperatur.

Nach erneuter Spülung in PBS wurden die Schnitte mit je $100 \mu \mathrm{l}$ Peroxidase konjugiertem Avidin (1:1000 in $10 \%$ FCS in PBS verdünnt) beschichtet und wiederum für eine Stunde bei Raumtemperatur inkubiert und anschließend in PBS gespült.

In einer Küvette mit DAB-Färbelösung wurden die Schnitte unter mikroskopischer Kontrolle entwickelt (Zeit abhängig von Färbung) und im Anschluss mehrfach in PBS gespült.

Die Gegenfärbung erfolgte mit Hämalaun (1 Minute), Spülen in Aqua dest. und anschließendem kurzen Eintauchen in $\mathrm{HCl}$-Alkohol. Es schloss sich ein10-minütiges Entwickeln in Leitungswasser an.

Nach Durchlaufen einer aufsteigenden Alkoholreihe (Isopropanol 50\%, 70\%, 90\%, 100\%; je 20 Sekunden), Isopropanol 100\% für 5 Minuten und viermal 10 Minuten in Xylol wurden die Schnitte mit Depex eingedeckt.

\subsection{Färbung nach Bielschowsky}

Die Präparate wurden nach dem Entparaffinieren für 20 Minuten in 20-prozentige Silbernitratlösung (15g $\mathrm{AgNO}_{3}$ auf $75 \mathrm{ml}$ Aqua dest.) gegeben und danach dreimal in Aqua dest. gespült. Die 20-prozentige Silbernitratlösung wurde in einen Kolben gegeben und tropfenweise Ammoniaklösung (32\%) dazugegeben, bis der entstandene Niederschlag wieder verschwand. Anschließend wurden 2 weitere Tropfen Ammoniak hinzugefügt. In dieser Lösung wurden die Schnitte dann für 15 Minuten im Dunkeln inkubiert. Anschließend wurden sie in einer Küvette mit Aqua dest. und 3 Tropfen Ammoniak geschwenkt. Die Ammoniak-Silberlösung wurde mit 10 Tropfen des Entwicklers $(20 \mathrm{ml}$ Formalin, $100 \mathrm{ml}$ Aqua bidest., 0,5 g Zitronensäure, 1 Tropfen konzentrierte Salpetersäure) versetzt und die Schnitte darin für 3-5 Minuten entwickelt. Dann wurden sie erneut mit Aqua dest. gespült und für 2 Minuten in Natrium-Thiosulfat (2\%) gestellt. Die Dehydrierung und das Eindecken erfolgten wie unter 2.5 .7 beschrieben. 


\subsection{Kombinierte In-situ-Hybridisierung (Y-Chromosom) mit Immunhistochemie}

\subsubsection{Immunhistochemie}

Zur Identifikation der unterschiedlichen Zelltypen wurde im Vorfeld der ISH zunächst eine Immunhistochemie durchgeführt, um das Y-Chromosom-Sondensignal entsprechend zuordnen zu können.

Die kryokonservierten Schnitte wurden zuerst für 20 Minuten bei $37^{\circ} \mathrm{C}$ getrocknet, anschließend in $4 \%$-igem Paraformaldehyd für 2 Minuten fixiert und in 0,3\%igem Wasserstoffperoxid für 20 Minuten die endogene Peroxidase blockiert. Die weiteren Schritte erfolgten wie oben unter „Immunhistochemie“ beschrieben. Die Färbungen und primären Antikörper können der folgenden Tabelle 02 entnommen werden.

\begin{tabular}{|c|c|c|c|c|c|c|c|c|c|}
\hline Färbung & CD31 & NogoA & NogoA & Olig2 & MAPII & SMI32 & NeuN & KiM1P & GFAP \\
\hline Typ & $\begin{array}{l}\text { mono- } \\
\text { klonal }\end{array}$ & $\begin{array}{l}\text { mono- } \\
\text { klonal }\end{array}$ & polyklonal & polyklonal & $\begin{array}{l}\text { mono- } \\
\text { klonal }\end{array}$ & $\begin{array}{l}\text { mono- } \\
\text { klonal }\end{array}$ & $\begin{array}{l}\text { mono- } \\
\text { klonal }\end{array}$ & $\begin{array}{l}\text { mono- } \\
\text { klonal }\end{array}$ & polyklonal \\
\hline Hersteller & Dako & $\begin{array}{l}\text { Santa } \\
\text { Cruz }\end{array}$ & Chemicon & IBL & $\begin{array}{l}\text { Neo- } \\
\text { markers }\end{array}$ & $\begin{array}{l}\text { Stern- } \\
\text { berger }\end{array}$ & Millipore & \begin{tabular}{|l|} 
Prof. \\
Radzun, \\
Pathologie \\
Göttingen \\
\end{tabular} & Dako \\
\hline $\begin{array}{l}\text { Spezies } \\
\text { primärer } \\
\text { Anti- } \\
\text { körper/ } \\
\text { Verdün- } \\
\text { nung }\end{array}$ & $\begin{array}{l}\text { Maus } \\
1: 10\end{array}$ & $\begin{array}{l}\text { Maus } \\
1: 15000\end{array}$ & $\begin{array}{l}\text { Kaninchen } \\
1: 1000\end{array}$ & $\begin{array}{l}\text { Kaninchen } \\
1: 50\end{array}$ & $\begin{array}{l}\text { Maus } \\
1: 400\end{array}$ & $\begin{array}{l}\text { Maus } \\
1: 1000\end{array}$ & $\begin{array}{l}\text { Maus } \\
1: 100\end{array}$ & $\begin{array}{l}\text { Maus } \\
1: 5000\end{array}$ & $\begin{array}{l}\text { Kaninchen } \\
1: 1000\end{array}$ \\
\hline $\begin{array}{l}\text { Ziel- } \\
\text { struktur }\end{array}$ & $\begin{array}{l}\text { Endothel- } \\
\text { zellen }\end{array}$ & $\begin{array}{l}\text { adulte } \\
\text { Oligoden- } \\
\text { drozyten }\end{array}$ & $\begin{array}{l}\text { adulte } \\
\text { Oligoden- } \\
\text { drozyten }\end{array}$ & $\begin{array}{l}\text { Oligoden- } \\
\text { drozyten / } \\
\text { Oligoden- } \\
\text { drozyten- } \\
\text { vorläufer- } \\
\text { zellen }\end{array}$ & Neurone & Neurone & Neurone & $\begin{array}{l}\text { Makro- } \\
\text { phagen, } \\
\text { Mikroglia }\end{array}$ & Astrozyten \\
\hline
\end{tabular}

Tabelle 02: primäre Antikörper für die kombinierte IHC und ISH

\subsubsection{In-situ-Hybridisierung (ISH)}

Mit Hilfe der In-situ-Hybridisierung ist es möglich, spezifische RNA- bzw. DNA-Abschnitte nachzuweisen. Dabei wird das Prinzip der Basenpaarung der komplementären Nukleinbasen ausgenutzt. Es wird eine Sonde erzeugt, deren Basenfolge das Gegenstück zum gesuchten Abschnitt darstellt. Diese kann sich entsprechend durch Basenpaarung an die Nukleinbasen dieses Abschnitts anlagern. Die Sonde ist bei meinen Untersuchungen gekoppelt an Digoxigenin (DIG), welches im Folgenden als Antigen für einen Anti-DIG-Antikörper dient, der selbst wiederum an alkalische Phosphatase gebunden ist. Die alkalische Phosphatase fungiert als Enzym für das Chromogen NBT-BCIP. Dabei entsteht ein indigoblauer Farbstoff.

Die verwendete Sonde wurde uns freundlicher Weise von Éva Mezey, NIH/NIDCR, Bethesda, USA bereitgestellt. Die Sondenherstellung erfolgte nach dem Protokoll ihrer Forschungsgruppe (Mezey et al. 2000; Mezey et al. 2003). Die Sonde bestand aus einer 1,3 kB langen RNA-Sequenz, die komplementär zu der Satellitenregion des menschlichen Y-Chromosoms erstellt wurde. Diese wurde an Dioxigenin-Uridin-5'- 
Triphosphat gebunden. Da ich eine RNA-Sonde verwendete, erfolgte die Durchführung der ISH unter RNAse-freien Bedingungen. Genutzte Geräte und Chemikalien wurden im Vorfeld sterilisiert.

Die fertig entwickelten Präparate aus der vorangegangenen Immunhistochemie wurden zunächst mehrfach in PBS gespült und anschließend in 2xSSC gestellt. Der Hybridisierungsmix wurde 10 Minuten vor Gebrauch im Thermoblock auf $81^{\circ} \mathrm{C}$ erwärmt. Parallel dazu wurden die Deckgläser auf einer Heizplatte auf dieselbe Temperatur gebracht und die Präparate in Formamid (70\% in 2xSSC) für 10 Minuten bei $81^{\circ} \mathrm{C}$ vorgewärmt. Pro Schnitt wurden $80 \mu \mathrm{l}$ des Hybridisierungsmix aufgetragen und ein Deckglas luftblasenfrei aufgelegt. Die Objekträger wurden für 12 Minuten auf die $81^{\circ} \mathrm{C}$-heiße Heizplatte gelegt und direkt im Anschluss in eine feuchte Kammer gegeben und für 30 Minuten bei $55^{\circ} \mathrm{C}$ inkubiert. Danach wurden in 2xSSC bei Raumtemperatur die Deckgläser abgelöst. Die Schnitte wurden nacheinander für je 5 Minuten in 1xSSC, $0,5 \times S S C$ und $0,1 \times S S C$ gestellt. Anschließend kamen sie für 30 Minuten bei $65^{\circ} \mathrm{C}$ in $0,1 \times S S C$ und wurden danach bei Raumtemperatur abgekühlt. Der Dig Blocker wurde aufgetragen und für 10 Minuten bei $37^{\circ} \mathrm{C}$ in einer feuchten Kammer inkubiert. Dann wurde die Anti-DIG-POD (1:2000 in Dig Blocker) auf die Schnitte gegeben und erneut für 60 Minuten bei $37^{\circ} \mathrm{C}$ inkubiert. Gewaschen wurden die Schnitte danach drei Mal für je 3 Minuten in Dig Buffer I und für 5 Minuten in Dig Buffer III. Im Anschluss erfolgte die lichtgeschützte Entwicklung mit NBT/BCIP bei Raumtemperatur. Dann wurden die Schnitte erneut drei Mal für je 3 Minuten in Dig Buffer I gespült und für 15 Minuten Aqua dest. gestellt. Die Gegenfärbung der Zellkerne erfolgte mit Hämalaun für 20 Sekunden mit anschließender Entwicklung in Leitungswasser für 5 Minuten. Dann wurde mit Aqua dest. gespült und danach mit Aquamount wässrig eingedeckelt. Bei jedem Durchlauf wurden ein männlicher Kontrollfall als Positiv-Kontrolle sowie ein weiblicher nicht-transplantierter Kontrollfall als Negativ-Kontrolle mitgeführt.

\subsection{Morphometrie}

\subsubsection{Immunhistochemie}

Zur Auswertung der immunhistochemischen Färbungen wurde ein Olympus BX41-Lichtmikroskop genutzt. Dabei wurde abhängig von der Art der Färbung eine vierhundertfache (Okular 10x, Objektiv 40x) oder eine tausendfache Vergrößerung (Okular 10x, Objektiv 100x) genutzt.

Die Färbungen mit den Antikörpern gegen CD3, CD8, CD 20, CD138, KiM1P, CR3/43, GFAP, NogoA und Olig2 wurden mit Hilfe eines Zählgitters ausgewertet, dessen Fläche bei der verwendeten vierhundertfachen Vergrößerung $95.000 \mu \mathrm{m}^{2}$ beträgt. Für den Antikörper APP wurde dasselbe Zählgitter bei einer tausendfachen Vergrößerung verwendet, so dass sich eine Gitterfläche von $10.000 \mu \mathrm{m}^{2}$ ergibt. Es wurde jeweils der Mittelwert aus 20 Gesichtsfeldern ermittelt und anschließend der Medianwert der Gruppe errechnet. Es erfolgte eine Umrechnung in Zellen bzw. axonale Sphäroide/ $\mathrm{mm}^{2}$.

Die Bestimmung der absoluten Axonzahl ist nicht möglich. Daher wurde die relative Axondichte durch Verwendung eines Vergleichswertes bestimmt. Hierzu wurde ein Zählgitter mit vorgegebenen Kreuzen genutzt und deren Überschneidungen mit Axonen gezählt. Der Median der Kontrollgruppe wurde mit einer axonalen Dichte von $100 \%$ gleichgesetzt (Vergleichswert) und die einzelnen Ergebnisse der Untersuchungsgruppe in Prozent dieses Vergleichswertes angegeben. 


\subsubsection{In-situ-Hybridisierung (ISH)}

Ähnlich wie bei der Immunhistochemie wurde zur Auswertung ein Lichtmikroskop genutzt mit einer vierhundertfachen (Okular 10x, Objektiv 40x) Vergrößerung. Aufgrund der geringen Anzahl der positiven Zellen wurde jeweils der gesamte Schnitt ausgewertet und mit dem Programm Olympus Life Cell Imaging die Fläche der ausgewerteten Areale bestimmt. Letztendlich erfolgte die Umrechnung in Zellen pro $\mathrm{mm}^{2}$. Dabei wurden zunächst die Zellen mit positiven Y-Chromosom-Sondensignal erfasst sowie dann die doppelt positiven Zellen mit Sonden- und Immunfärbungssignal. Somit konnte dann bestimmt werden, welchen Anteil eine bestimmte Zellpopulation (z.B. Oligodendrozyten, Astrozyten, Neurone) an der Gesamtzahl der Y-Chromosom-positiven Zellen ausmacht.

\section{$2.9 \quad$ Statistische Auswertung}

Die statistische Auswertung der Daten wurde mit dem Programm SOFA Statistics durchgeführt. Dabei wurde der Mann-Whitney-U-Test angewendet. In den Grafiken und Tabellen sind die Medianwerte der Gruppen angegeben.

\subsection{Chemikalienliste}

\subsubsection{Immunhistochemie}

\section{DAB Färbelösung}

Zur Herstellung wurden $1 \mathrm{ml}$ DAB (3,3'-Diaminobenzidine) in $49 \mathrm{ml}$ PBS gelöst und anschließend gefiltert. Direkt vor dem Gebrauch wurden $20 \mu \mathrm{l} 30 \% \mathrm{H}_{2} \mathrm{O}_{2}$ hinzugefügt.

\section{Hämalaun-Färbelösung}

Mayers Hämalaunlösung (Merck) wurde mit Aqua dest. im Verhältnis 1:2 verdünnt und filtriert.

\section{Puffer}

PBS (phosphate buffered saline)

Es wurden 9,55 g PBS in 1 I Aqua bidest. gelöst.

\section{Citratpuffer}

2,1 g Citrat wurden in 1 I Aqua bidest. gelöst und auf einen $\mathrm{pH}$-Wert von 2,0 eingestellt.

\section{EDTA-Puffer}

In $900 \mathrm{ml}$ Aqua bidest. wurden 1,21 g Trisma Base gelöst, dann wurde $1 \mathrm{ml}$ EDTA (1M; pH 8) zugefügt und der pH-Wert auf 9 eingestellt. Anschließend wurde die Lösung mit Aqua bidest. auf $1000 \mathrm{ml}$ Gesamtvolumen aufgefüllt. 


\subsubsection{In-situ-Hybridisierung (ISH)}

\section{$D M P C-\mathrm{H}_{2} \mathrm{O}$}

Es wurde $1 \mathrm{ml}$ DMPC (Dimethylpyrocarbonat) in 1 I Aqua bidest. gegeben, 1-2 Tage bei Raumtemperatur stehen gelassen und danach für 20 Minuten bei $120^{\circ} \mathrm{C}$ autoklaviert.

\section{Ribonukleinsäure-Mix (RNA-Mix)}

In 124,5 $\mu$ l nukleasefreiem Wasser wurden $250 \mu$ Salmon sperm DNA (10mg/ml; Sigma \# D-7656), $313 \mu \mathrm{l}$ Yeast total RNA type XI (20 mg/ml; Sigma \# R-6750) und 312,5 $\mu \mathrm{l}$ Yeast tRNA (20 mg/ml; Invitrogen \# 15401-011) gelöst.

\section{Puffer}

Tris-Stammlösung (1 M):

Es wurden 60,57 g Tris (Tris-(hydroxy-methyl)-aminomethan) in $500 \mathrm{ml} \mathrm{DMPC}-\mathrm{H}_{2} \mathrm{O}$ und $1 \mathrm{M} \mathrm{HCl}$ gelöst und auf $\mathrm{pH}$ 7,5 eingestellt. Anschließend wurde die Lösung mit DMPC- $\mathrm{H}_{2} \mathrm{O}$ auf 1 I aufgefüllt.

Hybridisierungspuffer:

$400 \mu \mathrm{l}$ Tris-Lösung ( $1 \mathrm{M}$; pH 7,4) wurden mit $40 \mu \mathrm{l}$ EDTA (Ethylendiamintetraessigsäure; 0,5M), 1,2 ml $\mathrm{NaCl}$-Lösung (5 M), $10 \mathrm{ml}$ Formamid (Fluka \# 47670), $4 \mathrm{ml}$ Dextransulfat (50\%) (Sigma \# D-8906), $400 \mu \mathrm{l}$ Denhardts Sol (50x) (Sigma \# 30915) und 3,96 ml nukleasefreiem Wasser versetzt.

\section{Digoxigenin-Puffer I (Dig Buffer I):}

Es wurden $30 \mathrm{ml} \mathrm{NaCl}$-Lösung $(5 \mathrm{M})$ und $100 \mathrm{ml}$ Tris-Stammlösung (1 M) mit $855 \mathrm{ml}$ Wasser gemischt und anschließend autoklaviert.

Digoxigenin-Puffer III (Dig Buffer III):

$200 \mathrm{ml}$ Tris-HCl-Lösung (1 M) (pH 8,0) werden mit 50 ml MgCl -Lösung (2 M) und $40 \mathrm{ml} \mathrm{NaCl-Lösung} \mathrm{(5} \mathrm{M)}$ in $1710 \mathrm{ml}$ Wasser gegeben, auf einen $\mathrm{pH}$-Wert von 9,5 eingestellt und danach autoklaviert.

\section{Digoxigenin-Blocker (Dig Blocker):}

$10 \mathrm{ml}$ Digoxigenin Puffer I wurden mit 0,5 ml Ziegenserum versetzt.

Anti-Digoxigenin-POD (Anti-Dig-POD):

Es wurden zu 2 ml Digoxigenin Blocker $5 \mu$ l Anti-Digoxigenin-POD (Roche \# 11207733910) hinzugefügt.

$10 \%$ SDS-Puffer

In 100 ml DMPC- $\mathrm{H}_{2} \mathrm{O}$ werden $10 \mathrm{~g}$ SDS(Natriumdodecylsulfat) gelöst. 
SSC-Puffer (Standard Saline Citrat Lösung):

20xSSC: Es wurden 175,32 g NaCl und 88,20 g Tri-Natrium-Citrat ind 1 I DMPC- $\mathrm{H}_{2} \mathrm{O}$ gelöst und auf einen pH-Wert von 7,0 eingestellt.

2xSSC: Der 20xSSC Puffer wurde mit DMPC- $\mathrm{H}_{2} \mathrm{O}$ auf ein Zehntel der Konzentration verdünnt.

1xSSC: Der 20xSSC Puffer wurde mit DMPC- $\mathrm{H}_{2} \mathrm{O}$ auf ein Zwanzigstel der Konzentration verdünnt.

0,5xSSC: Der 1xSSC Puffer wurde mit DMPC- $\mathrm{H}_{2} \mathrm{O}$ auf die Hälfte der Konzentration verdünnt.

0,1xSSC: Der 1xSSC Puffer wurde mit DMPC- $\mathrm{H}_{2} \mathrm{O}$ auf ein Zehntel der Konzentration verdünnt.

\section{NBT/BCIP-Puffer}

Aus $100 \mathrm{mM}$ Tris, $100 \mathrm{mM} \mathrm{NaCl}$ und $50 \mathrm{mM} \mathrm{MgCl}$, wurde mit 1 I Aqua bidest. eine Lösung hergestellt und anschließend mit $1 \mathrm{M} \mathrm{HCl}$ auf einen $\mathrm{pH}$-Wert von 9,5 eingestellt.

\section{$70 \%$ Formamid / $2 x S S C$}

$50 \mathrm{ml}$ des 20xSSC-Puffers wurden mit $350 \mathrm{ml}$ Formamid und $100 \mathrm{ml}$ Wasser gemischt und anschließend autoklaviert.

\section{Hybridisierungsmix (für ein Präparat)}

In $80 \mu$ l des Hybridisierungspuffers wurden 0,3 $\mu$ l der Sonde, $2 \mu$ INA-Mix, 0,5 $\mu$ l Natriumthiosulfat (10\%) und 0,5 $\mu$ I SDS Puffer (10\%) gegeben. Die Mengen wurden der jeweiligen Präparate-Anzahl angepasst.

\section{NBT/BCIP}

Es wurden $100 \mathrm{mg}$ NBT (Nitroblau-Tetrazoliumchlorid) in $1 \mathrm{ml}$ einer 70 prozentigen Dimethylformamidlösung gegeben. 50 mg BCIP (5-Brom-4-chlor-3-indolylphosphat) wurden in 100 prozentigem Formamid gelöst.

Die Substanzen wurden lichtgeschützt bei $-20^{\circ} \mathrm{C}$ gelagert.

Für den Gebrauch als Färbelösung wurden jeweils $225 \mu \mathrm{l}$ der NBT-Lösung und $175 \mu \mathrm{l}$ der BCIP-Lösung zusammen mit $400 \mu$ l Levamisol in 50 ml DIG Buffer III angesetzt. 


\section{Ergebnisse}

\subsection{Allgemeine ZNS-Pathologie}

\subsubsection{HE}

Von den insgesamt 19 untersuchten Patienten zeigten 7 Patienten (Siehe Tabelle 21 im Anhang; Patienten Nr.: 1 - 3, 13, 14, 16, 17) keine erkennbare ZNS-Erkrankung in der HE-Färbung und erfüllten damit die Einschlusskriterien für alle durchgeführten detaillierten histologischen Betrachtungen außer der ISH.

Weitere 10 Patienten (Siehe Tabelle 21 im Anhang; Patienten Nr.: 4 - 12, 15) zeigten neuropathologische Auffälligkeiten wie beispielsweise ein Rezidiv der Grunderkrankung oder opportunistische Infektionen, die jedoch keinen Einfluss auf die Oligodendrozyten haben sollten, und wurden daher zur genaueren Untersuchung dieser Zellpopulation und zur Erhöhung der Fallzahl in die Studie aufgenommen. Andere Zellpopulationen wie Lymphozyten, Astrozyten oder Makrophagen wurden bei diesen Patienten nicht untersucht. Genauere Informationen zu den einzelnen Befunden lassen sich der Tabelle 21 im Anhang entnehmen.

Die speziellen Einschlusskriterien der ISH wurden von 2 Patienten erfült (Siehe Tabelle 23 im Anhang; Patienten Nr.: ISH-1, ISH-2). Dabei waren weibliches Geschlecht und eine allogene Stammzelltransplantation mit einem männlichen Spender von Bedeutung. Die Patientin ISH-1 zeigte bei der neuropathologischen Untersuchung ein Hirnödem und hypoxische Nervenzellschäden, während die Patientin ISH-2 einen alters-entsprechenden Normalbefund aufwies.

Die 7 Fälle ohne spezifische Pathologie wurden im Folgenden detailliert mittels immunhistochemischer Färbungen analysiert.

\subsection{Lymphozyten}

\subsubsection{CD3 (T-Zellen)}

Insgesamt fand sich eine sehr geringe Anzahl von T-Zellen sowohl im ZNS-Gewebe der transplantierten Patienten als auch der Kontrollen. Die Färbung der T-Zellen ergab keinen Hinweis auf eine erhöhte Anzahl von T-Lymphozyten im Gewebe transplantierter Patienten.

Ganz vereinzelt waren im Parenchym bei den Kontrollen ebenfalls T-Zellen nachweisbar, diese wurden jedoch bei der zufälligen Auswahl der ausgewerteten Gesichtsfelder bzw. durch die Darstellung der Werte als Median nicht erfasst. 


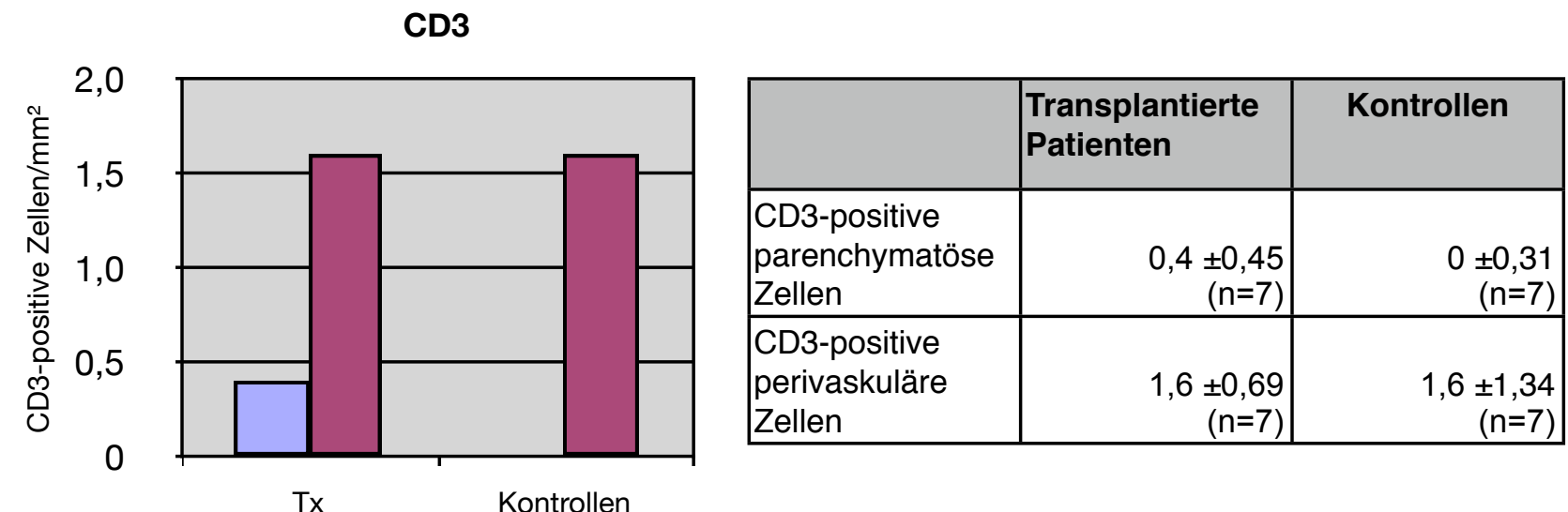

CD3-positive parenchymatöse Zellen CD3-positive perivaskuläre Zellen

Abb. 02: Diagramm - CD3 und Tabelle 03: Anzahl der T-Zellen (Die Werte sind angegeben als Zellen $/ \mathrm{mm}^{2} \pm$ Standardabweichung)

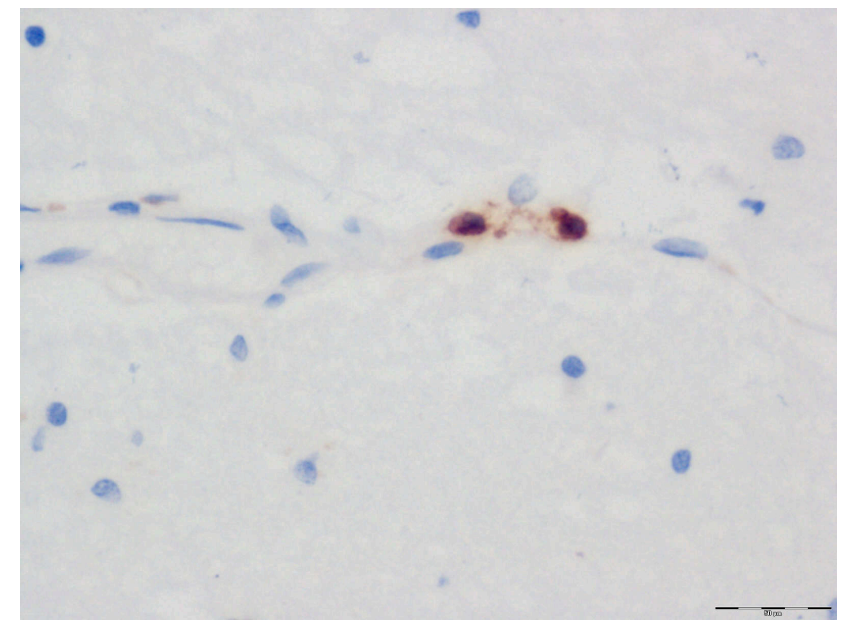

Abb. 03: CD3-positive Zellen, perivaskulär in Tx-Fall

(Messbalken unten rechts im Bild entspricht $50 \mu \mathrm{m}$ )

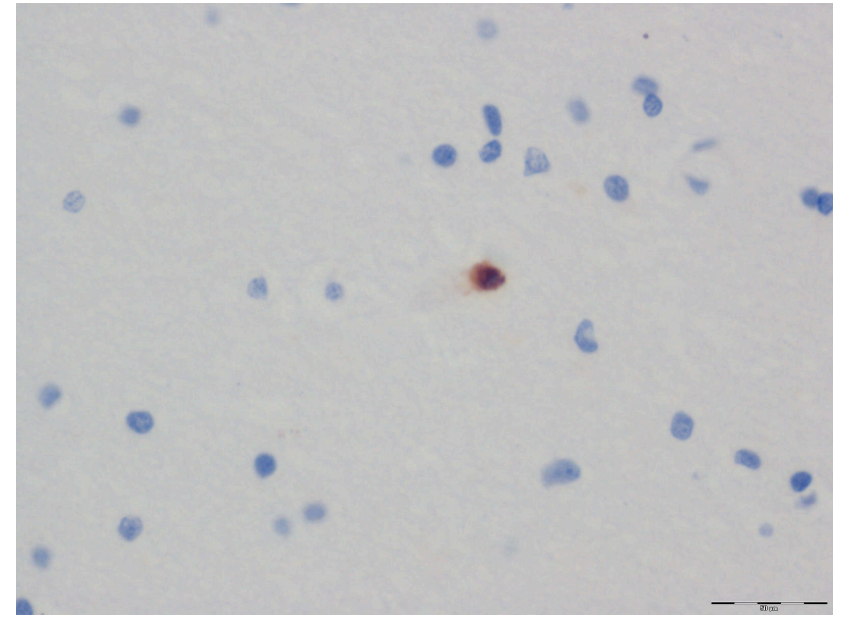

Abb. 04: CD3-positive Zellen, parenchymatös in Kontroll-Fall

(Messbalken unten rechts im Bild entspricht $50 \mu \mathrm{m}$ ) 


\subsubsection{CD8 (zytotoxische T-Zellen)}

Die Anzahl der CD8-positiven zytotoxischen T-Zellen zeigte keinen signifikanten Unterschied zwischen Patienten mit einer Stammzelltransplantation und den Kontrollen.

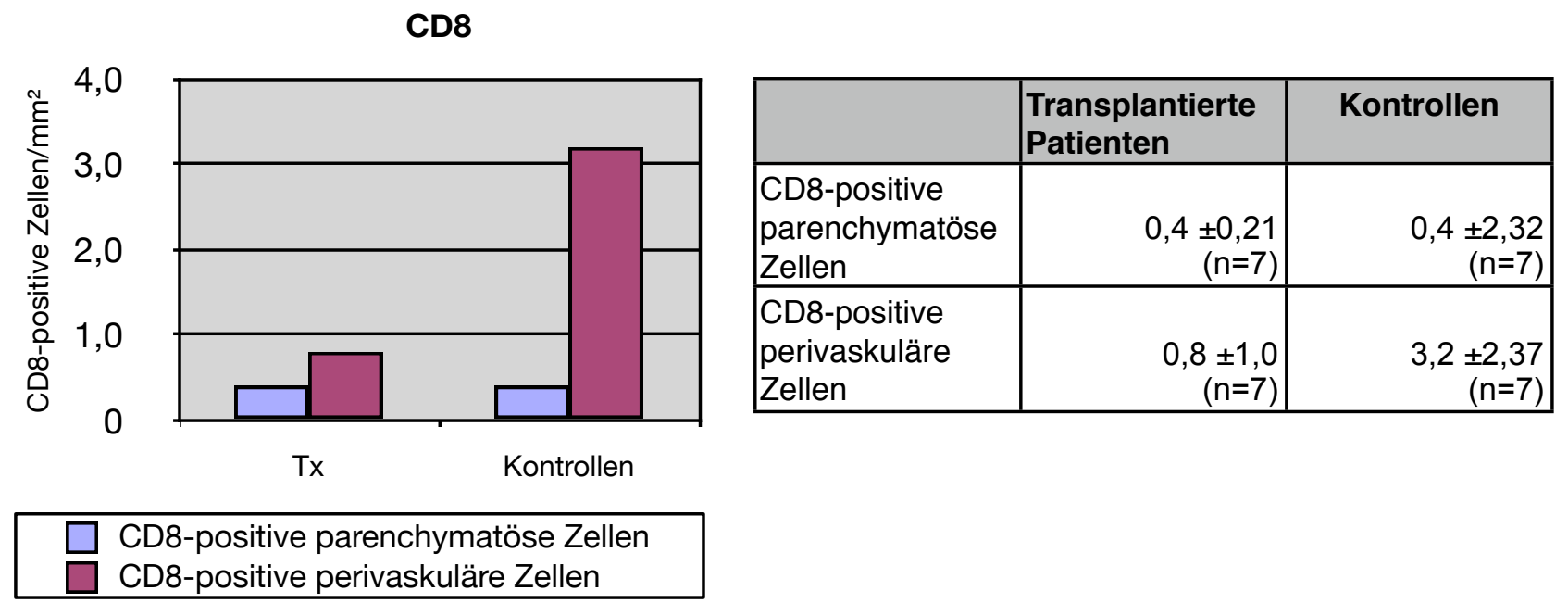

Abb. 05: Diagramm - CD8 und Tabelle 04: Anzahl zytotoxischer T-Zellen (Die Werte sind angegeben als Zellen $/ \mathrm{mm}^{2} \pm$ Standardabweichung)

\subsubsection{CD20 und CD138 (B-Zellen und Plasmazellen)}

Bei der Anti-CD20-Färbung wurden keine B-Zellen in den Präparaten gefunden. Es konnten auch bei der Anti-CD138-Färbung keine Plasmazellen im Gewebe nachgewiesen werden.

\subsection{Astrozyten}

\subsubsection{GFAP}

Mittels der Anti-GFAP-Färbung konnten keine signifikanten Unterschiede zwischen den transplantierten Patienten und den Kontrollen festgestellt werden. Es fanden sich keine Hinweise auf eine Astrozytenvermehrung oder eine vermehrte reaktive Gliose.

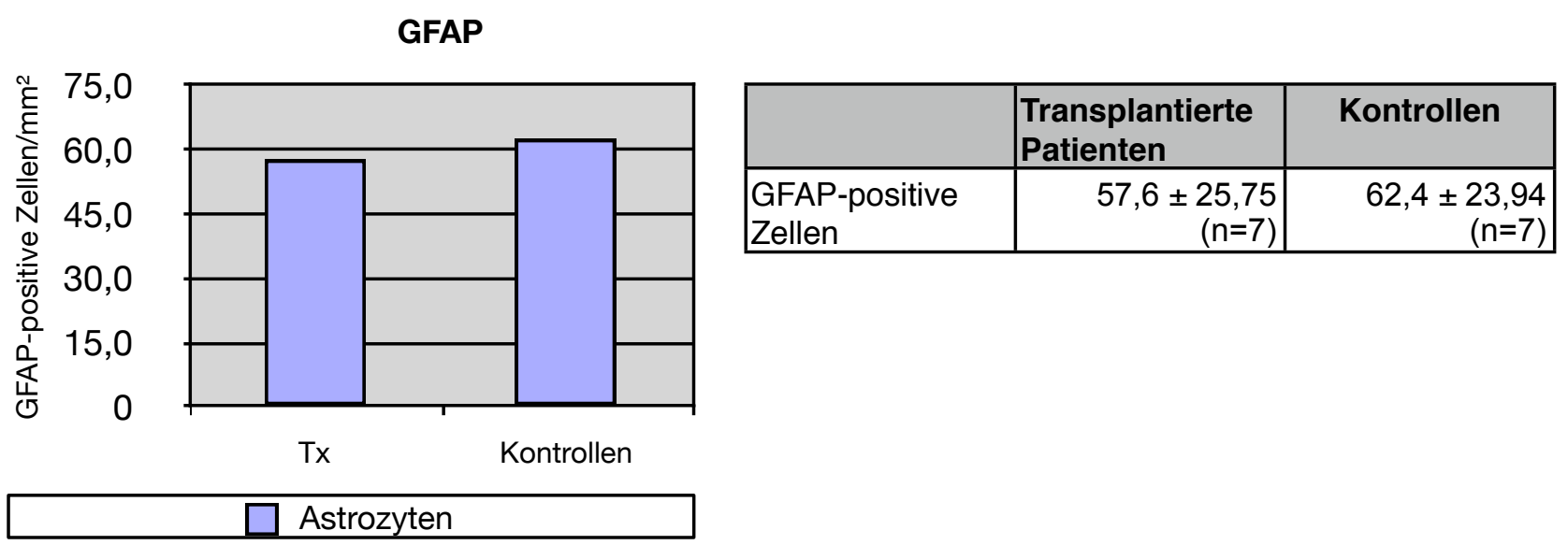

Abb. 06: Diagramm - GFAP und Tabelle 05: Anzahl der Astrozyten (Die Werte sind angegeben als Zellen $/ \mathrm{mm}^{2} \pm$ Standardabweichung) 


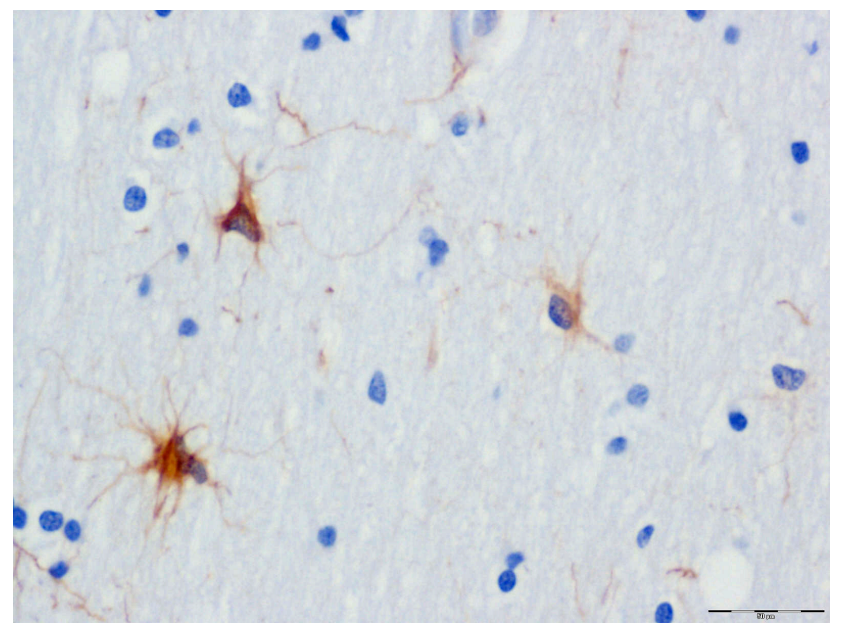

Abb. 07: GFAP-positive Zellen in Tx-Fall

(Messbalken unten rechts im Bild entspricht $50 \mu \mathrm{m}$ )

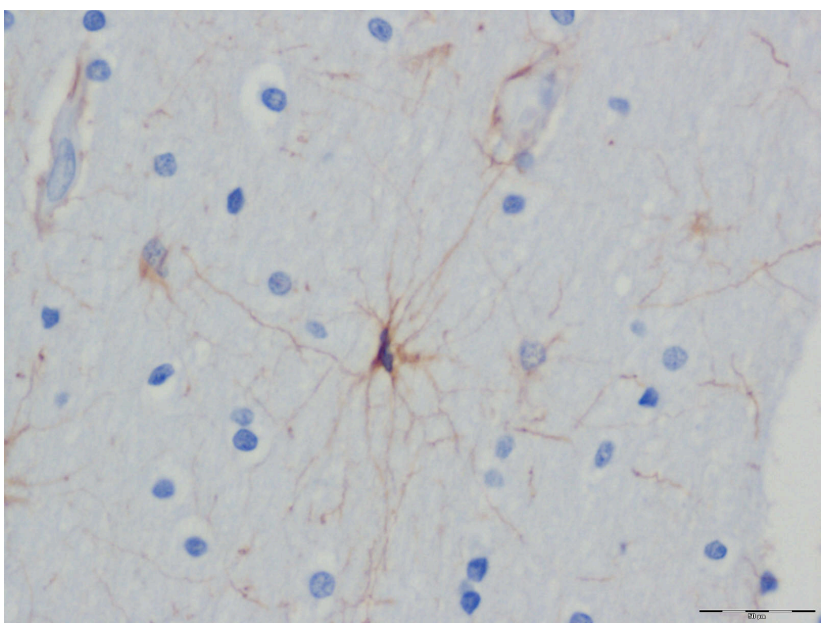

Abb. 08: GFAP-positive Zellen in Kontroll-Fall

(Messbalken unten rechts im Bild entspricht $50 \mu \mathrm{m}$ )

\subsection{Makrophagen / Mikroglia}

\subsubsection{KiM1P}

Die KiM1P-Färbung zeigte keine Zunahme der Makrophagen und keine Zeichen einer vermehrten Mikrogliaaktivierung.

Die Differenzierung von Makrophagen und Mikroglia erfolgte anhand morphologischer Merkmale. Runde Zellen ohne Fortsätze und mit schaumzelligen Zytoplasma wurden als Makrophagen gewertet, während die Mikrogliazellen einen stäbchenförmigen Zellkern und feine Ausläufer besaßen.

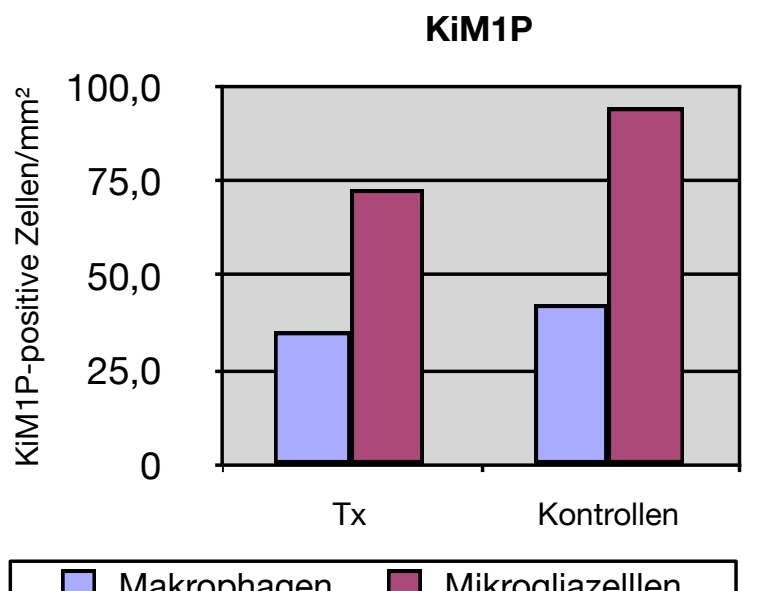

\begin{tabular}{|c|c|c|}
\hline & \begin{tabular}{|l} 
Transplantierte \\
Patienten
\end{tabular} & Kontrollen \\
\hline $\begin{array}{l}\text { KiM1P-positive } \\
\text { Makrophagen }\end{array}$ & $\begin{array}{r}35,2 \pm 9,6 \\
(\mathrm{n}=7)\end{array}$ & $\begin{array}{r}42,4 \pm 14,35 \\
(n=7)\end{array}$ \\
\hline $\begin{array}{l}\text { KiM1P-positive } \\
\text { Mikrogliazellen }\end{array}$ & $\begin{array}{r}72,8 \pm 28,37 \\
(n=7)\end{array}$ & $\begin{array}{r}94,4 \pm 24,48 \\
(n=7)\end{array}$ \\
\hline
\end{tabular}

Abb. 09: Diagramm - KiM1P und Tabelle 06: Anzahl von Makrophagen und Mikrogliazellen (Die Werte sind angegeben als Zellen/mm² \pm Standardabweichung) 


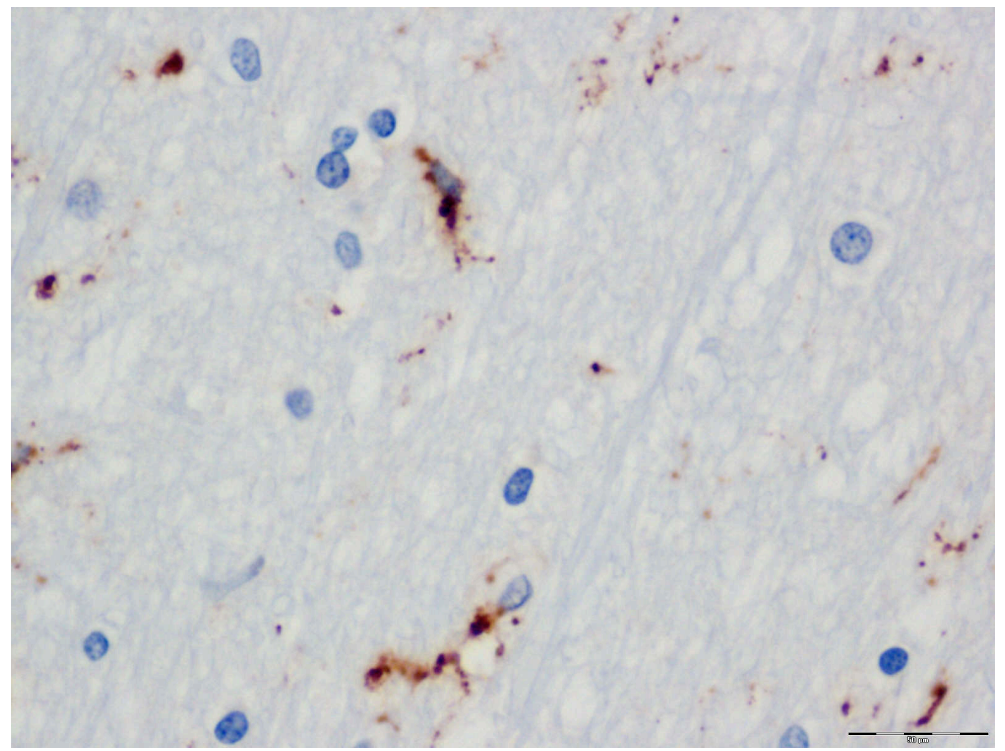

Abb. 10: KiM1P-positive Mikrogliazellen in Tx-Fall

(Messbalken unten rechts im Bild entspricht $50 \mu \mathrm{m}$ )

\subsubsection{CR3/43}

Die CR3/43-Färbung bestätigte die Ergebnisse der KiM1P-Färbung und zeigte keine signifikanten Unterschiede zu den Kontrollen. Es färbten sich tendenziell weniger Zellen bei der CR3/43-Färbung im Vergleich zur KiM1P-Färbung an.

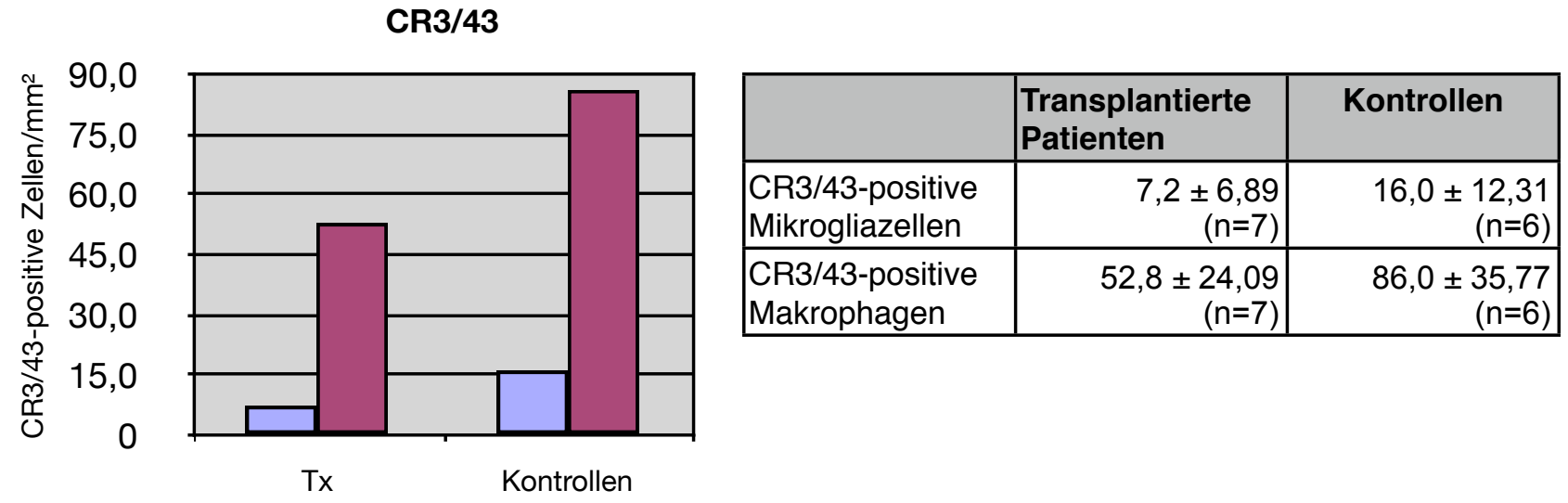

Makrophagen $\square$ Mikrogliazellen

Abb. 11: Diagramm - CR3/43 und Tabelle 07: Anzahl von CR3/43-positiven Makrophagen (Die Werte sind angegeben als Zellen $/ \mathrm{mm}^{2} \pm$ Standardabweichung)

\subsection{Axone}

\subsubsection{APP (akute axonale Schädigung)}

In der Anti-APP-Färbung fanden sich keine Zeichen eines vermehrten akuten axonalen Schadens bei den Patienten mit einer Stammzelltransplantation gegenüber den Kontrollen. 


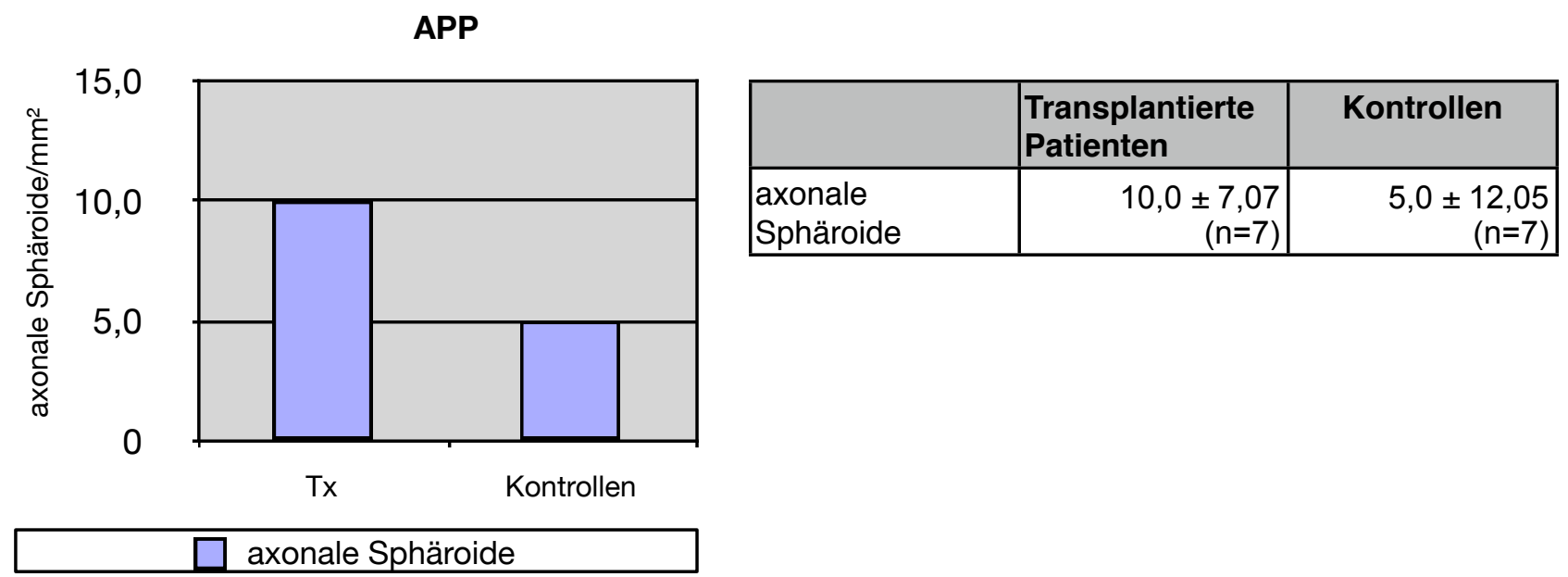

Abb. 12: Diagramm - APP und Tabelle 08: Anzahl von axonalen Sphäroiden (Die Werte sind angegeben als axonale Sphäroide $/ \mathrm{mm}^{2} \pm$ Standardabweichung)

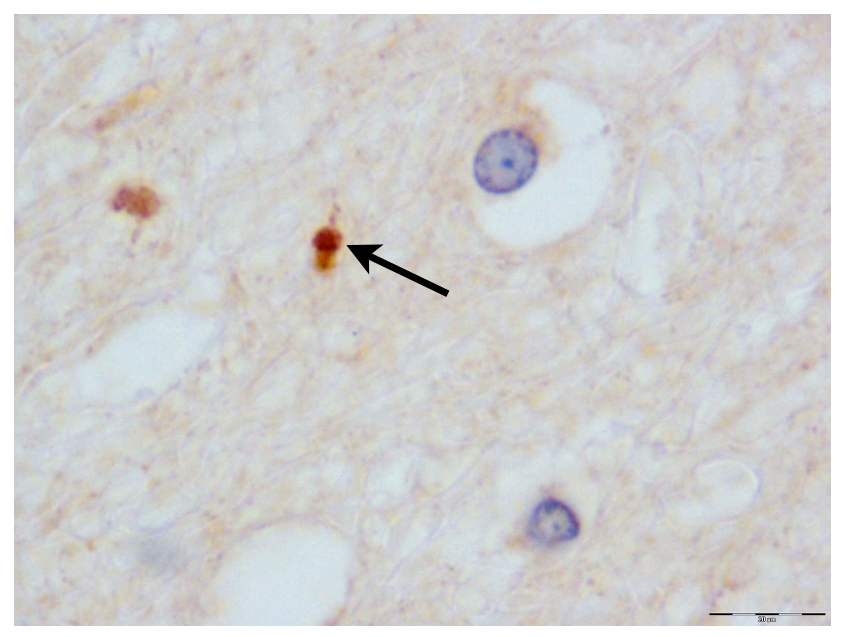

Abb. 13: Akute axonale Schädigung im Tx-Fall

(Pfeil = axonales Sphäroid)

(Messbalken unten rechts im Bild entspricht $20 \mu \mathrm{m}$ )

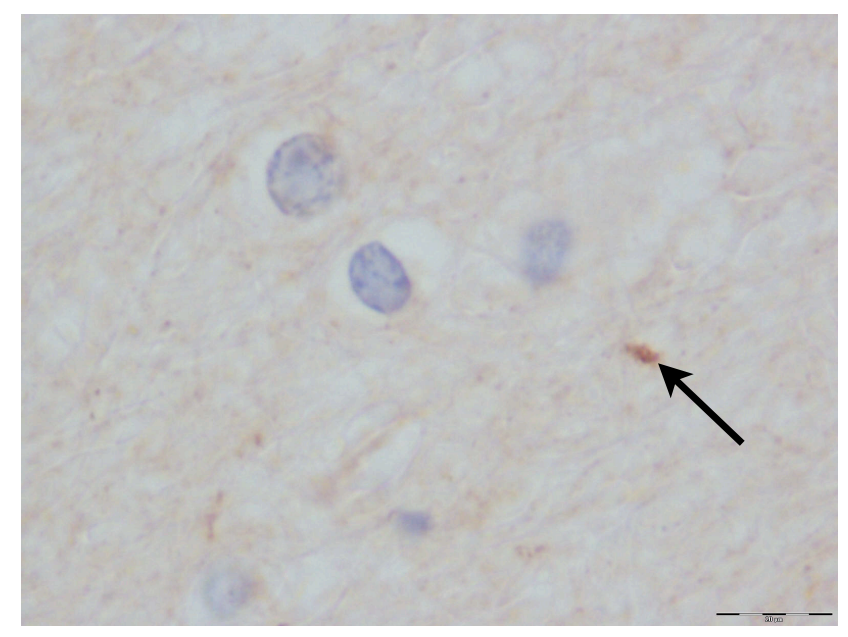

Abb. 14: Akute axonale Schädigung im Kontroll-Fall (Pfeil $=$ axonales Sphäroid) (Messbalken unten rechts im Bild entspricht $20 \mu \mathrm{m}$ )

\subsubsection{Bielschowsky-Versilberung (axonale Dichte)}

Die axonale Dichte zeigte sich bei den transplantierten Patienten nicht herabgesetzt und entsprach der der Kontrollen. Es war somit kein Axonverlust bei den transplantierten Patienten nachweisbar. 


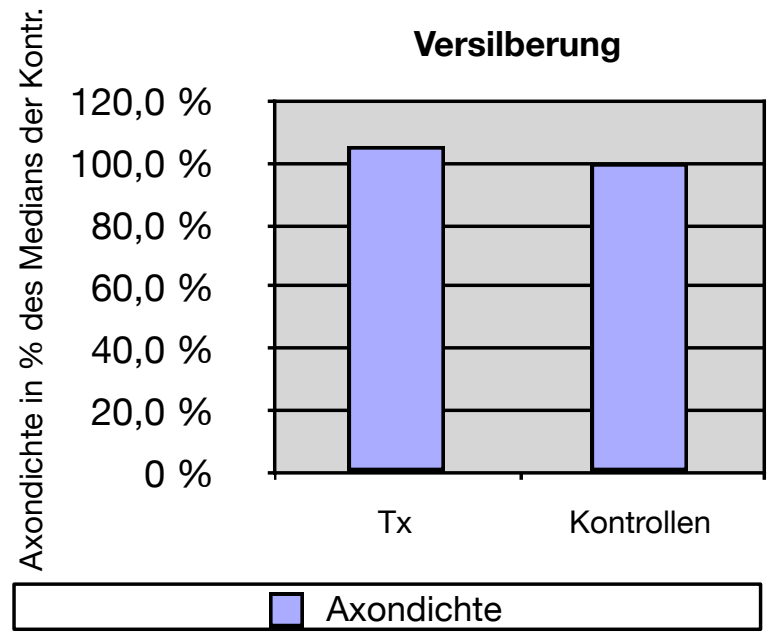

\begin{tabular}{|l|r|r|}
\hline & $\begin{array}{l}\text { Transplantierte } \\
\text { Patienten }\end{array}$ & Kontrollen \\
\hline Axondichte & $\begin{array}{r}105,5 \\
(\mathrm{n}=7)\end{array}$ & $\begin{array}{r}100 \\
(\mathrm{n}=7)\end{array}$ \\
\hline
\end{tabular}

Abb. 15: Diagramm - Versilberung nach Bielschowsky und Tabelle 09: Axondichte (Die Werte sind angegeben als Axondichte in \% des Medians der Kontrollen \pm Standardabweichung. Die Axondichte der Kontrollen entspricht definitionsgemäß 100\%.)

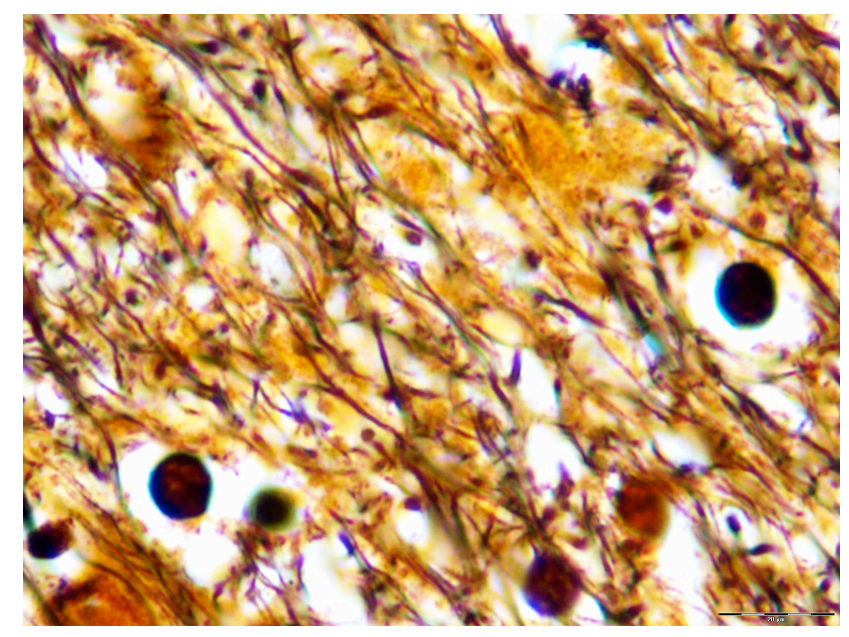

Abb. 16: Versilberung der Axone nach

\section{Bielschowsky in Tx-Fall}

(Messbalken unten rechts im Bild entspricht $20 \mu \mathrm{m}$ )

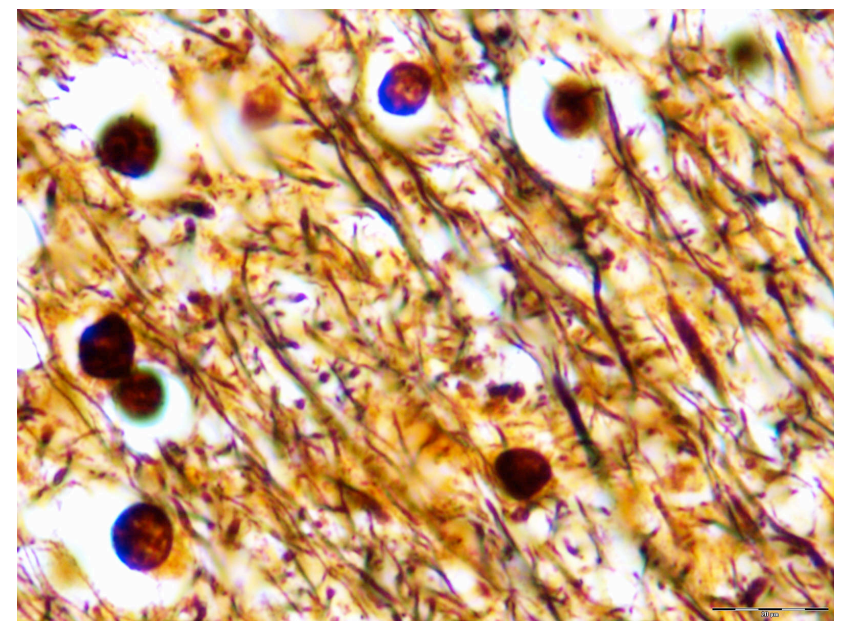

Abb. 17: Versilberung der Axone nach

Bielschowsky in Kontroll-Fall

(Messbalken unten rechts im Bild entspricht $20 \mu \mathrm{m}$ )

\subsection{Oligodendrozyten und Myelin}

Bei der Untersuchung der Oligodendrozytenpopulation wurden zusätzlich zu den Patienten ohne spezifische Pathologie $(n=7)$ auch Patienten mit ZNS-Erkrankungen $(n=10)$ einbezogen, so dass sich insgesamt eine größere Fallzahl ergab $(n=17)$. 


\subsubsection{NogoA (reife Oligodendrozyten)}

In der Anti-NogoA-Färbung fanden sich keine Hinweise auf eine veränderte Anzahl reifer Oligodendrozyten in den untersuchten Regionen (Marklager, Balken, SVZ). Die höchste Anzahl reifer Oligodendrozyten war in der SVZ Zone nachweisbar, während es im Balken nur etwa halb soviel waren und im Marklager circa $10 \%$.

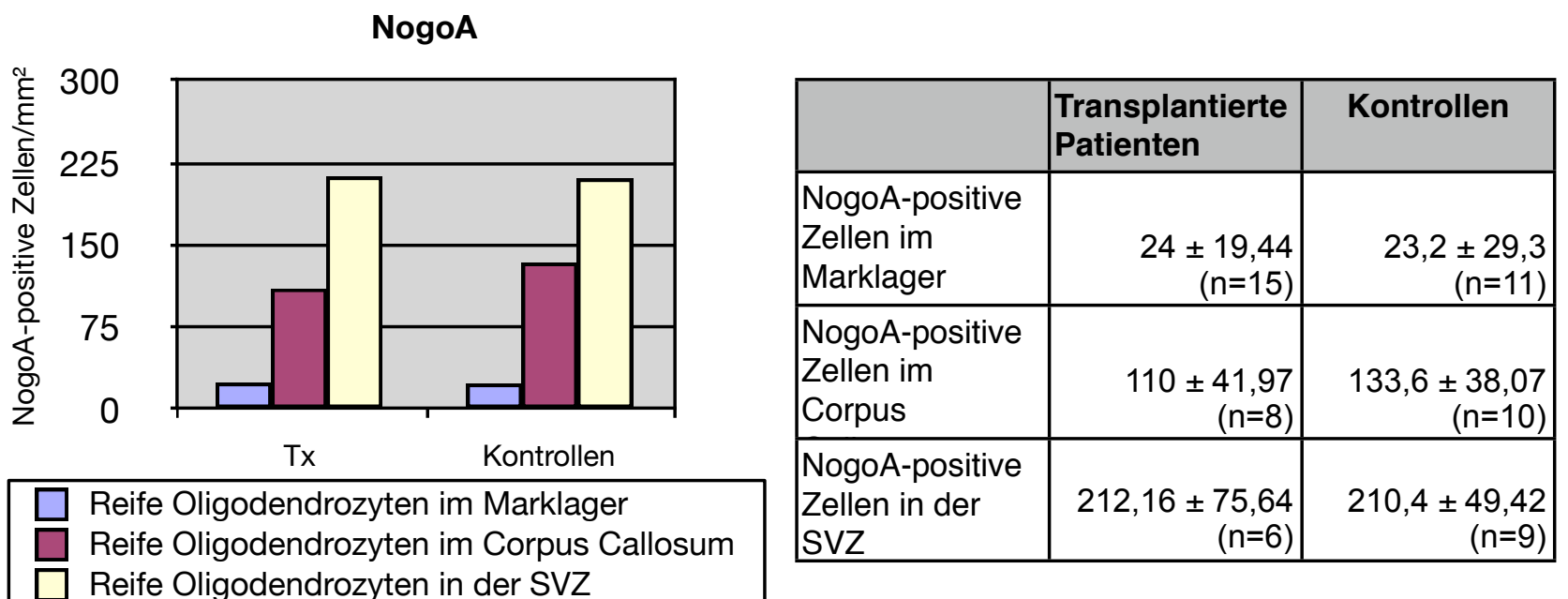

Abb. 18: Diagramm - NogoA und Tabelle 10: Anzahl von reifen Oligodendrozyten (Die Werte sind angegeben als Zellen/mm² \pm Standardabweichung)

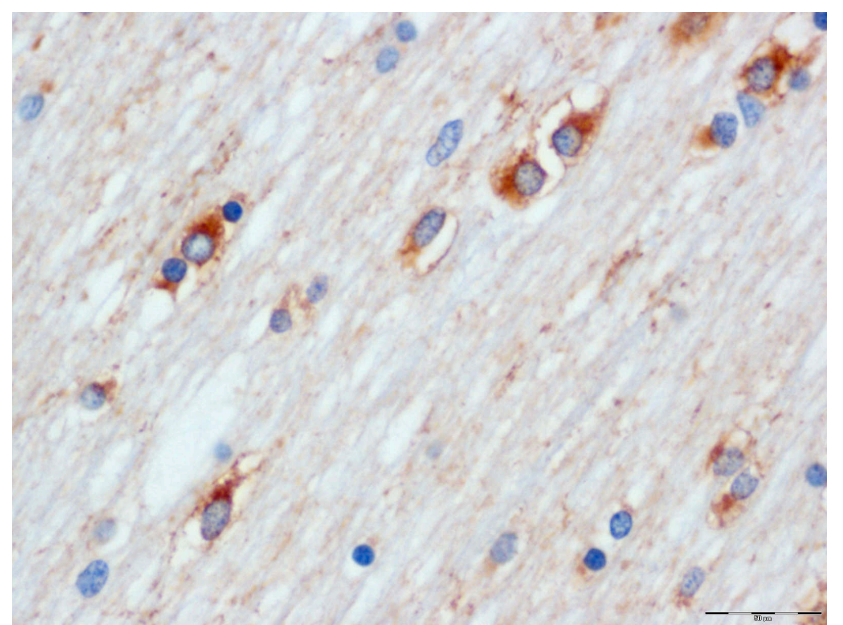

Abb. 19: NogoA-positive Zellen in Tx-Fall

(Messbalken unten rechts im Bild entspricht $50 \mu \mathrm{m}$ )

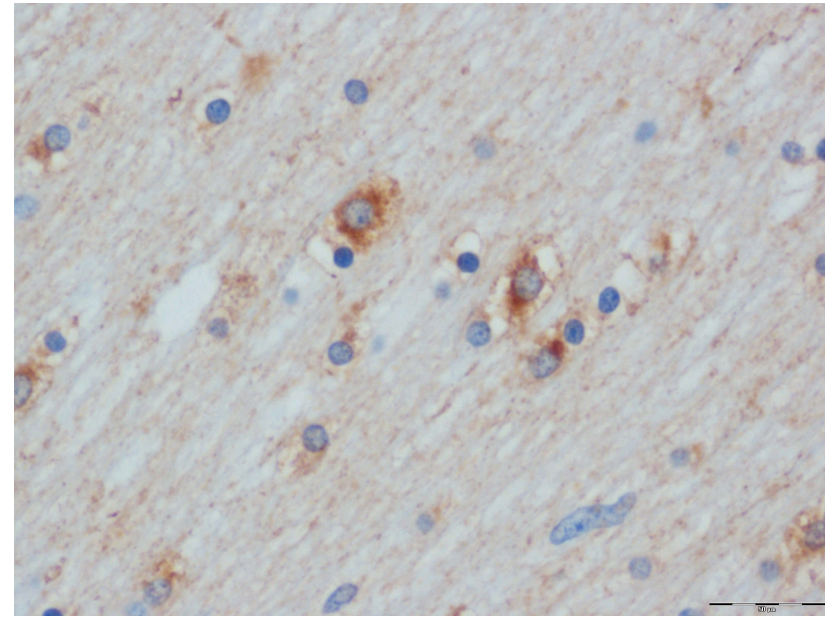

Abb. 20: NogoA-positive Zellen in Kontroll-Fall

(Messbalken unten rechts im Bild entspricht $50 \mu \mathrm{m}$ )

\subsubsection{Olig2 (Oligodendrozytenvorläuferzellen und reife Oligodendrozyten)}

Anhand der Färbeintensität der Zellkerne wurden stark gefärbte Oligodendrozytenvorläuferzellen und reife Oligodendrozyten, welche sich nur noch schwach anfärben, unterschieden (Kuhlmann et al. 2008). Die Anti-Olig2-Färbung zeigte keine Veränderungen in der Anzahl der Oligodendrozytenvorläuferzellen und der reifen Oligodendrozyten.

Olig2-positive Vorläuferzellen und reifen Oligodendrozyten fanden sich am häufigsten in der SVZ, weniger im Balken und die geringste Anzahl wurde im Marklager nachgewiesen. Die Anzahl der reifen Olig2-positiven 
Zellen war in der SVZ und im Balken vergleichbar mit den NOGO-A positiven Oligodendrozyten, zeigte im Marklager jedoch höhere Werte.

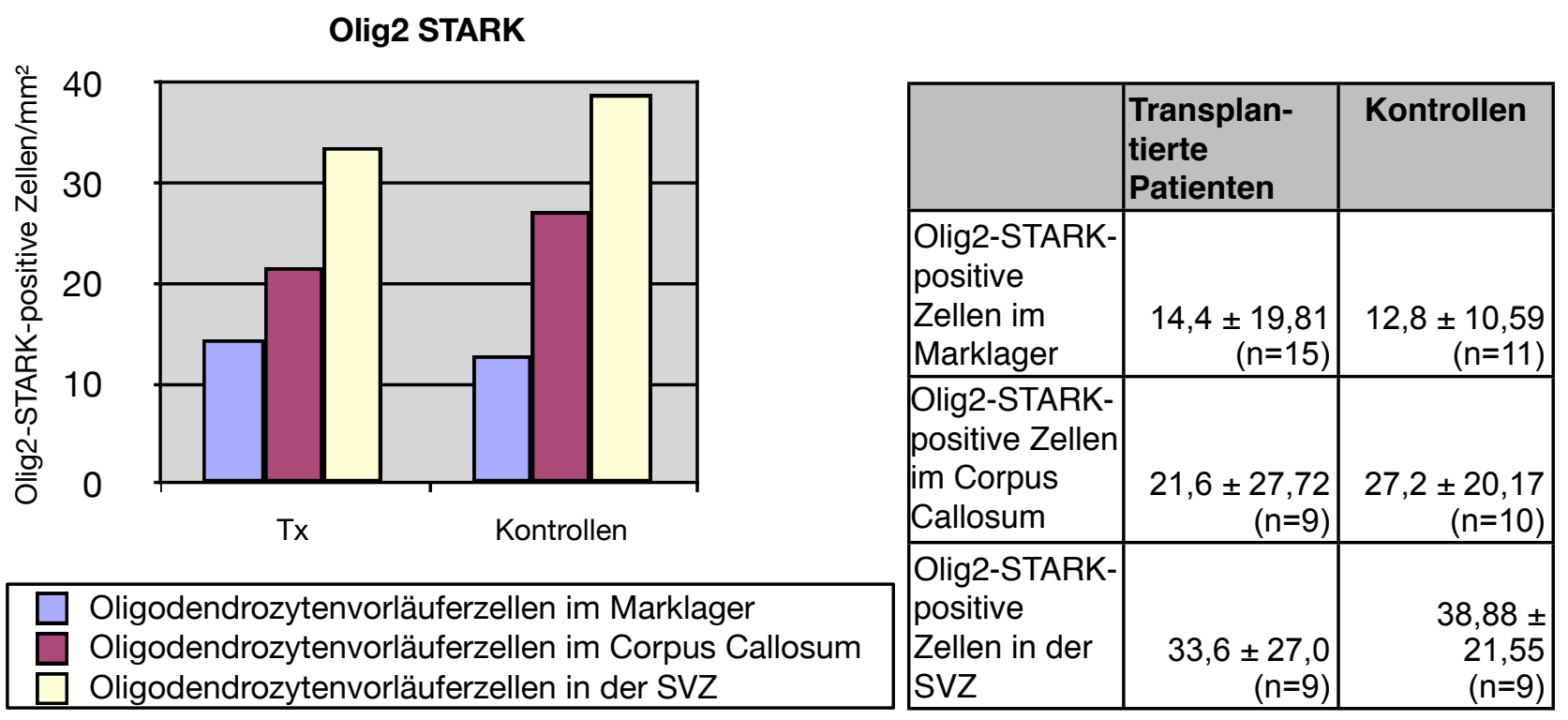

Abb. 21: Diagramm - Olig2 Stark und Tabelle 11: Anzahl von Oligodendrozytenvorläuferzellen (Die Werte sind angegeben als Zellen $/ \mathrm{mm}^{2} \pm$ Standardabweichung)

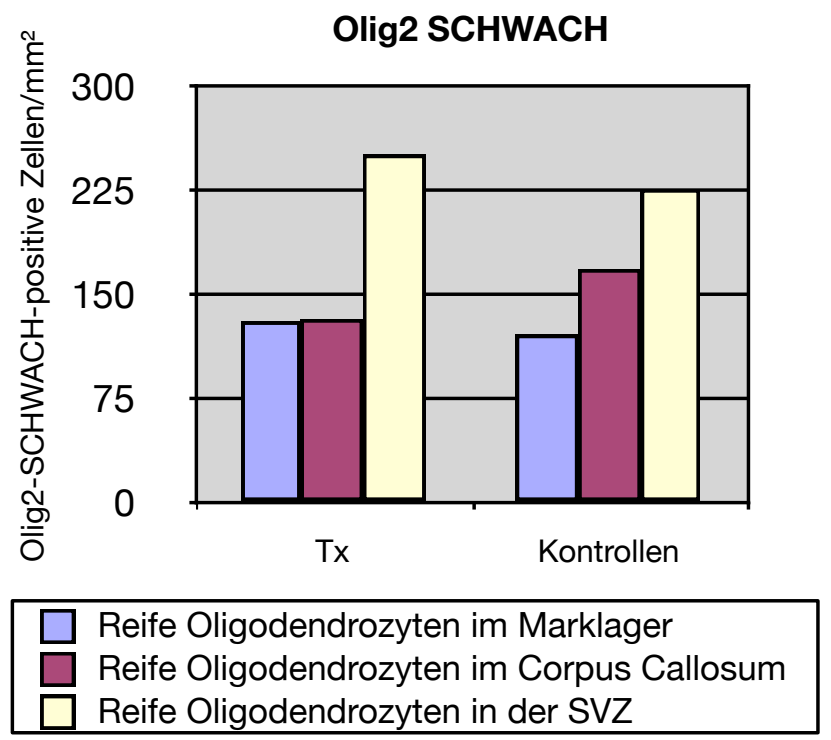

\begin{tabular}{|c|c|c|}
\hline & \begin{tabular}{|l|} 
Transplantierte \\
Patienten
\end{tabular} & Kontrollen \\
\hline $\begin{array}{l}\text { Olig2-SCHWACH- } \\
\text { positive Zellen im } \\
\text { Marklager }\end{array}$ & $\begin{array}{r}130,4 \pm 92,01 \\
(n=15)\end{array}$ & $\begin{array}{r}120,8 \pm 69,43 \\
(n=11)\end{array}$ \\
\hline \begin{tabular}{|l|} 
Olig2-SCHWACH- \\
positive Zellen im \\
Corpus Callosum
\end{tabular} & $\begin{array}{r}132 \pm 122,58 \\
(n=9)\end{array}$ & $\begin{array}{r}168 \pm 132,0 \\
(n=10)\end{array}$ \\
\hline \begin{tabular}{|l|} 
Olig2-SCHWACH- \\
positive Zellen in \\
der SVZ
\end{tabular} & $\begin{array}{r}250,4 \pm 200,62 \\
(n=9)\end{array}$ & $\begin{array}{r}225,6 \pm 134,32 \\
(n=9)\end{array}$ \\
\hline
\end{tabular}

Abb. 22: Diagramm - Olig2 Schwach und Tabelle 12: Anzahl von reifen Oligodendrozyten (Die Werte sind angegeben als Zellen $/ \mathrm{mm}^{2} \pm$ Standardabweichung) 


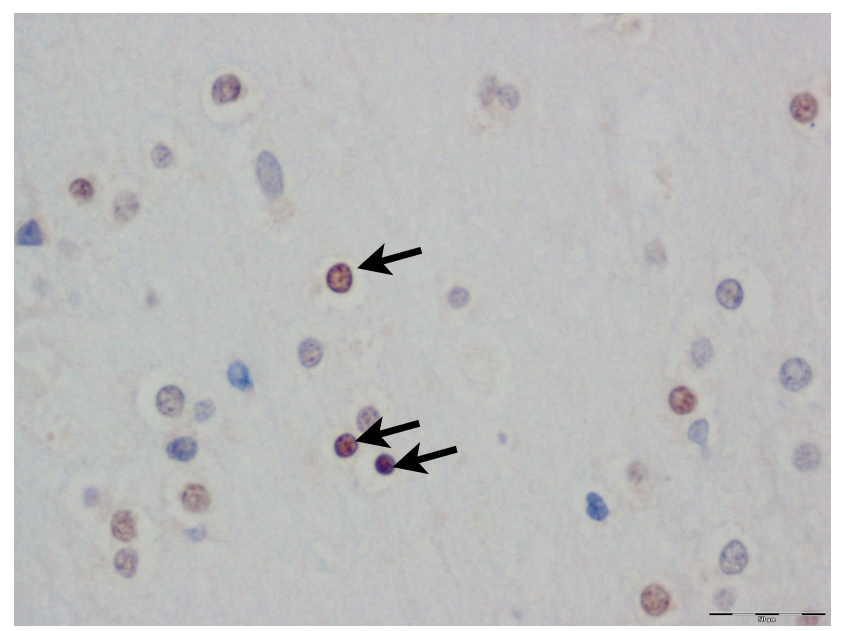

Abb. 23: Olig2-positive Zellen in Tx-Fall

(Pfeile = Oligodendrozytenvorläuferzellen)

(Messbalken unten rechts im Bild entspricht $50 \mu \mathrm{m}$ )

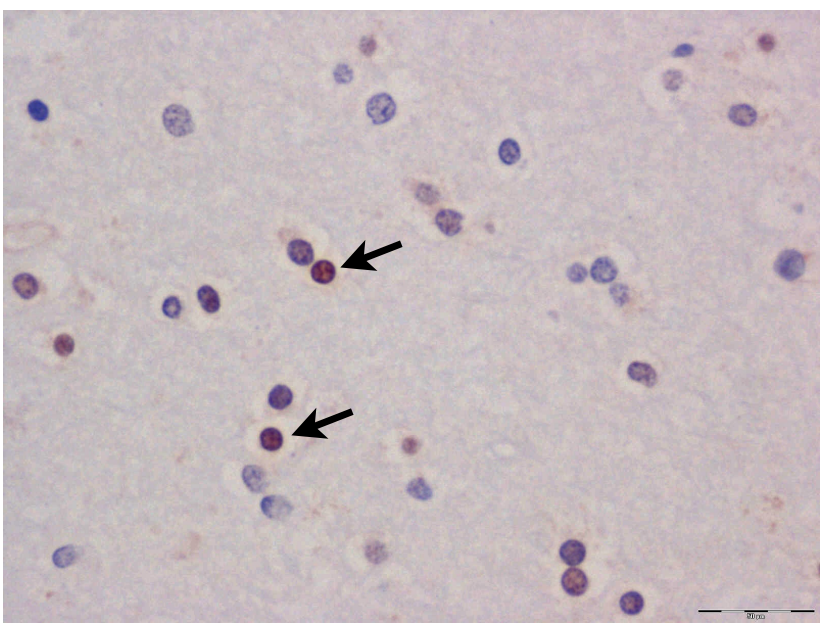

Abb. 24: Olig2-positive Zellen in Kontroll-Fall

(Pfeile = Oligodendrozytenvorläuferzellen)

(Messbalken unten rechts im Bild entspricht $50 \mu \mathrm{m}$ )

\subsubsection{Myelin-basisches Protein (Myelinfärbung)}

Es wurde eine Myelinfärbung mit Anti-MBP-Antikörpern durchgeführt. Diese wurde hinsichtlich einer Entmarkung oder Rarefizierung des Myelins untersucht. Es konnten sowohl bei den transplantierten Patienten als auch Kontrollen keine pathologischen Veränderungen nachgewiesen werden.

\subsection{Gefäße}

Die Auswertung der Gefäße erfolgte ohne spezifische immunhistochemische Färbung anhand der Morphologie. Es fand sich kein Hinweis auf eine verstärkte Angiogenese, wie es beispielsweise im Rahmen einer Entzündungsreaktion oder bei lokalen Ischämien typisch wäre. Eine Verminderung der Gefäße war ebenfalls nicht zu erkennen. Auch die Anzahl der perivaskulären Zellen war nicht erhöht (nicht dargestellt).

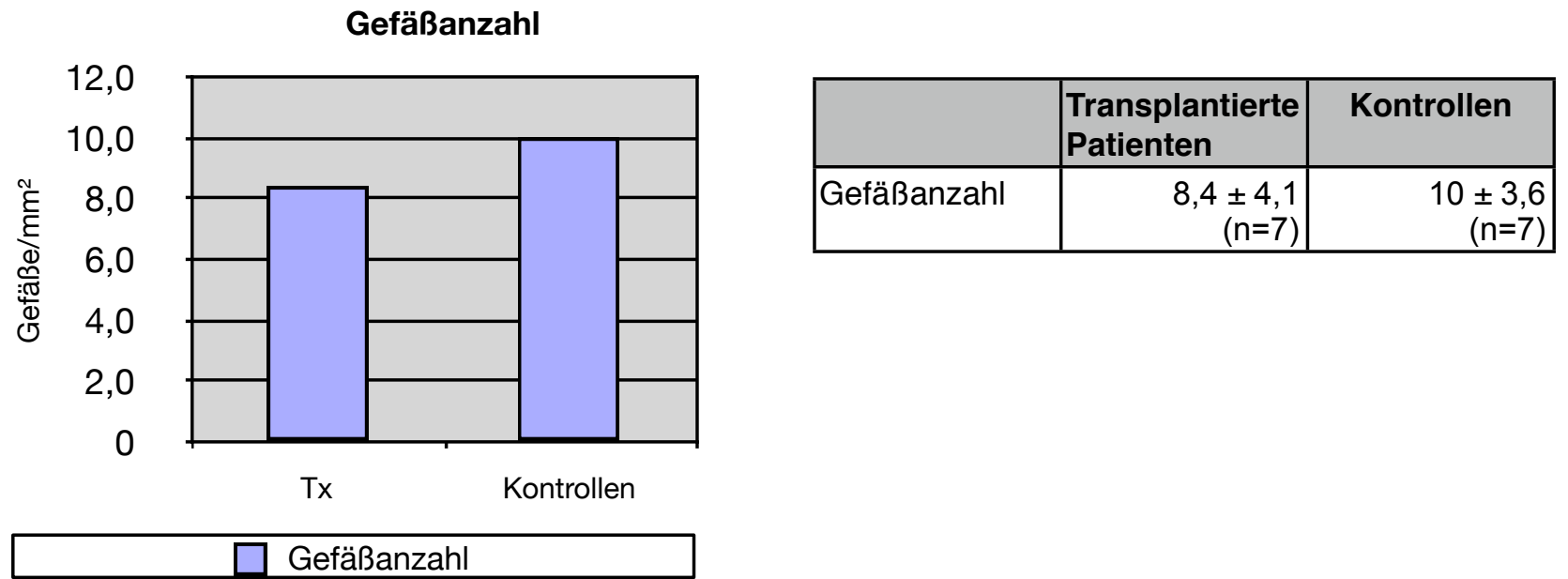

Abb. 25: Diagramm - Gefäßanzahl und Tabelle 13: Gefäßanzahl (Die Werte sind angegeben als Gefäße/mm² \pm Standardabweichung) 
Zusammenfassend betrachtet, fanden sich keine Unterschiede in der Entzündungsinfiltration, reaktiven Astrogliose, axonalen Schädigung, Myelin- und Oligodendrozytenpathologie oder der Gefäßpathologie bei Vergleich von transplantierten Patienten und Kontrollen.

\subsection{Korrelation des zeitlichen Abstandes der Stammzelltransplantation mit den histologischen Ergebnissen}

Der mediane zeitliche Abstand zwischen Transplantation und Tod der Patienten betrug 3 Monate. Die Patienten verstarben weniger als 1 Monat bis 19 Monate nach der Transplantation (siehe Tabelle $21 \mathrm{im}$ Anhang).

Da histopathologische Veränderungen möglicherweise zeitabhängig auftreten, erfolgte die Untersuchung des Zusammenhanges von zeitlichem Abstand der Stammzelltransplantation zum Entnahmezeitpunkt des Gewebes bzw. Tod des Patienten und den histopathologischen Veränderungen (Entzündung, Axonpathologie etc.). Hierbei zeigten sich keine signifikanten Auffälligkeiten. Die geringe Fallzahl erschwerte hier jedoch die Betrachtung.

\subsection{Korrelation des Patientenalters mit den Ergebnissen der Oligodendrozyten-Färbungen}

Um einen Einfluss des Patientenalters auf die Untersuchungsergebnisse der Oligodendrozyten-Färbungen unabhängig von der durchgeführten Therapie und Transplantation auszuschließen, wurde dieser Zusammenhang genauer untersucht. Das mediane Patientenalter betrug 54 Jahre $(s=9,25)$ in der Patientengruppe und 52,5 Jahre $(s=8,65)$ in der Kontrollgruppe. Weder bei den Kontrollen, bei den transplantierten Patienten noch bei Zusammenfassen der Kontrollen und transplantierten Patienten zeigte sich eine Korrelation zwischen dem Patientenalter und der Anzahl der Oligodendrozyten bzw. Oligodendrozytenvorläuferzellen. Auch in diesem Fall wurde die Auswertung durch eine geringe Fallzahl erschwert.

\subsection{Vergleich des Gehirngewichts von transplantierten Patienten und der Kontrollgruppe}

Die Gehirne der transplantierten Patienten zeigten im Vergleich zur Kontrollgruppe keine Auffälligkeiten in Bezug auf das mittlere Hirngewicht, welches hinweisend auf eine Atrophie und damit eine Neurodegeneration sein könnte. Im Mittel betrug das Gewicht der Gehirne 1359 Gramm bei den transplantierten Patienten und 1337 Gramm bei der Kontrollgruppe. 


\subsection{Einfluss einer Radiotherapie auf die Oligodendrozyten}

Die transplantierten Patienten, die im Rahmen ihrer Therapie eine TBI erhalten hatten, wurden gesondert auf Veränderungen in den Oligodendrozytenpopulationen untersucht.

In der Anti-NogoA-Färbung zeigten sich keine signifikanten Unterschiede bei Vergleich mit transplantierten Patienten ohne Radiotherapie und nicht-transplantierten Kontrollen. Die Anzahl der Olig2-SCHWACH-positiven, reifen Oligodendrozyten war erniedrigt, jedoch ohne statistische Signifikanz.

Die Oligodendrozytenvorläuferzellen in der SVZ zeigten sich jedoch bei den bestrahlten Fällen signifikant erniedrigt $(p=0,04)$ verglichen mit den nicht-bestrahlten transplantierten Patienten. Die Unterschiede zur Kontrollgruppe waren ebenfalls signifikant $(p=0,034)$.

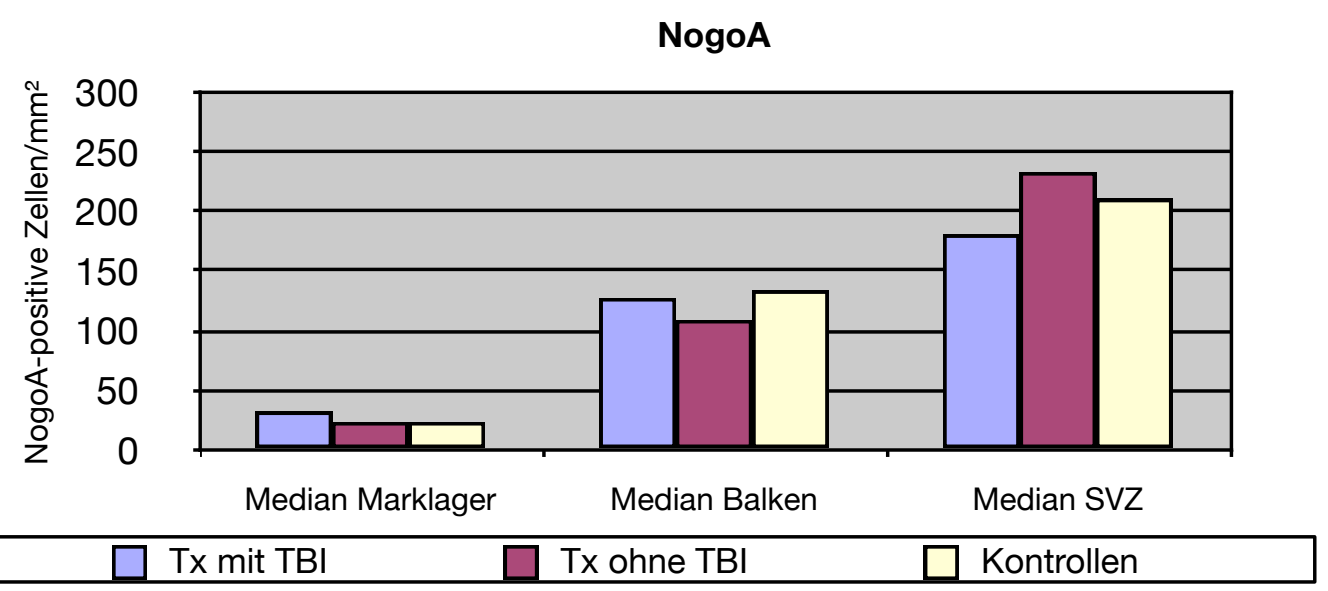

Abb. 26: Diagramm - NogoA bei Radiatio

\begin{tabular}{|l|r|r|r|}
\hline & \multicolumn{1}{|c|}{$\begin{array}{c}\text { Transplantierte } \\
\text { Patienten mit TBI }\end{array}$} & $\begin{array}{r}\text { Transplantierte } \\
\text { Patienten ohne TBI }\end{array}$ & Kontrollen \\
\hline $\begin{array}{l}\text { NogoA-positive Zellen im } \\
\text { Marklager }\end{array}$ & $\begin{array}{r}32 \pm 6,11 \\
(\mathrm{n}=3)\end{array}$ & $\begin{array}{r}23,2 \pm 21,77 \\
(\mathrm{n}=12)\end{array}$ & $\begin{array}{r}23,2 \pm 29,3 \\
(\mathrm{n}=11)\end{array}$ \\
\hline $\begin{array}{l}\text { NogoA-positive Zellen im } \\
\text { Corpus Callosum }\end{array}$ & $127,2 \pm \begin{array}{r}22,63 \\
(\mathrm{n}=2)\end{array}$ & $\begin{array}{r}108,8 \pm 48,61 \\
(\mathrm{n}=6)\end{array}$ & $\begin{array}{r}133,6 \pm 38,07 \\
(\mathrm{n}=10)\end{array}$ \\
\hline $\begin{array}{l}\text { NogoA-positive Zellen in } \\
\text { der SVZ }\end{array}$ & $\begin{array}{r}180,56 \pm \begin{array}{r}87,91 \\
(\mathrm{n}=2)\end{array} \\
\text { nat }\end{array}$ & $\begin{array}{r}232,8 \pm 77,45 \\
(\mathrm{n}=4)\end{array}$ & $\begin{array}{r}210,4 \pm 49,42 \\
(\mathrm{n}=9)\end{array}$ \\
\hline
\end{tabular}

Tabelle 14: Anzahl von reifen Oligodendrozyten (NogoA) bei Radiatio (Die Werte sind angegeben als Zellen $/ \mathrm{mm}^{2} \pm$ Standardabweichung)

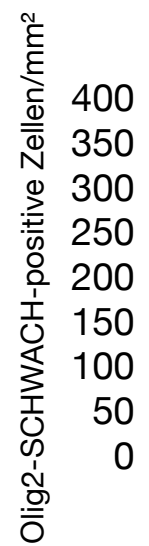

Olig2 SCHWACH

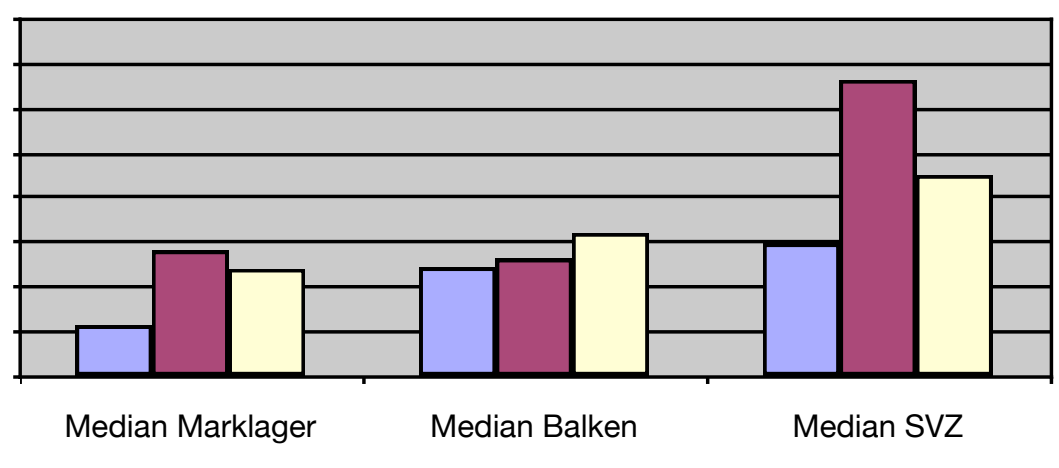

Tx mit TBI

Tx ohne TBI Kontrollen 


\begin{tabular}{|c|c|c|c|}
\hline & $\begin{array}{c}\text { Transplantierte } \\
\text { Patienten mit TBI }\end{array}$ & $\begin{array}{c}\text { Transplantierte } \\
\text { Patienten ohne TBI }\end{array}$ & Kontrollen \\
\hline $\begin{array}{l}\text { Olig2-SCHWACH-positive } \\
\text { Zellen im Marklager }\end{array}$ & $\begin{array}{r}57,6 \pm 47,93 \\
(\mathrm{n}=3) \\
\end{array}$ & $\begin{array}{r}141,2 \pm 93,06 \\
(n=12) \\
\end{array}$ & $\begin{array}{r}120,8 \pm 69,43 \\
(n=11) \\
\end{array}$ \\
\hline $\begin{array}{l}\text { Olig2-SCHWACH-positive } \\
\text { Zellen im Corpus } \\
\text { Callosum }\end{array}$ & $\begin{array}{r}122,4 \pm 89,38 \\
(n=2) \\
\end{array}$ & $\begin{array}{r}132 \pm 130,41 \\
(n=7) \\
\end{array}$ & $\begin{array}{r}160,8 \pm 132 \\
(n=10) \\
\end{array}$ \\
\hline $\begin{array}{l}\text { Olig2-SCHWACH-positive } \\
\text { Zellen in der SVZ }\end{array}$ & $\begin{array}{r}149,2 \pm 143,12 \\
(n=2)\end{array}$ & $\begin{array}{r}332 \pm 204,3 \\
(n=7)\end{array}$ & $\begin{array}{r}225,6 \pm 134,32 \\
(n=9)\end{array}$ \\
\hline
\end{tabular}

Tabelle 15: Anzahl von reifen Oligodendrozyten (Olig2 Schwach) bei Radiatio (Die Werte sind angegeben als Zellen $/ \mathrm{mm}^{2} \pm$ Standardabweichung)

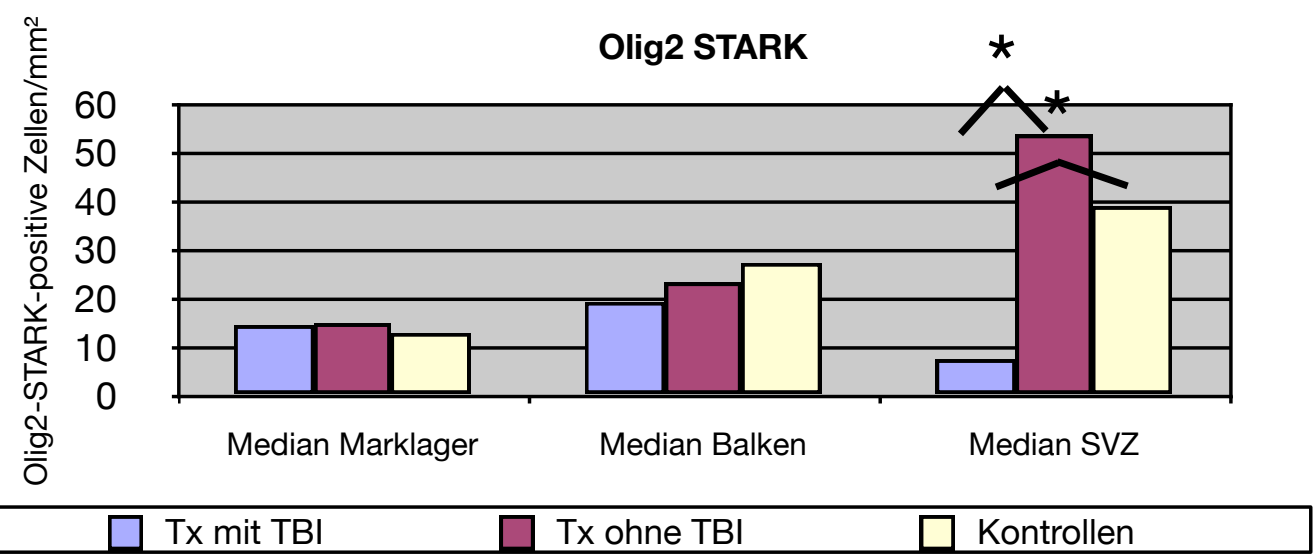

Abb. 28: Diagramm - Olig2 Stark bei Radiatio ${ }^{*} \triangleq$ signifikante Unterschiede)

\begin{tabular}{|c|c|c|c|}
\hline & $\begin{array}{l}\text { Transplantierte } \\
\text { Patienten mit TBI }\end{array}$ & $\begin{array}{c}\text { Transplantierte } \\
\text { Patienten ohne TBI }\end{array}$ & Kontrollen \\
\hline $\begin{array}{l}\text { Olig2-STARK-positive } \\
\text { Zellen im Marklager }\end{array}$ & $\begin{array}{r}14,4 \pm 2,4 \\
(n=3)\end{array}$ & $\begin{array}{r}14,8 \pm 21,96 \\
(n=12)\end{array}$ & $\begin{array}{r}12,8 \pm 10,59 \\
(n=11) \\
\end{array}$ \\
\hline $\begin{array}{l}\text { Olig2-STARK-positive } \\
\text { Zellen im Corpus } \\
\text { Callosum }\end{array}$ & $\begin{array}{r}19,2 \pm 0 \\
(n=2)\end{array}$ & $\begin{array}{r}23,2 \pm \begin{array}{r}30,47 \\
(n=7)\end{array}\end{array}$ & $\begin{array}{r}27,2 \pm 20,17 \\
(n=10)\end{array}$ \\
\hline $\begin{array}{l}\text { Olig2-STARK-positive } \\
\text { Zellen in der SVZ }\end{array}$ & $\begin{array}{r}7,4 \pm 7,64 \\
(n=2)\end{array}$ & $\begin{array}{r}53,6 \pm 21,26 \\
(n=7)\end{array}$ & $\begin{array}{r}38,88 \pm 21,55 \\
(n=9)\end{array}$ \\
\hline
\end{tabular}

Tabelle 16: Anzahl von Oligodendrozytenvorläuferzellen bei Radiatio (Die Werte sind angegeben als

Zellen $/ \mathrm{mm}^{2} \pm$ Standardabweichung)

Da nur eine geringe Anzahl der Patienten eine TBI erhalten hatte $(n=3)$ und von diesen nur einer keine ZNS-Pathologie aufwies, wurde lediglich eine Auswertung der Oligodendrozytenpopulation durchgeführt.

\subsection{Einfluss ausgewählter Chemotherapeutika auf die untersuchten Zellpopulationen}

\subsubsection{Ifosfamid}

Aufgrund der geringen Anzahl an Patienten ohne ZNS-Pathologie mit einer Ifosfamid-Therapie $(n=3)$ wurde lediglich eine Auswertung der Oligodendrozytenzahlen durchgeführt (siehe auch Material und Methoden; bzw. Tabelle 05 im Anhang). 
Bei den transplantierten Patienten, die Ifosfamid erhalten hatten ( $n=6$; Gesamtanzahl), zeigte sich bei der Untersuchung der Oligodendrozytenpopulation eine signifikante Erhöhung $(p=0,04)$ der Olig2-SCHWACH-positiven Zellen in der SVZ $(n=2)$ im Vergleich zu den transplantierten Fällen ohne Ifosfamid $(n=7)$. Im Verhältnis zur Kontrollgruppe $(n=9)$ zeigten sich keine signifikanten Unterschiede $(p=0,099)$.

Auch bei der Population der Oligodendrozytenvorläuferzellen lässt sich im Bereich der SVZ eine erhöhte Zellzahl erkennen bei den Patienten, die Ifosfamid erhalten haben $(n=2)$, jedoch ohne statistische Signifikanz. Eine ähnliche Tendenz zeigt sich bei der Darstellung der reifen Oligodendrozyten der SVZ in der Anti-NogoA-Färbung $(n=1)$. Dabei ist jedoch immer die geringe Fallzahl zu beachten. Die genauen Werte lassen sich den Darstellungen im Anhang entnehmen (Tabellen 32-34 und Abbildungen 42-44).

\subsubsection{Etoposid}

Bei den Patienten, die im Rahmen ihrer Therapie Etoposid erhalten hatten $(n=12)$, fanden sich keine signifikanten Unterschiede zur Kontrollgruppe in Bezug auf die Anzahl der Oligodendrozyten, Astrozyten, Makrophagen / Mikrogliazellen und der axonalen Schädigung.

Die Anzahl der Olig2-SCHWACH-positiven Zellen in der SVZ war jedoch im Vergleich zu den transplantierten Fällen, die kein Etoposid erhalten hatten, signifikant erhöht $(p=0,04)$. Der Unterschied zur Kontrollgruppe war

in diesem Fall jedoch nicht signifikant. Eine ähnliche Tendenz zeigte sich bei den Oligodendrozytenvorläuferzellen in der SVZ, allerdings ohne statistische Signifikanz. Angedeutet zeigt sich diese Verteilung auch bei den reifen Oligodendrozyten der SVZ in der Anti-NogoA-Färbung. Die genauen Werte lassen sich den Darstellungen im Anhang entnehmen (Tabellen 41-46 und Abbildungen 51-56).

\subsubsection{Cyclophosphamid und Busulfan}

Es wurden die transplantierten Fälle, die im Rahmen ihrer Therapie Cyclophosphamid ( $n=13)$ oder Busulfan $(n=10)$ erhalten hatten, im Vergleich zu den Fällen ohne Cyclophosphamid bzw. Busulfan und der Kontrollgruppe untersucht.

In Bezug auf die Oligodendrozyten und ihre Vorläuferzellen zeigten sich dabei keine signifikanten Unterschiede. Auch Makrophagen, Mikroglia und Astrozyten waren im Vergleich zur Kontrollgruppe nicht signifikant verändert. Bei den Patienten, die Busulfan erhalten haben, war die Zahl der axonalen APP-positiven Sphäroide zwar erhöht, jedoch ohne statistische Signifikanz. Die genauen Werte lassen sich den Darstellungen im Anhang entnehmen (Bulsufan: Tabellen 26-31 und Abbildungen 36-41; Cycophosphamid: Tabellen 35-40 und Abbildungen 45-50).

\subsubsection{Vincristin, Fludarabin und Cytarabin (AraC)}

Aufgrund der geringen Anzahl an Patienten ohne ZNS-Pathologie, die eine Therapie mit Vincristin $(n=1)$, Fludarabin $(n=3)$ oder Cytarabin $(\operatorname{AraC})(n=2)$ erhalten haben, wurde lediglich eine Auswertung der Oligodendrozytenzahlen durchgeführt (siehe auch Material und Methoden; bzw. Tabelle 05 im Anhang).

Es konnten keine signifikanten Veränderungen der Oligodendrozytenpopulationen bei den Patienten festgestellt werden, die Vincristin, Fludarabin oder Cytarabin erhalten hatten. Die genauen Werte lassen sich 
den Darstellungen im Anhang entnehmen (Vincristin: Tabellen 47-55 und Abbildungen 57-59; Fludarabin: Tabellen 47-55 und Abbildungen 60-62; Cytarabin: Tabellen 47-55 und Abbildungen 63-65).

Zusammenfassend konnten sowohl für die Bestrahlung als auch für die Chemotherapie (Ifosfamid, Etoposid) signifikante Unterschiede bei Gegenüberstellung der Patientengruppe und Vergleichsgruppen nachgewiesen werden. Dabei ist die Oligodendrozytenpopulation der SVZ betroffen.

\subsection{In-situ-Hybridisierung}

Für die ISH standen zwei transplantierte Patientinnen mit männlichen Spendern zur Verfügung. Von einer Patientin (ISH-1) standen 2 Kryoblöcke zur Auswertung zur Verfügung, von einer Patientin (ISH-2) ein Block. Es konnten bei beiden Patientinnen Y-Chromosom-positive Spenderzellen im Gewebe nachgewiesen werden, die durch die immunohistochemische Färbung zum größten Teil verschiedenen Zelltypen zugeordnet werden konnten.

Der Anteil der Y-Chromosom-positiv-markierten Zellkerne lag beim männlichen Kontrollfall bei etwa $50 \%$. Bei den transplantierten Patientinnen waren es im Mittel 0,5\%.

\begin{tabular}{|l|l|r|r|}
\hline & Untersuchte Region & $\begin{array}{c}\text { Gesamtanzahl der } \\
\text { Y-Chromosom-positiven } \\
\text { Zellen }\end{array}$ & \multicolumn{1}{|c|}{$\begin{array}{c}\text { Summe der } \\
\text { zugeordneten Zellen }\end{array}$} \\
\hline Patient ISH-1a & frontal & 0,73 & 0,69 \\
\hline Patient ISH-1b & fronto-parietal & 0,42 & 0,37 \\
\hline Patient ISH-2 & frontal & 0,49 & 0,36 \\
\hline $\begin{array}{l}\text { Patient ISH-3 (Männliche } \\
\text { Kontrolle) }\end{array}$ & frontal & 54,95 & nicht zugeordnet \\
\hline
\end{tabular}

Tabelle 17: Y-Chromosom-positive Zellen (Die Werte sind angegeben als Zellen/mm² \pm Standardabweichung)

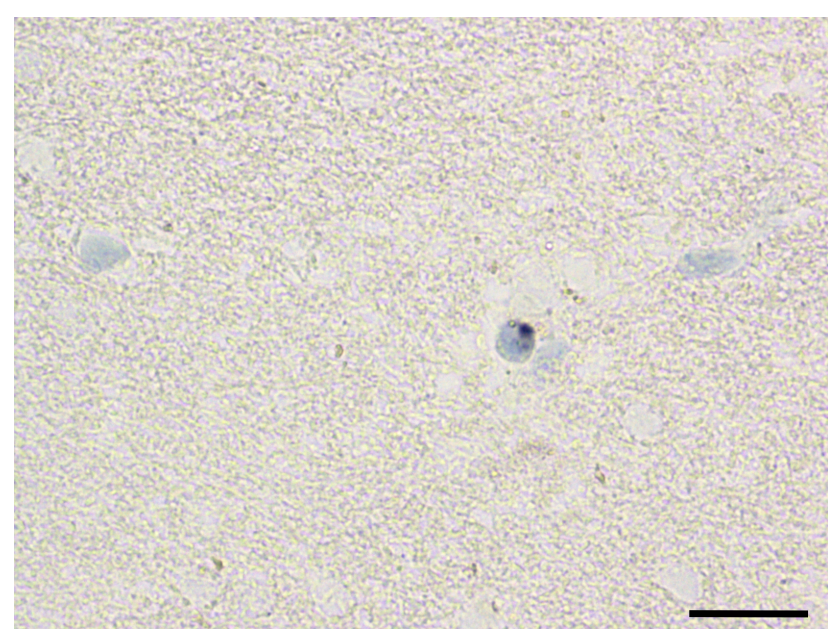

Abb. 29: Y-Chromosom-positive Zellen in weiblichem Tx-Fall (Patient ISH-1 Block a)

(Messbalken unten rechts im Bild entspricht $50 \mu \mathrm{m}$ )

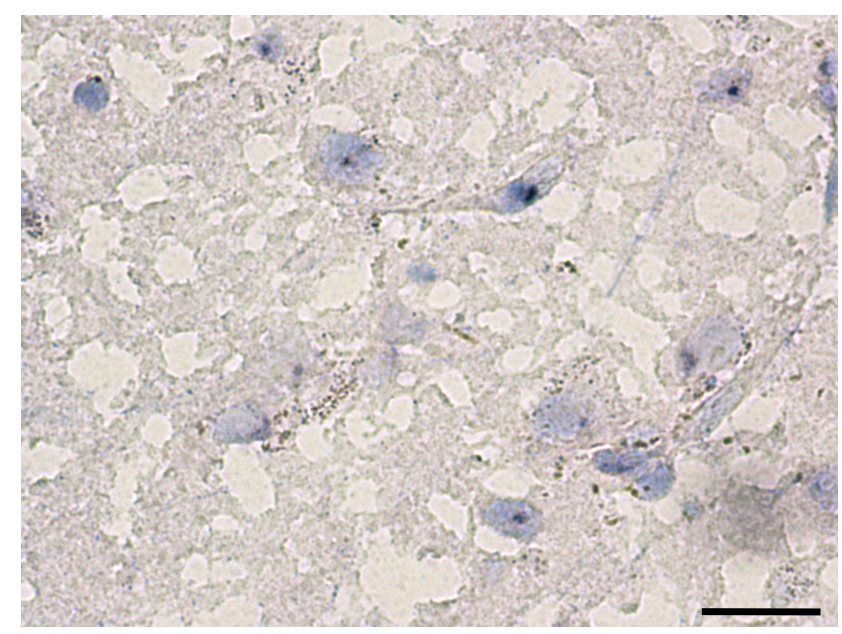

Abb. 30: Y-Chromosom-positive Zellen in männlichem Kontroll-Fall

(Messbalken unten rechts im Bild entspricht $50 \mu \mathrm{m}$ ) 


\subsubsection{Makrophagen / Mikroglia, Astrozyten und endotheliale Zellen}

Unter den Y-Chromosom-positiven Zellen fanden sich sowohl Makrophagen / Mikrogliazellen als auch Astrozyten und endotheliale Zellen. Die Auswertung der Y-Chromosom-positiven Oligodendrozyten und Neuronen gestaltete sich technisch schwierig und wird folgend gesondert dargestellt.

\begin{tabular}{|l|r|r|r|}
\hline & \multicolumn{1}{|c|}{$\begin{array}{c}\text { KiM1P- und } \\
\text { Y-Chromosom-positive } \\
\text { Zellen }\end{array}$} & $\begin{array}{c}\text { Y-Chromosom-positive } \\
\text { Zellen }\end{array}$ & $\begin{array}{c}\text { G-Chromosom-positive } \\
\text { Zellen }\end{array}$ \\
\hline Patient ISH-1a & 0,06 & 0,22 & 0,3 \\
\hline Patient ISH-1b & 0,03 & 0,15 & 0,16 \\
\hline Patient ISH-2 & 0,06 & 0,15 & 0,15 \\
\hline
\end{tabular}

Tabelle 18: Ergebnisse der kombinierten Immunhistochemie und ISH für Makrophagen / Mikroglia, Astrozyten und entdotheliale Zellen (Die Werte sind angegeben als Zellen $/ \mathrm{mm}^{2} \pm$ Standardabweichung)

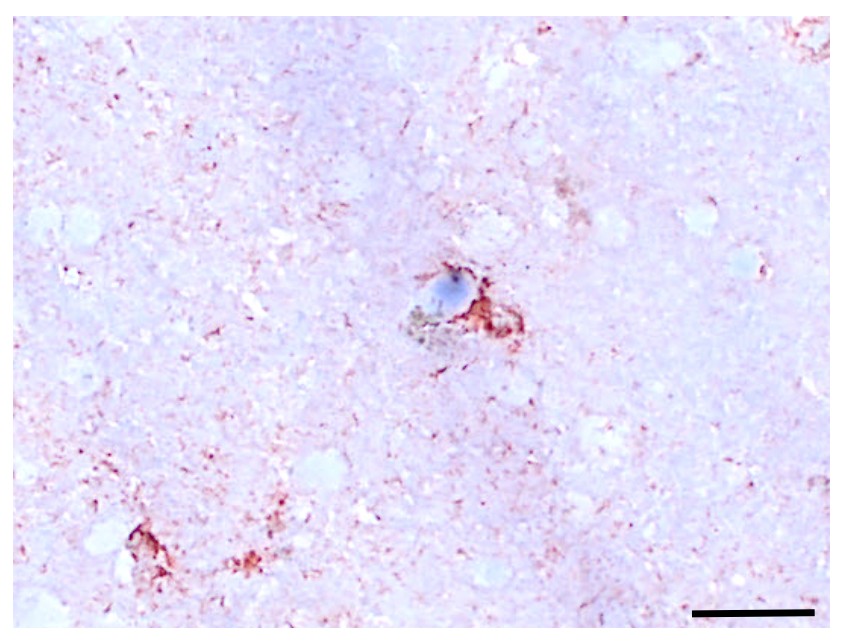

Abb. 31: Y-Chromosom-positiver Astrozyt in weiblichem Tx-Fall (Patient ISH-1 Block b) (Messbalken unten rechts im Bild entspricht $50 \mu \mathrm{m}$ )

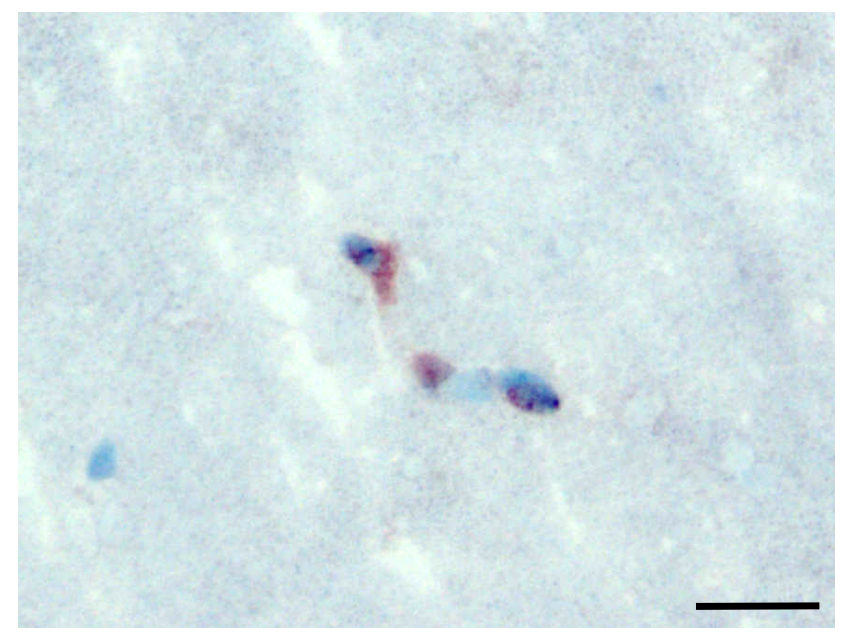

Abb. 32: Y-Chromosom-positiver endotheliale

Zelle in weiblichem Tx-Fall (Patient ISH-2)

(Messbalken unten rechts im Bild entspricht $50 \mu \mathrm{m}$ )

\subsubsection{Oligodendrozyten}

Die Untersuchung der Oligodendrozyten war aus technischen Gründen nur anhand der Anti-NogoA-Färbung möglich. Es konnten keine Y-Chromosom-positiven reifen Oligodendrozyten nachgewiesen werden.

\begin{tabular}{|l|r|l|}
\hline & $\begin{array}{c}\text { NogoA- und } \\
\text { Y-Chromosom-positive } \\
\text { Zellen }\end{array}$ & $\begin{array}{c}\text { Olig2- und } \\
\text { Y-Chromosom-positive } \\
\text { Zellen }\end{array}$ \\
\hline Patient ISH-1a & 0 & nicht auswertbar \\
\hline Patient ISH-1b & 0 & nicht auswertbar \\
\hline Patient ISH-2 & 0 & nicht auswertbar \\
\hline
\end{tabular}

Tabelle 19: Ergebnisse der ISH mit Oligodendrozytenfärbung (Die Werte sind angegeben als Zellen/mm² \pm Standardabweichung) 


\subsubsection{Neurone}

Auch die Färbung der Neurone kombiniert mit der ISH gestaltete sich schwierig. Für einen der beiden untersuchten Fälle konnten in zwei verschiedenen Blöcken Y-Chromosom-positive Neurone nachgewiesen werden.

\begin{tabular}{|l|l|r|lr|}
\hline & \multicolumn{1}{|c|}{$\begin{array}{c}\text { SMI32- und } \\
\text { Y-Chromosom-positive } \\
\text { Zellen }\end{array}$} & $\begin{array}{c}\text { NeuN- und } \\
\text { Y-Chromosom-positive } \\
\text { Zellen }\end{array}$ & $\begin{array}{c}\text { M-Chromosom-positive } \\
\text { Zellen }\end{array}$ \\
\hline Patient ISH-1a & \multicolumn{1}{|c|}{0,06} & 0,11 & nicht auswertbar \\
\hline Patient ISH- 1b & nicht auswertbar & 0,03 & 0,05 \\
\hline Patient ISH- 2 & nicht auswertbar & nicht auswertbar & nicht auswertbar \\
\hline
\end{tabular}

Tabelle 20: Ergebnisse der ISH mit Neuronenfärbungen (Die Werte sind angegeben als Zellen/mm² \pm Standardabweichung)

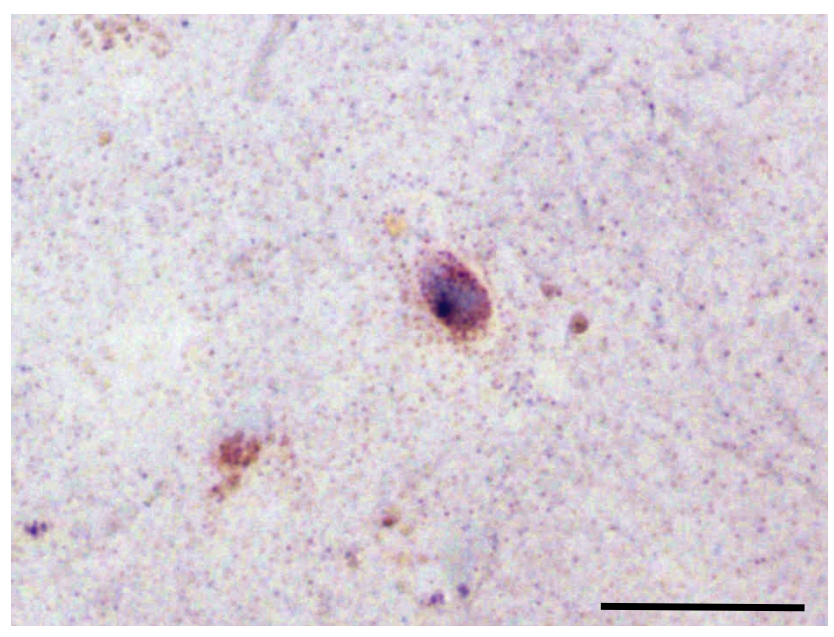

Abb. 33: Y-Chromosom- und SMI32-positive

Zelle in weiblichem Tx-Fall (Patient ISH-1 Block a)

(Messbalken unten rechts im Bild entspricht $50 \mu \mathrm{m}$ )

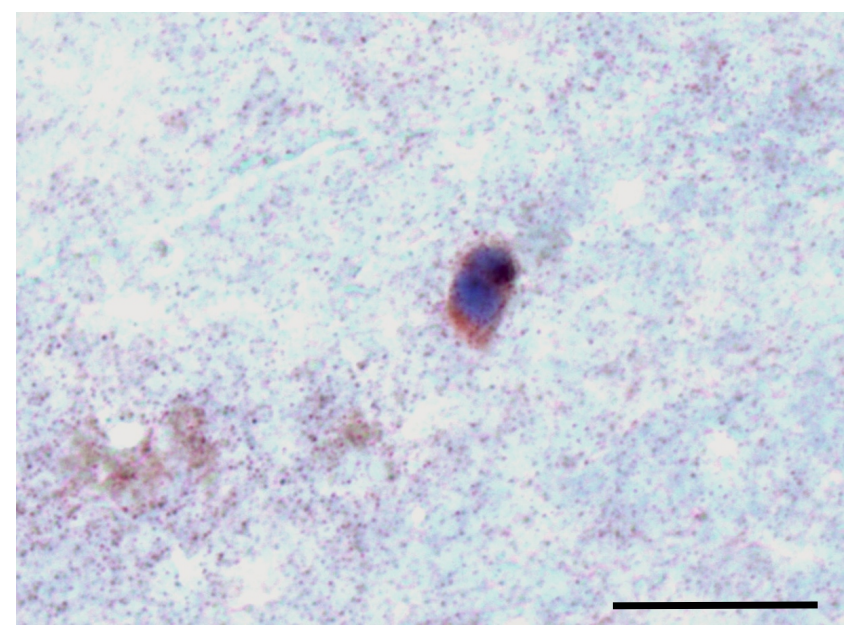

Abb. 34: Y-Chromosom- und MAP2-positive Zelle in weiblichem Tx-Fall (Patient ISH-1 Block b) (Messbalken unten rechts im Bild entspricht $50 \mu \mathrm{m}$ )

\subsubsection{Gesamtverteilung}

Aus den verschiedenen Einzelwerten wurde ein Überblick über die Gesamtverteilung der unterschiedlichen Zelltypen der Y-Chromosom-positiven Zellen erstellt. Mit Rücksicht auf die färbungsbedingten Ausfälle ergibt sich damit zumindest ein grober Eindruck von der Zusammensetzung der Y-Chromosom-positiven Zellen. Den größten Anteil machen endotheliale Zellen gefolgt von Astrozyten aus. 


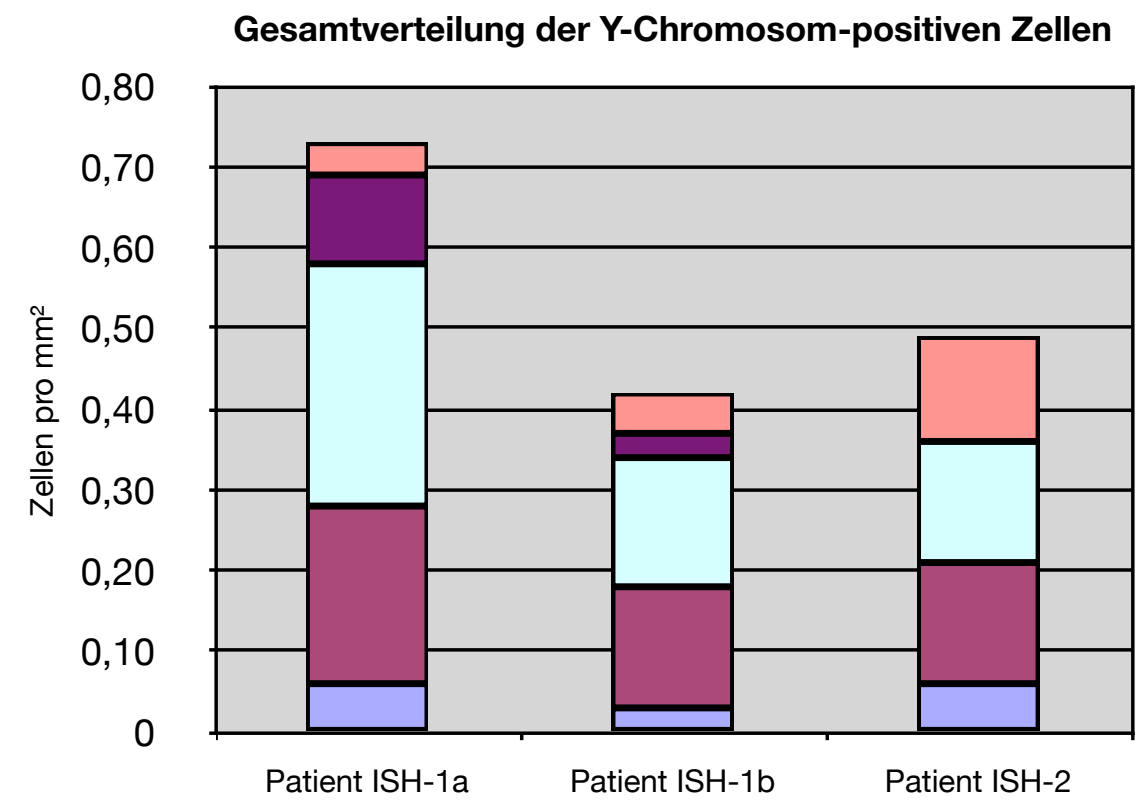

\begin{tabular}{|l|}
$\square$ unklarer Zelltyp / Differenz zur Gesamtanzahl y-chromosom-positiver Zellen \\
NeuN-positive Zellen pro $\mathrm{mm}^{2}$ / bei Patient 2 nicht auswertbar \\
endotheliale Zellen pro $\mathrm{mm}^{2}$ \\
NogoA-positive Zellen pro $\mathrm{mm}^{2}$ (nicht nachweisbar) \\
GFAP-positive Zellen pro $\mathrm{mm}^{2}$ \\
KiM1P-positive Zellen pro $\mathrm{mm}^{2}$
\end{tabular}

Abb. 35: Diagramm - Gesamtverteilung der Y-Chromosom-positiven Zellen 


\section{Diskussion}

\subsection{Stammzelltransplantation allgemein}

Die Transplantation von peripheren Blut-Stammzellen ist eine Therapiemöglichkeit der modernen Medizin, die es ermöglicht, viele Krankheiten, welche bisher als unheilbar galten, zu behandeln und teilweise sogar vollständig zu heilen.

Dabei ist jedoch nach wie vor das Risiko des Eingriffs nicht zu unterschätzen, denn die 7-Jahre-Überlebensrate der mit einer allogenen Transplantation behandelten Patienten liegt bei etwa 50 Prozent (Gooley et al. 2010). Etwas weniger als die Hälfte der letalen Ausgänge gehen auf Rezidive der Grunderkrankung zurück, den größeren Anteil machen Infektionen und Organschäden an Lunge, Leber und Nieren sowie akute Graft-versus-Host-Erkrankung aus (Gooley et al. 2010). Hinsichtlich dieser vergleichsweise sehr hohen therapieassoziierten Morbidität und Mortalität gilt dementsprechend eine sehr eng gefasste Indikationsstellung.

Neben den zahlreichen bis dato bekannten und relativ gut erforschten akuten und chronischen Nebenwirkungen der Therapie im Bereich der Inneren Medizin wie Kardio-, Pulmo- und Nephrotoxizität (Sorror 2010; Tichelli et al. 2008) mehren sich die Hinweise auf unerwünschte Wirkungen hinsichtlich kognitiv-mnestischer Funktionen und neurologischer Krankheitsbilder wie Enzephalopathien, ZNS-Infektionen und zerebrovaskuläre Symptome (de Brabander et al. 2000; Dietrich et al. 2008; Ying et al. 2002). Kognitive Veränderungen, die mit der Therapie in Verbindung gebracht werden können, sind zentrales Thema verschiedener Studien (Brey 2002; Syrjala et al. 2004; Syrjala et al. 2011; Wefel und Schagen 2012). So wurden beispielsweise 102 Patienten 100 Tage vor und 12 Monate nach einer allogenen Stammzelltransplantation mit Hilfe verschiedener neuropsychologischer Tests auf Merkfähigkeit, Aufmerksamkeit, Feinmotorik und ähnliches untersucht. Es zeigte sich bei 16 Prozent der Patienten eine Verschlechterung der Testergebnisse in mindestens 3 der 14 Tests (Scherwath et al. 2012). Dabei stellen die Autoren immer wieder fest, dass, besonders bei den öfter auftretenden leichten bis mäßigen neurologischen Veränderungen, die Klinik nicht mit den Ergebnissen der Bildgebung korrespondiert (Brown et al. 1998; Stemmer et al. 1994).

$\mathrm{Zu}$ den histopathologischen Veränderungen beim Menschen ist in diesen Fällen noch wenig bekannt. Eine Studie beschreibt einen Zusammenhang zwischen Radiochemotherapie und einer Abnahme der Neurogenese und Zunahme der Mikrogliaaktivierung im menschlichen Hippokampus anhand von Untersuchungen an Autopsiegewebe (Monje et al. 2007), die möglicherweise für kognitive Defizite verantwortlich sein könnten.

Theoretische Überlegungen, Ergebnisse aus Tierexperimenten und klinische Studien erwägen die Stammzelltransplantation als eine vielversprechende Therapieoption bei bestimmten Autoimmunerkrankungen wie beispielsweise der Multiplen Sklerose (MS) (Van Wijmeersch et al. 2008). Die MS ist charakterisiert durch eine ZNS-Pathologie mit Entmarkungsherden, einer axonalen Schädigung, Astrogliose und Makrophagen-/Mikrogliaaktivierung. Bei der Therapie der MS ist damit das Einbringen neuer myelinbildender Zellen bzw. von Vorläuferzellen, aus denen sich diese entwickeln können, eine 
vielversprechende Therapieoption, zumindest in der Theorie (Karussis und Kassis 2008). Außerdem wird angenommen, dass die Hauptwirkung der Stammzelltransplantation bei der MS auf den vollständigen bzw. teilweisen Ersatz des Empfängerimmunsystems durch Spenderzellen zustande kommt, sowie durch den sogenannten Graft-versus-Autoimmunity-Effekt (GVA) (Van Wijmeersch et al. 2008). Dabei kommt es ähnlich wie beim Graft-versus-Host-Effekt zu einer Reaktion der Spenderlymphozyten gegen die autoreaktiven Empfänger-T-Zellen, wobei dieser Effekt allerdings nur bei der allogenen Stammzelltransplantation auftritt (Van Wijmeersch et al. 2008).

Die MS selbst ist in der Mehrzahl der Fälle keine letale Erkrankung. Sie ist in ihrem jeweiligen Verlauf sehr unterschiedlich und schlecht vorhersagbar. Die Lebenserwartung ist im Durchschnitt um etwa 15 Jahre reduziert im Vergleich zur Allgemeinbevölkerung (Pugliatti et al. 2006). Daher ist es schwierig, eine begründete Indikation zu einer hoch riskanten Therapie wie der allogenen Stammzelltransplantion zu stellen. Die autologe Stammzelltransplantation hat eine deutlich geringere therapieassoziierte Mortalität mit einer 3-Jahres-Überlebensrate von etwa 90 Prozent bei MS-Patienten (Fassas und Kimiskidis 2004). Im Rahmen von Studien wurden seit 1995 bisher mehr als 200 Patienten mit schwerer therapierefraktärer Multipler Sklerose mit einer autologen Stammzelltransplantation behandelt (Fassas und Kimiskidis 2004). Die Ergebnisse erscheinen teilweise recht vielversprechend (Van Wijmeersch et al. 2008), allerdings gibt es auch Studien, die in der Betrachtung von Nutzen und Risiko zur Vorsicht im Umgang mit dieser Therapie bei MS anraten (Burt et al. 2003; Hintzen 2002). Zusätzlich zu den bekannten Risiken und Nebenwirkungen stellt sich die Frage, ob eine Stammzelltransplantation in einem vorgeschädigten Gehirn, wie bei der MS, nicht deutlich stärkere zentralnervöse Auswirkungen zeigen könnten (Moore-Maxwell et al. 2004).

Zur Untersuchung zerebraler histopathologischer Veränderungen nach einer Stammzelltransplantation wurden in dieser Arbeit gezielt Gewebeproben von Autopsien stammzelltransplantierter Patienten untersucht. Es wurden bewusst nur Fälle ausgewählt, die neuropathologisch keine zusätzliche spezifische Pathologie wie z.B. Hirninfarkte oder Infektionen aufwiesen, die die Untersuchungsergebnisse beeinflussen könnten. Aufgrund der geringen Fallzahl wurden jedoch für die Untersuchung der Oligodendrozytenpopulation auch Patienten mit einer spezifischen ZNS-Erkrankung aufgenommen, die aber keinen Einfluß auf die Oligodendrozytenpopulation haben sollte (siehe Methodenteil). Hinsichtlich der Entzündungsinfiltration, Mikroglia-Aktivierung, Astrogliose, axonalen Schädigung, Oligodendrozyten- und Myelinpathologie sowie Gefäßpathologie konnten im Hirngewebe transplantierter Patienten insgesamt keine signifikanten Unterschiede zur Kontrollgruppe festgestellt werden. Zur Untersuchung der Oligodendrozytenpopulation wurden unterschiedliche Hirnareale (Marklager, Balken und SVZ) untersucht und verglichen. Dabei wurden sowohl reife Oligodendrozyten als auch Oligodendrozytenvorläuferzellen, die insbesondere in der SVZ auftreten und für die Neubildung von Oligodendrozyten verantwortlich sind, untersucht. Diese Ergebnisse könnten dafür sprechen, dass es durch die Stammzelltransplantation zu keinen wesentlichen neuropathologischen Veränderungen außerhalb der beschriebenen Komplikationen wie Infektionen etc. kommt. Offen bleibt dabei jedoch, ob es zu pathologischen Veränderungen kommt, die durch die von uns durchgeführten Untersuchungen nicht nachweisbar sind.

Unsere Ergebnisse waren allerdings insgesamt nicht vollkommen unauffällig und zeigten für gewisse Medikamente bzw. die Bestrahlung (TBI) in Bezug auf die Anzahl der Oligodendrozyten oder 
Oligodendrozytenvorläuferzellen signifikante Unterschiede zu den Vergleichsgruppen $(p<0,05)$, die im Folgendem diskutiert werden.

\subsection{Histologische Veränderungen nach Radiotherapie}

Die Ganzkörperbestrahlung (TBI) ist Bestandteil einzelner Konditionierungsprotokolle (Therapieregime) im Rahmen einer Stammzelltransplantation. Unter den untersuchten Fällen finden sich drei Patienten, die im Rahmen ihrer Therapie eine TBI erhalten haben, die auch das zentrale Nervensystem mit einschließt. In der hiesigen Studie fanden sich bei keinem der Patienten Zeichen einer Strahlennekrose. Diese dosisabhängige Nebenwirkung der Strahlentherapie wird in vielen Studien beschrieben (Keime-Guibert et al. 1998; Ruben et al. 2006; Schultheiss et al. 1995) und ist gewöhnlich mit einer entsprechenden klinischen Symptomatik vergesellschaftet. Als kritischer Grenzwert für die Entwicklung einer Strahlennekrose des ZNS werden 50-60 Gy angegeben. Keiner der untersuchten Patienten hat diesen Wert erreicht bzw. überschritten.

Bei meinen Studien zeigte sich eine signifikante Reduktion der Oligodendrozytenvorläuferzellen nach einer TBI in der subventrikulären Zone. Die Oligodendrozytenvorläuferzellen wurden immunhistochemisch mit einem gegen Olig2 gerichtetem Antikörper untersucht. Der Antikörper Olig2 gilt als verlässlicher Marker von Oligodendrozyten und Oligodendrozytenvorläuferzellen. Dabei lassen sich anhand der Färbungsintensität Aussagen zum Differenzierungsgrad der jeweiligen Zellen machen. Die Oligodendrozyten-Vorläuferzellen (OPCs) färben sich stärker an als die adulten, ausdifferenzierten Oligodendrozyten (Kuhlmann et al. 2008). Entsprechend bietet sich eine Unterteilung in Olig2-stark- und Olig2-schwach-positive Zellen an. Im Allgemeinen überwiegen in der weißen Substanz die adulten Oligodendrozyten, d. h. die schwach-positiven Olig2- Zellen. Während sich in Marklager und Balken kaum Unterschiede zeigten, waren die Olig2-stark-positiven Oligodendrozytenorläuferzellen in der subventrikulären Zone (SVZ) der bestrahlten Patienten signifikant reduziert $(p=0,034)$ im Vergleich $z u$ den nicht-bestrahlten Patienten und der Kontrollgruppe. Ein ähnlicher Verlust von Oligodendrozytenvorläuferzellen nach Bestrahlung wurde bereits von anderen Autoren in einer Studie an tierischem und menschlichen Gewebe beschrieben (Panagiotakos et al. 2007). An humanen Gewebe konnte in dieser Studie ein Verlust von Oligodendrozytenvorläuferzellen und zu späten Zeitpunkten auch von Oligodendrozyten in der weißen Substanz nachgewiesen werden. Untersucht wurde jedoch die weiße Substanz in unmittelbarer Nachbarschaft zu Tumoren, so dass die Ergebnisse nur bedingt mit unseren vergleichbar sind. Zudem erfolgte eine Strahlentherapie mit deutlich höheren Dosen von 18-21 Gy. Bei den Tierversuchen erhielten Ratten eine einmalige Bestrahlung mit 25 Gy und wurden anschließend zu unterschiedlichen Zeitpunkten über einen Zeitraum von 15 Monaten untersucht. Hier fand sich ein progredienter Verlust von Oligodendrozytenvorläuferzellen in der SVZ, spät gefolgt von einer Entmarkung (Panagiotakos et al. 2007). Fasst man zusammen, so zeigt sich somit übereinstimmend mit unseren Ergebnissen nach einer Strahlentherapie ein Verlust von Oligodendrozytenvorläuferzellen. Es könnte sich hierbei einerseits um eine direkte Schädigung der Vorläuferzellen handeln oder um eine durch Regeneration bedingte Erschöpfung des Pools von Vorläuferzellen.

Die Anzahl der Olig2-schwach-positiven Zellen in der SVZ der bestrahlten Patienten ist nur leicht erniedrigt. Es fällt jedoch auf, dass das Ergebnis relativ genau mit der Anzahl der NogoA-positiven Zellen in diesem 
Gebiet übereinstimmt. Dies könnte sowohl dafür sprechen, dass es bei einer Bestrahlung des ZNS vorwiegend zu einer Schädigung der noch nicht vollständig ausdifferenzierten Oligodendrozyten kommt, als auch eine fehlende Differenzierung von Vorläuferzellen anzeigen.

Signifikante Unterschiede bei den adulten Oligodendrozyten konnten mittels der Färbung gegen NogoA nicht nachgewiesen werden. Dies könnte dafür sprechen, dass sie resistenter gegen Bestrahlung sind als die Vorläuferzellen, da sie bereits einen hohen Differenzierungsgrad besitzen (Panagiotakos et al. 2007). Zudem wäre ein Verlust NogoA-positiver Oligodendrozyten aufgrund einer unzureichenden Differenzierung von Vorläuferzellen bei den relativ kurzen Überlebenszeiten von 1, 5 und 9 Monaten nach Stammzelltransplantation nicht zu erwarten.

Zusammenfassend lässt sich feststellen, dass eine Schädigung der Oligodendrozytenvorläuferzellen durch eine Bestrahlung im Rahmen einer Stammzelltransplantation nicht ausgeschlossen werden kann und für eine geringere Regenerationskapazität der myelinbildenden Oligodendrozyten verantwortlich sein könnte. Zur Validierung dieser Ergebnisse ist jedoch die Untersuchung eines größeren Patientenkollektivs nötig, da die untersuchte Patientenzahl sehr gering ist.

\subsection{Histologische Veränderungen nach Chemotherapie}

Der Einsatz von Chemotherapeutika ist aus der modernen Medizin besonders im Bereich der Krebstherapie kaum mehr wegzudenken. Mit der erwünschten zytotoxischen Wirkung auf maligne Zellen geht jedoch unausweichlich eine Schädigung der gesunden Körperzellen einher. Die damit verbundenen Nebenwirkungen sind für die Vielzahl der unterschiedlichen Medikamente und Wirkungsweisen bei weitem nicht so gut untersucht wie für die Strahlentherapie. Hinzu kommen Wechselwirkungen, die nur bei der Kombination der Einzelpräparate in den meist multimodalen Therapiekonzepten auftreten. Im Rahmen der Konditionierung vor einer peripheren Stammzelltransplantation werden abhängig von Grunderkrankung, Patientenalter und Komorbidität unterschiedliche Protokolle angewandt. Bei den hier untersuchten Fällen kamen Kombinationen unterschiedlicher Chemotherapeutika zum Einsatz. Daher sind die Aussagen über die einzelnen Medikamente immer unter Vorbehalt zu beurteilen. Die genaue Untersuchung der Einzelsubstanzen wird wohl weiterhin den Einsatz von Tierexperimenten oder In-vitro-Versuchsreihen erfordern. In der klinischen Praxis stellen bei Konditionierungen vor Stammzelltransplantationen Kombinationschemotherapien den Standard dar.

Es sind in Studien an menschlichem Gewebe einzelne schwere Pathologien wie beispielsweise die toxische Leukenzephalopathie beschrieben (Moore-Maxwell et al. 2004), die sich durch weitreichende Entmarkungen, Astrogliosen und eine Makrophageninfiltration auszeichnen. Eine toxische Leukenzephalopathie konnten wir bei den transplantierten Patienten nicht nachweisen. Auch zeigten sich bei unseren Untersuchungen keine Auffälligkeiten des Myelins im Sinne einer Entmarkung oder Myelinrarefizierung. Eine Vielzahl von Untersuchungen setzt sich mit den klinischen Auffälligkeiten von Patienten nach einer Chemotherapie auseinander (Cheson et al. 1994; Keime-Guibert et al. 1998; Newton 2012; Sul und Deangelis 2006; Verstappen et al. 2003). Dabei versuchen einige Autoren über bildgebende Verfahren einen Zusammenhang der Symptome mit strukturellen Veränderungen des Gewebes herzustellen. In MRT-Untersuchungen wurden bei bis zu 70\% der behandelten Patienten Veränderungen der weißen Substanz festgestellt (Brown et al. 
1998; Stemmer et al. 1994). Es zeigte sich jedoch, dass gerade bei einer leichten bis mäßigen klinischen Symptomatik kein verlässlicher Zusammenhang mit dem morphologischen Bild besteht (Dropcho 1991).

Diese Arbeit beschäftigt sich genauer mit den Veränderungen auf zellulärer Ebene an menschlichem Gewebe, welche bisher nach unserem Wissen fast ausschließlich in Tierexperimenten oder In-vitro-Versuchen untersucht wurden.

Für die Gesamtheit der untersuchten Fälle, die eine Chemotherapie erhalten haben, konnten keine signifikanten Unterschiede zur Kontrollgruppe festgestellt werden. Da die Patienten jedoch mit unterschiedlichen Chemotherapeutika behandelt wurden, führten wir Subgruppenanalysen in Abhängigkeit des jeweiligen Chemotherapeutikums durch. Dabei richteten wir besonderes Augenmerk auf die bereits in der Einleitung erwähnten Stoffe Cyclophosphamid, Etoposid, Busulfan, Fludarabin, Cytarabin, Ifosfamid und Vincristin.

Bezogen auf die Substanz Cyclophosphamid zeigten sich unter den oben genannten Aspekten keine Auffälligkeiten im Vergleich zur Kontrollgruppe. Somit bestätigen sich die Ergebnisse anderer Autoren, die für Cyclophosphamid keine Neurotoxizität nachweisen konnten (Newton 2012).

Beim Etoposid zeigte sich eine signifikante Erhöhung der Olig2-schwach-positiven Zellen in der SVZ bei den Fällen mit Etoposidbehandlung gegenüber den Patienten, die dieses Medikament nicht erhalten haben. Gleichzeitig zeigten sich jedoch keine Unterschiede der mit Etoposid behandelten Patienten im Vergleich zur Kontrollgruppe. Somit ist eine Gewebetoxizität auch für Etoposid in meinem Kollektiv nicht direkt nachweisbar. Allerdings fällt auf, dass die reifen Oligodendrozyten und Oligodendrozytenvorläuferzellen in der SVZ leicht erhöht sind. Dies könnte als Zeichen einer Regeneration nach Schädigung des Gewebes gedeutet werden. Ähnliches wurde bereits bei der Untersuchung von Rückenmarksläsionen bei Ratten beschrieben, wobei in der Nähe der Läsionen eine reaktive Erhöhung der Oligodendrozytenzahl nachgewiesen wurde (McTigue und Tripathi 2008; Tripathi und McTigue 2007).

Die Subgruppenanalyse der mit Busulfan behandelten Patienten konnte keine signifikanten Veränderungen im Vergleich zur Kontrollgruppe in meinen Untersuchungen aufzeigen. Auch in der Literatur wurden keine Gewebeveränderungen beschrieben, jedoch akute klinische Symptome wie Krampfanfälle (Sul und Deangelis 2006).

Bei der Substanz Ifosfamid zeigte sich eine leichte Erhöhung der NogoA-positiven Zellen in der SVZ verglichen mit der Kontrollgruppe und den Patienten, die kein Ifosfamid erhalten haben. Gleichzeitig waren die Olig2-schwach-positiven Zellen in der SVZ signifikant erhöht im Vergleich zu den Patienten, die kein Ifosfamid erhalten hatten. Auch im Balken waren diese Zellen leicht, jedoch nicht signifikant, erhöht. Auch die Olig2-stark-positiven Zellen in der SVZ waren erhöht. Dies könnte wiederum ein Hinweis auf eine Gewebereaktion in Form einer Oligodendrozytenproliferation und den Versuch einer Regeneration sein. Der Wirkmechanismus der Neurotoxizität von Ifosfamid ist nach wie vor nicht eindeutig geklärt. Es wird davon ausgegangen, dass sich ein toxischer Metabolit des Stoffes anhäuft und zu Störungen der Mitochondrienfunktion führt (Ames et al. 2010). Von einer direkten Auswirkung auf Oligodendrozyten oder Myelin wird indes nicht berichtet.

Ein ähnliches Bild wie beim Ifosfamid, wenn auch in geringerer Ausprägung, zeigt sich auch bei der Behandlung mit Vincristin und Fludarabin. Es findet sich bei beiden Substanzen eine leichte, statistisch nicht signifikante Erhöhung der reifen Oligodendrozyten und Oligodendrozytenvorläuferzellen in der SVZ. Dies 
könnte bei der Vincristin-Therapie ein Anzeichen für die bereits in der Literatur beschriebene Vincristin-assoziierte Störung der Myelinstruktur sein (Hurwitz et al. 1988). Außerdem wurden für die Hochdosistherapie mit Fludarabin (> 40 bis $125 \mathrm{mg} / \mathrm{m}^{2}$ pro Tag für 5 bis 7 Tage) bereits lebensgefährliche Nebenwirkungen nachgewiesen, unter anderem mit weitreichender Demyelinisierung im ZNS (Cohen et al. 1993). Die Veränderungen in der Oligodendrozytenzahl könnten demnach ein Hinweis auf die Nebenwirkungen der Standarddosis von Fludarabin (18 bis 25 mg/m² pro Tag für 5 Tage) sein.

Bei den Transplantfällen, die Cytarabin erhalten haben, zeigte sich keine deutliche Veränderung der Oligodendrozytenpopulation.

Hier bewusst nicht erwähnt werden die Unterschiede der akuten axonalen Schädigung, nachgewiesen mittels der APP-Untersuchung vor allem bei der Therapie mit Etoposid und Busulfan. Sie erscheinen im Diagramm deutlich, sind aber nicht signifikant und entstehen durch sehr niedrige Werte axonaler Sphäroide. Zur weiteren Abklärung eventueller Unterschiede müsste eine weitere Untersuchung mit höherer Fallzahl erfolgen.

Da einige Autoren von einem Substanzverlust des Gehirns nach einer Chemotherapie berichten (Dietrich et al. 2008), überprüften wir das Hirngewicht der transplantierten Patienten im Vergleich zur Kontrollgruppe, konnten jedoch keine Unterschiede feststellen.

Zusammenfassend lässt sich für die Substanzen Ifosfamid und Etoposid möglicherweise ein Einfluss auf die Oligodendrozytenpopuplation und hier insbesondere die Vorläuferzellen in der SVZ ableiten. Die Zunahme der Oligodendrozytenvorläuferzellen könnte anders als bei der Bestrahlung, wo wir direkte Zeichen einer Schädigung nachweisen konnten, als ein Zeichen von Regeneration des Gewebes gedeutet werden, der eine entsprechende Schädigung vorausgegangen ist. Aufgrund der geringen Fallzahl lassen sich jedoch nur hypothetische Aussagen treffen.

\subsection{Einfluss zusätzlicher Faktoren sowie Studienlimitation}

Die Folgen (Wirkungen und Nebenwirkungen) einer Behandlung mit Chemotherapeutika oder Bestrahlung lassen sich nicht unmittelbar anhand der jeweiligen Gesamtdosis vorhersagen. Sie werden durch verschiedene Faktoren mit beeinflusst. Dabei spielt beispielsweise der zeitliche Ablauf der Behandlung eine Rolle. Um möglichst viel Wirkung bei möglichst wenig unerwünschter Nebenwirkung zu erreichen, wird die Gesamtdosis des Medikamentes bzw. der Strahlung in mehrere Einzeldosen aufgeteilt. Außerdem sind die meisten Therapiekonzepte multimodal, so dass sich die verschiedenen Therapien untereinander beeinflussen können. In diesem Zusammenhang ist auch die Integrität der Blut-Hirn-Schranke von großer Bedeutung. Beispielsweise für die Substanz Etoposid wurde nachgewiesen, dass sie ihre neurotoxischen Eigenschaften erst entfaltet, wenn sie in Kombination mit Medikamenten verabreicht wird, die die Durchlässigkeit der Blut-Hirn-Schranke erhöhen (Fortin et al. 2000). Zusätzlich vermuten einige Autoren, dass eine kognitive Beeinträchtigung nach der Therapie auch eine Folge der Kardiotoxizität von Chemotherapeutika sein könnte, wobei die Schädigung des Hirngewebes aufgrund einer anhaltenden Hypoxie zustande kommt (Wefel et al. 2008). Des Weiteren sollte gerade in Bezug auf kognitive Veränderungen die jeweilige Ausgangssituation des Patienten berücksichtigt werden (Dietrich et al. 2008). Nicht zuletzt ist die individuelle Verträglichkeit der Therapie für einen bestimmten Patienten von zentraler 
Bedeutung. Dabei spielen auch Alter und Allgemeinzustand des Patienten eine Rolle. Alle diese Faktoren erschweren eine Auswertung in unserem Kollektiv. Dazu kommt die kleine Anzahl von Patienten in den Subgruppenanalysen bei sehr unterschiedlichen Therapieschemata, die angewandt wurden. Zudem variieren die Überlebenzeiten nach Transplantation von $<1$ bis 19 Monaten.

Einige in der grafischen Darstellung auffallende Unterschiede, welche jedoch nicht statistisch signifikant warten, könnten die Folge der geringen Fallzahl sein, die sich mitunter durch die strengen Auswahlkriterien ergab. Hier wären möglicherweise bei höherer Fallzahl statistisch signifikante Unterschiede erkennbar. Zusätzlich verringert wurde die Aussagekraft einiger Untersuchungen durch das Fehlen der benötigten Hirnareale oder die beschränkte Anfärbbarkeit einzelner paraffinfixierter Präparate, so dass diese für die Auswertung nicht zur Verfügung standen.

\subsection{Therapieassoziierte Veränderungen der Oligodendrozyten/- vorläuferpopulation}

Die Ergebnisse dieser Arbeit zeigen, dass zu den mikroskopisch nachweisbaren Auswirkungen einer Stammzelltransplantation am ehesten eine Beeinflussung der Oligodendrozytenpopulation gehört. Besonders eine Bestrahlung im Rahmen der Konditionierung erscheint bedenklich, da sie zu einer Verminderung der Oligodendrozytenvorläufer in der SVZ führt. Inwiefern dies mit den beschriebenen klinischen Nebenwirkungen einer Bestrahlung wie langfristigen kognitiven Beeinträchtigungen zusammenhängt, lässt sich bis jetzt nur vermuten.

Oligodendrozyten haben eine zentrale Funktion bei der Aufrechterhaltung der physiologischen Prozesse im ZNS. Dazu gehören unter anderem die Versorgung und der Schutz der Axone, die Myelinisierung sowie die Aufrechterhaltung des axonalen Transports (Lee et al. 2012; McTigue und Tripathi 2008; Ndubaku und de Bellard 2008). Im adulten ZNS existieren Vorläuferzellen, die zur Erneuerung der Oligodendrozytenpopulation beispielsweise nach Läsionen beitragen können und sich in diesem Fall verstärkt teilen (Menn et al. 2006; Nait-Oumesmar et al. 2007). Einzelne Autoren vermuten jedoch, dass die Erneuerung der Vorläuferzellpopulation in der SVZ nach Abschluss einer Chemotherapie nur ein vorübergehendes Phänomen sein könnte und es letztendlich zu einer Erschöpfung des Vorläuferpools und zu einer irreversiblen Schädigung kommen könnte (Dietrich et al. 2006). Es gibt Daten von einer Studie an Meerschweinchen zu den Auswirkungen einer Bestrahlung, die für diese Theorie sprechen. Dabei wurden unterschiedliche Phasen der Myelinschädigung beobachtet, wobei auf eine vorübergehende Regeneration letztendlich eine dauerhafte Schädigung des Myelins folgte (Belka et al. 2001; Chiang et al. 1992). Dies wirft wiederum die Frage auf, ob eine solche Therapie bei Erkrankungen wie der MS, bei der bereits eine Myelinpathologie vorliegt, in der Gegenüberstellung von Risiko und Nutzen wirklich günstig erscheint (Hintzen 2002). Bei der MS finden sich pathologische Veränderungen insbesondere in periventrikulärer Lokalisation, so dass hier die Regenerationskapazität möglicherweise bereits eingeschränkt ist. Die Indikation zu einer Stammzelltransplantation sollte demnach sehr eng gestellt werden. 


\subsection{Differenzierung von Spenderzellen im Zentralnervensystem der Empfänger}

Eine Stammzelltransplantation kann möglicherweise auch eine Regeneration im ZNS durch einwandernde und sich differenzierende Zellen des Spendertransplantates bewirken. Um einen Eindruck von den Auswirkungen der Stammzelltransplantation selbst auf das ZNS zu gewinnen und eine Aussage über den Umfang und die Art der eingewanderten und differenzierten Spenderzellen treffen zu können, führten wir eine In-situ-Hybridisierung mit einer Sonde zum Nachweis des Y-Chromosoms durch. Die dafür ausgewählten Patienten mussten weiblich sein und eine allogene Stammzelltransplantation von einem männlichen Spender erhalten haben (Cogle et al. 2004; Crain et al. 2005; Mezey et al. 2003; Sostak et al. 2007).

Wir konnten auf diese Weise männliche Spenderzellen in den Gehirnen der Patientinnen nachweisen. Die Anzahl lag etwa bei 0,5 Y-Chromosom-positiven Zellen pro $\mathrm{mm}^{2}$, was etwa einem Prozent des Wertes der männlichen Kontrolle entspricht. Auch andere Autoren berichten, dass nicht alle Zellkerne von männlichen Patienten ein Y-Chromosom-Signal zeigten. Es fehlte bei etwa 16\% der Kerne (Sostak et al. 2007), in unserem Fall sogar bei etwa 50\% der Zellkerne. Dies ist wahrscheinlich auf die jeweilige Schnittebene der sehr dünnen Schnitte zurückzuführen und/oder auf eine unvollständige Hybridisierung. Außerdem erfolgte durch Doppelfärbungen mittels ISH und Immunhistochemie eine Zuordnung der Zellen zu unterschiedlichen Zelltypen. Den größten Anteil machten dabei die endothelialen Zellen aus, gefolgt von den Astrozyten, Neuronen und Mikroglia. Reife Oligodendrozyten konnten nicht nachgewiesen werden. In der Literatur wird oft das größte Augenmerk beim Nachweis von eingewanderten Spenderzellen auf die Neurone gerichtet, doch es wird auch teilweise vom Nachweis anderer Zelltypen wie Astrozyten und Mikrogliazellen berichtet, während Oligodendrozyten und endotheliale Zellen bisher nur anhand ihrer Morphologie und nicht durch Doppelfärbungen identifiziert wurden (Crain et al. 2005; Sostak et al. 2007). Allerdings zeigte sich bei den anderen Studien zu diesem Thema teilweise eine etwas andere Häufigkeitsverteilung der Zelltypen. In einer Studie machten Mikroglia und Makrophagen den größten Teil aus, während Astrozyten und Neurone nicht in allen Fällen nachweisbar waren (Cogle et al. 2004). Eine andere Untersuchung stimmte mit unserem Ergebnis in der Hinsicht überein, dass der größte Teil der Y-Chromosom-positiven Zellen gefäßassoziiert war (Sostak et al. 2007). Auch in diesem Fall waren die zweitgrößte Gruppe Makrophagen und Mikroglia, jedoch konnten keine Astrozyten nachgewiesen werden. Neuronen waren selten. Eine andere Studie fokussierte sich hauptsächlich auf die Neuronen, die jedoch auch nur einen sehr geringen Anteil zwischen 0,2 und 3,5 Prozent der Y-Chromosom-positiven Zellen ausmachten, und machte allein aufgrund von Lage und Morphologie Aussagen über die Art der übrigen Zellen. Sie beschrieben einige Oligodendrozyten und gefäßassoziierte Zellen (Crain et al. 2005; Mezey et al. 2003). Dies konnte in unseren Experimenten durch immunohistochemische Färbungen nicht bestätigt werden. In den von uns untersuchten Fällen fanden sich unter den eingewanderten Spenderzellen keine reifen Oligodendrozyten. Über den Anteil der Oligodendrozytenvorläuferzellen konnten wir leider keine Aussagen machen, da uns die Anfärbung mit Anti-Olig2 aus technischen Gründen nicht gelang.

Leider wurde die Auswertung der ohnehin schon geringen Fallzahl, zusätzlich durch technische Schwierigkeiten bei den Färbungen reduziert. Somit ist es schwer eine repräsentative quantitative Aussage 
zu treffen. Im Wesentlichen bestätigen unsere Ergebnisse die der vorangegangener Untersuchungen: Es lassen sich nach einer peripheren Stammzelltransplantation Y-Chromosom-positive Zellen unterschiedlicher Zelltypen im ZNS des Empfängers nachweisen, was auf ein Einwandern von Spenderzellen und deren Differenzierung in unterschiedliche Zelltypen, unter anderem auch in Neurone, hindeutet (Cogle et al. 2004; Crain et al. 2005; Mezey et al. 2003; Sostak et al. 2007). Genaue Aussagen, ob es auch zu einer Differenzierung in Oligodendrozyten und Oligodendrozytenvorläuferzellen kommt, stehen aus, wobei wir mit Hilfe unserer Studie schon etwas genauere Daten erheben konnten als andere Autoren, die ihre Anmerkungen zur Verteilung der Zelltypen allein aus den morphologischen Merkmalen begründet haben und an dieser Stelle noch grundsätzliche Nachforschungen empfehlen (Crain et al. 2005).

Neuere Erkenntnisse stellen in Frage, dass es sich bei den zerebral nachgewiesenen Y-Chromosom-positiven Zellen um transdifferenzierte Stammzellen handelt. So vermuten verschiedene Autoren, dass es viel mehr zu einer Zellfusion der transplantierten Stammzellen mit den lokalen Empfängerzellen kommt (Wurmser und Gage 2002). Bei In-vitro-Experimenten konnte durch eine spezielle Markierung der Zellen, die es ermöglichte im Nachhinein die Herkunft sicher zu bestimmen, nachgewiesen werden, dass es anders als erwartet weniger zu einer Transdifferenzierung als zu einer Zellfusion kam (Terada et al. 2002; Ying et al. 2002). Außerdem fiel bei der genauen Analyse der Zellen auf, dass bei mehreren Zelllinien die DNA-Menge vervielfacht war und in der genetischen Untersuchung Zellen mit 4 Geschlechtschromosomen nachgewiesen werden konnten, was für eine Fusion sprechen würde. Allerdings wurde von den Autoren dieser Studie darauf hingewiesen, dass die Anzahl der nachgewiesenen Zellfusionen insgesamt sehr gering war und dieser Vorgang kaum für die stabilen Transdifferenzierungsraten von 30-50\% aus verschiedenen Transplantationsstudien verantwortlich gemacht werden könnte (Terada et al. 2002). Es konnte in weiteren Untersuchungen nachgewiesen werden, dass Zellfusion im Tierversuch auch in vivo auftritt und Entzündungsprozesse vermehrt zu diesem Vorgang beitragen (Johansson et al. 2008; Nygren et al. 2008).

Eine Studie, die sich mit dem Nachweis mehrkerniger Purkinjezellen unter physiologischen Bedingungen (ohne eine Stammzelltransplantation) als Nachweis einer spontanen Zellfusion beschäftigte, konnte weder im Mausmodell noch in menschlichem Autopsiegewebe solche Zellen nachweisen (Nern et al. 2009). Dagegen konnten in menschlichen Gehirnen nach einer Stammzelltransplantation Purkinjezellen mit mehr als 2 Geschlechtschromosomen nachgewiesen werden, was von den Autoren als möglicher Nachweis einer Zellfusion angesehen wird (Weimann et al. 2003). Es konnten bisher keine doppelkernigen Nervenzellen nachgewiesen werden (Kemp et al. 2014).

Dafür, dass Zellfusionen nach Stammzelltransplantationen bei den meisten Zelltypen sehr selten sind, sprechen auch die Ergebnisse einer Untersuchung von Zellen der Mundschleimhaut (Tran et al. 2003). Dabei wurden Zellen von Patientinnen untersucht, die eine Stammzelltransplantation von einem männlichen Spender erhalten hatten. Es wurde eine Doppelmarkierung von X- und Y-Chromosomen vorgenommen, wobei sich unter den mehr als 9700 untersuchten Zellen insgesamt nur 2 Zellen mit mehr als 2 Geschlechtschromosomen fanden, die als Folge einer Fusion entstanden sein könnten. Dabei besaßen zwischen 0,8 \% und 12,7\% der Zellen je ein X- und ein Y-Chromosom. Diese Befunde sprechen somit klar für eine Transdifferenzierung und gegen ein Fusion von Stammzellen. 
Die Reichweite der physiologischen Auswirkungen einer Zellfusion ist nach wie vor nicht geklärt (Rice et al. 2013). Sowohl für die Hypothese der Transdifferenzierung als auch für die der Zellfusion gibt es Argumente, die dafür bzw. dagegen sprechen (Kemp et al. 2014). Weitere Untersuchungen sind an dieser Stelle noch notwendig, um die genauen Vorgänge besser zu verstehen.

\subsection{Stammzelltransplantation als zukünftige Therapieoption bei ZNS-Erkrankungen}

Insgesamt ist der Anteil der eingewanderten und differenzierten Spenderzellen im ZNS nach einer peripheren allogenen Stammzelltransplantation recht gering. Ob durch diese Zellen eine relevante Regeneration und ein klinischer Benefit für Patienten möglich sind, scheint zum jetzigen Zeitpunkt sehr fraglich. Ob die allogene Stammzelltransplantation einen klinischen Stellenwert in der Therapie von degenerativen Erkrankungen oder Verletzungen des ZNS bekommen könnte, bleibt abzuwarten. Vorerst sollte das Augenmerk auf die weitere Forschung in diesem Bereich gelegt werden, da noch viele Fragen ungeklärt sind. Erfüllen die nachgewiesenen Spenderzellen im Empfängerorganismus tatsächlich ihre physiologische Funktion? Dazu gibt es im Tierversuch schon vielversprechende Ergebnisse über Spender-T-Lymphozyten und -Makrophagen, die das Voranschreiten von Entzündungsherden in der weißen Substanz des Empfängers nachhaltig unterdrücken (van Gelder et al. 1996), doch die Übertragbarkeit auf den Menschen ist noch nicht ausreichend geklärt. Auch gibt es keine Studien über die Funktion von hirneigenen Zellen, die sich aus Spenderzellen differenzierten. Ist es möglich die Menge der ins ZNS einwandernden Zellen zu beeinflussen? Kann man die Art der Differenzierung der Stammzellen von außen beeinflussen und wenn ja wie?

Ein weiterer, nicht ausreichend erforschter Bereich sind die das ZNS betreffenden Abstoßungsreaktionen durch Spenderzellen gerichtet gegen den Empfängerorganismus, die Graft-versus-Host-Erkankung des ZNS. Einzelne Fälle werden in der Literatur beschrieben (Kamble et al. 2007). Doch die Diagnose ist schwierig zu stellen, und daher ist es nicht einfach, zuverlässige Aussagen über die tatsächliche Häufigkeit dieses Phänomens zu machen. Im von uns untersuchten Kollektiv konnten wir keine Graft-versus-Host-Reaktion beobachten. Der Vergleich mit der Kontrollgruppe erbrachte keinen vermehrten Nachweis von Entzündungszellen.

Auf mikroskopischer Ebene konnte diese Studie bis auf die diskutierten Veränderungen der Oliogdenrozytenpopulation keine Auffälligkeiten feststellen, doch wie sieht es beispielsweise auf der Ebene der Zellkommunikation, des Zellstoffwechsels oder im extrazellulären Bereich aus? Dies lässt sich an humanem Gewebe sicherlich nur schwer untersuchen. Doch es gibt einige interessante Ansätze, beispielsweise zu den Auswirkungen auf das Verhältnis von freiem und gebundenem Wasser im Gehirn in der MRT-Darstellung und auf die intrazellulären Prozesse wie Cytokinfreisetzung bis hin zur Auslösung von oxidativem Stress (Brown et al. 1995; Tofilon und Fike 2000).

Die allogene Stammzelltherapie ist bei malignen Erkrankungen häufig alternativlos. Auch die Vorteile, die eine allogene Stammzelltransplantation zur Therapie von Autoimmunerkrankungen wie der MS mit sich bringt, erscheinen für sich genommen zunächst recht vielversprechend. Zusätzlich zum immunmodulatorischen und immunsuppressiven Effekt, den auch eine autologe Stammzelltransplantation 
mit sich bringt, welche bereits im Rahmen klinischer Studien zur Therapie der MS durchgeführt wird (Rice et al. 2010), wäre es möglich, das gesamte „kranke“ Immunsystem auszutauschen (Van Wijmeersch et al. 2008). Darüber hinaus könnten die autoreaktiven T-Zellen des Empfängers durch den sogenannten Graft-versus-Autoimmunity-Effekt noch nachhaltiger beseitigt werden (Van Wijmeersch et al. 2007). Somit würde die Wahrscheinlichkeit einer Krankheitsprogression deutlich kleiner.

Dem gegenüber stehen die zusätzlichen Risiken der allogenen Therapie. Die Vorbehandlung durch Chemound Strahlentherapie ist deutlich aggressiver als bei der autologen Stammzelltransplantation. Die Infektionsgefahr ist durch die vollständige Ablation des Immunsystems höher. Außerdem besteht die Gefahr einer Graft-versus-Host-Reaktion. Alle diese Faktoren finden Ausdruck in der im Vergleich zur autologen Stammzelltransplantation deutlich höheren Mortalität. Dies macht zum momentanen Zeitpunkt eine allogene Stammzelltransplantation als Therapie einer in der Mehrzahl der Fälle nicht tödlichen Erkrankung wie der MS eher inakzeptabel (Karussis und Slavin 2004). Es ist nötig, die genauen Schädigungsmechanismen der einzelnen Therapiekomponenten genauer zu analysieren. Auf diesem Weg könnte es möglich sein, Nutzen und Risiko in ein günstigeres Verhältnis zu bringen und die Stammzelltransplantation als Therapiemöglichkeit für Erkrankungen wie die MS zu etablieren. Dabei werfen die Ergebnisse unserer Studie, die eine Beeinträchtigung der Oligodendrozytenpopulation durch Bestrahlung und bestimmte Chemotherapeutika aufzeigen, vorerst weitere Fragen auf. Die Auswirkungen einer solchen Behandlung könnten bei einem bereits vorgeschädigten Gehirn, wie dies bei MS-Patienten der Fall ist, deutlich tiefgreifender sein als bei dem hier untersuchten Testkollektiv. 


\section{$5 \quad$ Schlussfolgerung}

Es wurden histopathologische Veränderungen in Autopsiegewebe von Erwachsenengehirnen nach einer peripheren Blutstammzelltransplantation, verbunden mit den dazugehörigen Konditionierungen in Form von Chemo- bzw. Strahlentherapie, untersucht. Dabei zeigte sich vor allem ein Einfluss auf die Oligodendrozytenpopulation, der vereinbar sein könnte mit einer Schädigung der Oligodendrozytenvorläuferzellen. Hierbei scheint insbesondere eine Strahlentherapie zu einer Reduktion der Oligodendrozytenvorläuferzellen in der subventrikulären Zone (SVZ) zu führen. Eine wesentliche Axon- oder Myelinpathologie, entzündliche Infiltrate oder eine reaktive Gliose ließen sich bei transplantierten Patienten im Vergleich zu den Kontrollen nicht nachweisen.

Dementsprechend können wir in dieser Studie keine wesentliche Schädigung durch die Stammzelltransplantation nachweisen, aber die Reduktion von Oligodendrozyten und -vorläuferzellen macht den Benefit einer solchen Therapie für Krankheiten wie die MS, bei denen bereits von einer Vorschädigung der weißen Substanz des Gehirns auszugehen ist, durchaus weiter fraglich.

Im Allgemeinen verspricht eine allogene Stammzelltransplantation einen deutlich stärkeren therapeutischen Effekt bei jedoch gleichzeitig vermehrten Nebenwirkungen und erhöhter Mortalität im Vergleich zur autologen Stammzelltransplantation. Wir konnten übereinstimmend mit vorangegangenen Studien nachweisen, dass die Spenderzellen ins ZNS des Empfängers einwandern und sich in verschiedene Zelltypen differenzieren. Weitere Untersuchungen sind erforderlich, um genauere Aussagen über die Funktion und den Einfluss dieser eingewanderten Zellen auf den Empfängerorganismus treffen zu können.

Zum gezielten Einsatz der Stammzelltransplantation bei unterschiedlichen, auch nicht-neoplastischen Krankheitsbildern ist zur genauen Nutzen-Risiko-Abschätzung ein Verständnis der therapiebedingten, pathologischen zentralnervösen Veränderungen unabdingbar. Weitere Studien zu De- und Regnerationsprozessen sind hier nötig. 


\section{Anhang}

Tabelle 21: Klinische Charakteristika der transplantierten Patienten

(Immunhistochemie):

\begin{tabular}{|c|c|c|c|c|c|c|c|}
\hline $\begin{array}{l}\text { Art } \\
\text { der } \\
\text { Trans- } \\
\text { plan- } \\
\text { tation }\end{array}$ & $\begin{array}{l}\text { Patien- } \\
\text { ten-Nr. }\end{array}$ & $\begin{array}{l}\text { Ge- } \\
\text { schle } \\
\text { cht }\end{array}$ & $\begin{array}{l}\text { Al- } \\
\text { ter }\end{array}$ & $\begin{array}{l}\text { Neuropathologische } \\
\text { Diagnose }\end{array}$ & $\begin{array}{l}\text { Klinische } \\
\text { Angaben }\end{array}$ & $\begin{array}{l}\text { Zeitraum: } \\
\text { Trans- } \\
\text { plantation } \\
\text { - Tod }\end{array}$ & Todesursache \\
\hline \multirow[t]{9}{*}{ allogen } & 1 & $\mathrm{~m}$ & 49 & $\begin{array}{l}\text { ohne pathologischen Befund (o. } \\
\text { B.) }\end{array}$ & $\begin{array}{l}\text { chronische } \\
\text { myeloische }\end{array}$ & 9 Monate & $\begin{array}{l}\text { septisches } \\
\text { Kreislaufversagen }\end{array}$ \\
\hline & 2 & w & 54 & o. B. & $\begin{array}{l}\text { akute myeloische } \\
\text { Leukämie M4 }\end{array}$ & 2 Monate & $\begin{array}{l}\text { Nieren- und } \\
\text { Leberversagen }\end{array}$ \\
\hline & 3 & $\mathrm{~m}$ & 65 & o. B. & $\begin{array}{l}\text { myeloproliferatives } \\
\text { Syndrom; Typ: } \\
\text { essentielle } \\
\text { Thrombozythämie / } \\
\text { Osteomyelofibrose }\end{array}$ & 3 Monate & $\begin{array}{l}\text { respiratorisches } \\
\text { Versagen bei } \\
\text { Pneumonie }\end{array}$ \\
\hline & 4 & $\mathrm{~m}$ & 48 & $\begin{array}{l}\text { o. B. - revidierter Normalbefund: } \\
\text { Rezidiv }\end{array}$ & $\begin{array}{l}\text { hochmalignes } \\
\text { T-Non-Hodgkin-Ly } \\
\text { mphom, Stadium }\end{array}$ & $<1$ Monat & $\begin{array}{l}\text { toxisches } \\
\text { Multiorgan- } \\
\text { versagen }\end{array}$ \\
\hline & 5 & $\mathrm{~m}$ & 70 & Enzephalitis & $\begin{array}{l}\text { hereditäre } \\
\text { Hämochromatose } \\
\text { mit homozygoter } \\
\text { HFE-Gen(C282Y)- } \\
\text { Mutation; } \\
\text { Myelodysplastische } \\
\text { s Syndrom (MDS) }\end{array}$ & ca. 1 Monat & $\begin{array}{l}\text { septisches } \\
\text { Kreislaufversagen }\end{array}$ \\
\hline & 6 & $\mathrm{~m}$ & 55 & $\begin{array}{l}\text { 1. multiple, ältere Mikroblutungen; } \\
\text { 2. ältere Subarachnoidalblutung } \\
\text { parietooccipital links }\end{array}$ & $\begin{array}{l}\text { Mantellzelllymphom } \\
\text { Stadium IV }\end{array}$ & 6 Monate & $\begin{array}{l}\text { respiratorisches } \\
\text { Versagen bei } \\
\text { GVHD der Lunge, } \\
\text { Nierenversagen, } \\
\text { Kreislaufversagen }\end{array}$ \\
\hline & 7 & $\mathrm{~m}$ & 58 & \begin{tabular}{|l|} 
1. generalisiertes Hirnödem mit \\
subfalzialer Herniation der \\
Kleinhirnhemisphären und \\
konsekutiver Einblutungen im \\
Bereich des Mittelhirns und der \\
Pons; $2.2,1 \mathrm{~cm}$ große, ältere \\
Nekrose im Bereich des linken \\
Corpus mamillare sowie im Tractus \\
mamillothalamicus und dem \\
Mittelhirn linksseitig; 3 . Mehrere \\
$0,5 \mathrm{~cm}$ große, frische, \\
subarachnoidale Einblutungen \\
unterschiedlicher Lokalisation \\
(links frontal sowie rechts und links \\
parietal); $4.1,0 x 0,2 \mathrm{~cm}$ große, \\
intracerebrale Blutung im Bereich
\end{tabular} & $\begin{array}{l}\text { Osteomyelofibrose, } \\
\text { normochrome } \\
\text { Anämie } \\
\end{array}$ & 8 Monate & $\begin{array}{l}\text { septisches } \\
\text { Kreislaufversagen }\end{array}$ \\
\hline & 8 & w & 42 & $\begin{array}{l}\text { 1. intrazerebrale Blutung } \\
\text { fronto-parietal rechts sowie } \\
\text { Hirninfarkt rechts parietal; } 2 \text {. Infarkt } \\
\text { occipital und parietal links im } \\
\text { Versorgungsbereich der Arteria } \\
\text { cerebri posterior; } 3 \text {. zerebrale } \\
\text { Subarachnoidalblutung; } 4 \text {. } \\
\text { Hirnödem mit Uncusherniation und } \\
\text { Hirnstammelongation im } \\
\text { anterior/posteriorer Richtung sowie }\end{array}$ & $\begin{array}{l}\text { chronische } \\
\text { myeloische } \\
\text { Leukämie }\end{array}$ & $<1$ Monat & $\begin{array}{l}\text { V. a. cerebrale } \\
\text { Blutung mit } \\
\text { Hirnstammeinklem } \\
\text { mung; septischer } \\
\text { Schock mit } \\
\text { Multiorgan- } \\
\text { versagen mit } \\
\text { schwerer } \\
\text { metabolischer } \\
\text { Azidose }\end{array}$ \\
\hline & 9 & w & 54 & $\begin{array}{l}\text { nekrotisierende Pilzencephalitis } \\
\text { mit Nachweis multipler } \\
\text { Pilzabszesse }\end{array}$ & $\begin{array}{l}\text { akute myeloische } \\
\text { Leukämie - M1 }\end{array}$ & 8 Monate & $\begin{array}{l}\text { septisches } \\
\text { Kreislaufversagen }\end{array}$ \\
\hline
\end{tabular}




\begin{tabular}{|c|c|c|c|c|c|c|c|}
\hline $\begin{array}{l}\text { Art } \\
\text { der } \\
\text { Trans- } \\
\text { plan- } \\
\text { tation }\end{array}$ & $\begin{array}{l}\text { Patien- } \\
\text { ten-Nr. }\end{array}$ & $\begin{array}{l}\text { Ge- } \\
\text { schle } \\
\text { cht }\end{array}$ & $\begin{array}{l}\text { Al- } \\
\text { ter }\end{array}$ & $\begin{array}{l}\text { Neuropathologische } \\
\text { Diagnose }\end{array}$ & $\begin{array}{l}\text { Klinische } \\
\text { Angaben }\end{array}$ & $\begin{array}{l}\text { Zeitraum: } \\
\text { Trans- } \\
\text { plantation } \\
\text { - Tod }\end{array}$ & Todesursache \\
\hline & 10 & w & 39 & $\begin{array}{l}\text { regelhaft entwickeltes } \\
\text { Erwachsenengehirn mit multiplen } \\
\text { frischen kleinen Infarkten im } \\
\text { Bereich der weißen Substanz im } \\
\text { Stadium I und Zeichen der } \\
\text { Waller'schen Degeneration im } \\
\end{array}$ & $\begin{array}{l}\text { Philadelphia-Chrom } \\
\text { osom positive } \\
\text { akute } \\
\text { lymphoblastischen } \\
\text { Leukämie }\end{array}$ & 5 Monate & $\begin{array}{l}\text { akutes Nieren- und } \\
\text { Leberversagen }\end{array}$ \\
\hline & 11 & w & 51 & $\begin{array}{l}\text { adultes Gehirn mit hypoxischer } \\
\text { Enzephalopathie }\end{array}$ & $\begin{array}{l}\text { hochmalignes } \\
\text { B-Non-Hodgkin-Lyp } \\
\text { hom; primär } \\
\text { mediastinales } \\
\text { B-Zell-Lymphom } \\
\text { Stadium IIA mit } \\
\text { mediastinalem Bulk }\end{array}$ & 3 Monate & $\begin{array}{l}\text { septisches } \\
\text { Multiorgan- } \\
\text { versagen bei } \\
\text { septischem } \\
\text { Schock bei } \\
\text { Pneumonie }\end{array}$ \\
\hline & 12 & w & 60 & $\begin{array}{l}\text { Gehirn mit geringen senilen } \\
\text { Veränderungen }\end{array}$ & $\begin{array}{l}\text { immunoblastisches } \\
\text { Non-Hodgkin-Lymp } \\
\text { hom }\end{array}$ & 4 Monate & $\begin{array}{l}\text { septisches } \\
\text { Kreislaufversagen }\end{array}$ \\
\hline \multirow[t]{3}{*}{ autolog } & 13 & $\mathrm{~m}$ & 32 & o. B. & $\begin{array}{l}\text { Morbus Hodgkin } \\
\text { Stadium III }\end{array}$ & ca. 1 Monat & $\begin{array}{l}\text { septischer Schock } \\
\text { bei Pneumonie }\end{array}$ \\
\hline & 14 & $\mathrm{~m}$ & 55 & o. B. & $\begin{array}{l}\text { IgG-Kappa-Plasmo } \\
\text { zytom }\end{array}$ & ca. 1 Monat & $\begin{array}{l}\text { Muiltiorgan- } \\
\text { versagen }\end{array}$ \\
\hline & 15 & $\mathrm{~m}$ & 60 & $\begin{array}{l}\text { 1. kleiner Balkeninfarkt (Stadium } \\
\text { III); } 2 \text {. fokale lymphoide Infiltrate in } \\
\text { den Gefäßwänden als möglicher } \\
\text { Hinweis auf eine minimale } \\
\text { zerebrale Manifestation des } \\
\text { bekannten }\end{array}$ & $\begin{array}{l}\text { Morbus Hodgkin } \\
\text { Stadium III }(01 / 05)\end{array}$ & 19 Monate & $\begin{array}{l}\text { septischer Schock } \\
\text { bei Pneumonie }\end{array}$ \\
\hline \multirow[t]{2}{*}{$\begin{array}{l}\text { autolog } \\
\text { +alloge } \\
\mathbf{n}\end{array}$} & 16 & $\mathrm{~m}$ & 54 & o. B. & $\begin{array}{l}\text { Bence Jones } \\
\text { Plasmozytom } \\
\text { Stadium III B mit } \\
\text { Kappa-Leichtketten } \\
\text {-Ausscheidung und } \\
\text { schwerer } \\
\text { Hyperkalzämie }\end{array}$ & $\begin{array}{l}9 \text { Monate; } 5 \\
\text { Monate }\end{array}$ & $\begin{array}{l}\text { hyperchlorämische } \\
\text { Azidose }\end{array}$ \\
\hline & 17 & w & 52 & o. B. & $\begin{array}{l}\text { Plasmozytom Typ } \\
\text { IgG-Kappa, } \\
\text { Stadium II A; } \\
\text { Deletion 13q }\end{array}$ & $\begin{array}{l}6 \text { Monate; } 3 \\
\text { Monate }\end{array}$ & $\begin{array}{l}\text { septischer Schock } \\
\text { bei Pneumonie }\end{array}$ \\
\hline
\end{tabular}

Tabelle 22: Klinische Charakteristika der Kontrollgruppe

\begin{tabular}{|c|c|c|c|c|c|}
\hline $\begin{array}{c}\text { Art der } \\
\text { Trans- } \\
\text { plan- } \\
\text { tation }\end{array}$ & $\begin{array}{l}\text { Patienten } \\
\text { Nr. }\end{array}$ & $\begin{array}{l}\text { Ge- } \\
\text { schlecht }\end{array}$ & Alter & $\begin{array}{l}\text { Neuropathologische } \\
\text { Diagnose }\end{array}$ & Klinische Angaben \\
\hline \multirow[t]{5}{*}{ Kontrollen } & 18 & w & 49 & o. B. & $\begin{array}{l}\text { Pneumonie nach Sturz und Unterkühlung bei } \\
\text { bekanntem Alkoholabusus }\end{array}$ \\
\hline & 19 & w & 40 & o. B. & $\begin{array}{l}\text { fulminante Lungenembolie als Folge von } \\
\text { Immobilisation nach OP bei Adipositas }\end{array}$ \\
\hline & 20 & $\mathrm{~m}$ & 43 & o. B. & $\begin{array}{l}\text { chronischer Alkoholabusus; Steatosis hepatis; } \\
\text { nekrotisierende Pankreatitis, } \\
\text { Elektrolytentgleisung; Sepsis }\end{array}$ \\
\hline & 21 & $\mathrm{~m}$ & 48 & o. B. & $\begin{array}{l}\text { Multiorganversagen bei } \\
\text { septischem/kardiogenem Schock; fulminante } \\
\text { Lungenembolie; bestehende }\end{array}$ \\
\hline & 22 & w & 57 & o. B. & inneres Verbluten bei Ulcus duodeni \\
\hline
\end{tabular}




\begin{tabular}{|c|c|c|c|c|}
\hline 23 & $\mathrm{~m}$ & 48 & o. B. & $\begin{array}{l}\text { bekannter Alkoholabusus; wahrscheinlich } \\
\text { akuter Herztod im Rahmen eines } \\
\text { protrahierten generalisierten Krampfanfalles }\end{array}$ \\
\hline 24 & $\mathrm{~m}$ & 56 & o. B. & $\begin{array}{l}\text { dekompensierte Leberzirrhose mit } \\
\text { Multiorganversagen }\end{array}$ \\
\hline 25 & $\mathrm{~m}$ & 57 & o. B. & Aortenklappenstenose, Herzinsuffizienz \\
\hline 26 & $\mathrm{~m}$ & 39 & o. B. & $\begin{array}{l}\text { Z. n. Reanimation nach schwerem } \\
\text { hämolytischen Geschehen unklarer Genes } \\
\text { mit Multiorganversagen }\end{array}$ \\
\hline 27 & $\mathrm{~m}$ & 67 & o. B. & akute Pankreatitis \\
\hline 28 & $\mathrm{~m}$ & 59 & o. B. & Oberschenkelamputation bei Gangrän \\
\hline 29 & w & 59 & o. B. & $\begin{array}{l}\text { Epilepsie; chronisch rezidivierende } \\
\text { Pankreatitis }\end{array}$ \\
\hline
\end{tabular}

Tabelle 23: Klinische Charakteristika der transplantierten Patienten (ISH)

\begin{tabular}{|c|c|c|c|c|c|c|c|}
\hline $\begin{array}{l}\text { Art der } \\
\text { Trans- } \\
\text { plan- } \\
\text { tation }\end{array}$ & $\begin{array}{c}\text { Pa- } \\
\text { tien- } \\
\text { ten } \\
\text { Nr. }\end{array}$ & $\begin{array}{c}\text { Ge- } \\
\text { schlecht }\end{array}$ & Alter & $\begin{array}{c}\text { Neuropathologische } \\
\text { Diagnose }\end{array}$ & $\begin{array}{l}\text { Klinische } \\
\text { Angaben }\end{array}$ & $\begin{array}{r}\text { Zeitraum: } \\
\text { Transplan- } \\
\text { tation - Tod }\end{array}$ & $\begin{array}{l}\text { Todes- } \\
\text { ursache }\end{array}$ \\
\hline \multirow[t]{2}{*}{$\begin{array}{l}\text { ISH } \\
\text { allogen }\end{array}$} & ISH-1 & w & 52 & $\begin{array}{l}\text { Erwachsenengehirn mit } \\
\text { generalisiertem Hirnödem } \\
\text { und einer beginnenden } \\
\text { transtentoriellen Herniation } \\
\text { sowie einer akuten } \\
\text { hypoxischen } \\
\text { Nervenzellschädigung }\end{array}$ & $\begin{array}{l}\text { akute myeloische } \\
\text { Leukämie - M4; } \\
\text { idiopathische } \\
\text { Hyperammonämie }\end{array}$ & 2 Monate & $\begin{array}{l}\text { progredientes } \\
\text { malignes } \\
\text { Hirnödem mit } \\
\text { zerebraler } \\
\text { Herniation }\end{array}$ \\
\hline & ISH-2 & w & 61 & $\begin{array}{l}\text { Erwachsenengehirn ohne } \\
\text { wesentlichen } \\
\text { pathologischen Befund }\end{array}$ & $\begin{array}{l}\text { myelodysplastisches } \\
\text { Syndrom RAEB-1; } \\
\text { GvHD IV kutan und } \\
\text { intestinal }\end{array}$ & 2 Monate & $\begin{array}{l}\text { Multiorganvers } \\
\text { agen bei } \\
\text { therapierefrakt } \\
\text { ärer GvHD }\end{array}$ \\
\hline $\begin{array}{l}\text { Kontrolle } \\
\text { ISH }\end{array}$ & ISH-3 & $m$ & 83 & $\begin{array}{l}\text { Gehirn mit Hydrozephalus } \\
\text { internus und senilen } \\
\text { Veränderungen bei } \\
\text { ansonsten } \\
\text { altersentsprechendem } \\
\text { Normalbefund }\end{array}$ & $\begin{array}{l}\text { 3-Gefäß-KHK; } \\
\text { periphere arterielle } \\
\text { Verschlusskrankheit; } \\
\text { Amputation rechter } \\
\text { proximaler } \\
\text { Unterschenkel }\end{array}$ & & $\begin{array}{l}\text { Multiorganvers } \\
\text { agen bei } \\
\text { septischem/ka } \\
\text { rdiogenen } \\
\text { Schock }\end{array}$ \\
\hline
\end{tabular}


Tabelle 24: Chemotherapieschemata und Bestrahlung

\begin{tabular}{|c|c|c|c|c|c|c|}
\hline $\begin{array}{l}\text { Art der } \\
\text { Trans- } \\
\text { plan- } \\
\text { tation }\end{array}$ & Autopsie & $\begin{array}{l}\text { Chemotherapie / } \\
\text { Bestrahlung }\end{array}$ & $\begin{array}{l}\text { Zeitraum: } \\
\text { ERSTE } \\
\text { Chemo - Tod }\end{array}$ & $\begin{array}{l}\text { Zeitraum: } \\
\text { LETZTE } \\
\text { Chemo-Tod }\end{array}$ & $\begin{array}{l}\text { Radiatio } \\
\text { total }\end{array}$ & $\begin{array}{l}\text { Radiatio } \\
\text { lokal }\end{array}$ \\
\hline \multirow[t]{11}{*}{ allogen } & 1 & TBI/Cy & 9 Monate & 9 Monate & TBI 12 Gy & - \\
\hline & 2 & $\begin{array}{l}\text { ICE (1. Zyklus) } \\
\text { ICE (2. Zyklus) } \\
\text { BuCy }\end{array}$ & 5 Monate & 2 Monate & - & - \\
\hline & 3 & \begin{tabular}{|l|} 
FB-8 ATG \\
Alemtuzumab \\
G-CSF
\end{tabular} & 3 Monate & 2 Monate & - & - \\
\hline & 4 & $\begin{array}{l}\text { CHOEP (6x) } \\
\text { M-ICE (Stammzellasservation) } \\
\text { M-ICE } \\
\text { M-DHAP } \\
\text { FBC }\end{array}$ & \begin{tabular}{|l|}
2 Jahre 11 \\
Monate / 35 \\
Monate
\end{tabular} & 0 Monate & - & $\begin{array}{l}\text { Radiatio } \\
\text { inguinal / } \\
\text { paraaortal / } \\
\text { Parotisloge }\end{array}$ \\
\hline & 5 & $\begin{array}{l}\text { Induktion "5 + 2": } \\
5 \text { Tage Cytarabin (150 mg/m²/24h } \\
\text { continious infusion) und } 2 \text { Tage } \\
\text { Daunorubicin }\left(60 \mathrm{mg} / \mathrm{m}^{2} \text { i.v.) }\right. \\
\text { FLAMSA AMT + ATG }\end{array}$ & 3 Monate & 2 Monate & - & - \\
\hline & 6 & $\begin{array}{l}\text { R-CHOP-14 (6x) } \\
\text { R-ICE (1. Zyklus) } \\
\text { R-ICE (2. Zyklus) } \\
\text { FluBuCy }\end{array}$ & 17 Monate & 6 Monate & - & - \\
\hline & 7 & \begin{tabular}{|l|} 
Alpha-Interferon; ACHTUNG: \\
geändertes Transplantprotokoll! \\
(Fludarabin $30 \mathrm{mg} / \mathrm{m}^{2}$; Busulfan \\
3mg/kg; ATG 3x 1660mg) \\
\end{tabular} & $\begin{array}{l}15 \text { Jahre } 8 \\
\text { Monate; } 188 \\
\text { Monate }\end{array}$ & 9 Monate & - & - \\
\hline & 8 & $\begin{array}{l}\text { Interferon-alpha } \\
\text { TBI/Cy }\end{array}$ & 7 Monate & 1 Monat & TBI 12Gy & - \\
\hline & 9 & $\begin{array}{l}\text { ICE (1. Zyklus) } \\
\text { ICE (2. Zyklus) } \\
\text { HAM (1. Zyklus) } \\
\text { HAM (2. Zyklus) } \\
\text { Ida-Flag } \\
\text { RIT (CD45-Yttrium) } \\
\text { BuCy }\end{array}$ & 20 Monate & 8 Monate & - & - \\
\hline & 10 & $\begin{array}{l}\text { GMALL } 07 / 03 \\
\text { Induktion I mit Imatinib } \\
\text { Induktion II, Radiatio cerebrale } \\
\text { Konsolidierung I } \\
\text { Konditionierung mit TBI } 12 \mathrm{~Gy}+ \\
\text { Etoposid }(60 \mathrm{mg} / \mathrm{kg}) \text {, Thymoglobulin } \\
(6 \mathrm{mg} / \mathrm{kg}) \\
\text { Alemtuzumab } \\
\text { Rituximab (3x) }\end{array}$ & 10 Monate & 1 Monat & TBI 12Gy & $\begin{array}{l}\text { ZNS-Bestra } \\
\text { hlung } 24 \text { Gy } \\
\text { (GMALL) }\end{array}$ \\
\hline & 11 & $\begin{array}{l}\text { R-CHOP-21 (6x) } \\
\text { R-ICE (1. Zyklus) } \\
\text { R-ICE (2. Zyklus) } \\
\text { R-ICE (3. Zyklus) } \\
\text { B-ALL (Block C } 1 ; 1 \text {. Kurs) } \\
\text { B-ALL (Block C 1; 2. Kurs) } \\
\text { FluBuCy }\end{array}$ & 16 Monate & 3 Monate & - & $\begin{array}{l}\text { mediastinale } \\
\text { Radiatio } 54 \\
\text { Gy }\end{array}$ \\
\hline
\end{tabular}




\begin{tabular}{|c|c|c|c|c|c|c|}
\hline $\begin{array}{l}\text { Art der } \\
\text { Trans- } \\
\text { plan- } \\
\text { tation }\end{array}$ & Autopsie & $\begin{array}{l}\text { Chemotherapie / } \\
\text { Bestrahlung }\end{array}$ & $\begin{array}{l}\text { Zeitraum: } \\
\text { ERSTE } \\
\text { Chemo - Tod }\end{array}$ & $\begin{array}{l}\text { Zeitraum: } \\
\text { LETZTE } \\
\text { Chemo - Tod }\end{array}$ & $\begin{array}{l}\text { Radiatio } \\
\text { total }\end{array}$ & $\begin{array}{l}\text { Radiatio } \\
\text { lokal }\end{array}$ \\
\hline & 12 & $\begin{array}{l}\text { CHOEP }(6 x) \\
\text { DexaBEAM }(2 x) \\
\text { Hochdosis Cyclophosphamid } \\
\text { Yttrium-CD22 } \\
\text { R-CHOP }(6 x) \\
\text { Dexamethason + Rituximab } \\
\text { R-ICE }(2 x) \\
\text { FBC-12 }\end{array}$ & $\begin{array}{l}6 \text { Jahre } 6 \\
\text { Monate; } 78 \\
\text { Monate }\end{array}$ & 3 Monate & & $\begin{array}{l}\text { intraabdomi } \\
\text { nelles } \\
\text { Rezidiv - } \\
\text { Radiotherapi } \\
\text { e } 36 \text { Gy; } \\
\text { Radiatio der } \\
\text { Bauchhaut }\end{array}$ \\
\hline \multirow[t]{3}{*}{ autolog } & 13 & $\begin{array}{l}\text { BEACOPP (3x; Stufe 4, 3, Basis mit } \\
\text { Infektkomplikationen) und esc. } \\
\text { ABVD (4x) } \\
\text { DHAP (1. Zyklus) } \\
\text { DHAP (2. Zyklus) } \\
\text { DHAP (3. Zyklus) } \\
\text { DexaBEAM } \\
\text { BEAM }\end{array}$ & $\begin{array}{l}3 \text { Jahre } 8 \\
\text { Monate; } 44 \\
\text { Monate }\end{array}$ & 1 Monat & - & $\begin{array}{l}\text { Radiatio } \\
\text { Waldeyer- } \\
\text { scher } \\
\text { Rachenring, } \\
\text { cervikale LK } \\
\text { bis 30Gy; LK } \\
\text { supra-infracl } \\
\text { av. beidseits, } \\
\text { Mediastinum } \\
\text {, rechter } \\
\text { Hilus bis } \\
\text { 30Gy }\end{array}$ \\
\hline & 14 & $\begin{array}{l}\text { ID }(3 x) \\
\text { IEV (Stammzellasservation) } \\
\text { 1. Melphalan-Hochdosistherapie } \\
\text { 2. Melphalan-Hochdosistherapie }\end{array}$ & 11 Monate & 2 Monate & - & - \\
\hline & 15 & $\begin{array}{l}\text { BEACOPP-eskaliert-Protokoll (8 } \\
\text { Zyklen): } 5 .+6 \text {. Zyklus: Dosisstufe III, } \\
\text { kein Vincristin bei Polyneuropathie; } \\
6 .+7 . \text { Zyklus DS II } \\
\text { DHAP (1. Zyklus) } \\
\text { DHAP (2. Zyklus) } \\
\text { BEAM } \\
\text { Adriamycin + Gemcitabine }\end{array}$ & $\begin{array}{l}3 \text { Jahre } 9 \\
\text { Monate; } 45 \\
\text { Monate }\end{array}$ & 1 Monat & - & - \\
\hline \multirow[t]{2}{*}{$\begin{array}{l}\text { autolog } \\
\text { +alloge } \\
\text { n }\end{array}$} & 16 & $\begin{array}{l}\text { Dexamethason mono }(2 x) \\
\text { ID (4 Zyklen) } \\
\text { IEV } \\
\text { Melphalan-Hochdosistherapie }(200 \\
\left.\mathrm{mg} / \mathrm{m}^{2}\right) \\
\text { FluBuCy }\end{array}$ & 16 Monate & 4 Monate & - & LWS \\
\hline & 17 & $\begin{array}{l}\text { ID }(4 x) \\
\text { IEV } \\
\text { Melphalan-Hochdosis }\left(100 \mathrm{mg} / \mathrm{m}^{2}\right) \\
\text { FluBuCy-8 }\end{array}$ & 9 Monate & 3 Monate & - & - \\
\hline
\end{tabular}


Tabelle 25a: Chemotherapie (Einzelsubstanzen) $\left({ }^{*} \cong\right.$ Patient ohne ZNS-Pathologie)

\begin{tabular}{|c|c|c|c|c|c|c|c|c|c|c|c|c|c|c|c|c|c|}
\hline 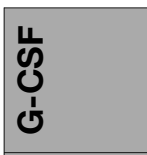 & & & $\times$ & & & & & & $\times$ & $x$ & & & & $\times$ & & $\times$ & \\
\hline$\frac{1}{\frac{1}{2}} \frac{\frac{1}{0}}{\frac{\pi}{\pi}}$ & & & $\times$ & $x$ & $\times$ & $x$ & $x$ & & $\times$ & & $x$ & $x$ & & & & $\times$ & $\times$ \\
\hline 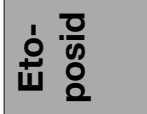 & & $x$ & & $x$ & & $\times$ & & & $\times$ & $\times$ & $x$ & $\times$ & $x$ & $\times$ & $x$ & $\times$ & $\times$ \\
\hline 立完 $\frac{\frac{5}{0}}{\frac{0}{2}}$ & & & & & & & & & . & 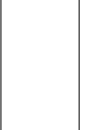 & . & 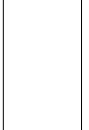 & & $x$ & & $\times$ & $\times$ \\
\hline 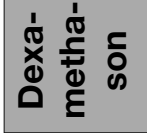 & & & & & & & & & $\times$ & $x$ & $x$ & $x$ & $x$ & $x$ & $\times$ & $\times$ & $\times$ \\
\hline 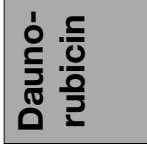 & & & & & $x$ & & & & & $x$ & & & & & & & \\
\hline 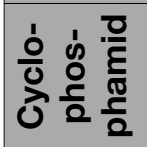 & $x$ & $x$ & & $\times$ & & $x$ & & $\times$ & $x$ & $x$ & $x$ & $x$ & $x$ & & $x$ & $x$ & $\times$ \\
\hline$\dot{\frac{\omega}{0}} \frac{\bar{\sigma}}{\frac{\pi}{\alpha}}$ & & & & & & & & & & & & & $x$ & & $x$ & & \\
\hline 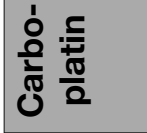 & & & & & & $\times$ & & & & & $x$ & $x$ & & & & & \\
\hline 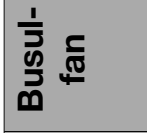 & & $x$ & $\times$ & $\times$ & & $\times$ & $x$ & & $\times$ & & $x$ & $\times$ & & & & $x$ & $\times$ \\
\hline$\frac{\dot{d}}{\dot{m}} \stackrel{\frac{c}{0}}{\grave{\varepsilon}}$ & & & & & & & & & & & & & $x$ & & $\times$ & & \\
\hline Z & & & & & & & & & & & & $x$ & $x$ & & $x$ & & \\
\hline 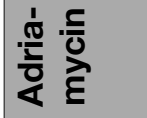 & & & & $x$ & & $\times$ & & & & & $x$ & $x$ & $x$ & & $x$ & & \\
\hline 志高 & & $x$ & & & $x$ & & & & $x$ & $x$ & $x$ & $x$ & $x$ & & $x$ & & \\
\hline 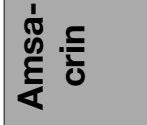 & & & & & $\times$ & & & & & & & & & & & & \\
\hline 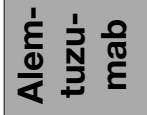 & & & $\times$ & $x$ & & & & & & $x$ & & & & & & & \\
\hline 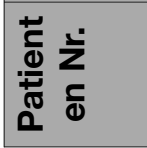 & * & * & ${ }_{\infty}^{*}$ & $\theta$ & م & 0 & $\Lambda$ & $\infty$ & o & 우 & $\mp$ & ؟ & $\stackrel{*}{m}$ & $\stackrel{*}{\square}$ & 10 & $\stackrel{*}{\stackrel{*}{\circ}}$ & $\stackrel{*}{\stackrel{*}{\sim}}$ \\
\hline
\end{tabular}


Tabelle 25b: Chemotherapie (Einzelsubstanzen) $\left({ }^{*} \triangleq\right.$ Patient ohne ZNS-Pathologie)

\begin{tabular}{|c|c|c|c|c|c|c|c|c|c|c|c|c|c|c|c|c|c|}
\hline \begin{tabular}{|l|}
$\frac{5}{5}$ \\
$\frac{1}{0}$ \\
0 \\
\\
5 \\
\end{tabular} & & & & & & & & & & & $\times$ & & & & & & \\
\hline 立竞 & & & & & & & & & & $x$ & $x$ & $x$ & $\times$ & & $x$ & & \\
\hline 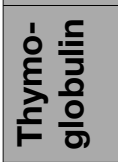 & & & & & & & & & & $x$ & & & & & & & \\
\hline 을 & & & & & & & & & & & & & & & & & \\
\hline$\frac{1}{\frac{1}{x}} \frac{0}{\widetilde{\pi}}$ & & & & & & & & & $x$ & & $x$ & $x$ & & & & & \\
\hline 일 & & & & & & & & & & & & & $x$ & & $x$ & & \\
\hline 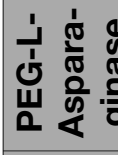 & & & & & & & & & & $x$ & & & & & & & \\
\hline 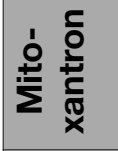 & & & & & & & & & $x$ & & & & & & & & \\
\hline 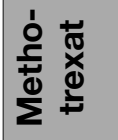 & & & & & & & & & $x$ & $x$ & $x$ & & & & & & \\
\hline 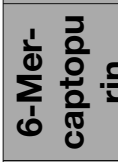 & & & & & & & & & & $x$ & & & & & & & \\
\hline$\sum^{\frac{1}{\infty}} \frac{\frac{c}{\pi}}{\frac{\pi}{0}}$ & $>$ & & & & & & & & & & & $x$ & $\times$ & $x$ & $\times$ & $\times$ & $\times$ \\
\hline 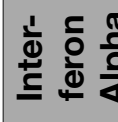 & & & & & & & & > & & & & & & & & & \\
\hline 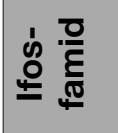 & & & & & & & & & & & $x$ & $\times$ & & $\times$ & & $\times$ & $x$ \\
\hline 흥 $\frac{\frac{5}{0}}{\frac{0}{2}}$ & & 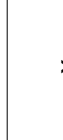 & & & & & & & $x$ & & & & & $\times$ & & $\times$ & $x$ \\
\hline 这 & & & & & & & & & & & & & & & $\times$ & & \\
\hline 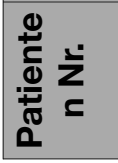 & * & $\stackrel{*}{N}$ & $\stackrel{*}{m}$ & $\theta$ & in & 0 & $\Lambda$ & $\infty$ & a & $\stackrel{\circ}{\circ}$ & $\mp$ & 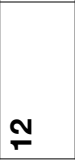 & $\stackrel{m}{\underline{m}}$ & $\dot{*}$ & $\stackrel{2}{\stackrel{2}{2}}$ & $\stackrel{*}{\varrho}$ & $\stackrel{*}{\sim}$ \\
\hline
\end{tabular}


Abb. 36: Diagramm - NogoA bei Busulfantherapie

NogoA
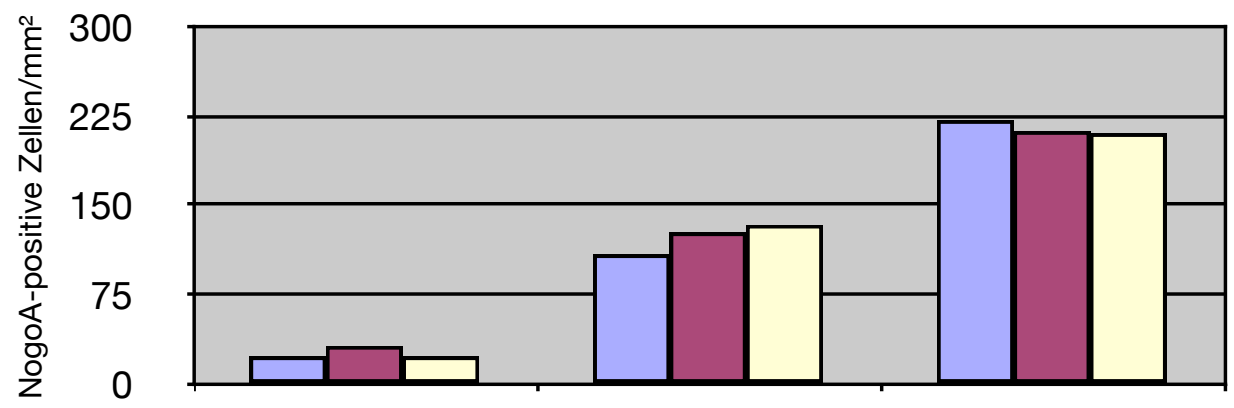

Median Marklager

Median Balken

Median SVZ

\begin{tabular}{|lll}
\hline$\square$ Tx mit Busulfan & $\square$ Tx ohne Busulfan
\end{tabular} Kontrollen

Tabelle 26: Anzahl der reifen Oligodendrozyten (NogoA) bei Busulfantherapie (Die Werte sind angegeben als Zellen $/ \mathrm{mm}^{2} \pm$ Standardabweichung)

\begin{tabular}{|c|c|c|c|}
\hline & $\begin{array}{c}\text { Transplantierte } \\
\text { Patienten mit Busulfan }\end{array}$ & $\begin{array}{c}\text { Transplantierte } \\
\text { Patienten ohne } \\
\text { Busulfan } \\
\end{array}$ & Kontrollen \\
\hline $\begin{array}{l}\text { NogoA-positive Zellen im } \\
\text { Marklager }\end{array}$ & $\begin{array}{r}23,2 \pm 8,84 \\
(n=10)\end{array}$ & $\begin{array}{r}32 \pm 30,45 \\
(\mathrm{n}=5)\end{array}$ & $\begin{array}{r}23,2 \pm 29,3 \\
(n=11) \\
\end{array}$ \\
\hline $\begin{array}{l}\text { NogoA-positive Zellen im } \\
\text { Corpus Callosum }\end{array}$ & $\begin{array}{r}108,8 \pm 11,07 \\
(n=4)\end{array}$ & 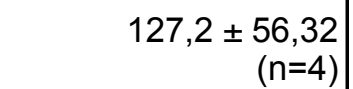 & $\begin{array}{r}133,6 \pm 38,07 \\
(n=10)\end{array}$ \\
\hline $\begin{array}{l}\text { NogoA-positive Zellen in } \\
\text { der SVZ }\end{array}$ & $\begin{array}{r}221,4 \pm 112,35 \\
(n=2)\end{array}$ & $\begin{array}{r}212,2 \pm 72,34 \\
(n=4)\end{array}$ & $\begin{array}{r}210,4 \pm 49,42 \\
(n=9)\end{array}$ \\
\hline
\end{tabular}

Abb. 37: Diagramm - Olig2 Stark bei Busulfantherapie

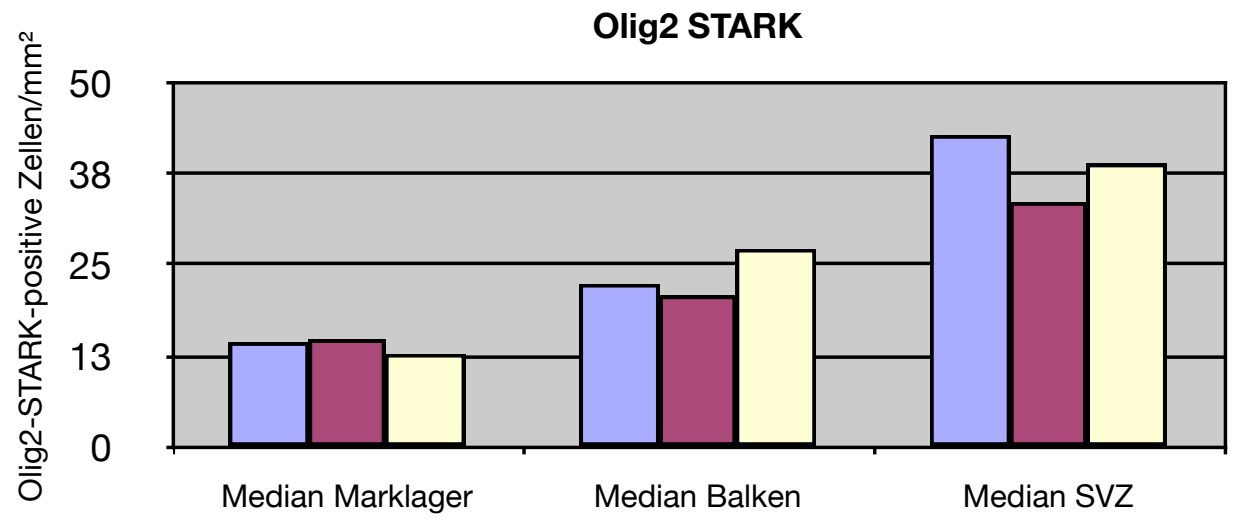

\begin{tabular}{|lll|}
\hline$\square$ Tx mit Busulfan & $\square$ Tx ohne Busulfan \\
\hline
\end{tabular}

Tabelle 27: Anzahl der Oligodendrozytenvorläuferzellen bei Busulfantherapie (Die Werte sind angegeben als Zellen/ $/ \mathrm{mm}^{2} \pm$ Standardabweichung)

\begin{tabular}{|l|r|r|r|}
\hline & $\begin{array}{r}\text { Transplantierte } \\
\text { Patienten mit Busulfan }\end{array}$ & $\begin{array}{r}\text { Transplantierte } \\
\text { Patienten ohne } \\
\text { Busulfan }\end{array}$ & Kontrollen \\
\hline $\begin{array}{l}\text { Olig2-STARK-positive } \\
\text { Zellen im Marklager }\end{array}$ & $\begin{array}{r}14,4 \pm 23,7 \\
(\mathrm{n}=9)\end{array}$ & $\begin{array}{r}14,8 \pm 12,27 \\
(\mathrm{n}=6)\end{array}$ & $\begin{array}{r}12,8 \pm 10,59 \\
(\mathrm{n}=11)\end{array}$ \\
\hline $\begin{array}{l}\text { Olig2-STARK-positive } \\
\begin{array}{l}\text { Zellen im Corpus } \\
\text { Callosum }\end{array}\end{array} \quad \begin{array}{r}22,4 \pm 36,65 \\
(\mathrm{n}=4)\end{array}$ & $\begin{array}{r}20,8 \pm 22,71 \\
(\mathrm{n}=5)\end{array}$ & $\begin{array}{r}27,2 \pm 20,17 \\
(\mathrm{n}=10)\end{array}$ \\
\hline $\begin{array}{l}\text { Olig2-STARK-positive } \\
\text { Zellen in der SVZ }\end{array}$ & $42,8 \pm \begin{array}{r}18,17 \\
(\mathrm{n}=4)\end{array}$ & $\begin{array}{r}33,6 \pm 34,55 \\
(\mathrm{n}=5)\end{array}$ & $\begin{array}{r}38,88 \pm 21,55 \\
(\mathrm{n}=9)\end{array}$ \\
\hline
\end{tabular}


Abb. 38: Diagramm - Olig2 Schwach bei Busulfantherapie

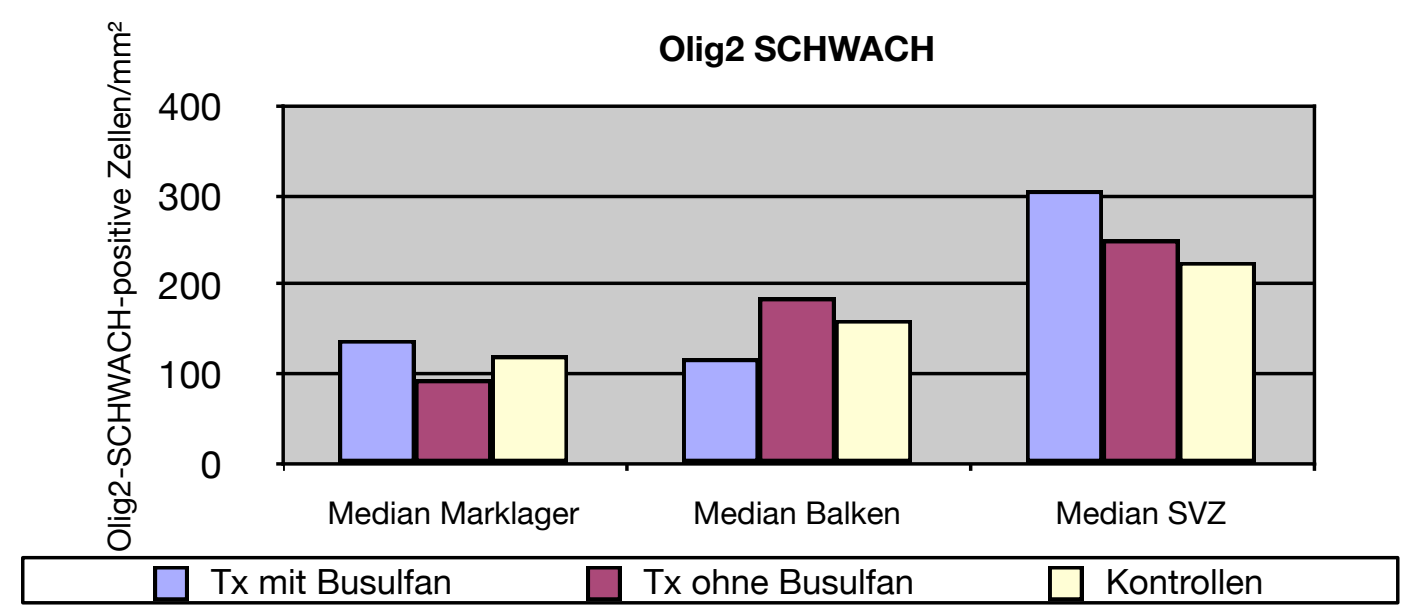

Tabelle 28: Anzahl der reifen Oligodendrozyten (Olig2 Schwach) bei Busulfantherapie (Die Werte sind angegeben als Zellen/mm² \pm Standardabweichung)

\begin{tabular}{|l|r|r|r|}
\hline & $\begin{array}{r}\text { Transplantierte } \\
\text { Patienten mit Busulfan }\end{array}$ & $\begin{array}{r}\text { Transplantierte } \\
\text { Patienten ohne } \\
\text { Busulfan }\end{array}$ & Kontrollen \\
\hline $\begin{array}{l}\text { Olig2-SCHWACH-positive } \\
\text { Zellen im Marklager }\end{array}$ & $138,4 \pm \begin{array}{r}84,24 \\
(\mathrm{n}=9)\end{array}$ & $\begin{array}{r}94 \pm 106,16 \\
(\mathrm{n}=6)\end{array}$ & $\begin{array}{r}120,8 \pm 69,43 \\
(\mathrm{n}=11)\end{array}$ \\
\hline $\begin{array}{l}\text { Olig2-SCHWACH-positive } \\
\begin{array}{l}\text { Zellen im Corpus } \\
\text { Callosum }\end{array}\end{array} \quad \begin{array}{r}117,6 \pm 128,8 \\
(\mathrm{n}=4)\end{array}$ & $\begin{array}{r}185,6 \pm 131,23 \\
(\mathrm{n}=5)\end{array}$ & $\begin{array}{r}160,8 \pm 132 \\
(\mathrm{n}=10)\end{array}$ \\
\hline $\begin{array}{l}\text { Olig2-SCHWACH-positive } \\
\text { Zellen in der SVZ }\end{array}$ & $\begin{array}{r}305,6 \pm 273,78 \\
(\mathrm{n}=4)\end{array}$ & $\begin{array}{r}250,4 \pm 141,72 \\
(\mathrm{n}=5)\end{array}$ & $\begin{array}{r}225,6 \pm 134,32 \\
(\mathrm{n}=9)\end{array}$ \\
\hline
\end{tabular}

Abb. 39: Diagramm - GFAP bei Busulfantherapie

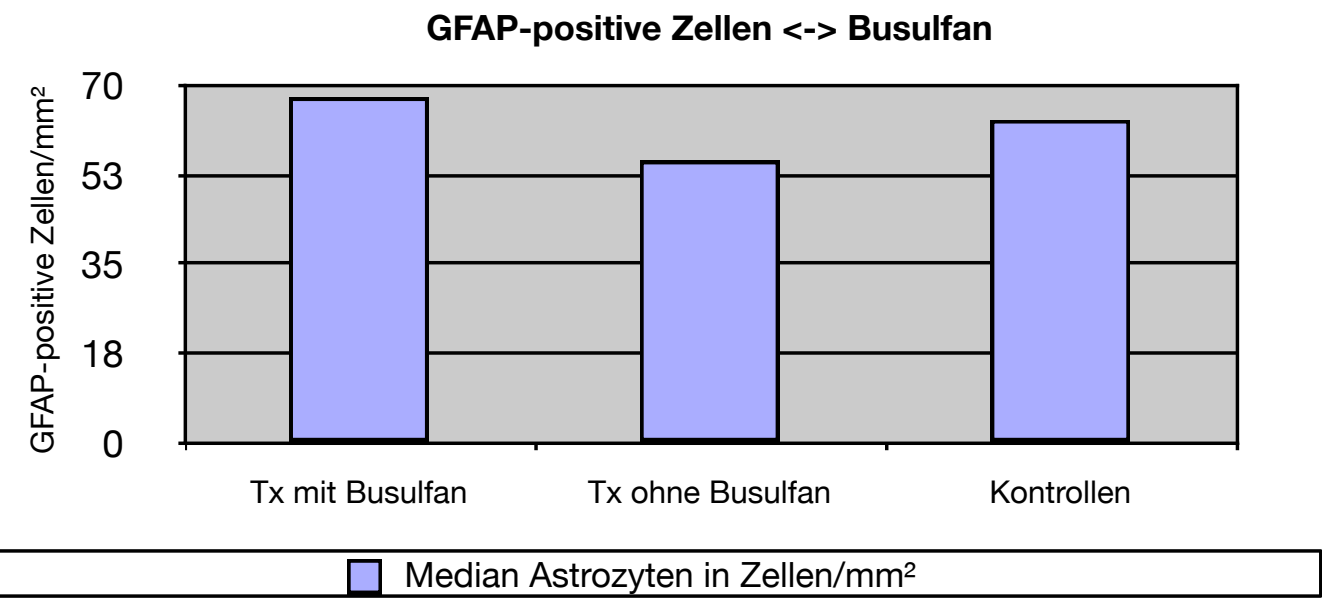

Tabelle 29: Anzahl der Astrozyten bei Busulfantherapie (Die Werte sind angegeben als Zellen/mm² \pm Standardabweichung)

\begin{tabular}{|l|r|r|r|}
\hline & \multicolumn{1}{|c|}{$\begin{array}{c}\text { Transplantierte } \\
\text { Patienten mit Busulfan }\end{array}$} & $\begin{array}{r}\text { Transplantierte } \\
\text { Patienten ohne } \\
\text { Busulfan }\end{array}$ & \multicolumn{1}{|c|}{ Kontrollen } \\
\hline GFAP-positive Zellen & $\begin{array}{r}67,6 \pm 24,43 \\
(\mathrm{n}=4)\end{array}$ & $\begin{array}{r}55,2 \pm 32,8 \\
(\mathrm{n}=3)\end{array}$ & $63,2 \pm 23,94$ \\
$(\mathrm{n}=7)$
\end{tabular}


Abb. 40: Diagramm - KiM1P bei Busulfantherapie

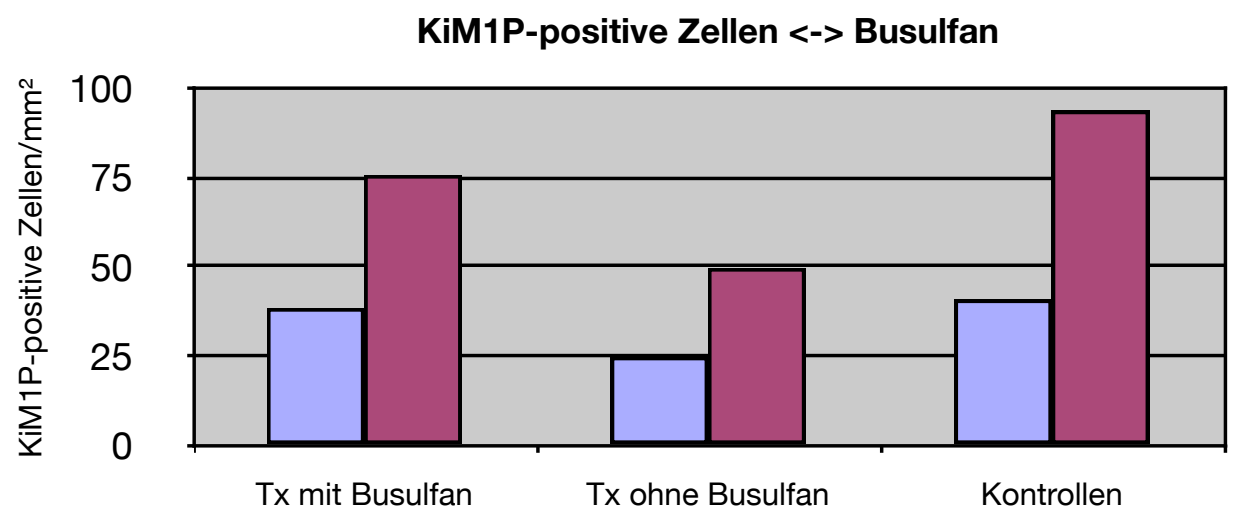

Median Makrophagen in Zellen/mm² $\square$ Median Mikroglia in Zellen/mm²

Tabelle 30: Anzahl der Makrophagen und Mikrogliazellen bei Busulfantherapie (Die Werte sind angegeben als Zellen/mm² \pm Standardabweichung)

\begin{tabular}{|l|r|r|r|}
\hline & $\begin{array}{r}\text { Transplantierte } \\
\text { Patienten mit Busulfan }\end{array}$ & $\begin{array}{r}\text { Transplantierte } \\
\text { Patienten ohne } \\
\text { Busulfan }\end{array}$ & Kontrollen \\
\hline $\begin{array}{l}\text { KiM1P-positive Zellen: } \\
\text { Makrophagen }\end{array}$ & $\begin{array}{r}24,4 \pm 8,87 \\
(\mathrm{n}=4)\end{array}$ & $\begin{array}{r}10,65 \\
(\mathrm{n}=3)\end{array}$ & $\begin{array}{r}40,8 \pm 14,35 \\
(\mathrm{n}=7)\end{array}$ \\
\hline $\begin{array}{l}\text { KiM1P-positive Zellen: } \\
\text { Mikroglia }\end{array}$ & $\begin{array}{r}75,6 \pm \begin{array}{r}19,81 \\
(\mathrm{n}=4)\end{array} \\
49,6 \pm 31,32 \\
(\mathrm{n}=3)\end{array}$ & $\begin{array}{r}93,6 \pm 24,48 \\
(\mathrm{n}=7)\end{array}$ \\
\hline
\end{tabular}

Abb. 41: Diagramm - APP bei Busulfantherapie

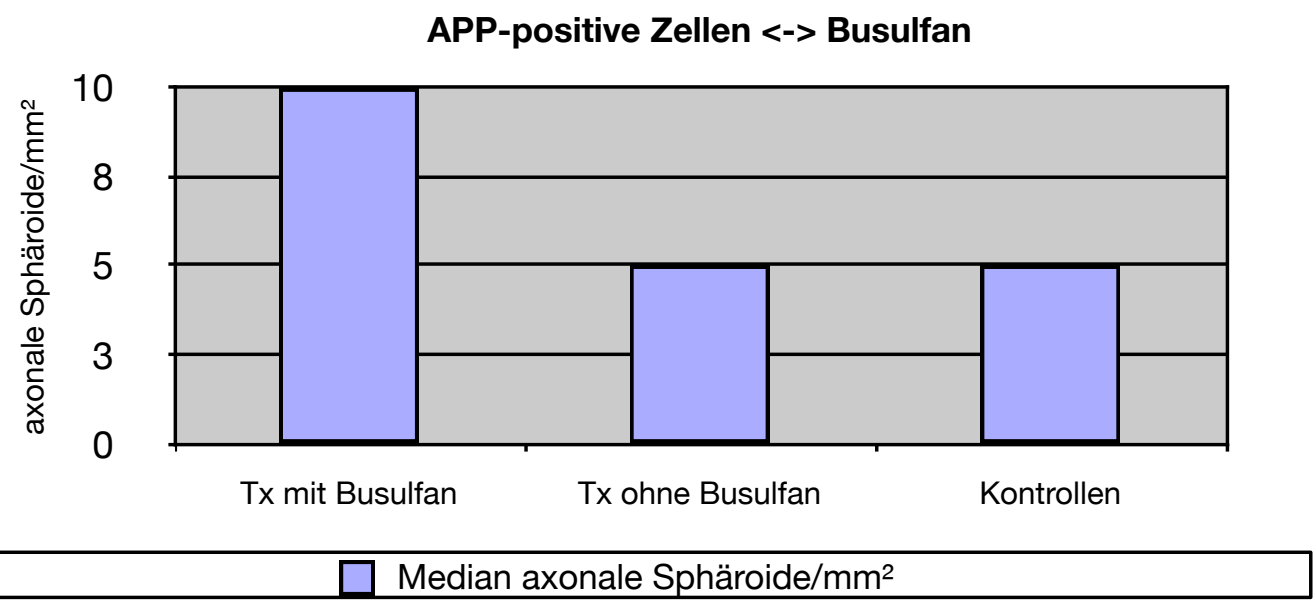

Tabelle 31: Anzahl der axonalen Sphäroide bei Busulfantherapie (Die Werte sind angegeben als axonale Sphäroide $/ \mathrm{mm}^{2} \pm$ Standardabweichung)

\begin{tabular}{|l|r|r|r|}
\hline & $\begin{array}{r}\text { Transplantierte } \\
\text { Patienten mit Busulfan }\end{array}$ & $\begin{array}{r}\text { Transplantierte } \\
\text { Patienten ohne } \\
\text { Busulfan }\end{array}$ & \multicolumn{1}{|c|}{ Kontrollen } \\
\hline Axonale Sphäroide & $10 \pm 8,66$ & $5 \pm 2,89$ \\
$(\mathrm{n}=4)$ & $(\mathrm{n}=3)$ & $5 \pm 12,05$ \\
$(\mathrm{n}=7)$
\end{tabular}


Abb. 42: Diagramm - NogoA bei Ifosfamidtherapie

NogoA
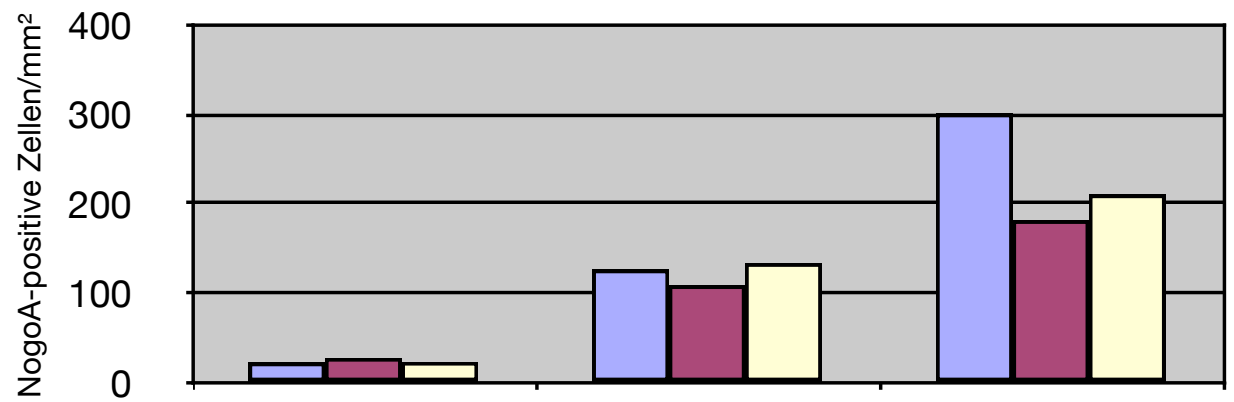

Median Marklager

Median Balken

Median SVZ

Tx mit Ifosfamid $\square$ Tx ohne Ifosfamid

Kontrollen

Tabelle 32: Anzahl der reifen Oligodendrozyten (NogoA) bei Ifosfamidtherapie (Die Werte sind angegeben als Zellen/mm² \pm Standardabweichung)

\begin{tabular}{|c|c|c|c|}
\hline & $\begin{array}{c}\text { Transplantierte } \\
\text { Patienten mit Ifosfamid }\end{array}$ & $\begin{array}{c}\text { Transplantierte } \\
\text { Patienten ohne } \\
\text { Ifosfamid }\end{array}$ & Kontrollen \\
\hline $\begin{array}{l}\text { NogoA-positive Zellen im } \\
\text { Marklager }\end{array}$ & $\begin{array}{r}22,4 \pm 3,44 \\
(n=5)\end{array}$ & $\begin{array}{r}27,6 \pm 23,17 \\
(\mathrm{n}=10) \\
\end{array}$ & $\begin{array}{r}23,2 \pm 29,3 \\
(n=11) \\
\end{array}$ \\
\hline \begin{tabular}{|l|} 
NogoA-positive Zellen im \\
Corpus Callosum \\
\end{tabular} & $\begin{array}{r}126,4 \pm 0 \\
(n=1) \\
\end{array}$ & $\begin{array}{r}108,8 \pm 45,33 \\
(n=7) \\
\end{array}$ & $\begin{array}{r}133,6 \pm 38,07 \\
(n=10) \\
\end{array}$ \\
\hline $\begin{array}{l}\text { NogoA-positive Zellen in } \\
\text { der SVZ }\end{array}$ & $\begin{array}{r}300,8 \pm 0 \\
(n=1)\end{array}$ & $\begin{array}{r}181,6 \pm 69,02 \\
(n=5)\end{array}$ & $\begin{array}{r}210,4 \pm 49,42 \\
(n=9)\end{array}$ \\
\hline
\end{tabular}

Abb. 43: Diagramm - Olig2 Stark bei Ifosfamidtherapie

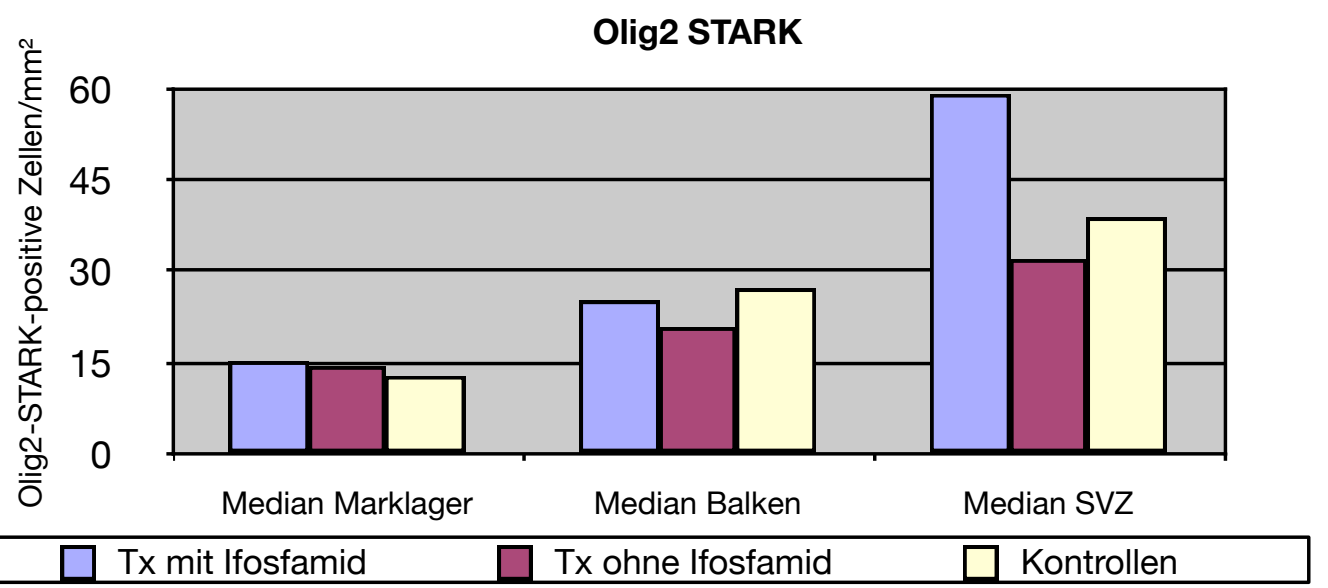

Tabelle 33: Anzahl der Oligodendrozytenvorläuferzellen bei Ifosfamidtherapie (Die Werte sind angegeben als Zellen $/ \mathrm{mm}^{2} \pm$ Standardabweichung)

\begin{tabular}{|c|c|c|c|}
\hline & $\begin{array}{c}\text { Transplantierte } \\
\text { Patienten mit Ifosfamid }\end{array}$ & $\begin{array}{c}\text { Transplantierte } \\
\text { Patienten ohne } \\
\text { Ifosfamid }\end{array}$ & Kontrollen \\
\hline $\begin{array}{l}\text { Olig2-STARK-positive } \\
\text { Zellen im Marklager }\end{array}$ & $\begin{array}{r}15,2 \pm 8,07 \\
(n=5)\end{array}$ & $\begin{array}{r}14,4 \pm 23,33 \\
(\mathrm{n}=10)\end{array}$ & $\begin{array}{r}12,8 \pm 10,59 \\
(n=11)\end{array}$ \\
\hline $\begin{array}{l}\text { Olig2-STARK-positive } \\
\text { Zellen im Corpus } \\
\text { Callosum }\end{array}$ & $\begin{array}{r}25,2 \pm 5,09 \\
(n=2)\end{array}$ & $\begin{array}{r}20,8 \pm 31,4 \\
(n=7)\end{array}$ & $\begin{array}{r}27,2 \pm 20,17 \\
(n=10) \\
\end{array}$ \\
\hline $\begin{array}{l}\text { Olig2-STARK-positive } \\
\text { Zellen in der SVZ }\end{array}$ & $\begin{array}{r}59,2 \pm 7,92 \\
(n=2)\end{array}$ & $\begin{array}{r}32 \pm 28,87 \\
(n=7)\end{array}$ & $\begin{array}{r}38,88 \pm 21,55 \\
(n=9)\end{array}$ \\
\hline
\end{tabular}


Abb. 44: Diagramm - Olig2 Schwach bei Ifosfamidtherapie ${ }^{*} \triangleq$ signifikante Unterschiede)

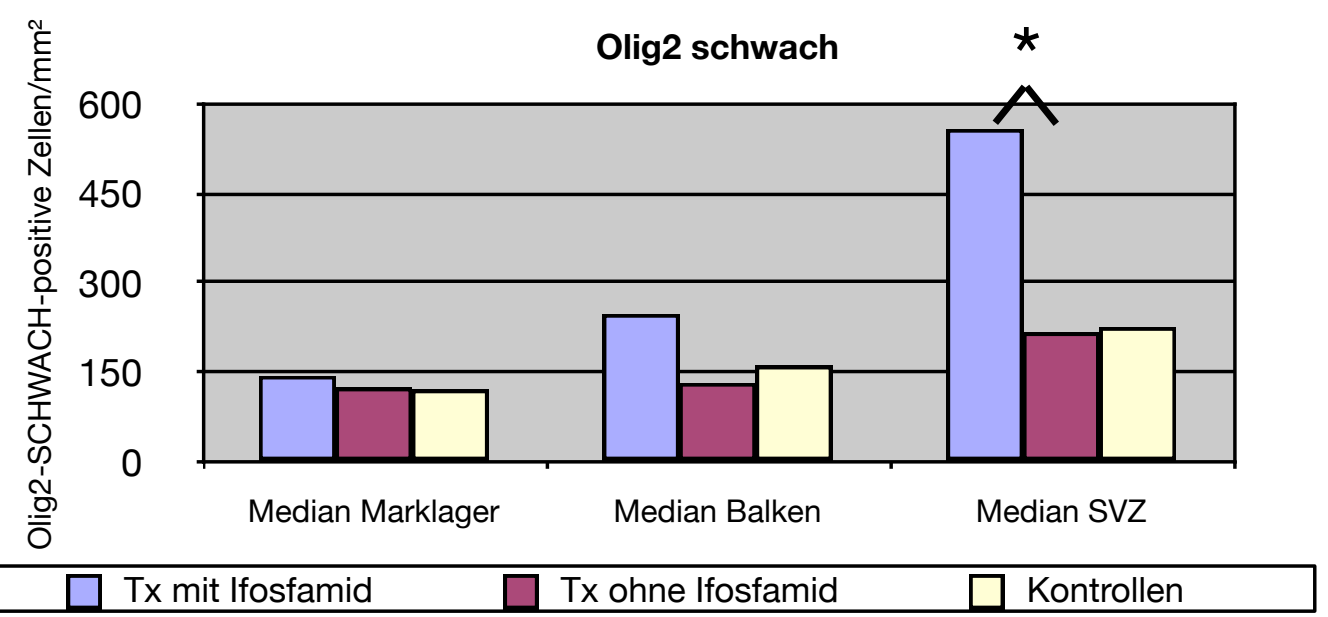

Tabelle 34: Anzahl der reifen Oligodendrozyten (Olig2 Schwach) bei Ifosfamidtherapie (Die Werte sind angegeben als Zellen $/ \mathrm{mm}^{2} \pm$ Standardabweichung)

\begin{tabular}{|c|c|c|c|}
\hline & $\begin{array}{c}\text { Transplantierte } \\
\text { Patienten mit Ifosfamid }\end{array}$ & $\begin{array}{l}\text { Transplantierte } \\
\text { Patienten ohne } \\
\text { Ifosfamid }\end{array}$ & Kontrollen \\
\hline $\begin{array}{l}\text { Olig2-SCHWACH-positive } \\
\text { Zellen im Marklager }\end{array}$ & $\begin{array}{r}144 \pm 66,3 \\
(n=5)\end{array}$ & $\begin{array}{r}124 \pm 104,83 \\
(n=10) \\
\end{array}$ & $\begin{array}{r}120,8 \pm 69,43 \\
(\mathrm{n}=11) \\
\end{array}$ \\
\hline $\begin{array}{l}\text { Olig2-SCHWACH-positive } \\
\text { Zellen im Corpus } \\
\text { Callosum }\end{array}$ & $\begin{array}{r}247,6 \pm 230,23 \\
(n=2)\end{array}$ & $\begin{array}{r}132 \pm 97,67 \\
(\mathrm{n}=7)\end{array}$ & $\begin{array}{r}160,8 \pm 132 \\
(n=10)\end{array}$ \\
\hline $\begin{array}{l}\text { Olig2-SCHWACH-positive } \\
\text { Zellen in der SVZ }\end{array}$ & $\begin{array}{r}558 \pm 188,37 \\
(n=2)\end{array}$ & $\begin{array}{r}216,8 \pm 130,38 \\
(n=7)\end{array}$ & $\begin{array}{r}225,6 \pm 134,32 \\
(n=9)\end{array}$ \\
\hline
\end{tabular}

Abb. 45: Diagramm - NogoA bei Cyclophosphamidtherapie

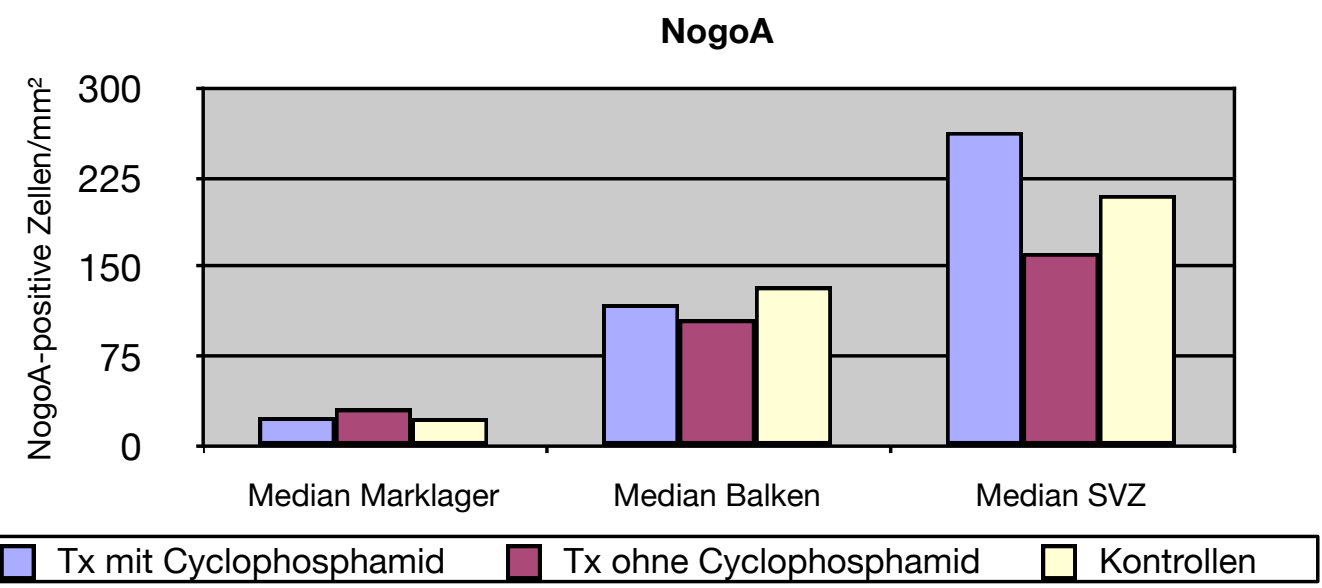

Tabelle 35: Anzahl der reifen Oligodendrozyten (NogoA) bei Cyclophosphamidtherapie (Die Werte sind angegeben als Zellen $/ \mathrm{mm}^{2} \pm$ Standardabweichung)

\begin{tabular}{|c|c|c|c|}
\hline & $\begin{array}{l}\text { Transplantierte } \\
\text { Patienten mit } \\
\text { Cyclophosphamid }\end{array}$ & $\begin{array}{l}\text { Transplantierte } \\
\text { Patienten ohne } \\
\text { Cyclophosphamid }\end{array}$ & Kontrollen \\
\hline $\begin{array}{l}\text { NogoA-positive Zellen im } \\
\text { Marklager }\end{array}$ & $\begin{array}{r}24 \pm 21,14 \\
(n=12)\end{array}$ & $\begin{array}{r}31,2 \pm 13,6 \\
(n=3)\end{array}$ & $\begin{array}{r}23,2 \pm 29,3 \\
(n=11)\end{array}$ \\
\hline $\begin{array}{l}\text { NogoA-positive Zellen im } \\
\text { Corpus Callosum }\end{array}$ & $\begin{array}{r}118,8 \pm 46,83 \\
(n=6)\end{array}$ & $\begin{array}{r}106 \pm 3,96 \\
(\mathrm{n}=2)\end{array}$ & $\begin{array}{r}133,6 \pm 38,07 \\
(n=10)\end{array}$ \\
\hline $\begin{array}{l}\text { NogoA-positive Zellen in } \\
\text { der SVZ }\end{array}$ & $\begin{array}{r}263,4 \pm 82,42 \\
(n=4)\end{array}$ & $\begin{array}{r}161,8 \pm 28,06 \\
(n=2)\end{array}$ & $\begin{array}{r}210,4 \pm 49,42 \\
(n=9)\end{array}$ \\
\hline
\end{tabular}


Abb. 46: Diagramm - Olig2 Stark bei Cyclophosphamidtherapie

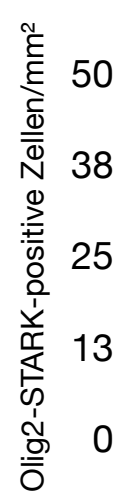

Olig2 STARK

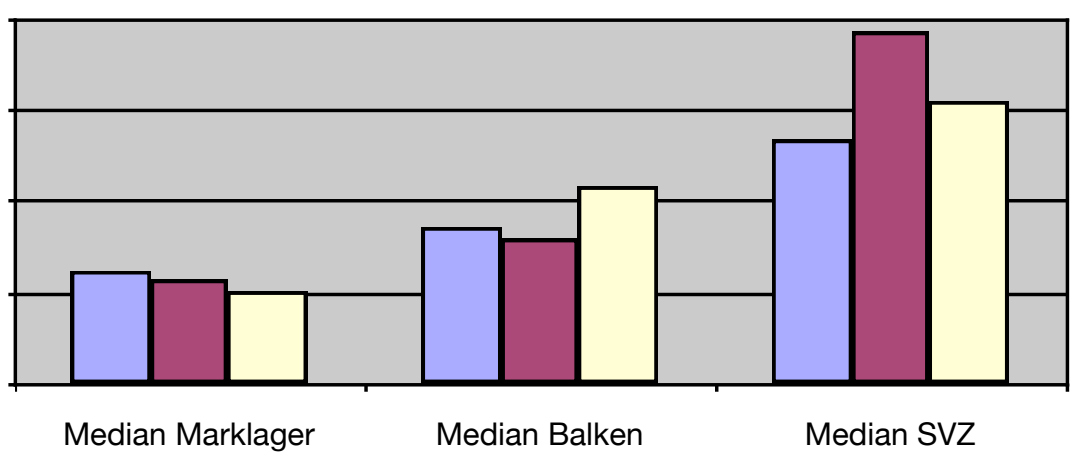

Tx mit Cyclophosphamid

Tx ohne Cyclophosphamid

Kontrollen

Tabelle 36: Anzahl der Oligodendrozytenvorläuferzellen bei Cyclophosphamidtherapie (Die Werte sind angegeben als Zellen $/ \mathrm{mm}^{2} \pm$ Standardabweichung)

\begin{tabular}{|c|c|c|c|}
\hline & $\begin{array}{c}\text { Transplantierte } \\
\text { Patienten mit } \\
\text { Cyclophosphamid } \\
\end{array}$ & $\begin{array}{c}\text { Transplantierte } \\
\text { Patienten ohne } \\
\text { Cyclophosphamid } \\
\end{array}$ & Kontrollen \\
\hline $\begin{array}{l}\text { Olig2-STARK-positive } \\
\text { Zellen im Marklager }\end{array}$ & $\begin{array}{r}15,6 \pm 21,98 \\
(n=12)\end{array}$ & $\begin{array}{r}14,4 \pm 0,8 \\
(n=3)\end{array}$ & $\begin{array}{r}12,8 \pm 10,59 \\
(n=11)\end{array}$ \\
\hline $\begin{array}{l}\text { Olig2-STARK-positive } \\
\text { Zellen im Corpus } \\
\text { Callosum }\end{array}$ & $\begin{array}{r}21,6 \pm 30,21 \\
(n=7)\end{array}$ & $\begin{array}{r}20 \pm 12,45 \\
(n=2)\end{array}$ & $\begin{array}{r}27,2 \pm 20,17 \\
(n=10)\end{array}$ \\
\hline $\begin{array}{l}\text { Olig2-STARK-positive } \\
\text { Zellen in der SVZ }\end{array}$ & $\begin{array}{r}33,6 \pm 29,4 \\
(n=7)\end{array}$ & $\begin{array}{r}48,4 \pm 23,19 \\
(n=2)\end{array}$ & $\begin{array}{r}38,88 \pm 21,55 \\
(n=9)\end{array}$ \\
\hline
\end{tabular}

Abb. 47: Diagramm - Olig2 Schwach bei Cyclophosphamidtherapie

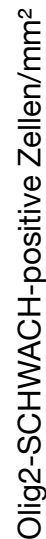

Olig2 schwach

300

225

150

75

0

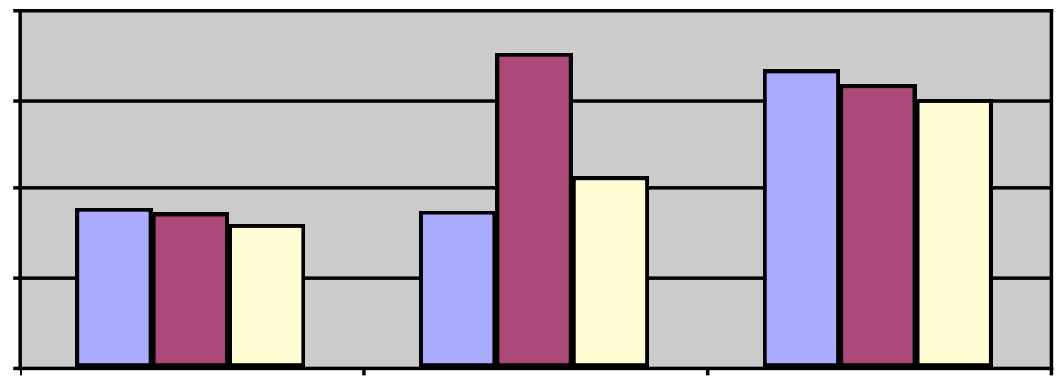

Median Marklager

Median Balken

Median SVZ

Tx mit Cyclophosphamid

Tx ohne Cyclophosphamid

Kontrollen 
Tabelle 37: Anzahl der reifen Oligodendrozyten (Olig2 Schwach) bei Cyclophosphamidtherapie (Die Werte sind angegeben als Zellen/mm² \pm Standardabweichung)

\begin{tabular}{|c|c|c|c|}
\hline & $\begin{array}{c}\text { Transplantierte } \\
\text { Patienten mit } \\
\text { Cyclophosphamid }\end{array}$ & $\begin{array}{l}\text { Transplantierte } \\
\text { Patienten ohne } \\
\text { Cyclophosphamid }\end{array}$ & Kontrollen \\
\hline $\begin{array}{l}\text { Olig2-SCHWACH-positive } \\
\text { Zellen im Marklager }\end{array}$ & $\begin{array}{r}134,4 \pm 100,31 \\
(n=12) \\
\end{array}$ & $\begin{array}{r}130,4 \pm 60,38 \\
(n=3)\end{array}$ & $\begin{array}{r}120,8 \pm 69,43 \\
(n=11) \\
\end{array}$ \\
\hline $\begin{array}{l}\text { Olig2-SCHWACH-positive } \\
\text { Zellen im Corpus } \\
\text { Callosum }\end{array}$ & $\begin{array}{r}132 \pm 101,25 \\
(n=7)\end{array}$ & $\begin{array}{r}264,4 \pm 206,48 \\
(n=2)\end{array}$ & $\begin{array}{r}160,8 \pm 132 \\
(n=10)\end{array}$ \\
\hline $\begin{array}{l}\text { Olig2-SCHWACH-positive } \\
\text { Zellen in der SVZ }\end{array}$ & $\begin{array}{r}250,4 \pm 202,16 \\
(n=7)\end{array}$ & $\begin{array}{r}238 \pm 264,18 \\
(n=2)\end{array}$ & $\begin{array}{r}225,6 \pm 134,32 \\
(n=9)\end{array}$ \\
\hline
\end{tabular}

Abb. 48: Diagramm - GFAP bei Cyclophosphamidtherapie

GFAP-positive Zellen <-> Cyclophosphamid

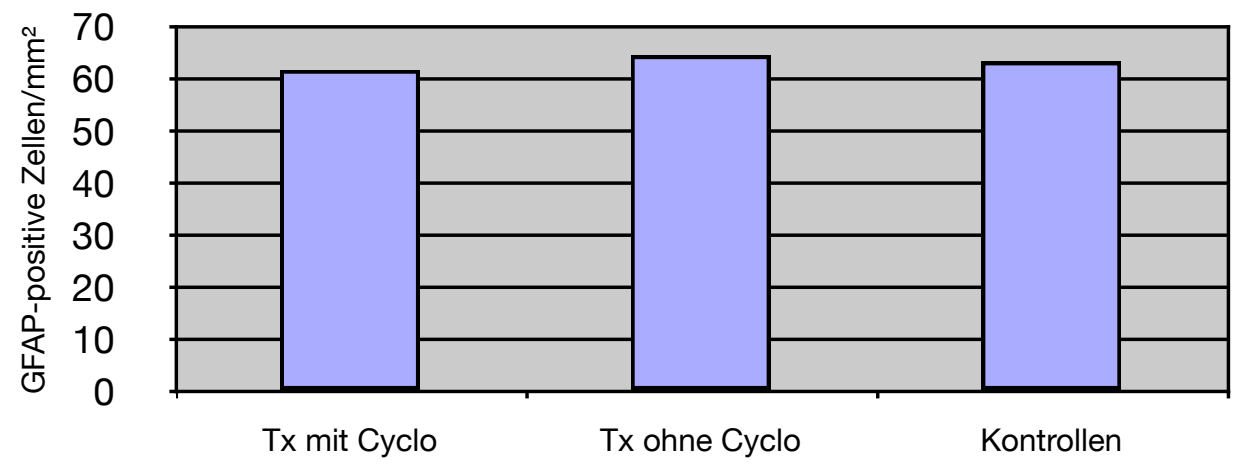

Median Astrozyten in Zellen/mm²

Tabelle 38: Anzahl der Astrozyten bei Cyclophosphamidtherapie (Die Werte sind angegeben als Zellen $/ \mathrm{mm}^{2} \pm$ Standardabweichung)

\begin{tabular}{|c|c|c|c|}
\hline & $\begin{array}{c}\text { Transplantierte } \\
\text { Patienten mit } \\
\text { Cyclophosphamid } \\
\end{array}$ & $\begin{array}{c}\text { Transplantierte } \\
\text { Patienten ohne } \\
\text { Cyclophosphamid }\end{array}$ & Kontrollen \\
\hline GFAP-positive Zellen & $\begin{array}{r}61,6 \pm 30,27 \\
(n=5)\end{array}$ & $\begin{array}{r}64,4 \pm 13,01 \\
(n=2)\end{array}$ & $\begin{array}{r}63,2 \pm 23,94 \\
(n=7)\end{array}$ \\
\hline
\end{tabular}

Abb. 49: Diagramm - KiM1P bei Cyclophosphamidtherapie

KiM1P-positive Zellen <-> Cyclophosphamid

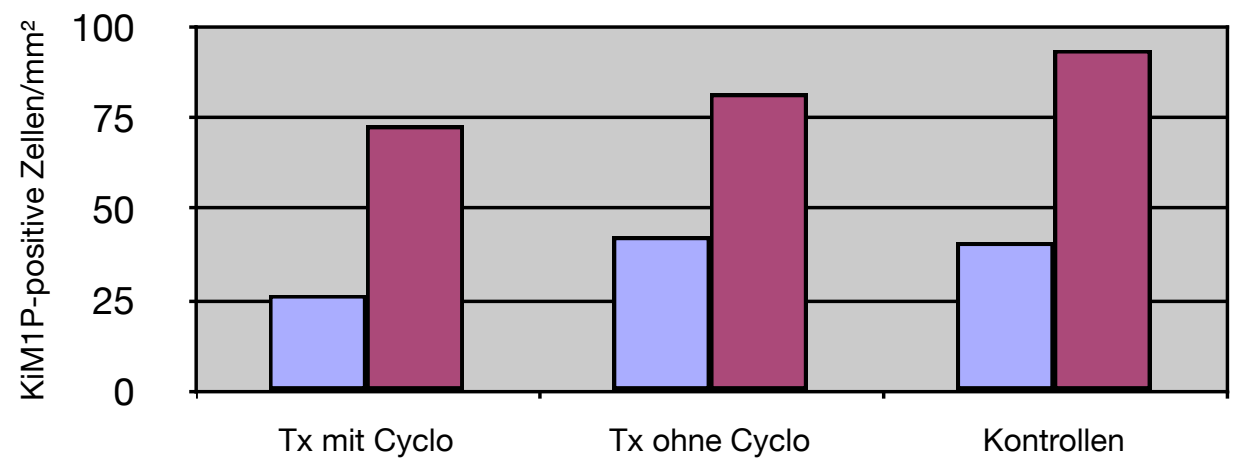

Median Makrophagen in Zellen/mm² $\square$ Median Mikroglia in Zellen/mm² 
Tabelle 39: Anzahl der Makrophagen und Mikrogliazellen bei Cyclophosphamidtherapie (Die Werte sind angegeben als Zellen $/ \mathrm{mm}^{2} \pm$ Standardabweichung)

\begin{tabular}{|l|r|r|r|}
\hline & \multicolumn{1}{|c|}{$\begin{array}{c}\text { Transplantierte } \\
\text { Patienten mit } \\
\text { Cyclophosphamid }\end{array}$} & $\begin{array}{r}\text { Transplantierte } \\
\text { Patienten ohne } \\
\text { Cyclophosphamid }\end{array}$ & Kontrollen \\
\hline KiM1P-positive Zellen: & $26,4 \pm 9,61$ \\
$(\mathrm{n}=5)$ & $\begin{array}{r}42,4 \pm 0 \\
(\mathrm{n}=2)\end{array}$ & $\begin{array}{r}40,8 \pm 14,35 \\
(\mathrm{n}=7)\end{array}$ \\
Makrophagen & $\begin{array}{r}72,8 \pm 24,75 \\
(\mathrm{n}=5)\end{array}$ & $\begin{array}{r}81,6 \pm 45,25 \\
(\mathrm{n}=2)\end{array}$ & $93,6 \pm 24,48$ \\
$(\mathrm{n}=7)$
\end{tabular}

Abb. 50: Diagramm - APP bei Cyclophosphamidtherapie

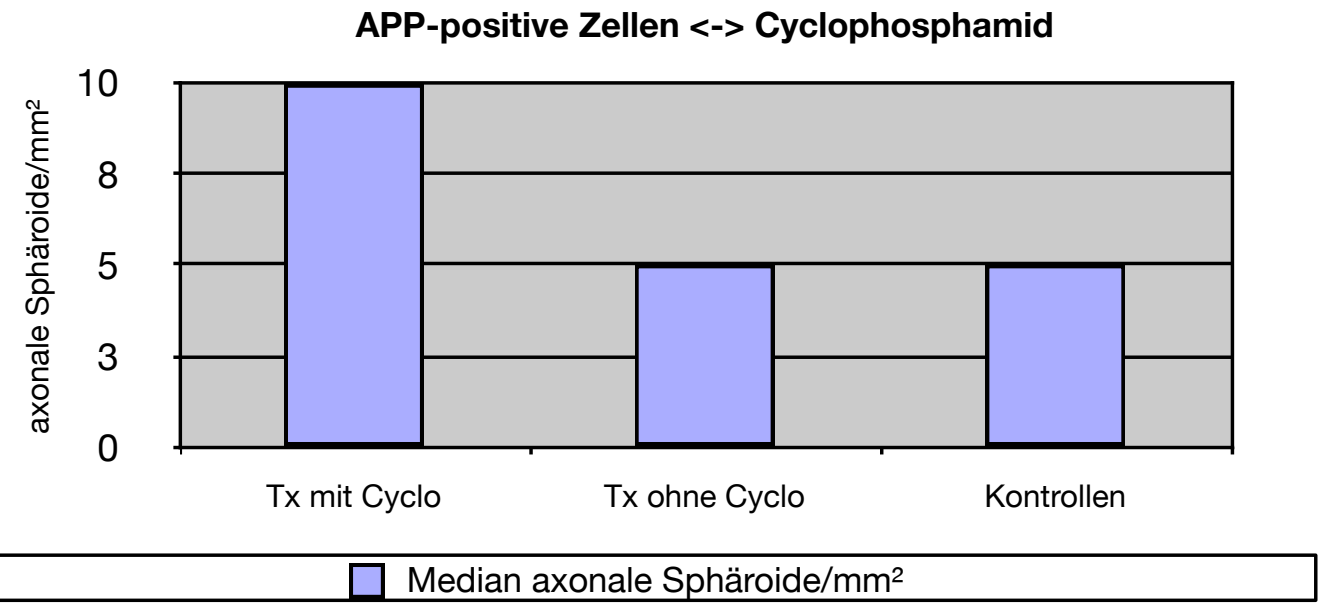

Tabelle 40: Anzahl der axonalen Sphäroide bei Cyclophosphamidtherapie (Die Werte sind angegeben als axonale Sphäroide $/ \mathrm{mm}^{2} \pm$ Standardabweichung)

\begin{tabular}{|l|r|r|r|}
\hline & $\begin{array}{c}\text { Transplantierte } \\
\text { Patienten mit } \\
\text { Cyclophosphamid }\end{array}$ & $\begin{array}{r}\text { Transplantierte } \\
\text { Patienten ohne } \\
\text { Cyclophosphamid }\end{array}$ & Kontrollen \\
\hline Axonale Sphäroide & $10 \pm 7,58$ & $5 \pm 0$ \\
$(\mathrm{n}=5)$ & $(\mathrm{n}=2)$ & $5 \pm 12,05$ \\
$(\mathrm{n}=7)$
\end{tabular}

Abb. 51: Diagramm - NogoA bei Etoposidtherapie

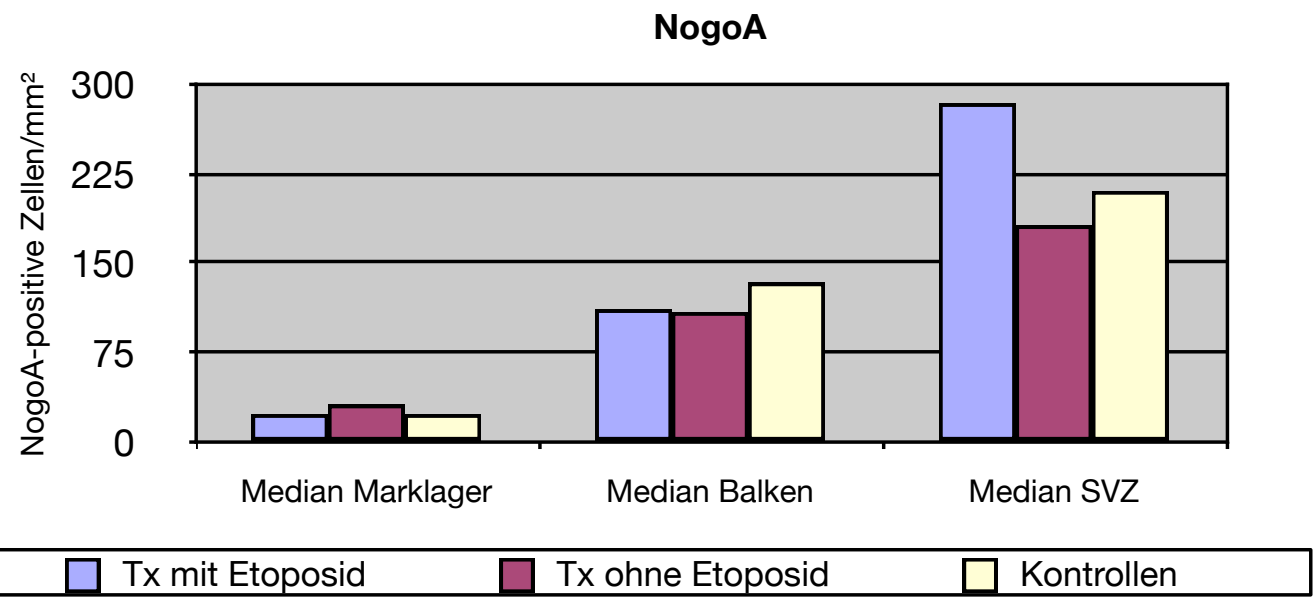


Tabelle 41: Anzahl der reifen Oligodendrozyten (NogoA) bei Etoposidtherapie (Die Werte sind angegeben als Zellen $/ \mathrm{mm}^{2} \pm$ Standardabweichung)

\begin{tabular}{|c|c|c|c|}
\hline & $\begin{array}{c}\text { Transplantierte } \\
\text { Patienten mit Etoposid }\end{array}$ & $\begin{array}{c}\text { Transplantierte } \\
\text { Patienten ohne } \\
\text { Etoposid }\end{array}$ & Kontrollen \\
\hline $\begin{array}{l}\text { NogoA-positive Zellen im } \\
\text { Marklager }\end{array}$ & $\begin{array}{r}23,2 \pm 23,19 \\
(\mathrm{n}=10)\end{array}$ & $\begin{array}{r}31,2 \pm 10,53 \\
(n=5)\end{array}$ & $\begin{array}{r}23,2 \pm 29,3 \\
(n=11) \\
\end{array}$ \\
\hline \begin{tabular}{|l|} 
NogoA-positive Zellen im \\
Corpus Callosum \\
\end{tabular} & $\begin{array}{r}111,2 \pm 52,21 \\
(n=5)\end{array}$ & $\begin{array}{r}108,8 \pm 21,66 \\
(n=3) \\
\end{array}$ & $\begin{array}{r}133,6 \pm 38,07 \\
(n=10)\end{array}$ \\
\hline $\begin{array}{l}\text { NogoA-positive Zellen in } \\
\text { der SVZ }\end{array}$ & $\begin{array}{r}284 \pm 100,81 \\
(n=3)\end{array}$ & $\begin{array}{r}181,6 \pm 50,78 \\
(n=3)\end{array}$ & $\begin{array}{r}210,4 \pm 49,42 \\
(n=9)\end{array}$ \\
\hline
\end{tabular}

\section{Abb. 52: Diagramm - Olig2 Stark bei Etoposidtherapie}

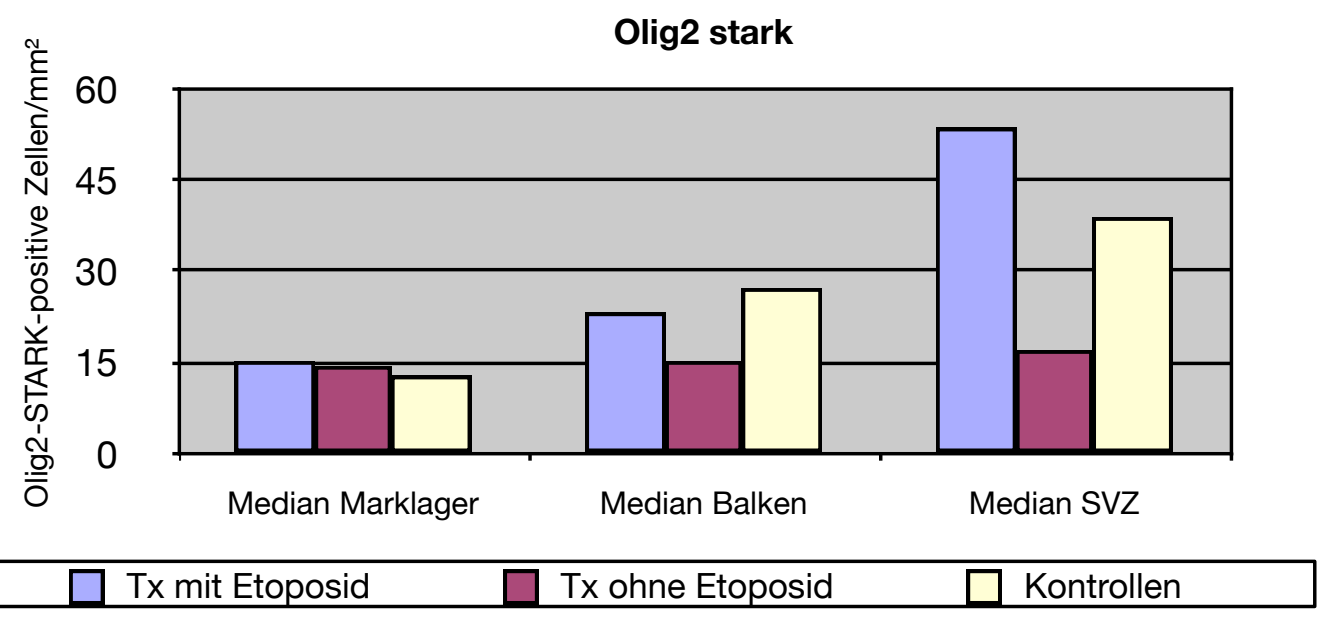

Tabelle 42: Anzahl der Oligodendrozytenvorläuferzellen bei Etoposidtherapie (Die Werte sind angegeben als Zellen/mm² \pm Standardabweichung)

\begin{tabular}{|c|c|c|c|}
\hline & $\begin{array}{c}\text { Transplantierte } \\
\text { Patienten mit Etoposid }\end{array}$ & $\begin{array}{c}\text { Transplantierte } \\
\text { Patienten ohne } \\
\text { Etoposid }\end{array}$ & Kontrollen \\
\hline $\begin{array}{l}\text { Olig2-STARK-positive } \\
\text { Zellen im Marklager }\end{array}$ & $\begin{array}{r}15,2 \pm 22,94 \\
(n=11)\end{array}$ & $\begin{array}{r}14,4 \pm 1,39 \\
(\mathrm{n}=4) \\
\end{array}$ & $\begin{array}{r}12,8 \pm 10,59 \\
(n=11) \\
\end{array}$ \\
\hline $\begin{array}{l}\text { Olig2-STARK-positive } \\
\text { Zellen im Corpus } \\
\text { Callosum } \\
\end{array}$ & $\begin{array}{r}23,2 \pm 29,42 \\
(n=7) \\
\end{array}$ & $\begin{array}{r}15,2 \pm 5,66 \\
(n=2) \\
\end{array}$ & $\begin{array}{r}27,2 \pm 20,17 \\
(\mathrm{n}=10) \\
\end{array}$ \\
\hline $\begin{array}{l}\text { Olig2-STARK-positive } \\
\text { Zellen in der SVZ }\end{array}$ & $\begin{array}{r}53,6 \pm 25,12 \\
(n=7)\end{array}$ & $\begin{array}{r}17 \pm 21,21 \\
(n=2)\end{array}$ & $\begin{array}{r}38,88 \pm 21,55 \\
(n=9)\end{array}$ \\
\hline
\end{tabular}


Abb. 53: Diagramm - Olig2 Schwach bei Etoposidtherapie
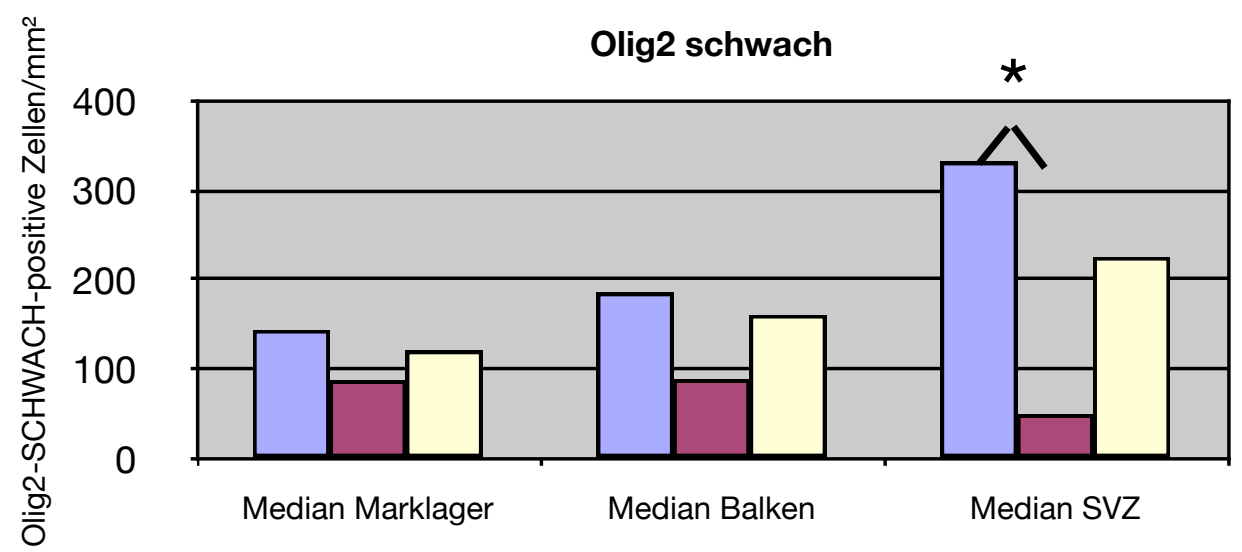

Tx mit Etoposid

Tx ohne Etoposid

Kontrollen

Tabelle 43: Anzahl der reifen Oligodendrozyten (Olig2 Schwach) bei Etoposidtherapie (Die Werte sind angegeben als Zellen/mm² \pm Standardabweichung)

\begin{tabular}{|c|c|c|c|}
\hline & $\begin{array}{c}\text { Transplantierte } \\
\text { Patienten mit Etoposid }\end{array}$ & $\begin{array}{c}\text { Transplantierte } \\
\text { Patienten ohne } \\
\text { Etoposid } \\
\end{array}$ & Kontrollen \\
\hline $\begin{array}{l}\text { Olig2-SCHWACH-positive } \\
\text { Zellen im Marklager } \\
\end{array}$ & $\begin{array}{r}144 \pm 96,38 \\
(n=11) \\
\end{array}$ & $\begin{array}{r}87,6 \pm 44,32 \\
(n=4) \\
\end{array}$ & $\begin{array}{r}120,8 \pm 69,43 \\
(\mathrm{n}=11) \\
\end{array}$ \\
\hline $\begin{array}{l}\text { Olig2-SCHWACH-positive } \\
\text { Zellen im Corpus } \\
\text { Callosum }\end{array}$ & $\begin{array}{r}185,6 \pm 125,5 \\
(n=7)\end{array}$ & $\begin{array}{r}88,8 \pm 41,86 \\
(n=2)\end{array}$ & $\begin{array}{r}160,8 \pm 132 \\
(n=10)\end{array}$ \\
\hline $\begin{array}{l}\text { Olig2-SCHWACH-positive } \\
\text { Zellen in der SVZ }\end{array}$ & $\begin{array}{r}332 \pm 169,91 \\
(n=7) \\
\end{array}$ & $\begin{array}{r}49,6 \pm 2,26 \\
(n=2)\end{array}$ & $\begin{array}{r}225,6 \pm 134,32 \\
(n=9) \\
\end{array}$ \\
\hline
\end{tabular}

Abb. 54: Diagramm - GFAP bei Etoposidtherapie

GFAP-positive Zellen <-> Etoposid

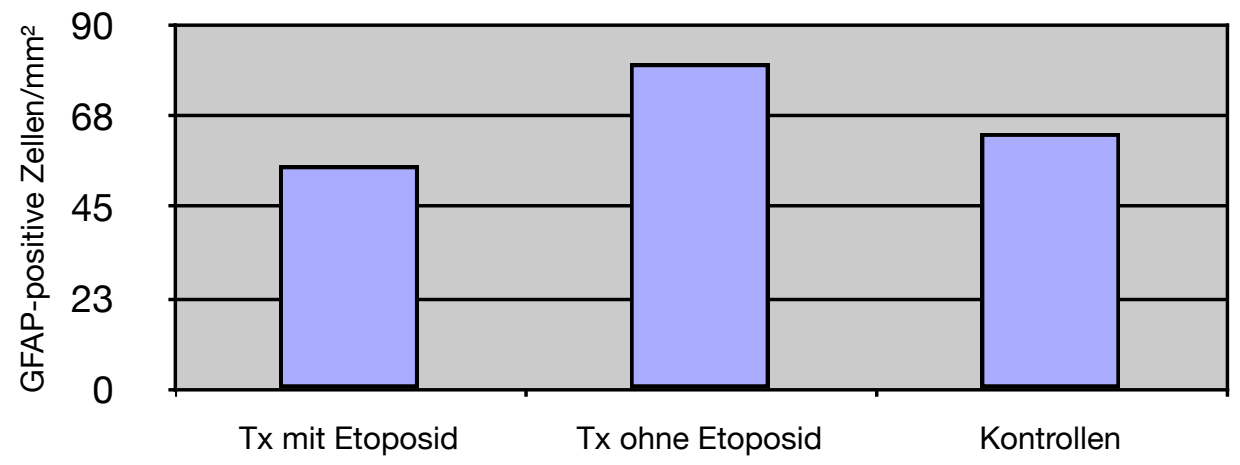

Median Astrozyten in Zellen/mm²

Tabelle 44: Anzahl der Astrozyten bei Etoposidtherapie (Die Werte sind angegeben als Zellen/mm² \pm Standardabweichung)

\begin{tabular}{|c|c|c|c|}
\hline & $\begin{array}{c}\text { Transplantierte } \\
\text { Patienten mit Etoposid }\end{array}$ & $\begin{array}{c}\text { Transplantierte } \\
\text { Patienten ohne } \\
\text { Etoposid }\end{array}$ & Kontrollen \\
\hline GFAP-positive Zellen & $\begin{array}{r}55,2 \pm 24,42 \\
(n=5)\end{array}$ & $\begin{array}{r}80,4 \pm 9,62 \\
(n=2)\end{array}$ & $\begin{array}{r}63,2 \pm 23,94 \\
(n=7)\end{array}$ \\
\hline
\end{tabular}


Abb. 55: Diagramm - KiM1P bei Etoposidtherapie

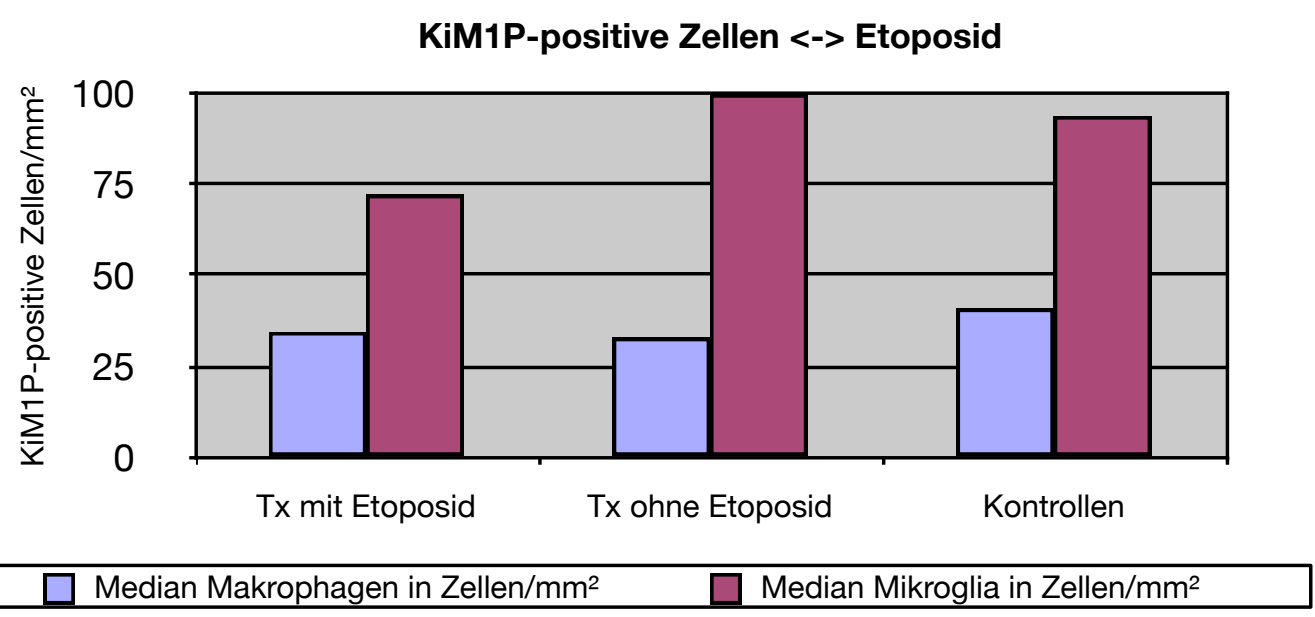

Tabelle 45: Anzahl der Makrophagen und Mikrogliazellen bei Etoposidtherapie (Die Werte sind angegeben als Zellen/mm² \pm Standardabweichung)

\begin{tabular}{|c|c|c|c|}
\hline & $\begin{array}{c}\text { Transplantierte } \\
\text { Patienten mit Etoposid }\end{array}$ & $\begin{array}{c}\text { Transplantierte } \\
\text { Patienten ohne } \\
\text { Etoposid } \\
\end{array}$ & Kontrollen \\
\hline $\begin{array}{l}\text { KiM1P-positive Zellen: } \\
\text { Makrophagen }\end{array}$ & $\begin{array}{r}34,4 \pm 9,53 \\
(n=5)\end{array}$ & $\begin{array}{r}32,8 \pm 13,58 \\
(n=2)\end{array}$ & $\begin{array}{r}40,8 \pm 14,35 \\
(n=7)\end{array}$ \\
\hline $\begin{array}{l}\text { KiM1P-positive Zellen: } \\
\text { Mikroglia }\end{array}$ & $\begin{array}{r}72 \pm 22,94 \\
(n=5)\end{array}$ & $\begin{array}{r}99,6 \pm 19,8 \\
(n=2)\end{array}$ & $\begin{array}{r}93,6 \pm 24,48 \\
(n=7)\end{array}$ \\
\hline
\end{tabular}

Abb. 56: Diagramm - APP bei Etoposidtherapie

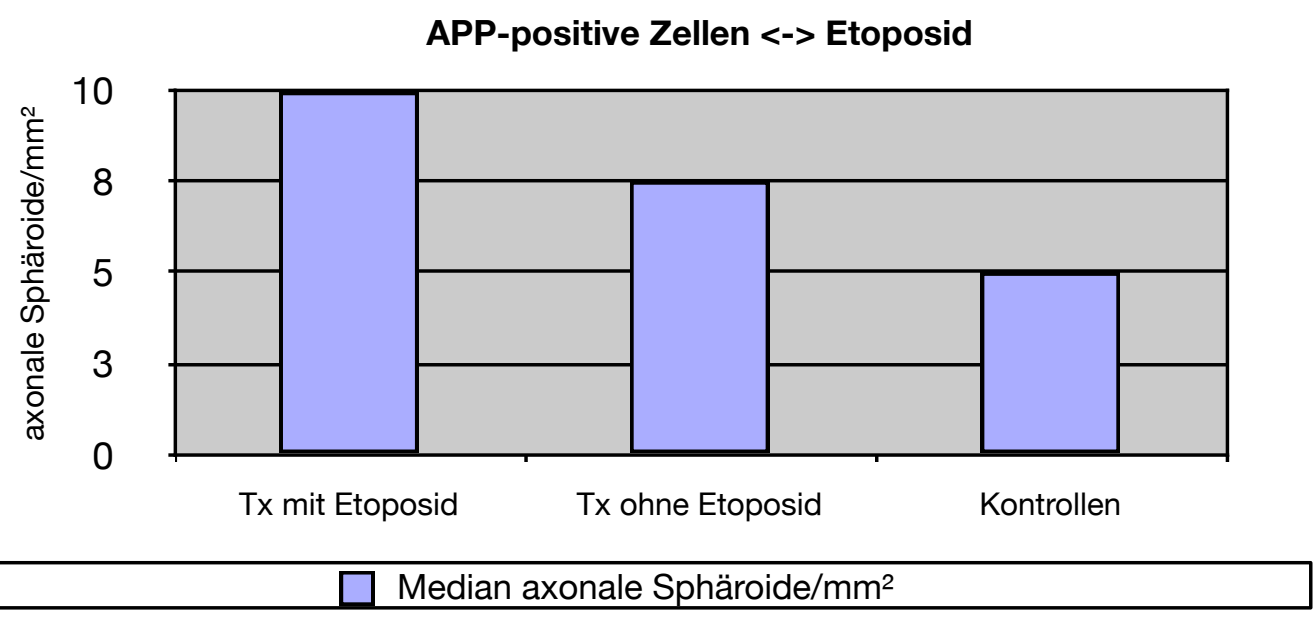

Tabelle 46: Anzahl der axonalen Sphäroide bei Etoposidtherapie (Die Werte sind angegeben als axonale Sphäroide $/ \mathrm{mm}^{2} \pm$ Standardabweichung)

\begin{tabular}{|l|r|r|r|}
\hline & \multicolumn{1}{|c|}{$\begin{array}{c}\text { Transplantierte } \\
\text { Patienten mit Etoposid }\end{array}$} & $\begin{array}{r}\text { Transplantierte } \\
\text { Patienten ohne } \\
\text { Etoposid }\end{array}$ & Kontrollen \\
\hline Axonale Sphäroide & $10 \pm 8,22$ \\
$(\mathrm{n}=5)$ & $\begin{array}{r}7,5 \pm 3,54 \\
(\mathrm{n}=2)\end{array}$ & $5 \pm 12,05$ \\
$(\mathrm{n}=7)$
\end{tabular}


Abb. 57: Diagramm - NogoA bei Vincristintherapie

NogoA

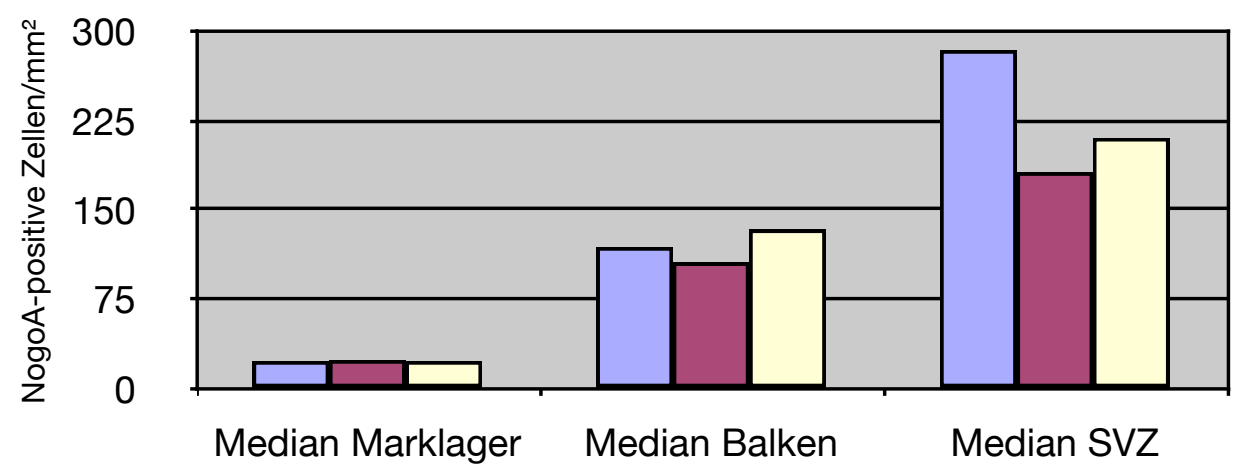

$\square$ Tx mit Vincristin $\square$ Tx ohne Vincristin Kontrollen

Tabelle 47: Anzahl der reifen Oligodendrozyten (NogoA) bei Vincristintherapie (Die Werte sind angegeben als Zellen $/ \mathrm{mm}^{2} \pm$ Standardabweichung)

\begin{tabular}{|c|c|c|c|}
\hline & $\begin{array}{c}\text { Transplantierte } \\
\text { Patienten mit Vincristin }\end{array}$ & $\begin{array}{c}\text { Transplantierte } \\
\text { Patienten ohne } \\
\text { Vincristin }\end{array}$ & Kontrollen \\
\hline $\begin{array}{l}\text { NogoA-positive Zellen im } \\
\text { Marklager }\end{array}$ & $\begin{array}{r}23,2 \pm 29,06 \\
(n=6)\end{array}$ & $\begin{array}{r}24 \pm 9,95 \\
(\mathrm{n}=9)\end{array}$ & $\begin{array}{r}23,2 \pm 29,3 \\
(n=11)\end{array}$ \\
\hline $\begin{array}{l}\text { NogoA-positive Zellen im } \\
\text { Corpus Callosum }\end{array}$ & $\begin{array}{r}118,8 \pm 56,01 \\
(n=4) \\
\end{array}$ & $\begin{array}{r}106 \pm 19,93 \\
(n=4) \\
\end{array}$ & $\begin{array}{r}133,6 \pm 38,07 \\
(n=10) \\
\end{array}$ \\
\hline $\begin{array}{l}\text { NogoA-positive Zellen in } \\
\text { der SVZ }\end{array}$ & $\begin{array}{r}284 \pm 100,81 \\
(n=3)\end{array}$ & $\begin{array}{r}181,6 \pm 50,78 \\
(n=3) \\
\end{array}$ & $\begin{array}{r}210,4 \pm 49,42 \\
(n=9) \\
\end{array}$ \\
\hline
\end{tabular}

Abb. 58: Diagramm - Olig2 Stark bei Vincristintherapie

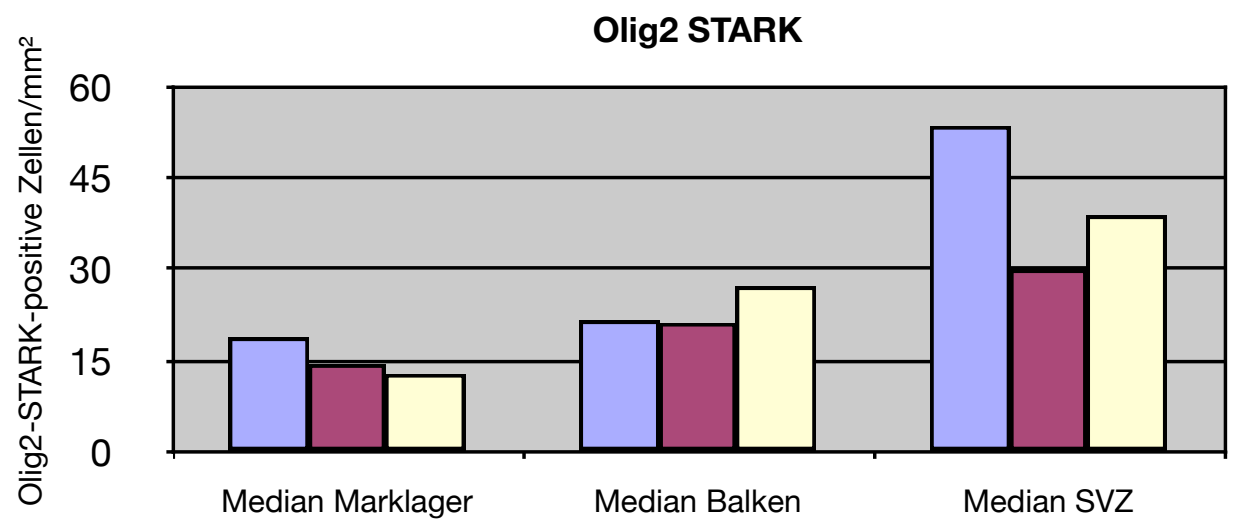

\begin{tabular}{|lll|}
\hline$\square$ Tx mit Vincristin & $\square$ Tx ohne Vincristin $\square$ Kontrollen \\
\hline
\end{tabular}

Tabelle 48: Anzahl der Oligodendrozytenvorläuferzellen bei Vincristintherapie (Die Werte sind angegeben als Zellen/mm² \pm Standardabweichung)

\begin{tabular}{|c|c|c|c|}
\hline & \begin{tabular}{c|} 
Transplantierte \\
Patienten mit Vincristin
\end{tabular} & $\begin{array}{c}\text { Transplantierte } \\
\text { Patienten ohne } \\
\text { Vincristin } \\
\end{array}$ & Kontrollen \\
\hline $\begin{array}{l}\text { Olig2-STARK-positive } \\
\text { Zellen im Marklager }\end{array}$ & $\begin{array}{r}18,8 \pm 24,32 \\
(n=6)\end{array}$ & $\begin{array}{r}14,4 \pm 17,48 \\
(\mathrm{n}=9)\end{array}$ & $\begin{array}{r}12,8 \pm 10,59 \\
(n=11) \\
\end{array}$ \\
\hline $\begin{array}{l}\text { Olig2-STARK-positive } \\
\text { Zellen im Corpus } \\
\text { Callosum }\end{array}$ & $\begin{array}{r}21,6 \pm 34,14 \\
(n=5)\end{array}$ & $\begin{array}{r}21,2 \pm 7,4 \\
(n=4)\end{array}$ & $\begin{array}{r}27,2 \pm 20,17 \\
(n=10)\end{array}$ \\
\hline $\begin{array}{l}\text { Olig2-STARK-positive } \\
\text { Zellen in der SVZ }\end{array}$ & $\begin{array}{r}53,6 \pm 27,8 \\
(n=5)\end{array}$ & $\begin{array}{r}30 \pm 25,76 \\
(n=4)\end{array}$ & $\begin{array}{r}38,88 \pm 21,55 \\
(n=9)\end{array}$ \\
\hline
\end{tabular}


Abb. 59: Diagramm - Olig2 Schwach bei Vincristintherapie

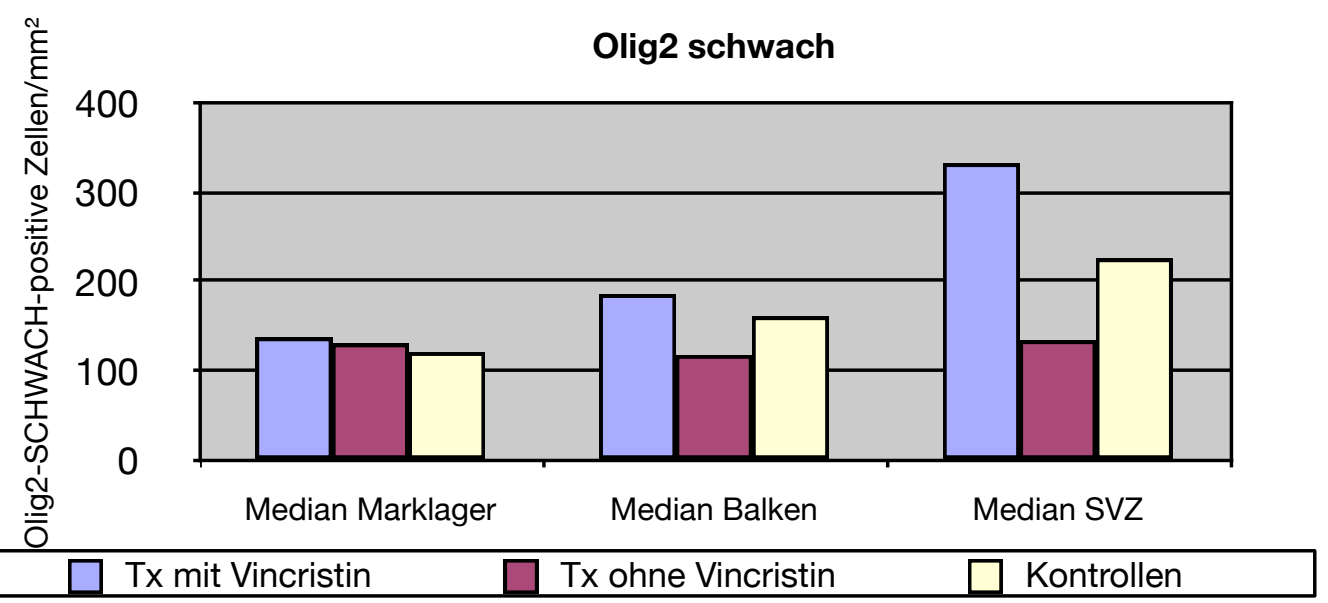

Tabelle 49: Anzahl der reifen Oligodendrozyten (Olig2 Schwach) bei Vincristintherapie (Die Werte sind angegeben als Zellen $/ \mathrm{mm}^{2} \pm$ Standardabweichung)

\begin{tabular}{|c|c|c|c|}
\hline & $\begin{array}{c}\text { Transplantierte } \\
\text { Patienten mit Vincristin }\end{array}$ & $\begin{array}{c}\text { Transplantierte } \\
\text { Patienten ohne } \\
\text { Vincristin } \\
\end{array}$ & Kontrollen \\
\hline $\begin{array}{l}\text { Olig2-SCHWACH-positive } \\
\text { Zellen im Marklager }\end{array}$ & $\begin{array}{r}137,2 \pm 105,18 \\
(n=6)\end{array}$ & $\begin{array}{r}130,4 \pm 88,73 \\
(\mathrm{n}=9)\end{array}$ & $\begin{array}{r}120,8 \pm 69,43 \\
(\mathrm{n}=11) \\
\end{array}$ \\
\hline $\begin{array}{l}\text { Olig2-SCHWACH-positive } \\
\text { Zellen im Corpus } \\
\text { Callosum }\end{array}$ & $\begin{array}{r}185,6 \pm 105,13 \\
(n=5)\end{array}$ & $\begin{array}{r}117,6 \pm 158,54 \\
(n=4)\end{array}$ & $\begin{array}{r}160,8 \pm 132 \\
(n=10)\end{array}$ \\
\hline $\begin{array}{l}\text { Olig2-SCHWACH-positive } \\
\text { Zellen in der SVZ }\end{array}$ & $\begin{array}{r}332 \pm 192,04 \\
(n=5)\end{array}$ & $\begin{array}{r}134 \pm 178,13 \\
(n=4)\end{array}$ & $\begin{array}{r}225,6 \pm 134,32 \\
(n=9)\end{array}$ \\
\hline
\end{tabular}

Abb. 60: Diagramm - NogoA bei Fludarabintherapie

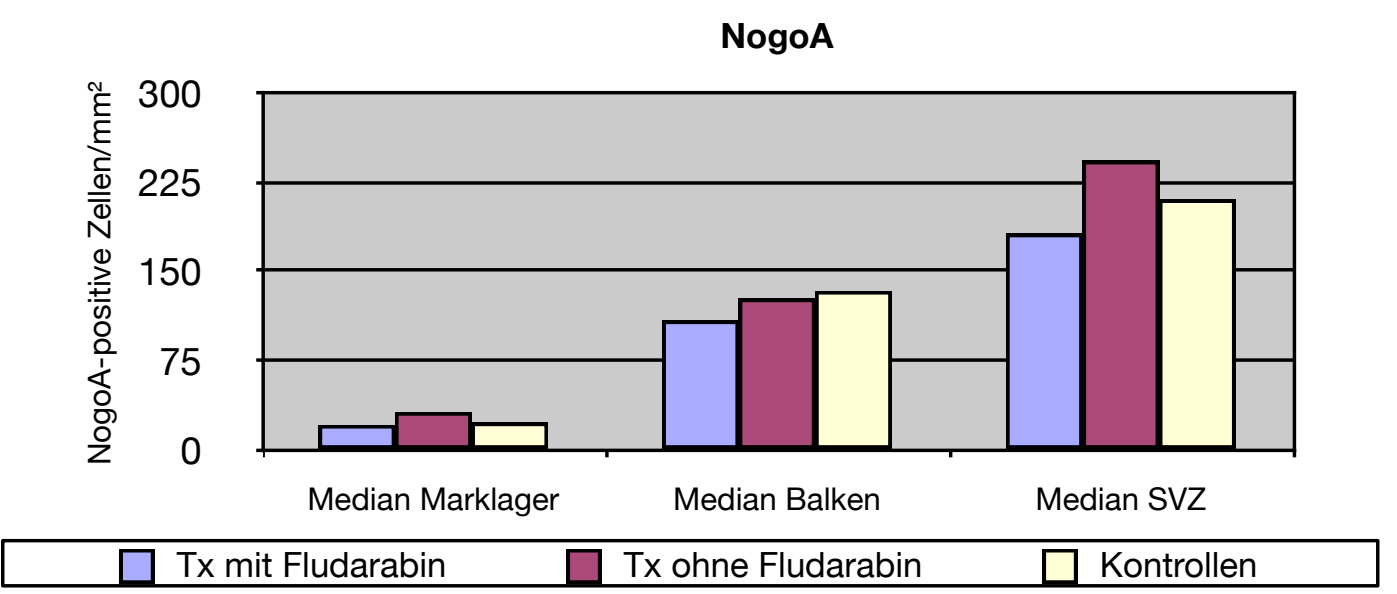

Tabelle 50: Anzahl der reifen Oligodendrozyten (NogoA) bei Fludarabintherapie (Die Werte sind angegeben als Zellen/mm² \pm Standardabweichung)

\begin{tabular}{|c|c|c|c|}
\hline & \begin{tabular}{c|} 
Transplantierte \\
Patienten mit Fludarabin
\end{tabular} & $\begin{array}{l}\text { Transplantierte } \\
\text { Patienten ohne } \\
\text { Fludarabin }\end{array}$ & Kontrollen \\
\hline $\begin{array}{l}\text { NogoA-positive Zellen im } \\
\text { Marklager }\end{array}$ & $\begin{array}{r}21,2 \pm 9,1 \\
(n=10) \\
\end{array}$ & $\begin{array}{r}32 \pm 29,35 \\
(n=5)\end{array}$ & $\begin{array}{r}23,2 \pm 29,3 \\
(n=11) \\
\end{array}$ \\
\hline $\begin{array}{l}\text { NogoA-positive Zellen im } \\
\text { Corpus Callosum } \\
\end{array}$ & $\begin{array}{r}108,8 \pm 10,08 \\
(n=4)\end{array}$ & $\begin{array}{r}127,2 \pm 57,14 \\
(n=4) \\
\end{array}$ & $\begin{array}{r}133,6 \pm 38,07 \\
(n=10) \\
\end{array}$ \\
\hline $\begin{array}{l}\text { NogoA-positive Zellen in } \\
\text { der SVZ }\end{array}$ & $\begin{array}{r}181,6 \pm 82,69 \\
(n=3)\end{array}$ & $\begin{array}{r}242,7 \pm 86,2 \\
(n=3)\end{array}$ & $\begin{array}{r}210,4 \pm 49,42 \\
(n=9) \\
\end{array}$ \\
\hline
\end{tabular}


Abb. 61: Diagramm - Olig2 Stark bei Fludarabintherapie

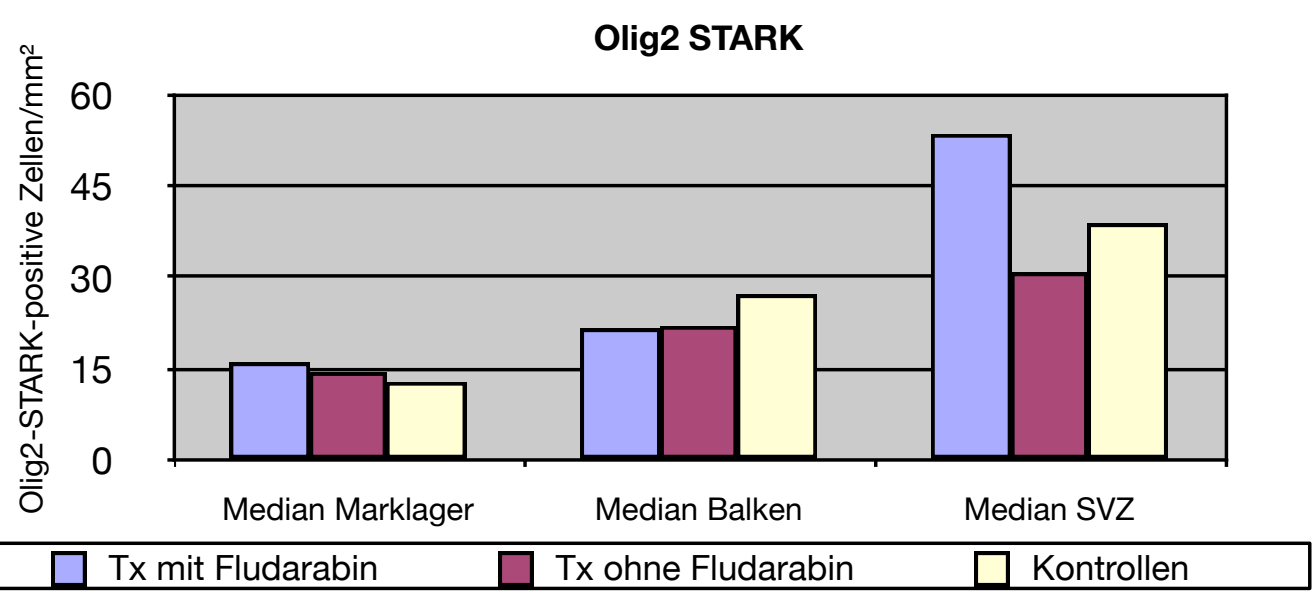

Tabelle 51: Anzahl der Oligodendrozytenvorläuferzellen bei Fludarabintherapie (Die Werte sind angegeben als Zellen/mm² \pm Standardabweichung)

\begin{tabular}{|c|c|c|c|}
\hline & $\begin{array}{c}\text { Transplantierte } \\
\text { Patienten mit Fludarabin }\end{array}$ & $\begin{array}{c}\text { Transplantierte } \\
\text { Patienten ohne } \\
\text { Fludarabin } \\
\end{array}$ & Kontrollen \\
\hline $\begin{array}{l}\text { Olig2-STARK-positive } \\
\text { Zellen im Marklager }\end{array}$ & $\begin{array}{r}16 \pm 24,17 \\
(n=8)\end{array}$ & $\begin{array}{r}14,4 \pm 11,9 \\
(n=7)\end{array}$ & $\begin{array}{r}12,8 \pm 10,59 \\
(n=11) \\
\end{array}$ \\
\hline $\begin{array}{l}\text { Olig2-STARK-positive } \\
\text { Zellen im Corpus } \\
\text { Callosum }\end{array}$ & $\begin{array}{r}21,6 \pm 43,5 \\
(n=3)\end{array}$ & $\begin{array}{r}22 \pm 20,63 \\
(n=6)\end{array}$ & $\begin{array}{r}27,2 \pm 20,17 \\
(n=10)\end{array}$ \\
\hline $\begin{array}{l}\text { Olig2-STARK-positive } \\
\text { Zellen in der SVZ }\end{array}$ & $\begin{array}{r}53,6 \pm 17,39 \\
(n=3)\end{array}$ & $\begin{array}{r}30,8 \pm 31,25 \\
(n=6) \\
\end{array}$ & $\begin{array}{r}38,88 \pm 21,55 \\
(n=9) \\
\end{array}$ \\
\hline
\end{tabular}

Abb. 62: Diagramm - Olig2 Schwach bei Fludarabintherapie

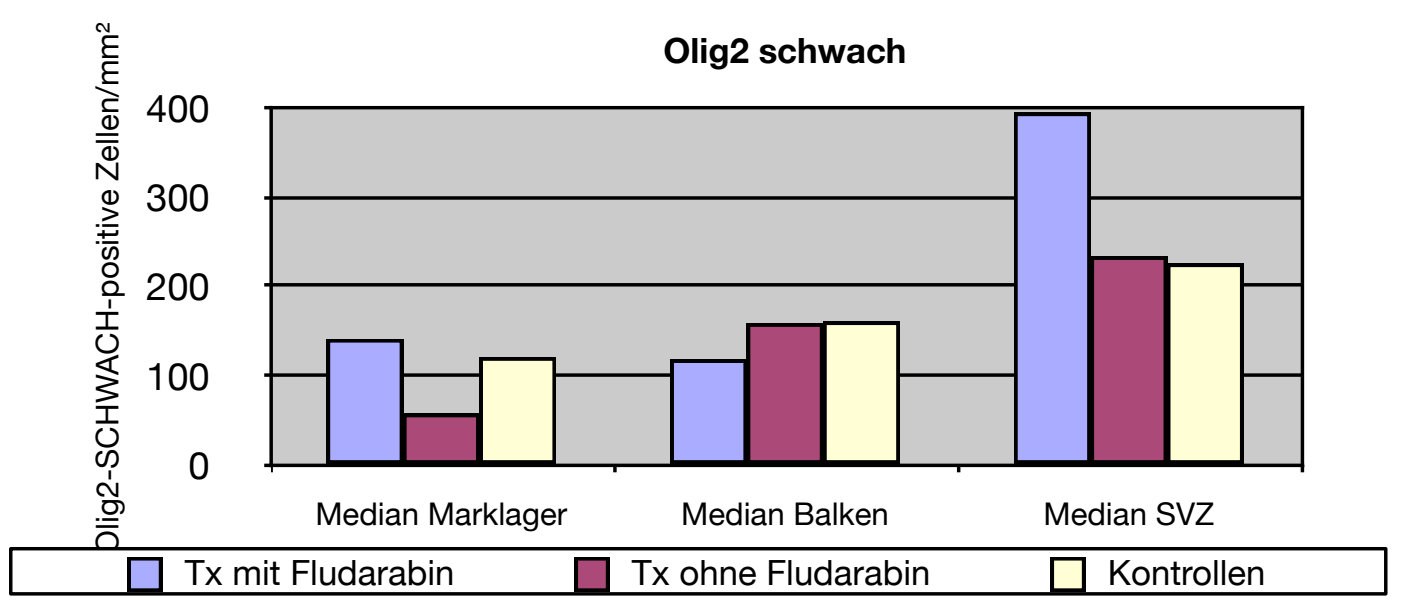

Tabelle 52: Anzahl der reifen Oligodendrozyten (Olig2 Schwach) bei Fludarabintherapie (Die Werte sind angegeben als Zellen $/ \mathrm{mm}^{2} \pm$ Standardabweichung)

\begin{tabular}{|c|c|c|c|}
\hline & $\begin{array}{c}\text { Transplantierte } \\
\text { Patienten mit Fludarabin }\end{array}$ & $\begin{array}{c}\text { Transplantierte } \\
\text { Patienten ohne } \\
\text { Fludarabin } \\
\end{array}$ & Kontrollen \\
\hline $\begin{array}{l}\text { Olig2-SCHWACH-positive } \\
\text { Zellen im Marklager }\end{array}$ & $\begin{array}{r}141,2 \pm 79,57 \\
(n=8) \\
\end{array}$ & $\begin{array}{r}57,6 \pm 100,12 \\
(n=7)\end{array}$ & $\begin{array}{r}120,8 \pm 69,43 \\
(n=11) \\
\end{array}$ \\
\hline $\begin{array}{l}\text { Olig2-SCHWACH-positive } \\
\text { Zellen im Corpus } \\
\text { Callosum }\end{array}$ & $\begin{array}{r}118,4 \pm 151,51 \\
(n=3)\end{array}$ & $\begin{array}{r}158,8 \pm 121,87 \\
(n=6)\end{array}$ & $\begin{array}{r}160,8 \pm 132 \\
(n=10)\end{array}$ \\
\hline $\begin{array}{l}\text { Olig2-SCHWACH-positive } \\
\text { Zellen in der SVZ }\end{array}$ & $\begin{array}{r}394,4 \pm 320,28 \\
(n=3)\end{array}$ & $\begin{array}{r}233,6 \pm 127,55 \\
(n=6)\end{array}$ & $\begin{array}{r}225,6 \pm 134,32 \\
(n=9)\end{array}$ \\
\hline
\end{tabular}


Abb. 63: Diagramm - NogoA bei Cytarabintherapie

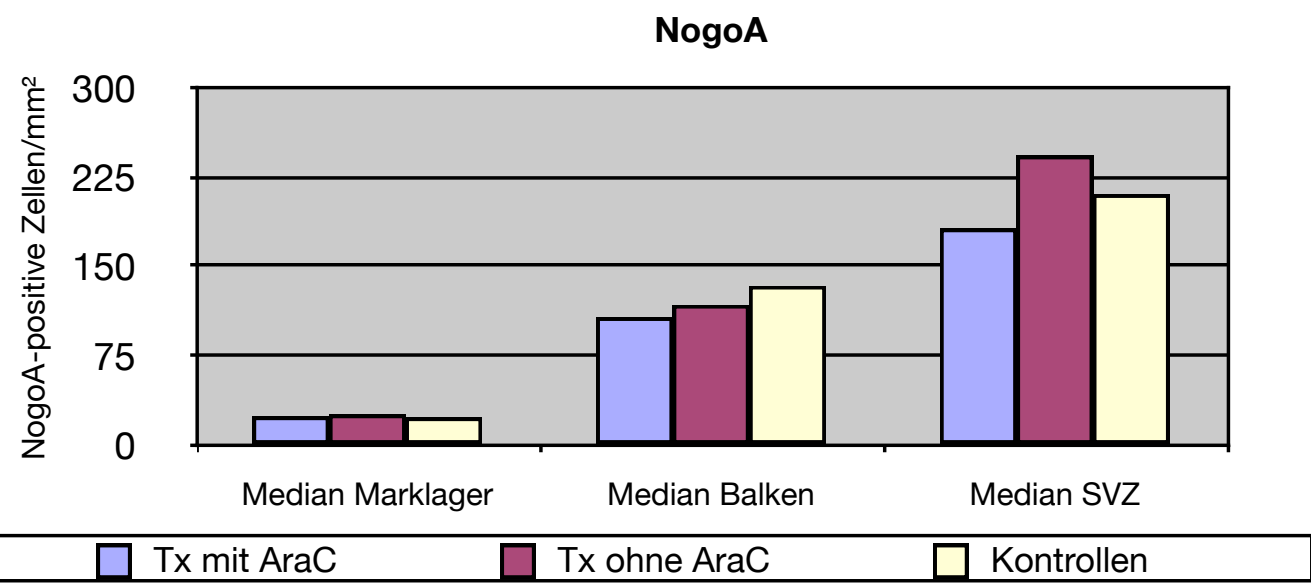

Tabelle 53: Anzahl der reifen Oligodendrozyten (NogoA) bei Cytarabintherapie (Die Werte sind angegeben als Zellen $/ \mathrm{mm}^{2} \pm$ Standardabweichung)

\begin{tabular}{|c|c|c|c|}
\hline & $\begin{array}{c}\text { Transplantierte } \\
\text { Patienten mit Cytarabin }\end{array}$ & $\begin{array}{c}\text { Transplantierte } \\
\text { Patienten ohne } \\
\text { Cytarabin }\end{array}$ & Kontrollen \\
\hline $\begin{array}{l}\text { NogoA-positive Zellen im } \\
\text { Marklager }\end{array}$ & $\begin{array}{r}24 \pm 27,75 \\
(n=7) \\
\end{array}$ & $\begin{array}{r}25,6 \pm 9,2 \\
(n=8) \\
\end{array}$ & $\begin{array}{r}23,2 \pm 29,3 \\
(n=11) \\
\end{array}$ \\
\hline $\begin{array}{l}\text { NogoA-positive Zellen im } \\
\text { Corpus Callosum }\end{array}$ & $\begin{array}{r}107,2 \pm 60,98 \\
(n=4) \\
\end{array}$ & $\begin{array}{r}117,6 \pm 16,5 \\
(n=4)\end{array}$ & $\begin{array}{r}133,6 \pm 38,07 \\
(n=10) \\
\end{array}$ \\
\hline $\begin{array}{l}\text { NogoA-positive Zellen in } \\
\text { der SVZ }\end{array}$ & $\begin{array}{r}181,6 \pm 83,57 \\
(n=3)\end{array}$ & $\begin{array}{r}242,7 \pm 80,39 \\
(n=3)\end{array}$ & $\begin{array}{r}210,4 \pm 49,42 \\
(n=9)\end{array}$ \\
\hline
\end{tabular}

Abb. 64: Diagramm - Olig2 Stark bei Cytarabintherapie

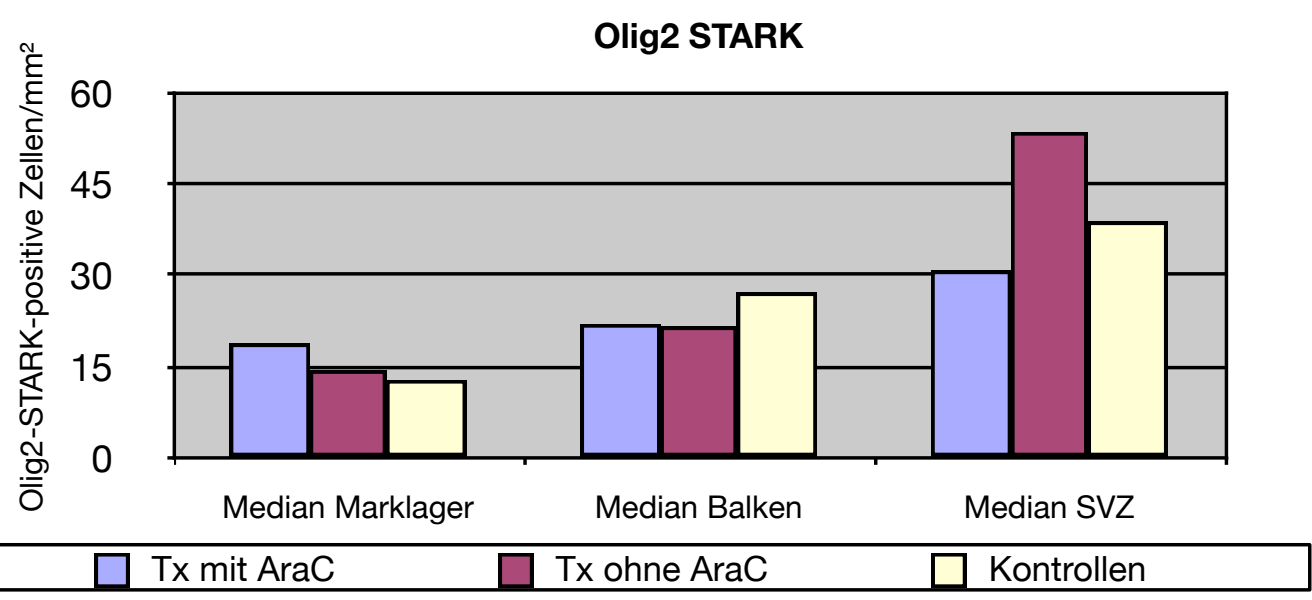

Tabelle 54: Anzahl der Oligodendrozytenvorläuferzellen bei Cytarabintherapie (Die Werte sind angegeben als Zellen/mm² \pm Standardabweichung)

\begin{tabular}{|c|c|c|c|}
\hline & $\begin{array}{c}\text { Transplantierte } \\
\text { Patienten mit Cytarabin }\end{array}$ & $\begin{array}{c}\text { Transplantierte } \\
\text { Patienten ohne } \\
\text { Cytarabin } \\
\end{array}$ & Kontrollen \\
\hline $\begin{array}{l}\text { Olig2-STARK-positive } \\
\text { Zellen im Marklager }\end{array}$ & $\begin{array}{r}18,8 \pm 24,06 \\
(n=6)\end{array}$ & $\begin{array}{r}14,4 \pm 17,64 \\
(\mathrm{n}=9)\end{array}$ & $\begin{array}{r}12,8 \pm 10,59 \\
(n=11) \\
\end{array}$ \\
\hline $\begin{array}{l}\text { Olig2-STARK-positive } \\
\text { Zellen im Corpus } \\
\text { Callosum }\end{array}$ & $\begin{array}{r}22 \pm 25,52 \\
(n=4)\end{array}$ & $\begin{array}{r}21,6 \pm 32,37 \\
(n=5)\end{array}$ & $\begin{array}{r}27,2 \pm 20,17 \\
(n=10)\end{array}$ \\
\hline $\begin{array}{l}\text { Olig2-STARK-positive } \\
\text { Zellen in der SVZ }\end{array}$ & $\begin{array}{r}30,8 \pm 30,88 \\
(n=4)\end{array}$ & $\begin{array}{r}53,6 \pm 27,08 \\
(n=5)\end{array}$ & $\begin{array}{r}38,88 \pm 21,55 \\
(n=9)\end{array}$ \\
\hline
\end{tabular}


Abb. 65: Diagramm - Olig2 Schwach bei Cytarabintherapie

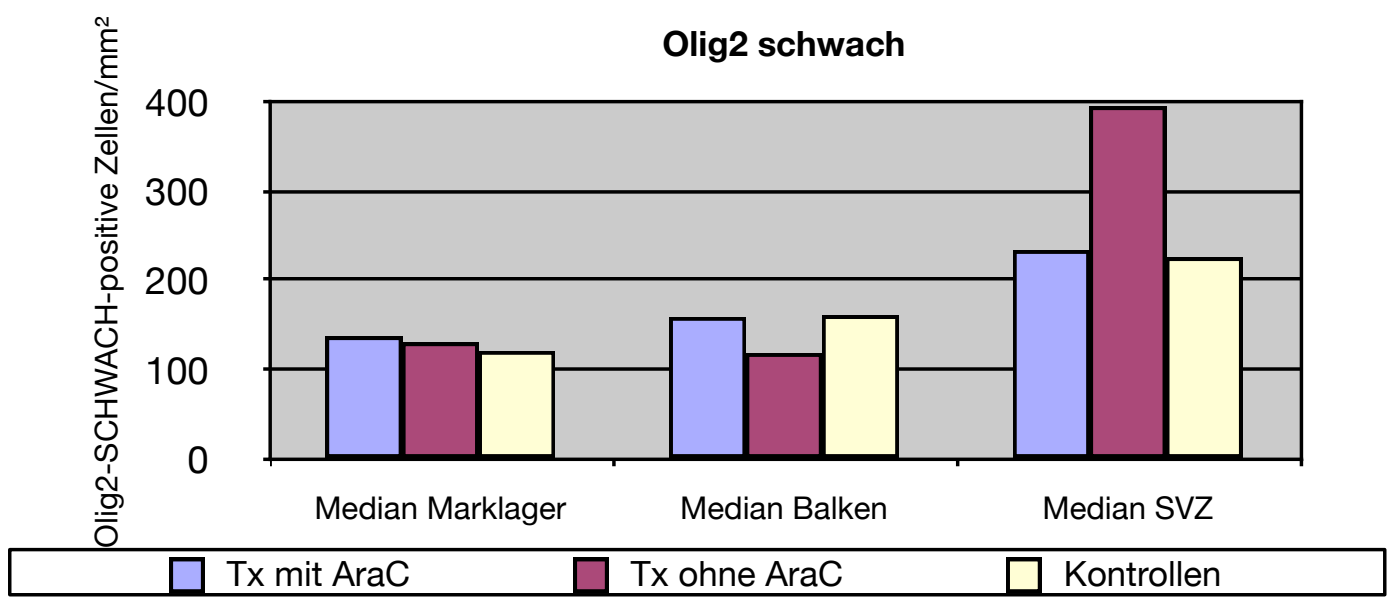

Tabelle 55: Anzahl der reifen Oligodendrozyten (Olig2 Schwach) bei Cytarabintherapie (Die Werte sind angegeben als Zellen $/ \mathrm{mm}^{2} \pm$ Standardabweichung)

\begin{tabular}{|l|r|r|r|}
\hline & $\begin{array}{r}\text { Transplantierte } \\
\text { Patienten mit Cytarabin }\end{array}$ & $\begin{array}{r}\text { Transplantierte } \\
\text { Patienten ohne } \\
\text { Cytarabin }\end{array}$ & Kontrollen \\
\hline $\begin{array}{l}\text { Olig2-SCHWACH-positive } \\
\text { Zellen im Marklager }\end{array}$ & $137,2 \pm \begin{array}{r}111,85 \\
(\mathrm{n}=6)\end{array}$ & $\begin{array}{r}130,4 \pm 83,49 \\
(\mathrm{n}=9)\end{array}$ & $\begin{array}{r}120,8 \pm 69,43 \\
(\mathrm{n}=11)\end{array}$ \\
\hline $\begin{array}{l}\text { Olig2-SCHWACH-positive } \\
\text { Zellen im Corpus }\end{array}$ & $158,8 \pm \begin{array}{r}39,86 \\
(\mathrm{n}=4)\end{array}$ & $\begin{array}{r}118,4 \pm 165,94 \\
(\mathrm{n}=5)\end{array}$ & $\begin{array}{r}160,8 \pm 132 \\
(\mathrm{n}=10)\end{array}$ \\
Callosum & $\begin{array}{r}233,6 \pm 58 \\
(\mathrm{n}=4)\end{array}$ & $\begin{array}{r}394,4 \pm 274,1 \\
(\mathrm{n}=5)\end{array}$ & $\begin{array}{r}225,6 \pm 134,32 \\
(\mathrm{n}=9)\end{array}$ \\
\hline $\begin{array}{l}\text { Olig2-SCHWACH-positive } \\
\text { Zellen in der SVZ }\end{array}$ &
\end{tabular}




\section{Literaturverzeichnis}

Abayomi OK (1996): Pathogenesis of irradiation-induced cognitive dysfunction. Acta Oncol $\underline{35,659-63}$

Ames B, Lewis LD, Chaffee S, Kim J, Morse R (2010): Ifosfamide-induced encephalopathy and movement disorder. Pediatr Blood Cancer 54, 624-6

Anderson VA, Godber T, Smibert E, Weiskop S, Ekert H (2000): Cognitive and academic outcome following cranial irradiation and chemotherapy in children: a longitudinal study. $\mathrm{Br} \mathrm{J}$ Cancer $\underline{82}, 255-62$

Baker WJ, Royer GL, Weiss RB (1991): Cytarabine and neurologic toxicity. J Clin Oncol 9, 679-93

Bashir R, Hochberg FH, Linggood RM, Hottleman K (1988): Pre-irradiation internal carotid artery BCNU in treatment of glioblastoma multiforme. J Neurosurg $\underline{68,917-9}$

Belka C, Budach W, Kortmann RD, Bamberg M (2001): Radiation induced CNS toxicity--molecular and cellular mechanisms. Br J Cancer 85, 1233-9

Berking C, Preiß J: Taschenbuch Onkologie: interdisziplinäre Empfehlungen zur Therapie 2012/2013. Zuckschwerdt, München 2012

Bishop B (1982): Neural plasticity: Part 3. Responses to lesions in the peripheral nervous system. Phys Ther $62,1275-82$

Bleggi-Torres LF, de Medeiros BC, Werner B, Neto JZ, Loddo G, Pasquini R, de Medeiros CR (2000): Neuropathological findings after bone marrow transplantation: an autopsy study of 180 cases. Bone Marrow Transplant $\underline{25}, 301-7$

Brey RL (2002): Severe neurologic complications after hematopoietic (peripheral blood) stem cell transplantation in children. Neurology $\underline{59}$, E13-5

Brezden CB, Phillips KA, Abdolell M, Bunston T, Tannock IF (2000): Cognitive function in breast cancer patients receiving adjuvant chemotherapy. J Clin Oncol 18, 2695-701

Brown DR (2009): Role of microglia in age-related changes to the nervous system. ScientificWorldJournal $\underline{9}$, 1061-71

Brown MS, Simon JH, Stemmer SM, Stears JC, Scherzinger A, Cagnoni PJ, Jones RB (1995): MR and proton spectroscopy of white matter disease induced by high-dose chemotherapy with bone marrow transplant in advanced breast carcinoma. AJNR Am J Neuroradiol 16, 2013-20

Brown MS, Stemmer SM, Simon JH, Stears JC, Jones RB, Cagnoni PJ, Sheeder JL (1998): White matter disease induced by high-dose chemotherapy: longitudinal study with MR imaging and proton spectroscopy. AJNR Am J Neuroradiol 19, 217-21 
Bruining DM, van Roon EN, de Graaf H, Hoogendoorn M (2011): Cyclophosphamide-induced symptomatic hyponatraemia. Neth J Med $69,192-5$

Burt RK, Cohen BA, Russell E, Spero K, Joshi A, Oyama Y, Karpus WJ, Luo K, Jovanovic B, Traynor A (2003): Hematopoietic stem cell transplantation for progressive multiple sclerosis: failure of a total body irradiation-based conditioning regimen to prevent disease progression in patients with high disability scores. Blood 102, 2373-8

Calvo W, Hopewell JW, Reinhold HS, Yeung TK (1988): Time- and dose-related changes in the white matter of the rat brain after single doses of $\mathrm{X}$ rays. $\mathrm{Br} \mathrm{J}$ Radiol $\underline{61}, 1043-52$

Cammer W (2000): Effects of TNFalpha on immature and mature oligodendrocytes and their progenitors in vitro. Brain Res 864, 213-9

Cheson BD, Vena DA, Foss FM, Sorensen JM (1994): Neurotoxicity of purine analogs: a review. J Clin Oncol 12. 2216-28

Chiang CS, Mason KA, Withers HR, McBride WH (1992): Alteration in myelin-associated proteins following spinal cord irradiation in guinea pigs. Int J Radiat Oncol Biol Phys 24, 929-37

Chiang CS, McBride WH, Withers HR (1993): Radiation-induced astrocytic and microglial responses in mouse brain. Radiother Oncol 29, 60-8

Chow BM, Li YQ, Wong CS (2000): Radiation-induced apoptosis in the adult central nervous system is p53dependent. Cell Death Differ $\underline{7,}, 712-20$

Chun HG, Leyland-Jones BR, Caryk SM, Hoth DF (1986): Central nervous system toxicity of fludarabine phosphate. Cancer Treat Rep 70, 1225-8

Cogle CR, Yachnis AT, Laywell ED, Zander DS, Wingard JR, Steindler DA, Scott EW (2004): Bone marrow transdifferentiation in brain after transplantation: a retrospective study. The Lancet $\underline{363}, 1432-1437$

Cohen RB, Abdallah JM, Gray JR, Foss F (1993): Reversible neurologic toxicity in patients treated with standard-dose fludarabine phosphate for mycosis fungoides and chronic lymphocytic leukemia. Ann Intern Med $118,114-6$

Cordier PY, Nau A, Ciccolini J, Oliver M, Mercier C, Lacarelle B, Peytel E (2011): 5-FU-induced neurotoxicity in cancer patients with profound DPD deficiency syndrome: a report of two cases. Cancer Chemother Pharmacol 68, 823-6

Crain BJ, Tran SD, Mezey E (2005): Transplanted human bone marrow cells generate new brain cells. J Neurol Sci 233, 121-3

Crossen JR, Garwood D, Glatstein E, Neuwelt EA (1994): Neurobehavioral sequelae of cranial irradiation in adults: a review of radiation-induced encephalopathy. J Clin Oncol 12, 627-42 
d'Avella D, Cicciarello R, Albiero F, Mesiti M, Gagliardi ME, Russi E, d'Aquino A, Tomasello F, d'Aquino S (1992): Quantitative study of blood-brain barrier permeability changes after experimental whole-brain radiation. Neurosurgery $\underline{30,} 30-4$

Debess J, Riis JØ, Engebjerg MC, Ewertz M (2010): Cognitive function after adjuvant treatment for early breast cancer: a population-based longitudinal study. Breast Cancer Res Treat 121, 91-100

de Brabander C, Cornelissen J, Smitt PA, Vecht CJ, van den Bent MJ (2000): Increased incidence of neurological complications in patients receiving an allogenic bone marrow transplantation from alternative donors. J Neurol Neurosurg Psychiatry $\underline{68,36-40}$

Dietrich J, Han R, Yang Y, Mayer-Pröschel M, Noble M (2006): CNS progenitor cells and oligodendrocytes are targets of chemotherapeutic agents in vitro and in vivo. J Biol $\underline{5}, 22$

Dietrich J, Monje M, Wefel J, Meyers C (2008): Clinical patterns and biological correlates of cognitive dysfunction associated with cancer therapy. Oncologist $13,1285-95$

Diserbo M, Agin A, Lamproglou I, Mauris J, Staali F, Multon E, Amourette C (2002): Blood-brain barrier permeability after gamma whole-body irradiation: an in vivo microdialysis study. Can J Physiol Pharmacol $\underline{80}$, $670-8$

Doetsch F, García-Verdugo JM, Alvarez-Buylla A (1999a): Regeneration of a germinal layer in the adult mammalian brain. Proc Natl Acad Sci U S A 96, 11619-24

Doetsch F, Caille I, Lim DA, Garcia-Verdugo JM, Alvarez-Buylla A (1999b): Subventricular zone astrocytes are neural stem cells in the adult mammalian brain. Cell $97,703-716$

Dropcho EJ (1991): Central nervous system injury by therapeutic irradiation. Neurol Clin $\underline{9}, 969-88$

Dropcho EJ (2004): Neurotoxicity of cancer chemotherapy. Semin Neurol 24, 419-26

Dropcho EJ (2010): Neurotoxicity of cancer chemotherapy. Semin Neurol 30, 273-86

Duffner P (2006): The long term effects of chemotherapy on the central nervous system. Journal of Biology $\underline{5,21}$

Eriksson PS, Perfilieva E, Björk-Eriksson T, Alborn AM, Nordborg C, Peterson DA, Gage FH (1998): Neurogenesis in the adult human hippocampus. Nature medicine 4 , 1313-1317

Fassas A, Kimiskidis VK (2004): Autologous hemopoietic stem cell transplantation in the treatment of multiple sclerosis: rationale and clinical experience. J Neurol Sci 223, 53-8

Ferrer I, Olivé M, Blanco R, Cinós C, Planas AM (1996): Selective c-Jun overexpression is associated with ionizing radiation-induced apoptosis in the developing cerebellum of the rat. Brain Res Mol Brain Res $\underline{38}$, $91-100$

Filley CM (1999): Toxic leukoencephalopathy. Clin Neuropharmacol 22, 249-60 
Fleming RA (1997): An overview of cyclophosphamide and ifosfamide pharmacology. Pharmacotherapy 17. 146S-154S

Fortin D, McCormick Cl, Remsen LG, Nixon R, Neuwelt EA (2000): Unexpected neurotoxicity of etoposide phosphate administered in combination with other chemotherapeutic agents after blood-brain barrier modification to enhance delivery, using propofol for general anesthesia, in a rat model. Neurosurgery 47 , 199-207

Franklin RJ, Bayley SA, Milner R, Ffrench-Constant C, Blakemore WF (1995): Differentiation of the O-2A progenitor cell line CG-4 into oligodendrocytes and astrocytes following transplantation into glia-deficient areas of CNS white matter. Glia 13, 39-44

Gage FH, Temple S (2013): Neural stem cells: generating and regenerating the brain. Neuron $80,588-601$

Gobbel GT, Bellinzona M, Vogt AR, Gupta N, Fike JR, Chan PH (1998): Response of postmitotic neurons to $X$-irradiation: implications for the role of DNA damage in neuronal apoptosis. J Neurosci 18, 147-55

Gomber S, Dewan P, Chhonker D (2010): Vincristine induced neurotoxicity in cancer patients. Indian J Pediatr $\underline{77,97-100}$

Gooley TA, Chien JW, Pergam SA, Hingorani S, Sorror ML, Boeckh M, Martin PJ, Sandmaier BM, Marr KA, Appelbaum FR (2010): Reduced mortality after allogeneic hematopoietic-cell transplantation. N Engl J Med 363, 2091-101

Han R, Yang YM, Dietrich J, Luebke A, Mayer-Pröschel M, Noble M (2008): Systemic 5-fluorouracil treatment causes a syndrome of delayed myelin destruction in the central nervous system. J Biol $\underline{7}, 12$

Hintzen RQ (2002): Stem cell transplantation in multiple sclerosis: multiple choices and multiple challenges. Mult Scler $\underline{8}, 155-60$

Hopewell JW, van der Kogel AJ (1999): Pathophysiological mechanisms leading to the development of late radiation-induced damage to the central nervous system. Front Radiat Ther Oncol 33, 265-75

Hurwitz RL, Mahoney DH, Armstrong DL, Browder TM (1988): Reversible encephalopathy and seizures as a result of conventional vincristine administration. Med Pediatr Oncol 16, 216-9

Imai H, McCulloch J, Graham DI, Masayasu H, Macrae IM (2002): New method for the quantitative assessment of axonal damage in focal cerebral ischemia. J Cereb Blood Flow Metab 22, 1080-9

Jansen J, Hanks S, Thompson JM, Dugan MJ, Akard LP (2005): Transplantation of hematopoietic stem cells from the peripheral blood. J Cell Mol Med $\underline{9}, 37-50$

Johansson CB, Youssef S, Koleckar K, Holbrook C, Doyonnas R, Corbel SY, Steinman L, Rossi FM, Blau HM (2008): Extensive fusion of haematopoietic cells with Purkinje neurons in response to chronic inflammation. Nat Cell Biol 10, 575-83 
Kamble RT, Chang CC, Sanchez S, Carrum G (2007): Central nervous system graft-versus-host disease: report of two cases and literature review. Bone Marrow Transplant 39, 49-52

Kargiotis O, Markoula S, Kyritsis AP (2011): Epilepsy in the cancer patient. Cancer Chemother Pharmacol 67. 489-501

Karussis D, Slavin S (2004): Hematopoietic stem cell transplantation in multiple sclerosis: experimental evidence to rethink the procedures. J Neurol Sci 223, 59-64

Karussis D, Kassis I (2008): The potential use of stem cells in multiple sclerosis: an overview of the preclinical experience. Clin Neurol Neurosurg 110, 889-96

Keime-Guibert F, Napolitano M, Delattre JY (1998): Neurological complications of radiotherapy and chemotherapy. J Neurol 245, 695-708

Kemp K, Wilkins A, Scolding N (2014): Cell fusion in the brain: two cells forward, one cell back. Acta Neuropathol

Kramer JH, Crowe AB, Larson DA, Sneed PK, Gutin PH, McDermott MW, Prados MD (1997): Neuropsychological sequelae of medulloblastoma in adults. International journal of radiation oncology, biology, physics $\underline{38}, 21$

Kuhlmann T, Miron V, Cui Q, Cuo Q, Wegner C, Antel J, Brück W (2008): Differentiation block of oligodendroglial progenitor cells as a cause for remyelination failure in chronic multiple sclerosis. Brain $\underline{131}$. 1749-58

Lee PW, Hung BK, Woo EK, Tai PT, Choi DT (1989): Effects of radiation therapy on neuropsychological functioning in patients with nasopharyngeal carcinoma. J Neurol Neurosurg Psychiatry $\underline{52}, 488-92$

Lee Y, Morrison BM, Li Y, Lengacher S, Farah MH, Hoffman PN, Liu Y, Tsingalia A, Jin L, Zhang PW (2012): Oligodendroglia metabolically support axons and contribute to neurodegeneration. Nature $487,443-8$

Leff RS, Thompson JM, Daly MB, Johnson DB, Harden EA, Mercier RJ, Messerschmidt GL (1988): Acute neurologic dysfunction after high-dose etoposide therapy for malignant glioma. Cancer $62,32-5$

Li YQ, Jay V, Wong CS (1996): Oligodendrocytes in the adult rat spinal cord undergo radiation-induced apoptosis. Cancer Res $\underline{56}, 5417-22$

Li YQ, Chen P, Haimovitz-Friedman A, Reilly RM, Wong CS (2003): Endothelial apoptosis initiates acute blood-brain barrier disruption after ionizing radiation. Cancer Res $\underline{63,5950-6}$

Lyubimova N, Hopewell JW (2004): Experimental evidence to support the hypothesis that damage to vascular endothelium plays the primary role in the development of late radiation-induced CNS injury. $\mathrm{Br} \mathrm{J}$ Radiol 77, 488-92

Mahoney DH, Shuster JJ, Nitschke R, Lauer SJ, Steuber CP, Winick N, Camitta B (1998): Acute neurotoxicity in children with B-precursor acute lymphoid leukemia: an association with intermediate-dose 
intravenous methotrexate and intrathecal triple therapy--a Pediatric Oncology Group study. J Clin Oncol $\underline{16}$, $1712-22$

McTigue DM, Tripathi RB (2008): The life, death, and replacement of oligodendrocytes in the adult CNS. J Neurochem 107, 1-19

Menn B, Garcia-Verdugo JM, Yaschine C, Gonzalez-Perez O, Rowitch D, Alvarez-Buylla A (2006): Origin of oligodendrocytes in the subventricular zone of the adult brain. J Neurosci $\underline{26,7907-18}$

Mezey E, Chandross KJ, Harta G, Maki RA, McKercher SR (2000): Turning blood into brain: cells bearing neuronal antigens generated in vivo from bone marrow. Science 290, 1779

Mezey E, Key S, Vogelsang G, Szalayova I, Lange GD, Crain B (2003): Transplanted bone marrow generates new neurons in human brains. Proc Natl Acad Sci U S A 100, 1364-9

Mildenberger M, Beach TG, McGeer EG, Ludgate CM (1990): An animal model of prophylactic cranial irradiation: histologic effects at acute, early and delayed stages. Int J Radiat Oncol Biol Phys 18, 1051-60

Mohrmann RL, Mah V, Vinters HV (1990): Neuropathologic findings after bone marrow transplantation: An autopsy study. Human Pathology 21, 630-639

Monje ML, Mizumatsu S, Fike JR, Palmer TD (2002): Irradiation induces neural precursor-cell dysfunction. Nat Med 8, 955-62

Monje ML, Vogel H, Masek M, Ligon KL, Fisher PG, Palmer TD (2007): Impaired human hippocampal neurogenesis after treatment for central nervous system malignancies. Ann Neurol 62, 515-20

Montgomery DL (1994): Astrocytes: form, functions, and roles in disease. Vet Pathol 31, 145-67

Moore BD, Copeland DR, Ried H, Levy B (1992): Neurophysiological basis of cognitive deficits in long-term survivors of childhood cancer. Arch Neurol $\underline{49}, 809-17$

Moore-Maxwell CA, Datto MB, Hulette CM (2004): Chemotherapy-induced toxic leukoencephalopathy causes a wide range of symptoms: a series of four autopsies. Mod Pathol 17, 241-7

Nait-Oumesmar B, Picard-Riera N, Kerninon C, Decker L, Seilhean D, Höglinger GU, Hirsch EC, Reynolds R, Baron-Van Evercooren A (2007): Activation of the subventricular zone in multiple sclerosis: evidence for early glial progenitors. Proc Natl Acad Sci U S A 104, 4694-9

Nakagawa M, Bellinzona M, Seilhan TM, Gobbel GT, Lamborn KR, Fike JR (1996): Microglial responses after focal radiation-induced injury are affected by alpha-difluoromethylornithine. Int J Radiat Oncol Biol Phys 36. $113-23$

Nalivaeva NN, Turner AJ (2013): The amyloid precursor protein: a biochemical enigma in brain development, function and disease. FEBS Lett $\underline{587,2046-54}$

Ndubaku U, de Bellard ME (2008): Glial cells: old cells with new twists. Acta Histochem 110, 182-95 
Nern C, Wolff I, Macas J, von Randow J, Scharenberg C, Priller J, Momma S (2009): Fusion of hematopoietic cells with Purkinje neurons does not lead to stable heterokaryon formation under noninvasive conditions. J Neurosci 29, 3799-807

Newton HB (2012): Neurological complications of chemotherapy to the central nervous system. Handb Clin Neurol $105,903-16$

Nguyen V, Gaber MW, Sontag MR, Kiani MF (2000): Late effects of ionizing radiation on the microvascular networks in normal tissue. Radiat Res 154, 531-6

Nishiguchi T, Mochizuki K, Shakudo M, Takeshita T, Hino M, Inoue Y (2009): CNS complications of hematopoietic stem cell transplantation. AJR Am J Roentgenol 192, 1003-11

Noel F, Tofilon PJ (1998): Astrocytes protect against X-ray-induced neuronal toxicity in vitro. Neuroreport $\underline{9}$, 1133-7

Norton WT, Aquino DA, Hozumi I, Chiu FC, Brosnan CF (1992): Quantitative aspects of reactive gliosis: a review. Neurochem Res 17, 877-85

Nygren JM, Liuba K, Breitbach M, Stott S, Thorén L, Roell W, Geisen C, Sasse P, Kirik D, Björklund A, . . Jacobsen SE (2008): Myeloid and lymphoid contribution to non-haematopoietic lineages through irradiationinduced heterotypic cell fusion. Nat Cell Biol 10, 584-92

Panagiotakos G, Alshamy G, Chan B, Abrams R, Greenberg E, Saxena A, Bradbury M, Edgar M, Gutin P, Tabar V (2007): Long-term impact of radiation on the stem cell and oligodendrocyte precursors in the brain. PLoS One $\underline{\text { 2, e588 }}$

Phillips TL (1966): An ultrastructural study of the development of radiation injury in the lung. Radiology $\underline{87}$. 49-54

Pratt CB, Green AA, Horowitz ME, Meyer WH, Etcubanas E, Douglass E, Hayes FA, Thompson E, Wilimas J, Igarashi M (1986): Central nervous system toxicity following the treatment of pediatric patients with ifosfamide/mesna. J Clin Oncol 4, 1253-61

Pratt CB, Goren MP, Meyer WH, Singh B, Dodge RK (1990): Ifosfamide neurotoxicity is related to previous cisplatin treatment for pediatric solid tumors. J Clin Oncol 8, 1399-401

Preiß J, Dornoff W, Schmieder A, Honecker F, Claßen J: Taschenbuch Onkologie: Interdisziplinäre Empfehlungen zur Therapie 2014/2015. Zuckschwerdt, München 2014

Pugliatti M, Rosati G, Carton H, Riise T, Drulovic J, Vécsei L, Milanov I (2006): The epidemiology of multiple sclerosis in Europe. Eur J Neurol 13, 700-22

Raff MC, Miller RH, Noble M (1983): A glial progenitor cell that develops in vitro into an astrocyte or an oligodendrocyte depending on culture medium. Nature $\underline{303}, 390-6$ 
Reinhold HS, Calvo W, Hopewell JW, van der Berg AP (1990): Development of blood vessel-related radiation damage in the fimbria of the central nervous system. Int J Radiat Oncol Biol Phys 18, 37-42

Rice CM, Mallam EA, Whone AL, Walsh P, Brooks DJ, Kane N, Butler SR, Marks DI, Scolding NJ (2010): Safety and feasibility of autologous bone marrow cellular therapy in relapsing-progressive multiple sclerosis. Clin Pharmacol Ther 87, 679-85

Rice CM, Kemp K, Wilkins A, Scolding NJ (2013): Cell therapy for multiple sclerosis: an evolving concept with implications for other neurodegenerative diseases. Lancet $382,1204-13$

Riga M, Psarommatis I, Korres S, Varvutsi M, Giotakis I, Apostolopoulos N, Ferekidis E (2007): Neurotoxicity of vincristine on the medial olivocochlear bundle. Int J Pediatr Otorhinolaryngol $\underline{71,63-9}$

Roman DD, Sperduto PW (1995): Neuropsychological effects of cranial radiation: current knowledge and future directions. Int J Radiat Oncol Biol Phys 31, 983-98

Ruben JD, Dally M, Bailey M, Smith R, McLean CA, Fedele P (2006): Cerebral radiation necrosis: incidence, outcomes, and risk factors with emphasis on radiation parameters and chemotherapy. Int J Radiat Oncol Biol Phys $\underline{65,}$ 499-508

Ryan SA, Maceneaney P, O'Reilly SP, Moylan EJ, Power DG (2012): Reversible posterior leukoencephalopathy induced by carboplatin and etoposide. Med Oncol 29, 1287-91

Sanai N, Tramontin AD, Quiñones-Hinojosa A, Barbaro NM, Gupta N, Kunwar S, Lawton MT, McDermott MW, Parsa AT, Manuel-García Verdugo J, Alvarez-Buylla A (2004): Unique astrocyte ribbon in adult human brain contains neural stem cells but lacks chain migration. Nature $\underline{427,740-4}$

Sawamura S, Sawada M, Ito M, Nagatsu T, Nagatsu I, Suzumura A, Shibuya M, Sugita K, Marunouchi T (1995): The bipotential glial progenitor cell line can develop into both oligodendrocytes and astrocytes in the mouse forebrain. Neurosci Lett $188,1-4$

Saynak M, Cosar-Alas R, Yurut-Caloglu V, Caloglu M, Kocak Z, Uzal C (2008): Chemotherapy and cerebrovascular disease. J BUON 13, 31-6

Scherwath A, Schirmer L, Kruse M, Ernst G, Eder M, Dinkel A, Kunze S, Balck F, Bornhäuser M, Ehninger G (2012): Cognitive functioning in allogeneic hematopoietic stem cell transplantation recipients and its medical correlates: a prospective multicenter study. Psychooncology

Schultheiss TE, Stephens LC (1992): Invited review: permanent radiation myelopathy. Br J Radiol 65, 737-53

Schultheiss TE, Stephens LC, Maor MH (1988): Analysis of the histopathology of radiation myelopathy. Int J Radiat Oncol Biol Phys 14, 27-32

Schultheiss TE, Kun LE, Ang KK, Stephens LC (1995): Radiation response of the central nervous system. Int J Radiat Oncol Biol Phys 31, 1093-112 
Shin YJ, Kim JY, Moon JW, You RM, Park JY, Nam JH (2011): Fatal Ifosfamide-induced metabolic encephalopathy in patients with recurrent epithelial ovarian cancer: report of two cases. Cancer Res Treat 43, 260-3

Sioka C, Kyritsis AP (2009): Central and peripheral nervous system toxicity of common chemotherapeutic agents. Cancer Chemother Pharmacol 63, 761-7

Sorror ML (2010): Comorbidities and hematopoietic cell transplantation outcomes. ASH Education Program Book 2010, 237-247

Sostak P, Theil D, Stepp H, Roeber S, Kretzschmar HA, Straube A (2007): Detection of bone marrow-derived cells expressing a neural phenotype in the human brain. J Neuropathol Exp Neurol 66, 110-6

Spriggs DR, Stopa E, Mayer RJ, Schoene W, Kufe DW (1986): Fludarabine phosphate (NSC 312878) infusions for the treatment of acute leukemia: phase I and neuropathological study. Cancer research $\underline{46}$. 5953

Stemmer SM, Stears JC, Burton BS, Jones RB, Simon JH (1994): White matter changes in patients with breast cancer treated with high-dose chemotherapy and autologous bone marrow support. AJNR Am $\mathrm{J}$ Neuroradiol 15, 1267-73

Sul JK, Deangelis LM (2006): Neurologic complications of cancer chemotherapy. Semin Oncol 33, 324-32

Sullivan S, Eggan K (2006): The potential of cell fusion for human therapy. Stem Cell Rev $\underline{2}, 341-9$

Surma-aho O, Niemelä M, Vilkki J, Kouri M, Brander A, Salonen O, Paetau A, Kallio M, J Pyykkönen LP, Jääskeläinen $J$ (2001): Adverse long-term effects of brain radiotherapy in adult low-grade glioma patients. Neurology $\underline{56}, 1285-1290$

Syrjala KL, Dikmen S, Langer SL, Roth-Roemer S, Abrams JR (2004): Neuropsychologic changes from before transplantation to 1 year in patients receiving myeloablative allogeneic hematopoietic cell transplant. Blood 104, 3386-92

Syrjala KL, Artherholt SB, Kurland BF, Langer SL, Roth-Roemer S, Elrod JB, Dikmen S (2011): Prospective neurocognitive function over 5 years after allogeneic hematopoietic cell transplantation for cancer survivors compared with matched controls at 5 years. J Clin Oncol 29, 2397-404

Tada E, Yang C, Gobbel GT, Lamborn KR, Fike JR (1999): Long-term impairment of subependymal repopulation following damage by ionizing irradiation. Exp Neurol 160, 66-77

Terada N, Hamazaki T, Oka M, Hoki M, Mastalerz DM, Nakano Y, Meyer EM, Morel L, Petersen BE, Scott EW (2002): Bone marrow cells adopt the phenotype of other cells by spontaneous cell fusion. Nature $\underline{416}$, $542-5$

Thomas ED, Blume KG (1999): Historical markers in the development of allogeneic hematopoietic cell transplantation. Biol Blood Marrow Transplant $\underline{5}, 341-6$ 
Tichelli A, Rovó A, Gratwohl A (2008): Late pulmonary, cardiovascular, and renal complications after hematopoietic stem cell transplantation and recommended screening practices. Hematology Am Soc Hematol Educ Program 125-33

Tofilon PJ, Fike JR (2000): The radioresponse of the central nervous system: a dynamic process. Radiat Res $153,357-70$

Toker E, Yenice O, Oğüt MS (2004): Isolated abducens nerve palsy induced by vincristine therapy. J AAPOS 8, 69-71

Tran SD, Pillemer SR, Dutra A, Barrett AJ, Brownstein MJ, Key S, Pak E, Leakan RA, Kingman A, Yamada $\mathrm{KM}, \ldots$ Mezey $\mathrm{E}$ (2003): Differentiation of human bone marrow-derived cells into buccal epithelial cells in vivo: a molecular analytical study. Lancet $\underline{361,1084-8}$

Tripathi R, McTigue DM (2007): Prominent oligodendrocyte genesis along the border of spinal contusion lesions. Glia $\underline{55}, 698-711$

van Gelder M, Mulder AH, van Bekkum DW (1996): Treatment of relapsing experimental autoimmune encephalomyelitis with largely MHC-matched allogeneic bone marrow transplantation. Transplantation $\underline{62}$. 810-8

van Vulpen M, Kal HB, Taphoorn MJ, El-Sharouni SY (2002): Changes in blood-brain barrier permeability induced by radiotherapy: implications for timing of chemotherapy? (Review). Oncol Rep $\underline{9}, 683-8$

Van Wijmeersch B, Sprangers B, Rutgeerts O, Lenaerts C, Landuyt W, Waer M, Billiau AD, Dubois B (2007): Allogeneic bone marrow transplantation in models of experimental autoimmune encephalomyelitis: evidence for a graft-versus-autoimmunity effect. Biol Blood Marrow Transplant 13, 627-37

Van Wijmeersch B, Sprangers B, Dubois B, Waer M, Billiau AD (2008): Autologous and allogeneic hematopoietic stem cell transplantation for Multiple Sclerosis: perspective on mechanisms of action. $\mathrm{J}$ Neuroimmunol 197, 89-98

Vassal G, Deroussent A, Hartmann O, Challine D, Benhamou E, Valteau-Couanet D, Brugières L, Kalifa C, Gouyette A, Lemerle J (1990): Dose-dependent neurotoxicity of high-dose busulfan in children: a clinical and pharmacological study. Cancer Res $\underline{50,6203-7}$

Vaughn DJ, Jarvik JG, Hackney D, Peters S, Stadtmauer EA (1993): High-dose cytarabine neurotoxicity: MR findings during the acute phase. Am J Neuroradiol 14, 1014-6

Verheij M, Dewit LG, Boomgaard MN, Brinkman HJ, van Mourik JA (1994): Ionizing radiation enhances platelet adhesion to the extracellular matrix of human endothelial cells by an increase in the release of von Willebrand factor. Radiat Res 137, 202-7

Verstappen CC, Heimans JJ, Hoekman K, Postma TJ (2003): Neurotoxic complications of chemotherapy in patients with cancer: clinical signs and optimal management. Drugs $63,1549-63$ 
Vogel H, Horoupian DS (1993): Filamentous degeneration of neurons. A possible feature of cytosine arabinoside neurotoxicity. Cancer $71,1303-1308$

Wefel JS, Schagen SB (2012): Chemotherapy-Related Cognitive Dysfunction. Curr Neurol Neurosci Rep

Wefel JS, Witgert ME, Meyers CA (2008): Neuropsychological sequelae of non-central nervous system cancer and cancer therapy. Neuropsychol Rev 18, 121-31

Wefel JS, Saleeba AK, Buzdar AU, Meyers CA (2010): Acute and late onset cognitive dysfunction associated with chemotherapy in women with breast cancer. Cancer 116, 3348-56

Weimann JM, Charlton CA, Brazelton TR, Hackman RC, Blau HM (2003): Contribution of transplanted bone marrow cells to Purkinje neurons in human adult brains. Proc Natl Acad Sci U S A 100, 2088-93

Wurmser AE, Gage FH (2002): Stem cells: cell fusion causes confusion. Nature $\underline{416,485-7}$

Ying QL, Nichols J, Evans EP, Smith AG (2002): Changing potency by spontaneous fusion. Nature $\underline{416}$. 545-8

Yuan H, Gaber MW, Boyd K, Wilson CM, Kiani MF, Merchant TE (2006): Effects of fractionated radiation on the brain vasculature in a murine model: blood--brain barrier permeability, astrocyte proliferation, and ultrastructural changes. International Journal of Radiation Oncology* Biology* Physics $\underline{66,860-866}$

Zollinger HU (1970): [Radiation vasculopathy]. Pathol Eur $\underline{5,145-63}$

Zucker-Franklin D, Warfel A, Grusky G, Frangione B, Teitel D (1987): Novel monocyte-like properties of microglial/astroglial cells. Constitutive secretion of lysozyme and cystatin-C. Lab Invest $\underline{57}$, 176-85 


\section{Lebenslauf}

Ich wurde als drittes Kind meiner Eltern am 25.05.1987 in Magdeburg geboren.

Meine schulische Ausbildung beendete ich im Juli 2006 nach dreizehn Jahren mit dem Abitur am GutsMuths-Gymnasium in Quedlinburg. Danach verbrachte ich ein Dreivierteljahr als Au-pair in Rusper, Südengland. Im Oktober 2007 immatrikulierte ich mich für das Studium der Humanmedizin an der Georg-August-Universität in Göttingen und legte im Sommer 2009 den Ersten Abschnitt der Ärztlichen Prüfung ab. Im Anschluss setzte ich ein Semester aus, um an meiner Dissertation zu arbeiten. Danach stieg ich in den klinischen Abschnitt meines Studiums ein und legte im April 2014 den schriftlichen Teil meines Staatsexamens ab. Im Mai folgte die mündliche Prüfung. Ende Juni 2014 erhielt ich meine Approbation als Ärztin. Im Oktober 2014 begann ich meine Facharztausbildung in Allgemeinmedizin als Assistenzärztin in der Abteilung für Innere Medizin des Harzklinikums Dorothea Erxleben in Quedlinburg. 